$\left.3^{3}\right)^{\mid 91} \quad W B$.

(1)

SANDIA REPORT

$10-18-91$

SAND89-0837 - UC-814

Unlimited Release

Printed December 1991

Yucca Mountain Site Characterization Project

\title{
Drift Design Methodology and \\ Preliminary Application for the Yucca \\ Mountain Site Characterization Project
}

M. P. Hardy, Stephen J. Bauer

Prepared by

Sandia National Laboratories

Albuquerque, New Mexico 87185 and Livermore, California 94550

for the United States Department of Energy

under Contract DE-AC04-76DP00789 
"Prepared by Yucca Mountain Site Characterization Project (YMSCP) participants as part of the Civilian Radioactive Waste Management Program (CRWM). The YMSCP is managed by the Yucca Mountain Project Office of the U.S. Department of Energy, DOE Field Office, Nevada (DOE/NV). YMSCP work is sponsored by the Office of Geologic Repositories (OGR) of the DOE Office of Civilian Radioactive Waste Management (OCRWM)."

Issued by Sandia National Laboratories, operated for the United States Department of Energy by Sandia Corporation.

NOTICE: This report was prepared as an account of work sponsored by an agency of the United States Government. Neither the United States Government nor any agency thereof, nor any of their employees, nor any of their contractors, subcontractors, or their emplovees, makes any warranty, express or implied, or assumes any legal liability or responsibility for the accuracy, completeness, or usefulness of any information, apparatus, product, or process disclosed, or represents that its use would not infringe privately owned rights. Reference herein to any specific commercial product, process, or service by trade name, trademark, manufacturer, or otherwise, does not necessarily constitute or imply its endorsement, recommendation, or favoring by the United States Government, any agency thereof or any of their contractors or subcontractors. The views and opinions expressed herein do not necessarily state or reflect those of the United States Government, any agency thereof or any of their contractors.

Printed in the United States of America. This report has been reproduced directly from the best available copy.

Available to DOE and I)OF contractors from

Office of Scientific and Technical Information

P() Box 62

Oak Ridge. TN :378:31

Prices available from (615) 576-8401, FTS 626-8401

Available to the public from

National Technical Information Service

US Department of ('ommerce

528.5 Port Roval Rd

Springfield, VA 22161

N'TIS price codes

Printed copy: Ars

Microfiche copy: A(b) 
Distribution

Category UC-814

SAND89-0837

Unlimited Release

Printed December, 1991

\title{
DRIFT DESIGN METHODOLOGY AND PRELIMINARY APPLICATION FOR THE YUCCA MOUNTAIN SITE CHARACTERIZATION PROJECT
}

\author{
by \\ M. P. Hardy \\ J. F. T. Agapito \& Associates, Inc. \\ Grand Junction, CO 81506 \\ and \\ Stephen J. Bauer \\ Sandia National Laboratories \\ Albuquerque, NM 87185
}

\begin{abstract}
Excavation stability in an underground nuclear waste repository is required during construction, emplacement, retrieval (if required), and closure phases to ensure worker health and safety, and to prevent development of potential pathways for radionuclide migration in the post-closure period. Stable excavations are developed by appropriate excavation procedures, design of the room shape, design and installation of rock support reinforcement systems, and implementation of appropriate monitoring and maintenance programs. In addition to the loads imposed by the in situ stress field, the repository drifts will be impacted by thermal loads developed after waste emplacement and, periodically, by seismic loads from naturally occurring earthquakes and underground nuclear events. A priori evaluation of stability is required for design of the ground support system, to confirm that the thermal loads are reasonable, and to support the license application process. In this report, a design methodology for assessing drift stability is presented. This is based on site conditions, together with empirical and analytical methods. Analytical numerical methods are emphasized at this time because empirical data are unavailable for excavations in welded tuff either at elevated temperatures or under seismic loads. The analytical methodology incorporates analysis of rock masses that are systematically jointed, randomly jointed, and sparsely jointed. In situ thermal and seismic loads are considered. Methods of evaluating the analytical results and estimating ground support requirements for the full range of expected ground conditions are outlined. The results of a preliminary application of the methodology using the limited available data are presented. This methodology is expected to evolve as excavation observation at the Exploratory Shaft Facility demonstrates the controlling deformation mechanisms and allows site-specific evaluation of in situ properties. As more experience is gained at the site, design based on empirical and observational methods will emerge for application during construction of the repository.
\end{abstract}


This report was prepared under WBS Element 124232. 


\section{PREFACE}

The drift design methodology outlines procedures for drift design for a potential repository in welded tuff at the Yucca Mountain Site, but does not discuss who will be responsible for implementing these procedures. Until this date, the repository design has been the responsibility of Sandia National Laboratories with architect engineering (A/E) support.

Implementation of the drift design procedures includes interpretation of data from laboratory, field and prototype tests; compliance with regulatory requirements, numerical analysis, and tradeoff studies; integration with other aspects of the repository layout and operations; consideration of licensing strategies; postclosure performance constraints; and development of specific procedures suitable to meet Quality Assurance requirements. It is anticipated that most of this work will be completed by the repository designer with input and review from other departments. Once underground excavation begins, procedures for data collection from exposed rock surfaces and feedback to the drift design team must be developed.

It is recommended a drift design review team be established by the Project Office during the prelicensing phases of repository design to advise an implementation of the drift design methodology and to review proposed drift designs, including the ground support/reinforcement details. This review team should include representatives with expertise in the geological sciences, laboratory testing, computation mechanics, construction, waste handling, repository design and performance assessment. 


\section{ACKNOWLEDGEMENTS}

This report was prepared by the authors with significant assistance from supporting staff and review consultants, and input from technical reviewers. Mr. B. Ehgartner, A. Mansure, and R. Stinebaugh of Sandia National Laboratories were instrumental in initiating the concept of the drift design methodology and contributed to the overall report outline. Dr. C. St. John, formerly of J. F. T. Agapito \& Associates, Inc. and presently acting as a consultant, was also initially involved in development of the concept of the drift design methodology and has been involved throughout its history of development as a technical reviewer.

Significant technical contributions have been made by Mr. C. E. Brechtel and M. Lin of J. F. T. Agapito \& Associates, Inc. They are responsible for the ground support designs and all numerical analyses, respectively, in the preliminary application of the drift design methodology, Chapter 12.

Dr. L. S. Costin and Mr. R. E. Finley of Sandia National Laboratories performed a formal technical review. Messrs. R. H. Price and E. E. Ryder of Sandia National Laboratories also provided review comments to a draft version of the report.

Prof. W. Hustrulid of the Colorado School of Mines and Dr. Z. T. Bieniawski of Pennsylvania State University have performed external technical reviews.

The authors also wish to acknowledge the professional contribution of Ms. K. L. Greathouse for her typing and editing of all drafts of this report. 


\section{TABLE OF CONTENTS}

Section

Page

1.0

INTRODUCTION $1-1$

$1.1 \quad$ Purpose ...............................................................................1

1.2 Report Organization ................................................................1-1

2.0

DRIFT DESIGN METHODOLOGY

2.1 Methodology Outline .............................................................. 2-1

2.2 Limitations of Design Methodology ............................................2-4

2.3 Implementation of Drift Design Methodology ................................ 2-4

3.1 Functional Requirements ............................................................ 3-1

3.1.1 Size and Shape ........................................................... $3-1$

3.1.2 Drift Cross-Sectional Area ……………………………....3-2

3.2 Performance Goals .........................................................................3-2

3.2.1 Temperature ...................................................................

3.2.2 Stability .................................................................

3.2.3 Materials ....................................................................... $3-5$

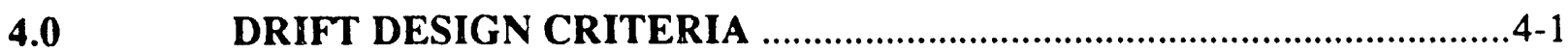

4.1 Ground Support/Rock Reinforcement Design ................................. 4-1

4.2 Safety Factors..................................................................................4-1

4.3 Drift Design Criteria .................................................................... 4-4

5.0 DESIGN BASIS ….........................................................................

$5.1 \quad$ Stress at Drift Location ............................................................. $5-1$

5.1.1 In Situ Stress .......................................................... 5-1

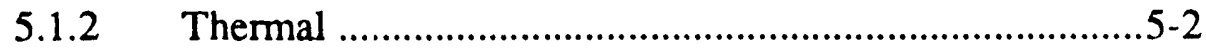

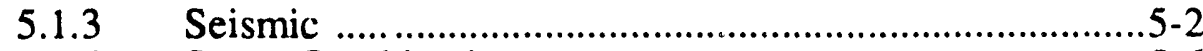

5.1.4 Stress Combinations ...................................................5-6

5.1.5 Design Basis Loads for Specific Rock

5.2 Information for Design ..................................................................

5.2.1 Stratigraphy and Rock Structure ......................................5-7

5.2.2 In Situ Conditions ........................................................5-8

5.2.3 Thermal Properties …………………………….............. 5-8

5.2.4 Mechanical Properties ..................................................... 5-9

5.2.5 Waste Characteristics .................................................... 5-14

5.2.6 Ground Support Properties .................................................5-15

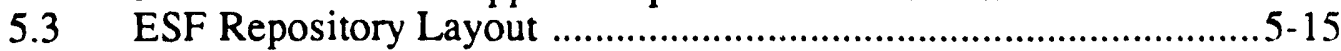

5.3.1 Exploratory Shaft Facility ………………………........ 5-19

5.3.2 Repository ..................................................................

6.0 ANALYSIS OF UNSUPPORTED DRIFTS ……....................................

6.1 Candidate Drift Designs ..............................................................6-1

6.2 Parametric and Tradeoff Studies ...............................................6-1 


\section{TABLE OF CONTENTS (Concluded)}

Section

Page

6.3 Select Preliminary Drift Configurations

6-1

6.4

Empirical Methods

$6-1$

6.4.1 Technique Selection .......................................................6-6

6.4.2 Application of Empirical Techniques ...............................6-7

6.4.3 Results of Empirical Techniques .....................................6-8

6.4.4 Interaction of Empirical and Numerical

Methods

6.5 Numerical Methods for Unsupported Drifts ...................................6-8

6.5.1 Model Selection ..........................................................6-8

6.5.2 Application of Numerical Models .....................................6-11

6.5.3 Results of Analyses .......................................................... 6-16

6.6 Drift Intersections .....................................................................6-17

6.7 Borehole Drift Intersections ......................................................6-19

6.8 Fault Zones and Zones of Poor Rock Quality ...............................6-19

6.9 Preliminary Ground Support Design ...............................................6-20

7.0 EVALUATION OF DRIFT ANALYSIS ……….................................

7.1 Evaluation of Drift Design ............................................................. 7-1

7.1.1 Evaluation of Thermal Goals ...........................................7-1

7.1.2 Evaluation of Drift Stability ..............................................

7.1.3 Drift Stability Criteria ......................................................7-2

7.2 Evaluation of Field Demonstration Studies ...................................... 7-4

7.3 Preliminary Modifications ............................................................... 7-4

8.0 GROUND SUPPORT DESIGN ………...............................................

8.1 Inputs for Ground Support Design .................................................8-1

8.1.1 In Situ Stress Relief and Ground Support

Loading .........................................................................

8.1.2 Rock Mass Failure Mechanisms ........................................8-4

8.1.3 Functional Requirements of Ground Support ...................8-4

8.1.4 Ground Support Material Behavior .................................. 8-5

8.1.5 Ground Support Failure Mechanisms …………................8-5

8.2 Ground Support Design Analysis .....................................................8-6

8.2.1 Uncoupled Analysis .......................................................... 8-7

8.2.2 Coupled Analysis .............................................................. 8-7

8.3 Ground Support Evaluation............................................................8-7

9.0 FINAL DESIGN EVALUATIONS ……….........................................

9.1 Evaluation of Final Design .........................................................

9.2 Final Modifications ....................................................................

9.3 Final Design Specifications .............................................................9-1

9.4 Field Prucedures..........................................................................

10.0 SUMMARY OF METHODOLOGY ………..................................... 10-1

11.0 DEVELOPMENT OF DRIFT DESIGN METHODOLOGY ….................11-1 


\section{TABLE OF CONTENTS (Concluded)}

Section

12.0

\section{PRELIMINARY APPLICATION OF DRIFT DESIGN METHODOLOGY AT YMP}

12.1 Establish Functional Requirements, Performance Goals and Develop Drift Stability Requirements

12.2 Establish Site Characteristics and Credible Range for Design

12.2.1 Rock Mass Quality

12.2.2 Properties for the Compliant Joint Model

12.2.3 Elasto-Plastic Mechanical Properties

12.2.4 Thermal Properties

12.3 Repository Layout

12.4 Design Basis Loads

12.4.1 In Situ Stresses ............................................................12-18

12.4.2 Thermal Stresses .......................................................12-18

12.4.3 Seismic Stresses ........................................................12-20

12.4.4 Combined In Situ, Thermal, and Seismic Stresses ....... 12-21

12.4.5 Finite-Element Boundary Conditions in Drift

Analysis

12.5 Develop Candidate Drift Designs and Perform Parametric/

Tradeoff Studies

12.6 Select Preliminary Drift Shapes and Sizes

12.7 Perform Analysis of Drift and Intersections

12.7.1 Empirical Analysis

12.7.2 Numerical Methods

12.7.3 Preliminary Ground Support Parameters ....................... 12-35

12.8 Evaluate Drift Design ...............................................................12-36

12.9 Modify Drift Shape/Loads and Review Goals and Criteria .........12-37

12.10 Ground Support Design

12.10.1 Uncoupled Analysis ..............................................12-38

12.10.2 Coupled Analysis ...................................................12-41

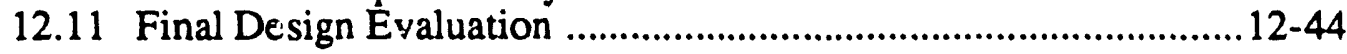

13.0 REFERENCES

APPENDIX A-Maximum Allowable Compressive Strain .........................................A-1

APPENDIX B-Repository Drift Performance Using Compliant Joint Model ..............B-1

APPENDIX C-Information from, and Candidate Information for, the Site and Engineering Property Data Base and Reference Information Base 


\section{LIST OF TABLES}

Table

3-1 Stability Performance Measures and Goals for Repository

4-3 Recommended Safety Factors for Design of Ground

Support/Rock Reinforcement Components.

5-1 Frec-Field Strains Caused by Earthquake Events for

Steep Angle of Incidence

5-2 Free-Field Strains Caused by UNE Events for Shallow

Angle of Incidence

5-3 Criteria for Assessing Seismic Wave Impact Angle

6-1 Material Properties for the Elasto-Plastic Continuum

Model

6-2 Material Properties for Equivalent Continuum Model and

Compliant Joint Model

8-1 Suggested Percentage of Excavation-Induced Ground

Deformation

12-1 Function of Drift During Phases of Repository Development

12-2 Classification Parameters and Estimated Range of Value

12-3 Level of Probability for Selected NGI Parameters

12-4 Level of Probability for Selected RMR Parameters

12-5 Final RMR Values for Levels of Probability

12-6 Fracture Frequencies Derived from Yucca Mountain Core Hole

$$
\text { Data }
$$

12-7 Fracture Frequency and Spacing Based on RQD

12-8 Preliminary Characterization of Fracture Continuity in TSw2

12-9 Estimated Joint Continuity for Probability Level 


\section{LIST OF TABLES (Cont'd)}

Table

Page

12-10 Range of Joint and Intact Rock Strength Parameters

12-11 Joint Intact Rock and Weighted Average Joint Strength Used for the CJM Model

12-12 CJM Joint Stiffness Parameters for Probability Levels $12-14$

12-13 Estimated Strength of Intact Blocks $12-15$

12-14 Power Law Failure Criteria for Levels of Probability $12-16$

12-15 Mohr-Coulomb Failure Criteria for Various Rock Mass Quality $12-16$

12-16 Rock Mass Tensile Strength for Rock Mass Quality $12-17$

$12-17$

Rock Mass Elastic Modulus for the Range of Rock Mass Quality $12-17$

12-18 Magnitude and Orientation of In Situ Principal Stresses $12-19$

12-19 Thermal Stress Change Used for Midpanel Access Drift 12-19

12-20 Thermal Stress Change Used for Tuff Main Access Drift $12-20$

12-21 Seismic Loads for All Drift Analysis $12-21$

12-22 Combined Loads (in MPa) for Midpanel Access Drift at 100 Years $12-22$

12-23 Parameters in Assessing Ground Support Requirements for Hoek Method $12-25$

12-24 Ruck Support Requirements Based on NGI-Q System Design Tables

12-25 Modified $Q\left(Q^{M}\right)$ Adjusted for Thermal and Seismic Loads $12-27$

12-26 Rock Support Requirements Based on NGI-Q System Design Tables for In Situ + Thermal + Seismic Loadings

12-27 Rock Support Pressures (MPa) Based on Equation 13 and $Q^{M}$

12-28 Standup Time Based on Bieniawski's RMR Rock Mass Rating

12-29 Maximum Extent of Failed Zone for the Tuff Main Access Drift

12-30 Maximum Extent of Failed Zone for the Midpanel Access Drift 


\section{LIST OF TABLES (Concluded)}

Table

Page

12-31 Maximum Extent of Failed Zone for Waste-Emplacement Drift for In Situ Plus Thermal Loads

12-32 Maximum Extent of Failed Zone for Waste-Emplacement Drift for In Situ Plus Thermal Plus Seismic Loads

12-33 Rockbolt Support Systems Based on Numerical Analysis of Unsupported Drifts

12-34 Cases Where Maximum Allowable Compressive Strain Exceeded When Loaded by In Situ Plus Thermal Plus Seismic Stresses

12-35 Predicted Bolt Loads (MPa), Tuff Main Access Drift, Uncoupled Analysis

12-36 Predicted Shotcrete Loads (MPa), Tuff Main Access Drift, Uncoupled Analysis

12-37 Predicted Bolt Loads (MPa), Midpanel Access Drift, Uncoupled Analysis

12-38 Predicted Shotcrete Loads (MPa), Midpanel Access Drift, Uncoupled Analysis

12-39 Predicted Bolt Loads (MPa), Vertical Waste Emplacement Drift, Uncoupled Analysis

12-40 Predicted Shotcrete Loads (MPa), Emplacement Drift, Uncoupled Analysis

12-41 Comparison of Coupled and Uncoupled Shotcrete Stresses for Elastic Rock Mass

12-42 Comparison of Coupled and Uncoupled Shotcrete Stresses for Compliant Joint Rock Model

12-43 Comparison of Coupled and Uncoupled Shotcrete Stresses for Mohr-Coulomb Rock Model

12-44 Preliminary Ground Support Systems for Three Repository Drift Types 


\section{LIST OF FIGURES}

5-1 Wavefront Angle of Incidence $\theta$ Relative to Drift

5-2 Estimation of In Situ Deformation Modulus from Classification

5-3 Averaging of Hoek and Brown and Yudhbir Failure Criteria for $\mathrm{RMF} \quad 32.5$..

5-4 Repository Layout (from SCP-CDR)

5-6 Isometric and Profile Views of the Waste-Emplacement Panels as Modeled with STRES3D

5-8 Drift and Ramp Cross Sections (Vertical Emplacement)

6-1 Range of Rock Mass Quality, Q, Projected for Excavation Conditions at the Repository Horizon

6-2 Approximate Support Guidelines for Underground Excavations Proposed by Hoek (1981)

Chart for Estimating Modes of Failure Around Drifts Proposed by Schmidt (1987)

6-4 Calculated Peak Particle Velocities and Acceleration and Associated Damage Observations on Underground Openings

6-7 Schematic Illustrating Geometry and Loads for Calculation of Wall Support Pressure.

7-1 Flowchart lllustrating Application of Drift Support Design Criteria to Drift Analysis. 


\section{LIST OF FIGURES (Concluded)}

Figure

8-1 Illustration of Interaction of the Ground Reaction Curve and Ground Support System

12-1 RQD Data (Langkopf and Gnirk, 1986) for Four YMP Core Holes

Showing an 80-ft Interval Used to Develop the Estimate of

Lateral Variation

12-2 RQD Versus Cumulative Probability of Occurrence Showing Selected Levels of Probability Used for Parameter Selection

12-3 RMR Joint Frequency Parameter Versus Cumulative Frequency of Occurrence Assuming a Uniform Distribution of the Range Reported by Langkopf and Gnirk (1986)

12-4 Approximate Support Guidelines for Underground Excavations Proposed by Hoek (1981) With Range of Expected Conditions for Emplacement Drifts at the YMP

12-5 Chart for Estimating Modes of Failure Around Drifts Proposed by Schmidt (1987) With Projected Conditions for Emplacement Drift at YMP

12-6 Range of Rock Mass Quality, Q, Projected for Excavation Conditions at the Repository Horizon

12-7 Expected Conditions Shown on Barton Rock Mass Quality Design Shaft 


\subsection{INTRODUCTION}

Sandia National Laboratories (SNL), a participant in the Yucca Mountain Site Characterization Project (YMP), is investigating the feasibility of locating a high-level nuclear waste repository at Yucca Mountain, Nevada. The conceptual design of the repository includes shafts and ramps as accesses to the repository horizon, which are 200 to $300 \mathrm{~m}$ below the surface within the densely welded section of the Topopah Spring Member of the Paintbrush tuff formation. At the repository level, main access and emplacement drifts will be excavated to allow disposal of the waste in either horizontally or vertically oriented boreholes. These drifts must provide safe access for waste emplacement, inspection, and maintenance following emplacement, closure, and possibly, waste retrieval. The design methodology presented in this report defines the steps for repository drift design to ensure that the drifts meet stability and other regulatory requirements through repository decommissioning.

\section{$1.1 \quad$ Purpose}

The purpose of this report is to define, for the underground excavations of a repository in tuff, a design methodology, establish a design criteria, and demonstrate the application of the methodology to the Yucca Mountain Site. For the purposes of this document, the design of underground excavations cor ists of two components: (1) the drift dimensions and shape, and (2) the ground support/rock reinforcement. Repository drift size and shape depends primarily on functional requirements, whereas the ground support/rock reinforcement depends on local geologic conditions and loadings. The ground support/rock reinforcement design can, at this stage, consist of only multiple design possibilities to be selected after local ground conditions have been established.

Not included in the drift design, but considered in the methodology, is the design of the mining, ventilation, utility, backfill, and sealing systems. The design of the emplacement borehole (borehole, liner, and plug), repository panels (layout, drift spacing, and standoff), and shafts is outside the scope of this document, although the interaction and effect on drift design are considered where appropriate. For example, density of emplaced waste [areal power density (APD)] and standoff to the waste are parameters of panel design that may require adjustment if thermal loads on the drift become excessive.

\section{$1.2 \quad$ Report Organization}

The repor is structured to follow the application of the proposed design methodology. Chapter 2 provides a synopsis of the methodology. This is followed by chapters which describe in detail major elements of the methodology. These are:

Chapter 3-Design Requirements and Goals

Chapter 4-Drift Design Criteria

Chapter 5-Design Basis

Chapter 6-Analysis of Unsupported Drifts

Chapter 7-Drift Evaluations

Chapter 8-Ground Support Design

Chapter 9-Final Drift Evaluations and Design 
A summary of the methodology is presented in Chapter 10. Chapter 11 briefly outlines how data developed from the Exploratory Shaft Facility (ESF) program will be used to enhance the design methodology. To illustrate the use of the methodology, it has been applied using the available site-specific data and the current reference repository layout. The results of this preliminary application are presented in Chapter 12.

Appendixes A and B provide example analytical results for two of the analytical models: the elasto-plastic continuum and compliant joint models (CJM). Appendix C provides examples of coupled analysis of the interaction between the rock and ground support system. These appendixes support the design study documented in Chapter 12. 


\subsection{DRIFT DESIGN METHODOLOGY}

\subsection{Methodology Outline}

The methodology, which is divided into a determination phase and a two-part design process, is presented in Figures $2-1$ and 2-2. Figure 2-1 provides a summary of the entire methodology, while Figure 2-2 provides a more detailed logic chart of the methodology. In the first part (Part A) of the design process, analyses are performed on unsupported drifts and a preliminary ground support design is established to support any yielding rock. In the second part (Part B), the drift including the ground support components is analyzed to assess ground support component loadings and drift stability. A final ground support system is selected when all design criteria are met by the drift and ground support system.

The first step in the design methodology is to define the functional requirements of the drifts and to establish criteria and goals for their performance. Once functional requirements and the range of expected site characteristics are established, a range of appropriate drift sizes and shapes can be selected. The second step is analysis using all the appropriate tools that are available. Analysis includes application of heuristic, empirical, and numerical methods to assess the structural impacts of excavation, thermal, and seismic loads on candidate drift configurations for the range of expected site characteristucs. At this stage, only the general characteristics of the rock mass at the repository horizon are known. Hience, it is not possible to define a single set of parameters that describe the rock mass, or even how such parameters might vary throughout the site. The expected ground conditions are grouped into five categories and the thermomechanical properties are assessed for each category. Analysis is then completed for each rock mass category. In Part A the analysis does not explicitly include the function of the ground support. The intent is to verify that for most of the expected ground conditions and loads, the drifts are stable and require only minimal ground support or reinforcement. The third step (evaluation) is a review of the candidate designs relative to the performance goals, criteria, and when appropriate, the results of in situ and demonstration tests, resulting in a judgment as to the practicality and feasibility of the design.

After completion of the evaluation phase in Part A, attention is directed to Phase $\mathrm{B}$, the detailed design of a compatible ground support system. The performance of the ground support system and drifts is assessed by coupled numerical analysis using models that account for interaction between the rock mass and the ground support, as well as the effect of seismic and thermal loadings.

For the repository drifts, several alternative ground support designs will be developed to accommodate the complete range of expected ground conditions. Part of the overall drift design is to describe the conditions appropriate for each alternative ground support system.

The logic chart (Figure 2-2) shows in some detail the application of the basic design steps in the proposed drift design methodology and emphasizes that iteration loops may be required if one or more of the design criteria are not met for a particular proposed design. During Part A, if the design criteria are not met by a particular drift, it is possible either to modify its shape or size or to reduce the thermal loads by modifying the repository layout. If the design criteria can be proven overly conservative or if the performance goals can be achieved in some other manner, the design criteria may be reevaluated and modified. After practical drift shapes and loads have been selected during Part A of the design methodology, detailed ground support design (Part B) is completed. Part B may also require modification of the drift shape or loads to accommodate particular ground support requirements. 


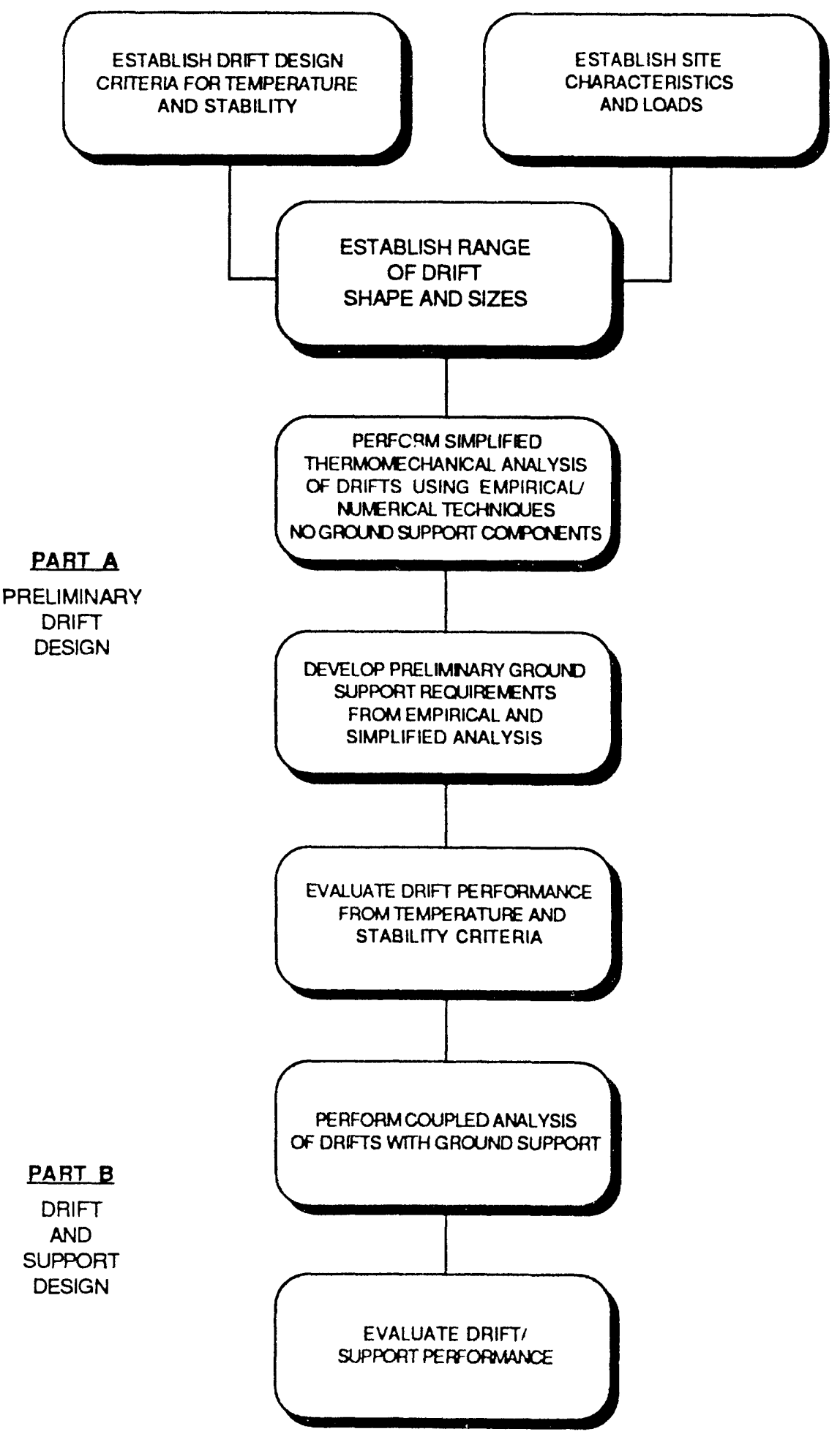

BASIC DESIGN STEPS

DEFINITION

ANALYSIS

EVALUATION

ANALYSIS

EVALUATION

Figure 2-1. Summary of Drift Design Methodology 


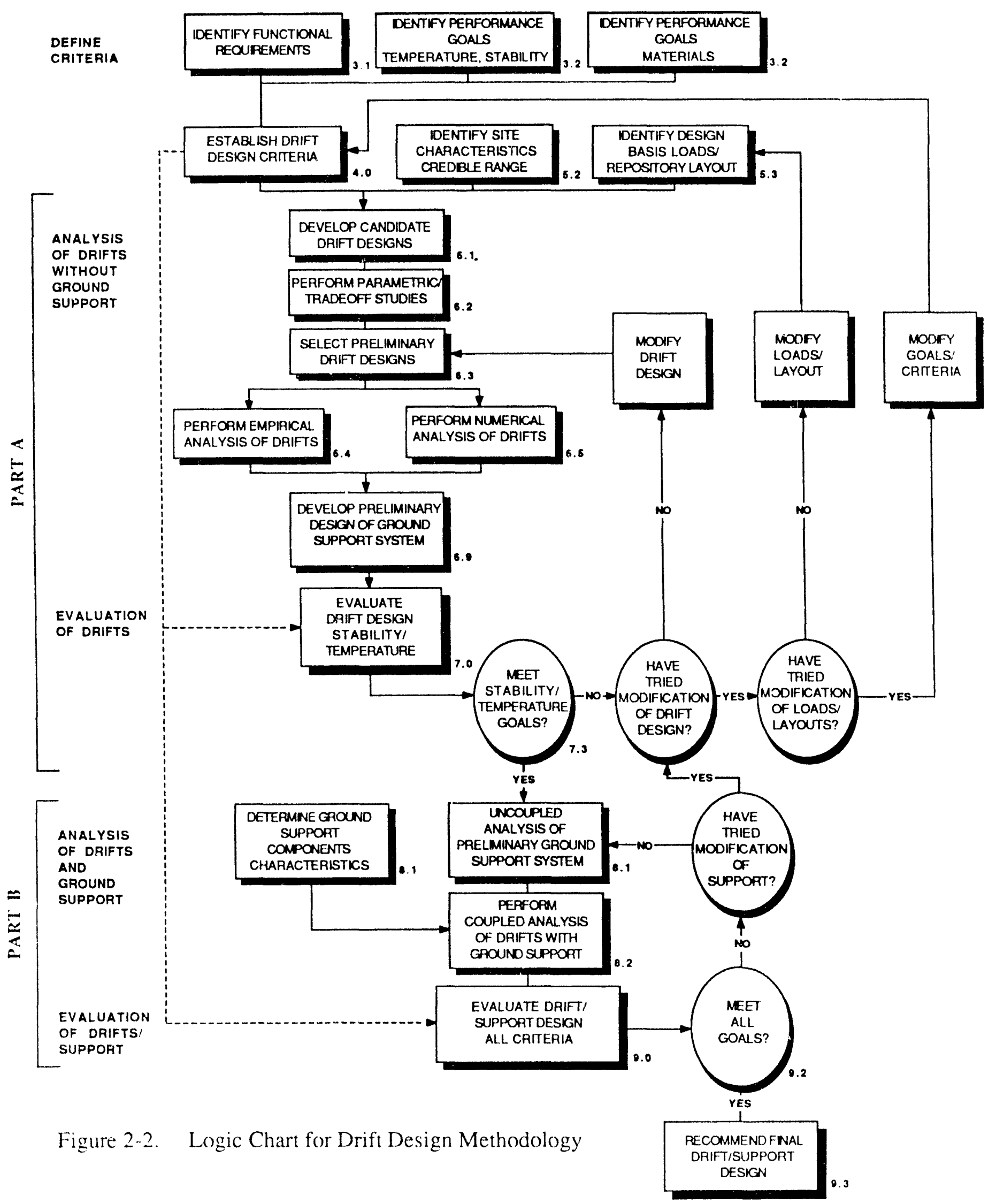


The design methodology will be used first in Title II design of the ESF. As more detail is developed during the site characterization phase, the design methodology will be verified or modified and reapplied for repository design before license application and construction initiation. Validation of the design methodology can be achieved by prototype testing and demonstrations of drift performance. Comparisons of analyses incorporating the ground support components with results of in situ tests and demonstrations will also be performed as part of the model validation process.

The design steps and output of each step shown in Figure 2-2 are listed in Table 2-1. Also shown in the table are the report sections that provide detailed discussion of each step.

\subsection{Limitations of Design Methodology}

The application of drift design methodology to the Yucca Mountain site presented in Chapter 12 is considered preliminary for two important reasons: first, our knowledge of the ground conditions at the repository location is limited; and second, the application of empirical and analytical design techniques for drifts in a thermal environment are novel and largely unproven by practice. Empirical methods are limited by the lack of case studies of excavations in similar rock subjected to combinations of in situ stress, seismic loads, and thermally induced loads. In application of the methodology, practical considerations may limit analyses to simplified idealizations of the rock mass structure and repository geometry. It is expected that limitations in the empirical and analytical methods used in this methodology will be reduced as a result of experiments, tests, and field demonstrations in the ESF.

\subsection{Implementation of Drift Design Methodology}

The drift design methodology uses empirical and analytical techniques that require, in some instances, input data that are poorly defined and/or can be expected to be variable throughn'ai the repository. The implementation of the drift design methodology incorporates estimates of the mean and range of those parameters based on comparable case examples, laboratory data, limited site-specific data, and engineering judgment. Combinations of parameters from those ranges must recognize coupling between parameters such as strength and porosity, strength and modulus, etc. It is proposed that five ground support options be designed to accommodate the credible range of rock characteristics and loadings at the repository location. The design methodology will be applied to each set of conditions, and part of the product of the initial designs will be to define the subranges and combinations of rock characteristics for each of these limited sets.

Chapter 12 provides a preliminary application of the methodology to the YMP for the tuff main, midpanel, and emplacement drifts. Procedures to incorporate the existing database into the design are illustrated.

The drift design methodology will be applied and improved during consiruction of the ESF. Improvements will be derived from the abundance of site characterization data collected during this phase and also from the verification/validation of the methodology from back analysis and comparison with drift performance. Should this comparison be unacceptable, the field data will provide a basis for modifications and improvements of the design methodology. 


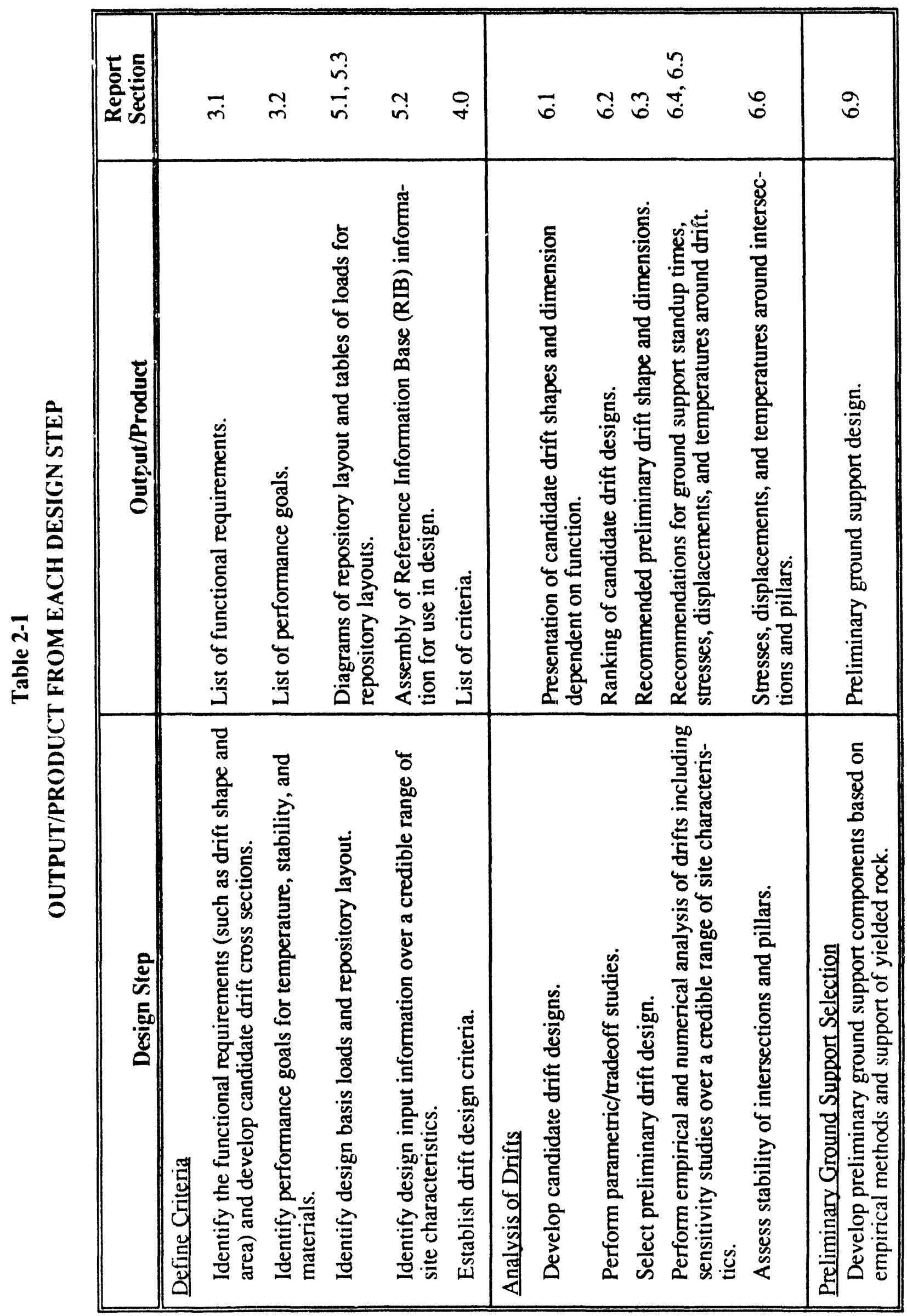




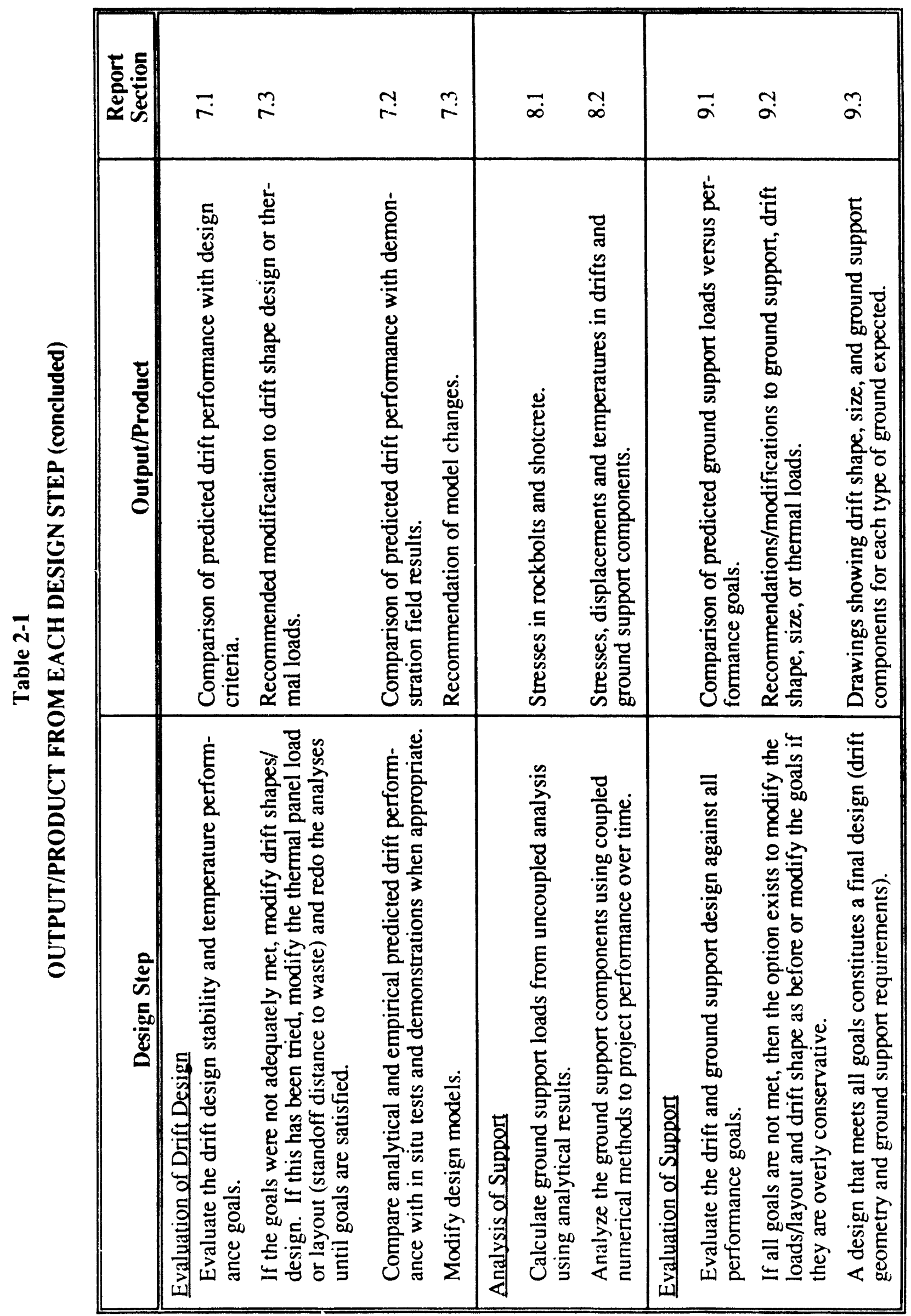




\subsection{DESIGN REQUIREMENTS AND GOALS}

The repository layout, drifts, and support systems must meet the design requirements. Violation of a requirement results in unsatisfactory performance of the repository and possibly violation of a licensing requirement. Requirements include the highest level technical directives issued by the U. S. Nuclear Regulatory Commission (NRC) and other government agencies concerned with worker health and safety and environmental protection, such as the Mine Safety and Health Administration (MSHA) and the Occupational Safety and Health Administration (OSHA). Goals may be established to promote desirable characteristics but are not necessary for stable drift design or long-term repository performance. Goals may also be estabiished when considerable interpretation and judgment are required in evaluating subjective performance measures. Failure to meet one or more of the goals does not indicate noncompliance with a requirement.

Both requirements and goals should propose numbers that can be compared to the results of performance analyses so that an evaluation or assessment can be made. Functional requirements (Section 3.1) and performance goals (Section 3.2) are discussed below. For application to drift design, these requirements and performance goals are summarized as drift design criteria (Chapter 4).

The goals have been proposed in the Site Characterization Plan (SCP) (U. S. Department of Energy (DOE), 1988) and in this document. Their impact on design and the sensitivity of the design to these goals and criteria have yet to be assessed. After the results of preliminary scoping studies and field data are available from the ESF, the goals and criteria may be modified or expressed using different control parameters.

\subsection{Functional Requirements}

Functional considerations, such as the ability of the drift to accommodate equipment, ventilation, and auxiliary systems, lead to functional requirements that specify drift shape and cross-sectional area. The functional requirements for individual drifts also dictate the stability requirements. For example, the main access drifts will be in constant use throughout the preclosure period, so rock falls that impact operations should be avoided. In contrast, minor roof fallouts can be tolerated in the emplacement drifts after waste emplacement. Minor deterioration of the support system is tolerable if routine and planned maintenance can ensure stability and uninterrupted operation of the repository.

Functional requirements dictate two basic parameters, shape and area, during the preclosure period (up to 100 years after waste emplacement). There are no functional requirements placed on the drifts during the postclosure period.

The shape and area functional requirements imply that the drift should be available when required and not unusable because of concern for worker health and safety. An unstable drift is unusable, so a basic requirement for the drift is stability and availability when required. This implies that maintenance or rehabilitation, if required, should be regularly scheduled and not interfere with operations.

\subsubsection{Size and Shape}

The drift must be sized and shaped to accommodate mining and waste emplacement equipment. Adequate clearances for traveling, turning, passing, and rotation of equipment or equipment components (such as booms and emplacement equipment), utilities, auxiliary systems, and ground support components will be required. 


\subsubsection{Drift Cross-Sectional Area}

The drift cross-sectional area requirements stem from ventilation requirements. Minimum air velocities and quantities are required for worker health and safety during mining, emplacement, maintenance, and retrieval. These constraints are met by providing a sufficient cross-sectional area for the drift. Maximum air velocities are also imposed in areas where personnel are exposed.

\subsection{Performance Goals}

Performance goals that influence the design of drifts relate to temperature, stability (nonradiological health and safety), materials, and long-term performance. In most instances, the performance goals are determined by the specific function of each drift. Stability requirements differ depending on the function of each drift. Preliminary performance goals are presented and discussed in the SCP in the context of the issue resolution strategy. These goals serve as an initial definition of performance goals for repository drift design, but are to be interpreted to be compatible with specific design methods and reevaluated periodically as more data become available and the repository design matures.

\subsubsection{Temperature}

Thermal goals are aimed at maintaining the feasibility of drift reentry by personnel for drift inspection, maintenance, or possible waste retrieval after drift cooling. Thermal goals that limit access drift temperature to $50^{\circ} \mathrm{C}$ at the latest possible retrieval time (50 years after waste emplacement) have been proposed. Design variables that allow this goal to be achieved are waste emplacement spacings and the extent of ventilation. Other temperature goals imposed on the waste, canister or container, and rock in the immediate vicinity of the waste may also control waste emplacement spacings.

\subsubsection{Stability}

3.2.2.1 Preclosure Performance Several 10 Codes of Federal Regulations (CFR) 60 regulatiuns address tock stability in the repository. Regulations addressing preclosure stability are concerned with noriradiological worker safety and with maintair.ing the option to retrieve waste up to 50 years after it is emplaced. The regulations do not define the specifics that are needed to judge rock stability. In the SCP (DOE, 1988), goals are identified for closure rates, total closure, drift maintenance, and rock fall quantity and type to ensure drift stability.

Although rock stability is a regulatory requirement, the performance measures used to interpret stability are goals. These goals have been identified in the SCP (DOE, 1988) in discussion of stability requirements to ensure (nonradiological) worker health and safety.

The major factors that impact worker safety are opening stability and ventilation. Opening stability requires that design and construction procedures be established to accommodate conditions expected in construction, waste emplacement, and waste retrieval. The design methodology for the repository drift must include the following:

- the ability to identify unacceptable or marginal areas of ground;

- the ability of the repository construction to adapt to constraints imposed by rock characteristics; and 
maintenance of underground openings during the repository operational period, retrieval operation, and closure.

Section 8.3.2.4 of the SCP (DOE, 1988) discusses project-imposed goals such as the maximum size of rock fall, total rock fall per length of drift, acceptable opening closure, and maintenance frequencies. The goals specific to drift stability from Section 8.3.2.4 of the SCP are summarized in Table 3-1. It is recommended that ground support/rock reinforcement for the areas that are highly trafficked throughout the operational life of the repository, such as the main access drifts and underground workshops, be designed and installed such that no major maintenance or rehabilitation is required during that time. In Table 3-1, minor maintenance refers to maintenance activities schedilled with normal operations and may be completed daily or weekly. Major maintenance requires i hat the drift be taken out of operation while the ground support/rock reinforcement is rehabilitated or replaced.

3.2.2.2 Postc'osure Performance Long-term performance of the drifts refers to postclosure stability of the repository and drifts in particular. Postclosure performance of the repository is concerned with containment of the nuclear waste within the cani-ter and solation of radionuclides from the accessible erivironment. Specific concerns directly related to drift stability are the potential for deleterious rock movement and development of preferential pathways, within the host rock, that could affect waste containment and isolation. Concerns about waste containment are not directly related to drift stability but could be impacted by stability of the boreholes. The drift(s) could conceivably be the initiation location of deleterious rock movements that could develop preferential pathways in the rock mass.

Specific postclosure drift stability goals are identified in Section 8.3.2.2 of the SCP (DOE, 1988) where the issue resolution strategy for Issue 1.11 is presented. Part of the resolution of this issue involves development of the postclosure repository design. The current design basis in the Site Characterization Plan-Conceptual Design Report (SCP-CDR) (SNL, 1987) is that the underground excavations will be backfilled before closure of the underground facility.

Performance measures related to postclosure rock movements around the drifts are identified in Tables 8.3.2.2.1 and 8.3.2.2.4, Volume VI, Part B of the SCP (DOE, 1988). The intent of defining these measures is to ensure that deleterious rock movement is limited and that there is no development of preferred pathways to the accessible environment. The tentative goals derived from these performance measures are:

- to limit relative motion along the top of the upper Topopah Spring Member (TSw1) to less than $1 \mathrm{~m}$,

- to avoid intact rock failure beyond the disturbed zone, and

- to avoid continuous joint slip from the surface to the disturbed zone or from the disturbed zone to the water table.

Another performance measure identified in the SCP that impacts postclosure drift design is the requirement to limit the potential for excavation-induced changes in rock mass permeability. The tentative performance goal listed in the SCP limits the permeability change in the rock $3 \mathrm{~m}$ beyond the drift perimeter to be less than one order of magnitude.

Specific detailed evaluation of postclosure performance of the drifts is not part of the drift design methodology because the postclosure drift performance will be assessed as part of performance confirmation. Should the specific drift design not meet the postclosure requirements, goals will be defined and incorporated into the criteria. 
Table 3-1

STABILITY PERFORMANCE MEASURES AND GOALS FOR REPOSITORY DRIFTS

\begin{tabular}{|c|c|c|}
\hline $\begin{array}{l}\text { Performance } \\
\text { Measure }\end{array}$ & $\begin{array}{l}\text { Tentative Goal from SCP } \\
\text { (DOE, 1988) }\end{array}$ & $\begin{array}{l}\text { Impact } \\
\text { on Design }\end{array}$ \\
\hline $\begin{array}{l}\text { Limit rock damage } \\
\text { (all drifts) }\end{array}$ & $\begin{array}{l}\text { Overbreak }<15 \mathrm{~cm} \text { average } \\
\text { Measurable excavation-technique- } \\
\text { induced damage limited to within } 1 \mathrm{~m} \text { of } \\
\text { the excavation }\end{array}$ & Selection of construction method \\
\hline $\begin{array}{l}\text { Closure } \\
\text { Access drifts } \\
\text { Emplacement drift }\end{array}$ & $\begin{array}{l}\text { Closure rate }<1 \mathrm{~mm} / \mathrm{yr} \\
\text { Total closure in ramps }<7 \mathrm{~cm} \text { in } 100 \mathrm{yr}^{\mathrm{b}} \\
\text { Closure rate }<3 \mathrm{~mm} / \mathrm{yr} \\
\text { Total closure }<15 \mathrm{~cm} \text { in } 100 \mathrm{yr}^{\mathrm{b}}\end{array}$ & $\begin{array}{l}\text { Conservative ground support design } \\
\text { Conservative ground support design } \\
\text { Moderately conservative ground } \\
\text { support design } \\
\text { Moderately conservative ground } \\
\text { support design }\end{array}$ \\
\hline $\begin{array}{l}\text { Rock fall } \\
\text { Main access drifts } \\
\text { All other drifts }\end{array}$ & $\begin{array}{l}\text { No rock falls } \\
<5 \text { tonne average } / 300 \mathrm{~m} \text { of drift/yr } \\
\text { Maximum rock or slab size }<2 \text { tonnes } \\
\text { Rock fall contained by support system }\end{array}$ & $\begin{array}{l}\text { Conservative ground support design } \\
\text { Ground support/rock reinforcement } \\
\text { spacings and capacities recognizing } \\
\text { potential variability down drift and } \\
\text { fallout mechanism } \\
\text { Ground support/rock reinforcement } \\
\text { spacings and capacities } \\
\text { Design spacings and capacities of } \\
\text { support/reinforcement components }\end{array}$ \\
\hline $\begin{array}{l}\text { Maintenance } \\
\text { Main access drifts }\end{array}$ & $\begin{array}{l}\text { Inspection and minor maintenance will be } \\
\text { performed on a continuing basis } \\
\text { Major maintenance frequencies }{ }^{\mathrm{d}}>100 \mathrm{yr} \\
\text { Inspection and minor maintenance fre- } \\
\text { quencies }>5 \mathrm{yr} \\
\text { Major maintenance frequencies }>25 \mathrm{yr}\end{array}$ & $\begin{array}{l}\text { Selection of ground support materi- } \\
\text { als, conservative design } \\
\text { Selection of ground support materi- } \\
\text { als } \\
\text { Selection of ground support materi- } \\
\text { als, conservative design }\end{array}$ \\
\hline \multicolumn{3}{|c|}{$\begin{array}{l}\text { a. SCP recommends blast-induced fracture extent into intact roc } \\
\text { b. Deformation expected to be significantly less. } \\
\text { c. Not currently in } S C P \text {, recommended in this report. } \\
\text { d. SCP recommends }>25 \text { yr. }\end{array}$} \\
\hline
\end{tabular}




\subsubsection{Materials}

Goals that are identified for the materials used in the drift result from potential geochemical interactions, corrosion, and usable life considerations. The concerns, mechanisms, and chemistry are not developed sufficiently to allow quantification of specific design goals. However, some restriction may be placed on the use of Portland cement based grouts and concretes in areas where groundwater could contact both the cement and the waste package because of the adverse effect of these materials on water $\mathrm{pH}$ and possible reduction of the waste package containment period (see SCP Section 8.3.4.2, page 8.3.4.2-31, Volume VI, Part B (DOE, 1988)). Additional studies are required to define specific goals related to the types and quantities of cementitious, organic, and metallic materials emplaced in a drift. The use of specific materials in the repository is primarily a postclosure concern; however, material design life is a preclosure concern affecting maintenance frequency. 


\subsection{DRIFT DESIGN CRITERIA}

The stability, material, and postclosure drift performance goals are a mix of qualitative and quantitative goals that are the basis for the drift design criteria. The drift design criteria are directly used in the evaluation of the adequacy of a particular design. For the numerical design methods, the drift design criteria become limits set on the ground support/rock reinforcement system and components.

Criteria used in assessing the stability of drifts may be specific to either the particular design method or the particular deformation mechanism of concern. For example, an empirical method, such as proposed by Barton et al. (1974) and discussed in Section 6.4, cannot be used to predict the drift closure rate, although by selection of the appropriate excavation support ratio (ESR) - a parameter specific to that methodology - a stable opening suitable for civil engineering applications (which implies low closure rates) would result. An adequate drift design system is one that meets the functional requirements, is constructable, and whose ground support/rock reinforcement system is both practical and economical to install. A practical and economical ground supportirock reinforcement is one that meets the maintenance frequency goals and is not excessive. Selection of ground support components anchored in elastic rock with a high safety factor (SF) on the capacity of the support components would be expected to yield a stable opening.

\subsection{Ground Support/Rock Reinforcement Design}

In Part A of the methodology, a conservative loading on the ground support/rock reinforcement components is assumed, that is, the ground support/rock reinforcement system must support the gravity-induced load of the yielded rock material. If there is no yield in the rock, then no ground support/rock reinforcement is required. This approach is considered conservative because the rock mass will maintain some post-yield strength that is not accounted for in the design method. In Part B of the methodology, the interaction of the rock and the ground support/rock reinforcement components are analyzed and the ground support/rock reinforcement components designed with a suitable SF.

The degree of conservatism in the overall design is reflected in the SF of the ratio of strength to load in those components. The criteria listed in Table 4-1 combine the performance goals of the previous sections and the additional quantitative criteria selected specifically for drift design. These additional quantitative criteria are proposed either to satisfy the qualitative goals identified in the SCP or translate the goals into criteria directly applicable to drift design.

\subsection{Safety Factors}

The SF is defined as the assumed strength divided by the applied stress. This is a difficult parameter to determine for an underground excavation since the SF for the rock mass can only be calculated on a point by point basis and there is no accepted method for integrating such information to obtain a single value representative of the excavation. This problem can be avoidsd by focusing on the design of the engineered components intended to ensure stability.

For the design of underground ground support/rock reinforcement components, there is no universally accepted standard for assessing the loads on the components nor for selecting the SF for design, however, some guidance in this selection of the SF can be found from the design of structural steel and concrete.

Gaylord and Gaylord (1957) suggest that the magnitude of the SF must be based upon considerations of the following: 
Table 4-1

DRIFT DESIGN STABILITY CRITERIA

\begin{tabular}{|c|c|c|}
\hline Perf. Measure & Tentative Goal & Drift Design Criteria \\
\hline Limit rock damage & see Table 3-1 & No criteria \\
\hline $\begin{array}{l}\text { Closure } \\
\text { Main access drift } \\
\text { and ramps }\end{array}$ & $\begin{array}{l}\text { Closure rate }<1 \mathrm{~mm} / \mathrm{yr} \\
\text { Total closure in ramps }<15 \\
\mathrm{~cm} \text { in } 100 \mathrm{yr} \\
\text { Closure rate }<3 \mathrm{~mm} / \mathrm{yr} \\
\text { total closure }<15 \mathrm{~cm} \text { in } \\
100 \mathrm{yr}\end{array}$ & $\begin{array}{l}\text { SF, see Table } 4-3 \text {. Stability equivalent } \\
\text { to major road and railway tunnels } \\
\text { (ESR=1.0). } \\
\text { SF, see Table } 4-3 \text {. Stability equivalent } \\
\text { to storage rooms, water treatment plants, } \\
\text { minor railway tunnels (ESR }=1.3 \text { ). }\end{array}$ \\
\hline $\begin{array}{l}\text { Rock falls } \\
\text { Main access drifts } \\
\text { and ramps } \\
\text { All other drifts }\end{array}$ & $\begin{array}{l}\text { Rock falls } \\
<5 \text { tonne average } / 300 \mathrm{~m} \text { of } \\
\text { drift/yr } \\
\text { Maximum rock or slab size } \\
<2 \text { tonne } \\
\text { Rock fall contained by sup- } \\
\text { port system }\end{array}$ & $\begin{array}{l}\text { Full lining of drift. } \\
\text { Same as for drift closure. } \\
\text { Spacing between support components* } \\
\text { not greater than } 1.5 \text { times the average } \\
\text { joint spacing, r rown bolts anchored in } \\
\text { elastic rock. } \\
\text { Appropriate safety factor for ground } \\
\text { support components*. }\end{array}$ \\
\hline $\begin{array}{l}\text { Maintenance } \\
\text { Main access drifts } \\
\text { and ramps }\end{array}$ & $\begin{array}{l}\text { Inspection and minor main- } \\
\text { tenance will be performed } \\
\text { on a continuing basis } \\
\text { Major maintenance frequen- } \\
\text { cies }>100 \mathrm{yr} \\
\text { Inspection frequency }>5 \mathrm{yr} \\
\text { Major maintenance frequen- } \\
\text { cies }>25 \mathrm{yr}\end{array}$ & $\begin{array}{l}\text { Selection of ground support materials } \\
\text { and sizes to provide adequate unaltered } \\
\text { cross section at } 100 \mathrm{yr} \text {. } \\
\text { Selection of ground support materials } \\
\text { and sizes to provide adequate unaltered } \\
\text { cross section at } 25 \mathrm{yr} \text {. }\end{array}$ \\
\hline Postclosure effects & $\begin{array}{l}\text { No intact rock failure } \\
\text { beyond disturbed zone } \\
\text { No continuum joint slip } \\
\text { beyond disturbed zone } \\
\text { Permeability change within } \\
3 \text { m of excavation limited to } \\
\text { one order of magnitude }\end{array}$ & $\begin{array}{l}\text { Final evaluation of drift/repository per- } \\
\text { formance. }\end{array}$ \\
\hline
\end{tabular}


- variability of the material with respect to strength and other pertinent physical properties,

- $\quad$ uncertainty in the expected live loads in regard to possible future change as well as with respect to present magnitude,

- $\quad$ precision with which the internal forces in the various parts of a structure are determined,

- possibility of deterioration due to corrosion and other causes, and

- $\quad$ extent of damage and loss of life which might result from failure.

For structural steel components, SF are described for various uses. For example, the allowable tension in steel American Institution of Steel Construction (AISC) (Art 9-6) specifies a basic allowable unit tensile stress, $F_{t}=0.6 F_{y}$ where $F_{y}$ is the yield strength of the steel. For bridges, American Association of State Highways and Transportation Officials (AASHTO) (Art 9-6) specifies allowable tensile stresses as the smaller of $0.55 F_{y}$ or $0.46 F_{\mu}$ where $F_{\mu}$ is the ultimate strength. Those numbers were recommended to give a SF range from 1.7 to 1.8 on the yield strength and 2.2 on the ultimate strength.

For design in concrete (or shotcrete) using the working stress theory for reinforced concrete beams, the allowable stress for flexure is $0.45 f^{\prime} c$ in buildings and $0.4 f^{\prime} c$ for bridges, where $f^{\prime} c$ is the specified compressive strength in psi at 28 days. This is a SF of 2.2 or 2.5. Using the ultimate strength theory of reinforced concrete beams, the loads are increased to represent a margin of safety. For example, the member should be designed to have the following ultimate strength $U$ under the following combinations of loads:

$$
U=1.4 D+1.7 L
$$

when wind and earthquake loads are not applied,

$$
U=0.9 D+1.3 W
$$

when wind loads are applied, or

$$
U=0.9 D+1.43 E
$$

when earthquake loads are applied, where $D$ is the effect of basic loads consisting of dead loads plus any shrinkage or temperature loads, $L$ is the live load plus impact, $W$ is the wind load, and $E$ is the earthquake load. The strength of the concrete used to assess the ultimate strength of the member is $0.85 f c$. The combination of the reduction in strength and the increased loads result in a SF as listed in Table 4-2. The simplified representation shown in Table 4-2 can be misleading because when the wind and earthquake loads are considered, the dead load is reduced to 0.9D. The worst combinations of loads as expressed in Equations 1, 2, and 3 would be used for design.

The SF for the design of ground support/rock reinforcement components have been selected to reflect the materials used and the nature of the loads, and are considered conservative with regard to the design methods in structural steel and concrete. Table 4-3 lists the SF for design of the ground support/rock reinforcement components; the steel refers to the steel in rockbolts, plates, straps, or shotcrete/concrete reinforcement and any structural steel that might be specified. Different SF are recommended for the main access and the other drifts and when acted on by "static" and "dynamic" loads. The values listed in Table 4-3 should be used during both Part A and B of the design 
Table 4-2

\section{SAFETY FACTOR FOR CONCRETE DESIGN USING ULTIMATE STRENGTH THEORY}

\begin{tabular}{|l|c|}
\hline Load Type & $\begin{array}{c}\text { Factor of Safety for Ultimate Strength Design for } \\
\text { Reinforced Concrete }\end{array}$ \\
\hline Dead & 1.6 \\
\hline Live & 2.0 \\
\hline Wind & 1.7 \\
\hline Earthquake & 1.7 \\
\hline
\end{tabular}

Table 4-3

\section{RECOMMENDED SAFETY FACTORS FOR DESIGN OF GROUND SUPPORT/ROCK REINFORCEMENT COMPONENTS}

\begin{tabular}{|c|c|c|c|c|}
\hline \multirow[b]{2}{*}{ Load Type } & \multicolumn{2}{|c|}{ Main Access Drift and Ramps } & \multicolumn{2}{|c|}{$\begin{array}{l}\text { Emplacement and Other } \\
\text { Access Drifts }\end{array}$} \\
\hline & Concrete/Shotcrete & Steel & Concrete/Shotcrete & Steel \\
\hline In situ + Thermal & 2.5 & 1.8 & 2.3 & 1.7 \\
\hline In situ + Thermal + Seismic & 2.0 & 1.5 & 1.8 & 1.4 \\
\hline
\end{tabular}

methodology. The SF is higher for shotcrete/concrete components because of the higher variability in the strength of concrete as compared to steel. If other materials are used, appropriate SF should be selected.

\subsection{Drift Design Criteria}

The drift design criteria are summarized in Table 4-1. Incorporated in this table are the SF for the ground support/rock reinforcement components listed in Table 4-3.

The criteria listed above do not specifically address the performance goals listed in Table 3-1, such as rates of movement, rock fall volumes, or maintenance frequency; however, it is argued that the criteria listed above are conservative and should result in stable underground openings with low deformation rates. The selection of the specific ground support components with appropriate hardware (plates, straps, wire mesh, or shotcrete) should ensure that the maximum block fallout between the bolts will be smaller than the 2-tonne limit. The SF on the bolts, shotcrete, or concrete should be adequate to inhibit large roof falls. The conservatism of these evaluation criteria must be validated by field data from the ESF excavation and confirmation testing, and detailed analyses incorporating coupled interaction of the drift, loadings, and ground support components (see Chapter 8). 


\subsection{DESIGN BASIS}

The design basis comprises three components: the stress at the drift location (Section 5.1), the information base (Section 5.2), and the repository conceptual layout (Section 5.3). The stress at the drift location can be considered to be the load(s); the information base, the materials properties, and the repository layout provide a conceptual presentation of the drifts and their functions. At all times, the best data available for the site should be used for design. Ultimately, this will be the site-specific data collected during detailed investigation of the repository horizon. Both now and in the future, a range of feasible rock mass characteristics must be recognized. The partitioning of this range into five design categories is discussed in Section 5.2 of this chapter.

\subsection{Stress at Drift Location}

Stresses resulting from three sources must be considered in designing the drifts: in situ, thermal, and seismic [caused by earthquakes or underground nuclear explosions (UNE)]. The stress at the drift location assumed in the discussion refers to the stress that would exist at the center of the drift if the drift were not present.

The stress at the drift location can be used as an independent input to drift design if the rock mass remains essentially elastic after drift construction. The site was selected because of its overall suitability for repository construction and waste isolation, and preliminary indications are that the tuff at the repository location will respond elastically; see, for example, Dravo Engineers, Inc. (1984), Langkopf and Gnirk (1986), and St. John (1987a). However, if significant rock yielding or joint slip were to occur, the approach of superposition of the regional stresses at the drift locations would be inaccurate, but most probably conservative. (Large-scale rock yielding or slip along a joint or fault would relieve the thermally induced loads thereby reducing the compressive stresses.) The requirement that the rock mass remain essentially elastic does not preclude the potential for localized inelastic behavior around the drift following construction or accompanying thermal loading.

The assessment of the stress effect at the drift location due to each of the loading mechanisms provides a preliminary assessment of the stress environment at the drift location. For the waste emplacement drifts, more detailed assessment of the thermal/mechanical interaction is recommended and discussed in Section 6.5.

The stress at the drift location will change during the life of the repository because of the thermal and seismic loads. In situ stresses are present before drift excavation and will remain unchanged during the preclosure period. Thermal stresses occur after waste emplacement; the timing and magnitude of the temperature-induced load at any particular location is primarily dependent upon its position relative to waste containers, the APD of the waste, the thermal output of individual containers, and the rock mass thermomechanical properties. Seismic induced stress magnitudes and duration are a function of the intensity of the earthquake or UNE, the distance from the event to the drift, and the direction and size of the seismic wave relative to the drift axis.

Superimposed upon the general distribution of stress there will be spatial variation of stresses within the repository caused by material anomalies, the presence of faults, variations in stratigraphy, surface topography, and drift elevations.

\subsubsection{In Situ Stress}

The state of stress existing before disturbance by excavation is the in situ or geostatic state of stress. Bauer et al. (1985a) indicate that three main components contribute to that state of stress 
in shallowly buried tuffs at the Nevada Test Site (NTS). One component, gravitational stress, is induced by the weight of the overburden. A second component, residual stress, is contributed by strain energy stored in the rock during the geologic past. The third component, tectonic stress, is caused by current tectonic forces affecting the region. Stress measurements sense the combined effects of all three components.

The in situ stress state has not been measured directly at the proposed repository horizon. In situ stress values to be used for design will be recommended by the project.

\subsubsection{Thermal}

The thermally induced stresses are generated by the thermal expansion of the rock mass that accompanies temperature change associated with the thermal energy released by the waste. Because the confinement of the rock is principally in the horizontal direction, the horizontal stress component of the thermally induced loads tends to be greater than the vertical stress component.

Thermal stresses at any location depend on the proximity and timing of waste emplacement, the waste heat generation, the age of the waste, and the thermomechanical properties of the rock mass. Repository ventilation during emplacement, maintenance and possibly retrieval can reduce the thermal loads. The thermal loads are dependent on the overall repository design and are a design variable. The thermal loads on the drifts are primarily sensitive to the APD and thermomechanical characteristics, with minor sensitivity to local standoff distance and repository layout details. The thermal stresses can be calculated using two- and three-dimensional thermal and thermomechanical models (discussed in Chapter 6) and the current conceptual layout of the repository, presented in Section 5.3 of the SCP-CDR (SNL, 1987). The thermal stress should be calculated during design at representative locations throughout the repository using the waste forms, ages, and spacings for the candidate repository design.

For waste-emplacement drift design, the thermal loads can be calculated directly in the thermomechanical model as part of the stability analysis. This is possible because symmetry conditions can be assumed at the center of the drift and pillar.

\subsection{3 $\underline{\text { Seismic }}$}

Ground motion associated with either earthquakes or underground nuclear weapons testing could influence the design of the drifts. Such motion may cause damage either as a consequence of shear displacement along faults intersecting the drifts or by failure of the rock mass due to the transient seismic event. This section of the report describes a simplified method of assessing the consequences of ground shaking. Specified provisions for the support of drifts intersected by faults are addressed in Section 6.6.

For the drift design methodology, the seismic events will be assessed analytically following procedures established in the shaft design methodology (Parsons Brinckerhoff Quade \& Douglas, Inc. (PBQD), 1990) and with the event magnitudes established in the Working Group Report, Exploratory' Shaft Seismic Design Basis (SNL, 1990). The Working Group was convened to determine appropriate seismic events for the design of the shafts associated with the ESF, but their report states that much of the design base is also appropriate for seismic design of other shafts and underground structures that do not affect public safety.

The procedures adopted for the shaft lining design assume that the seismic impact can be assessed by static analysis. St. John and Zahrah (1987) conclude that static analysis should be perfectly acceptable when evaluating the response of simple excavations and structures to ground motion with dominant wavelengths typical of earthquakes. Hendron and Fernandez (1983) propose 
that there will be little dynamic amplification if the wavelength is at least eight opening diameters. Frequencies in the range of 0.2 to $20 \mathrm{~Hz}$, which includes both UNEs and earthquakes, and se ismic velocities of 2 to $3.2 \mathrm{~km} / \mathrm{sec}$, result in a minimum wavelength of approximately $100 \mathrm{~m}$, or approximately 15 times the drift cross-sectional dimension.

Recommended control motions from the Exploratory Shaft Seismic Design Basis (SNL, 1990) are as follows:

For Earthquakes:

Maximum horizontal component of acceleration $0.3 \mathrm{~g}$

Maximum vertical component of acceleration $0.3 \mathrm{~g}$

Maximum horizontal component of velocity $30 \mathrm{~cm} / \mathrm{sec}$

Maximum vertical component of velocity $20 \mathrm{~cm} / \mathrm{sec}$

For UNEs:

Maximum vertical component of acceleration $0.2 \mathrm{~g}$

Maximum radial component of acceleration $0.1 \mathrm{~g}$

Maximum traverse component of acceleration $0.1 \mathrm{~g}$

Maximum vertical component of velocity $9 \mathrm{~cm} / \mathrm{sec}$

Maximum radial component of velocity $12 \mathrm{~cm} / \mathrm{sec}$

Maximum traverse component of velocity $12 \mathrm{~cm} / \mathrm{sec}$

where $g$ is acceleration caused by gravity, $9.8 \mathrm{~m} / \mathrm{sec}^{2}$. The Working Group Report further recommends that the performance of the exploratory shaft be confirmed using best estimate conditions when subject to ground motions that are a factor of 1.67 times the proposed control motions on drift stability.

The control motions converted into quasi-static strains or stresses can be treated in the opening design as additional quasi-static design loads. The seismic stresses can be either tensile or compressive and both need to be assessed because different failure mechanisms can be induced by the tensile or compressive stresses. The orientation of the seismic wave relative to the drift axis and rock structure affects the impact of the seismic event on drift stability. In the absence of a preferred direction for earthquakes or UNEs, drifts of all orientation are assumed equally impacted by the seismic events.

The Working Group Report (SNL, 1990) provides guidance as to the methodology to translate the control motions to design strains or stresses. The ground motions can be converted into strains using Tables 5-1 or 5-2, depending on the orientation of the incident wave. In these tables, the ground motion has been decomposed into three different wave forms, each traveling with a different velocity but in the same direction. The propagation speed of the compressional wave (P-wave) is $C_{p}$, while the propagational speed of the shear waves (SH and SV) is $C_{2}$. The Working Group Report suggests that earthquake waves be restricted to an angle of incidence of 0 to 30 degrees from the vertical, whereas the UNEs are expected to arrive at angles of incidence that are near horizontal. Figure 5-1 illustrates the coordinate system and defines the angle of incidence, $\theta$. As noted earlier, the direction of the $x$ and $y$ coordinates or the direction of travel of the seismic wave is not restricted.

Alternate incidence angles and combinations of $\mathrm{P}, \mathrm{SV}$, and $\mathrm{SH}$ waves should be evaluated to assess the maximum impact of the seismic wave on drift stability. When P, SV, and SH waves are combined, it must be recognized that the compressional and shear waves do not travel at the same velocity, but because of uncertainty in the duration of the wave and the source location, a conservative assumption regarding addition of $P$ and $S$ waves must be adopted. The approach adopted for the YMP shaft design methodology (PBQD, 1990) is recommended. This approach is 
Table 5.1

FREE-FIELD STRAINS CAUSED BY EARTHQUAKE EVENTS

FOR STEEP ANGLE OF INCIDENCE

\begin{tabular}{|c|c|c|c|c|c|c|}
\hline \multirow[b]{2}{*}{$\begin{array}{l}\text { Wave } \\
\text { Type }\end{array}$} & \multicolumn{6}{|c|}{ Free-Field Strains } \\
\hline & $\varepsilon_{x x}$ & $\varepsilon_{y y}$ & $\varepsilon_{z z}$ & $\tau_{x y}$ & $\tau_{y z}$ & $\tau_{x z}$ \\
\hline$P$ & $\frac{v_{v}}{c_{p}} \frac{\sin ^{2} \theta}{\cos \theta}$ & 0 & $\frac{v_{v}}{c_{p}} \cos \theta$ & 0 & 0 & $\frac{v_{v}}{c_{p}} 2 \sin \theta$ \\
\hline SV & $\frac{v_{h}}{C_{s}} \sin \theta$ & 0 & $\frac{v_{h}}{c_{t}} \sin \theta$ & 0 & 0 & $\frac{v_{h}}{c_{1}} \frac{\cos 2 \theta}{\cos \theta}$ \\
\hline SH & 0 & 0 & 0 & $\frac{v_{h}}{c_{1}} \sin \theta$ & $\frac{v_{k}}{c_{l}} \cos \theta$ & 0 \\
\hline
\end{tabular}

Table 5-2

FREE-FIELD STRAINS CAUSED BY UNE EVENTS FOR SHALLOW ANGLE OF INCIDENCE

\begin{tabular}{|c|c|c|c|c|c|c||}
\hline $\begin{array}{c}\text { Wave } \\
\text { Type }\end{array}$ & $\varepsilon_{x x}$ & $\varepsilon_{y y}$ & $\varepsilon_{z z}$ & $\tau_{x y}$ & $\tau_{y z}$ & $\tau_{x z}$ \\
\hline \hline $\mathrm{P}$ & $\frac{v_{h}}{c_{p}} \sin \theta$ & 0 & $\frac{v_{h}}{c_{p}} \frac{\cos ^{2} \theta}{\sin \theta}$ & 0 & 0 & $\frac{v_{h}}{c_{p}} 2 \cos \theta$ \\
\hline $\mathrm{SV}$ & $\frac{v_{v}}{c_{s}} \cos \theta$ & 0 & $\frac{v_{v}}{c_{s}} \cos \theta$ & 0 & 0 & $\frac{v_{v}}{c_{s}} \frac{\cos 2 \theta}{\sin \theta}$ \\
\hline $\mathrm{SH}$ & 0 & 0 & 0 & $\frac{v_{h}}{c_{s}} \sin \theta$ & $\frac{v_{h}}{c_{s}} \cos \theta$ & 0 \\
\hline
\end{tabular}

where $v_{n}=$ horizontal component of velocity in $x$ direction

$v_{v}=$ vertical component of velocity

$c_{p}=$ compressional wave velocity

$C_{1}=$ shear wave velocity

$\theta=$ angle of incidence (from vertical) 


\section{FAR-FIELD STRAINS}
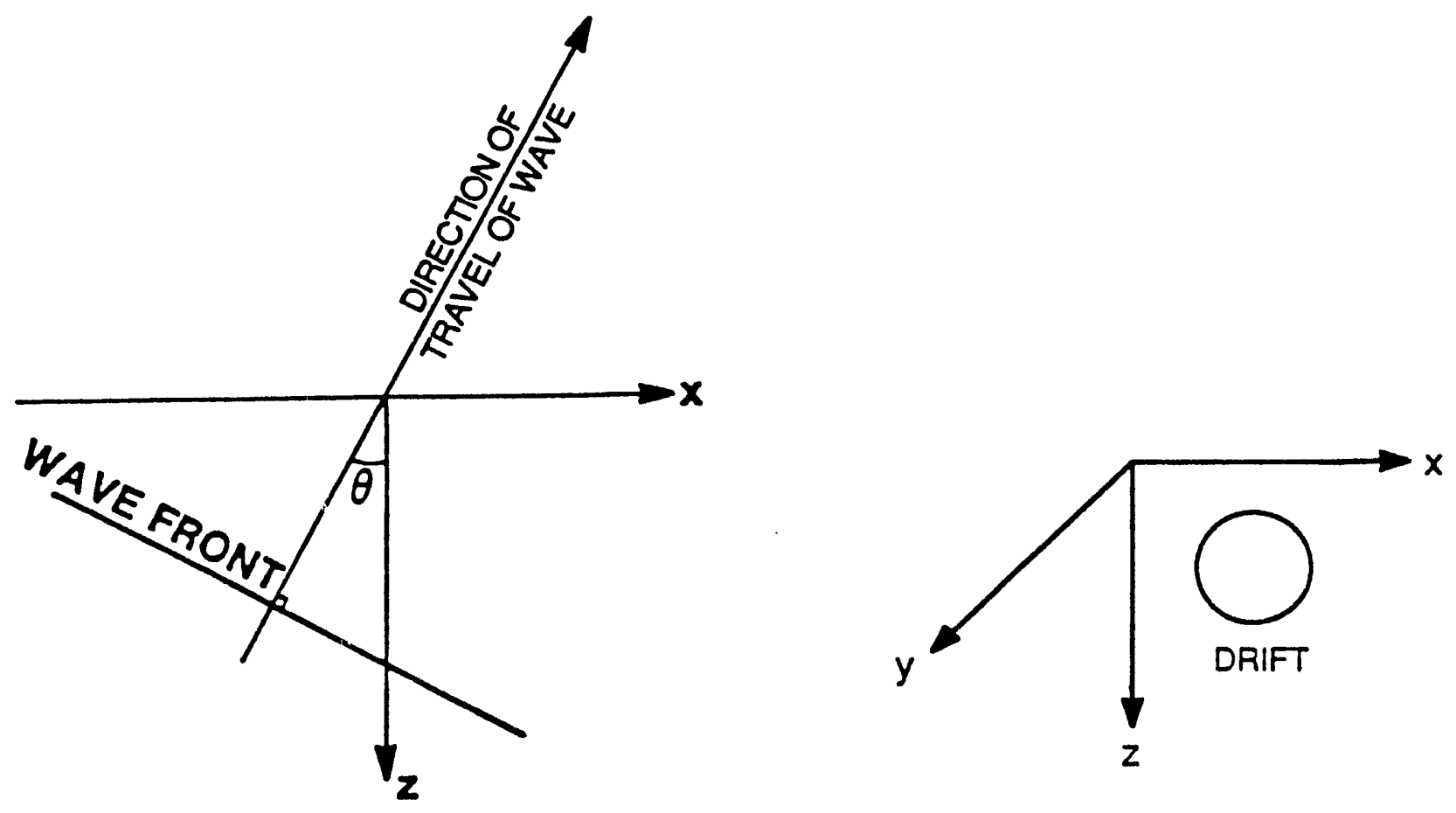

\section{Angle of Incidence $\theta$ \\ (Body wave propagating in $\mathrm{X}-\mathrm{Z}$ plane)}

Figure 5-1. Wavefront Angle of Incidence $\theta$ Relative to Drift 
based on the 100-40-40 combination rule published by Newmark and Hall (1977). Simply stated, this rule combines $100 \%$ of the peak of all stress combinations that must occur simultaneously with $40 \%$ of the peak value of those stress effects caused by different wave types. The combinatiun that produces the most adverse conditions for drift stability is chosen for the design basis.

For drift design, several criteria for determining the maximum impact of the seismic wave on drift stability are suggested in Table 5-3. Incidence angles and combinations of $\mathrm{P}, \mathrm{SV}$, and $\mathrm{SH}$ waves should be varied to maximize one of the listed criteria (Table 5-3). The first criterion is directed toward the potential for compressive failure in the roof or floor. The second criterion evaluates the impact of the seismic load on existing joints in the geologic unit of interest, and the third and fourth assess the possibility of tensile stresses allowing block movement in the ribs or crown. The concentration of the seismic wave caused by the excavation must be taken into account in assessing the orientation of the seismic wave that causes the most impact on drift stability. To simplify the assessment of the critical seismic wave orientation, the drift can be assumed circular. Once the critical angles are assessed, the equivalent far-field stress can be calculated.

Table 5-3

CRITERIA FOR ASSESSING SEISMIC WAVE IMPACT ANGLE

\begin{tabular}{|l|l|}
\hline \multicolumn{1}{|c|}{ Criterion } & Potential Impact \\
\hline \hline Maximum compressive stress in the crown or floor of the drift & $\begin{array}{l}\text { Roof or floor slab- } \\
\text { bing }\end{array}$ \\
\hline Maximum shear stress on joints (one or more sets) & Slip along joints \\
\hline Maximum tensile stress in ribs of the drifts & Wall slabbing \\
\hline Maximum tensile stress in the crown of the drift & Block fallout \\
\hline
\end{tabular}

\subsubsection{Stress Combinations}

Seismic stresses are considered transient. On the other hand, thermal stresses are considered static because the rate of change of the thermal stresses are low relative to the response of the rock and the period of interest (preclosure period). In situ stresses are static and do not change over the time period of concern. Because of these differences (static versus transient), the in situ and thermal stresses are analyzed separately from the seismic loads.

For elastic rock and support system response, the stress contribution from seismic, in situ, and thermal sources can be added algebraically. If any component of the system responds nonlinearly, then the time sequence of stress application should be evaluated. Combinations of stresses should consider the following:

- $\quad$ in situ plus seismic stresses,

- $\quad$ in situ minus seismic stresses,

- $\quad$ in situ plus thermal stresses,

- in situ plus thermal plus seismic stresses, and

- $\quad$ in siiu plus thermal minus seismic stresses. 


\subsubsection{Design Basis Loads for Specific Rock Categories}

For specific rock categories, the rock mass modulus and other properties may differ; Hence, the seismic and thermally induced stresses will not be the same for each category. If all other parameters are the same but the elastic modulus differs between each category, then the stress change can be scaled as illustrated in Equation 4.

$$
\Delta \sigma_{D A}=\frac{E_{D A}}{E_{R}} \Delta \sigma_{R}
$$

where $\Delta \sigma_{D A}=$ stress change in drift analysis,

$\Delta \sigma_{R}=$ stress change from reference analysis,

$E_{D A}=$ elastic modulus in drift analysis, and

$E_{R}=$ elastic modulus used in reference calculation.

\subsection{Information for Design}

Data on the stratigraphy, thermal and mechanical properties, and characteristics of waste, rock structure, and ground support are required to perform the analyses and evaluate the design. The database for design is presented in the YMP (1989). The methodology document identifies additional parameters that need to be included in the RIB. These new parameters will have to be defined during the site characterization phase.

To simplify the application of the design methodology to the spacially variable in situ conditions, it is recommended that the methodology be applied to five categories selected to represent the credible range of expected conditions. The assumption has been made that the range of a parameter is normally distributed about the mean value, unless site-specific data or other fundamental considerations indicate otherwise. The parameters for each of the five categories ranging from poorest to best (from a structural stability viewpoint) can be selected so that the percentage of rock better than each individual category is $95,80,60,30$ and 10 . Note that the percentage of rock encountered underground in each of the five categories will differ from the percentages indicaied by this section because the least and most favorable characteristics are combined into Categories 1 and 5, respectively.

Both naturally occurring structural characteristics and the effect of construction method on the rock and structural characteristics local to the drift wall must be considered in the design of the drifts. Although this design methodology will not provide input to the decision or selection of the excavation method, it is necessary to assume that the excavation method will be benign with respect to stability; i.e., the blast damage zone will be minimized (as required by 10 CFR 60 ) through the use of either smooth wall blasting or mechanical mining.

\subsubsection{Stratigraphy and Rock Structure}

5.2.1.1 Stratigraphy Analyses typically require information on the three-dimensional distribution of stratigraphic units or subunits as well as their thermomechanical properties. Generally, the Topopah Spring Formation is gently dipping and will encompass all repository excavations, excluding ramps and shafts. However, the Formation is intersected by faults, is fractured, and exhibits variability in the degree of welding and porosity. The relationship between porosity and welding and other rock mechanical properties should be assessed to assist in the prediction of variability of the mechanical properties throughout the Topopah Spririg Formation. 
5.2.1.2 Jointing The geometric description of the jointing is important in estimating drift stability. This description includes the orientation of joints or joint sets, joint spacings, joint continuity, and joint roughness, as well as the nature and thickness of any infilling materials.

The mechanical characteristics of the jointing include the relationship between joint closure, shear deformation, normal and shear stresses. Parameters required for models of the joirted rock system include half-closure stress, friction, cohesion, continuity, dispersion, length, and orientation. Each is discussed briefly in Section 5.2.4. The empirical design methods use specific numbers such as the rock quality designation (RQD), joint set number $\left(J_{N}\right)$, joint roughness coifficient $\left(J_{R}\right)$, and joint alteration coefficient $\left(J_{A}\right)$ to define joint parameters. These parameters are specifically defined by Barton et al. (1974).

5.2.1.3 Rock Quality Designation The RQD is a convenient and simple index used to quantify the degree of jointing in a rock mass. It is used in many of the empirical schemes and as an imporant index in the estimate of the rock mass physical properties.

It is recommended that the RQD be assessed for the five rock mass quality categories based on the available core hole or drift mapping data. For the ESF drift design, the RQD data for core holes intersecting the main test level and exploratory drift horizons plus or minus $12 \mathrm{~m}$ within the repository block should be used to assess the statistical variability of RQD.

The joint spacings required for many analytical models can be determined directly from core, drift mapping, or estimated from RQD data. Variations in the $R Q D$ provide a rational basis for developing the different spacings for each rock quality category. Equation 5, proposed by Hudson and Priest (1979), can be used to relate total joint frequency to RQD:

$$
R Q D=100 e^{-0.1 \lambda}(0.1 \lambda+1),
$$

where $\lambda=$ mean joint frequency $m^{-1}$.

\subsubsection{In Situ Conditions}

In situ conditions refer to the initial conditions existing before repository construction and waste emplacement. Initial conditions include the temperature distribution, in situ stress and groundwater saturations, pore pressures, and groundwater velocity gradients. The in situ stresses have been discussed in Section 5.1.1.

The temperature distribution is generally described by the surface temperature and thermal gradient. The surface temperature fluctuates with the seasons, but 20 to $30 \mathrm{~m}$ below the surface, temperature is generally independent of the seasons. For repository design, the temperature profile near the repository horizon is of consequence and can be obtained from borehole data in the repository block.

For a location above the water table, the degree of saturation describes the groundwater condition. Many thermal/mechanical properties are dependent on the degree of saturation and vary with temperature because of vaporization of the groundwater. Heat transfer can also be affected by migration of fluid or fluid vapor.

\subsubsection{Thermal Properties}

Conduction is assumed to be the predominant heat transfer mechanism of concern for drift design. Thermal properties include thermal capacitance, thermal conductivity, and the thermal expansion coefficient. The thermal diffusivity can be calculated from the thermal capacitance and 
thermal conductivity. The above properties are known to be dependent on temperature, moisture, and porosity for the rock units at the repository location. For drift design, the effect of moisture on the thermal properties is accommodated in a temperature dependence of the thermal capacitance. The thermal properties of the rock mass can be determined by laboratory tests on small representative samples of rock, whereas the mechanical rock mass properties are more complex and dependent on joint and matrix properties.

\subsubsection{Mechanical Properties}

Mechanical properties are required to describe the deformational response of the rock mass to changes in stress or temperature. Mechanical properties are defined for different constitutive models used to characterize the deformational response. These models include equivalent-continuum, ranging from linear elastic to compliant joint, and discontinuum. The equivalent-continuum, linear elastic models use rock mass properties selected to represent the response of a large-scale rock mass including the response of joint and intact rock. The rock mass properties often are scaled down from the intact rock properties to account for size effects, jointing, and inhomogeneities. The compliant joint continuum models incorporate the specific properties of joints and intact rock to develop a continuum model that generally assumes a uniform and pervasive presence of joints. These models may be nonlinearly elastic and/or incorporate yielding along joint planes. Both static and dynamic mechanical properties are required for design.

Values for mechanical rock properties, such as strength and modulus, are generally scale-dependent and can represent laboratory (intact) or rock mass scales. Laboratory values are generally based on small samples of rock with neither local nor large-scale discontinuities nor inhomogeneities present. Intact values determined in the laboratory represent the behavior of the rock between discontinuities. The intact rock modulus and strength values are generally based on laboratory values determined at standard room temperature with strain rate and moisture conditions following standardized procedures from the American Society of Testing Materials (ASTM) or International Society of Rock Mechanics (ISRM). Laboratory values form the basis for estimating in situ field or design values to account for such factors as strain rate, water saturation, temperature, and sample shape, which in laboratory tests may differ from the field conditions. Rock mass values incorporate the effect of intact rock properties with the effect of joints and inhomogeneities evident in large volumes of rock containing a representative sampling of large-scale discontinuities. The presence of joints reduces the modulus (stiffness) of the rock and reduces the overall strength in most cases.

5.2.4.1 Elastic Modulus Values of parameters defining the rock mass properties are required for application of any numerical model in which the properties of individual joints are not recognized (the equivalent-continuum model). Unfortunately, there are no standardized methods for calculating rock mass properties from intact rock, and joint characteristics have been developed. Given the complexity of natural jointed rock mass systems, it is unlikely that a simple, universally applisable method will evolve.

The methods used to estimate rock mass properties include empirical schemes and mechanistic approaches that include intact and joint properties; see, for example, Singh (1973) and Gerrard (1982). The empirical methods correlate indices of rock mass quality, such as the Norwegian Geotechnical Institute (NGI) geomechanics Q classification (Barton et al., 1974) or rock mass rating (RMR) (Bieniawski, 1979), to the rock mass modulus $(E)$ measured in the field-see, for example, Figure 5-2. One such correlation, originally suggested by Serafim and Pereira (1983) and recently recommended by Hoek and Brown (1988), is as follows:

$$
E=10^{\left(\frac{R M R \cdot 10}{\omega}\right)},
$$



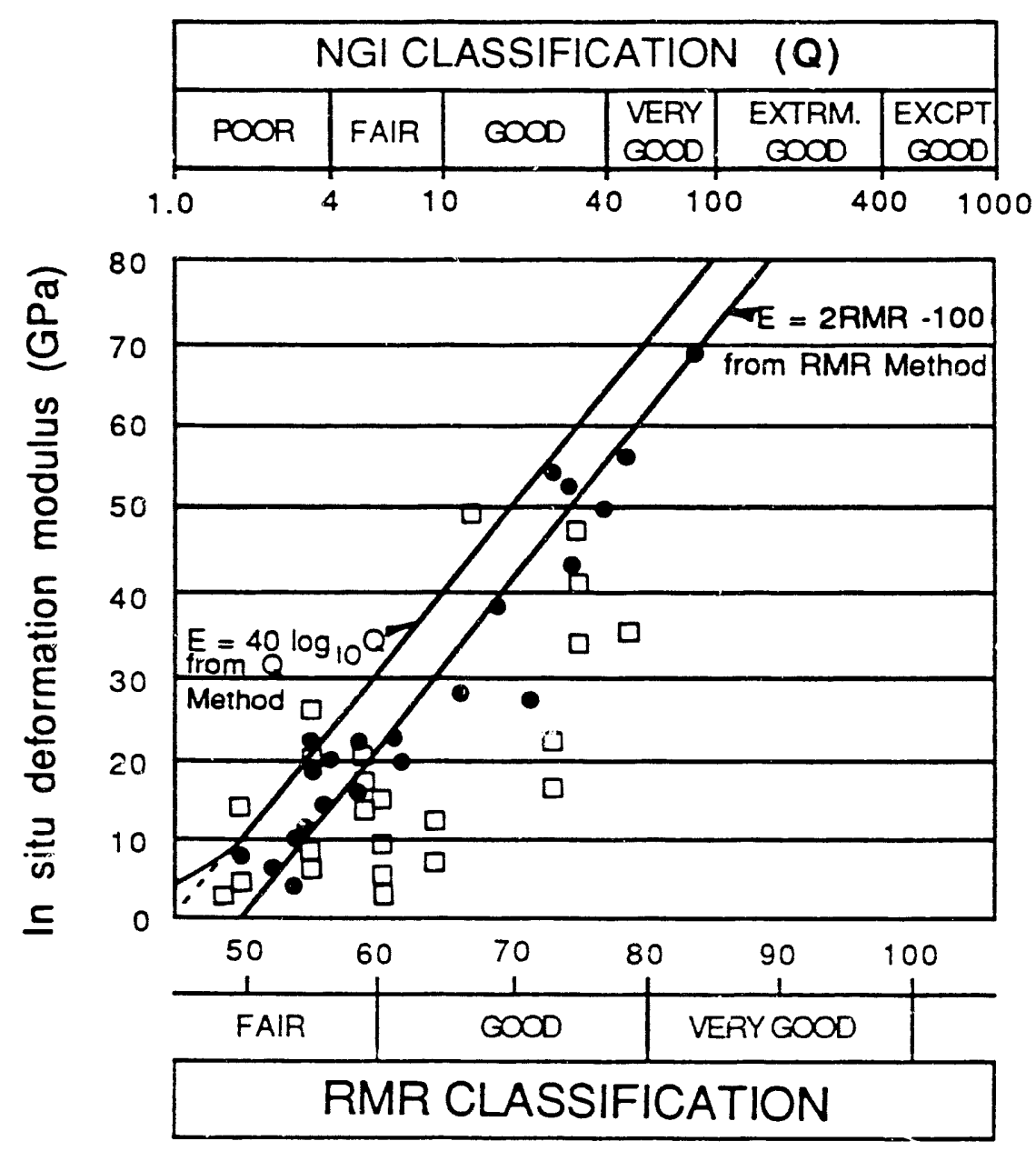

\section{LEGEND}

- RMR Classification System

Barton Data

Figure 5-2. Estimation of In Situ Deformation Modulus from Classification Methods (Barton et al., 1980) 
where $E$ is in GPa. This expression is considered preferable to alternatives shown in Figure 5-2, and has been adopted for this methodology because it does not generate negative $E$ values. One obvious limitation of all the empirically based formulae is that the resulting $E$ value is independent of the intact rock elastic modulus. But in practice, the upper limit for the rock mass modulus should be the intact, rock modulus.

5.2.4.2 Poisson's Ratio Poisson's ratio is defined for isotropic rock as the ratio of lateral strain to vertical strain when stressed in the vertical direction. Very few full-scale field measurements of the Poisson's ratio have been recorded and there is no evidence of how it might vary with rock quality. Accordingly, it is recommended that the value obtained through laboratory testing of intact samples be used for design analysis.

5.2.4.3 Mechanical Properties of Intact Blocks . The mechanical properties of blocks of intact rock are required for input to the equivalent-continuum and discrete block models. For these the laboratory elastic modulus parameters are used. To assess crushing of intact blocks, the strength of the intact blocks is required.

The strength of individual, intact blocks of matrix material should recognize the influence of size on the block strength as indicated by Price (1986). Block size can be defined by the frequency of vertical joints with the strength of the block calculated by the size-strength relationship developed by Price (1986),

$$
\sigma_{c}=1944 D^{-0.846}+69.5
$$

where $\sigma_{c}=$ uniaxial compressive strength (MPa), and

$D=$ sample diameter $(\mathrm{mm})$.

Failure of confined intact blocks can then be evaluated using a Hoek and Brown strength equation of the form shown in Equation 9, with the uniaxial compressive strength defined by Equation 7 and $s=1.0$.

5.2.4.4 Rock Mass Strength The estimation of the rock mass strength from empirical evidence follows similar logic to that adopted for the elastic modulus, but because field measurements are fewer, the algorithms for estimating rock mass strength are based more on analogy with small-scale testing of fractured materials and engineering judgment. The empirical methods start from the assumption that the strength can be characterized by a failure envelope involving the least confining stress, but provides no description of the post-yield behavior of the rock mass. The recommended procedure for estimating rock mass strength is to average two credible methods and fit the resulting curve to a power law form. The empirical strength criteria of Yudhbir et al. (1983) and Hoek and Brown (1988) are both considered credible because they are based on laboratory testing of fractured rocks and extensive field experience. Their estimated strengths are not the same as shown in Figure 5-3. Both algorithms include the RMR and the laboratory compressive strength of the rock $\left(\sigma_{c}\right)$.

Yudhbir et al. (1983) used the generalized form of the equation first proposed by Bieniawski (1974) to represent the rock mass strength dependence on confining stress. The Yudhbir et al. (1983) general equation is:

$$
\sigma_{1}=A \sigma_{c}+B \sigma_{c}\left(\frac{\sigma_{3}}{\sigma_{c}}\right)^{\alpha},
$$




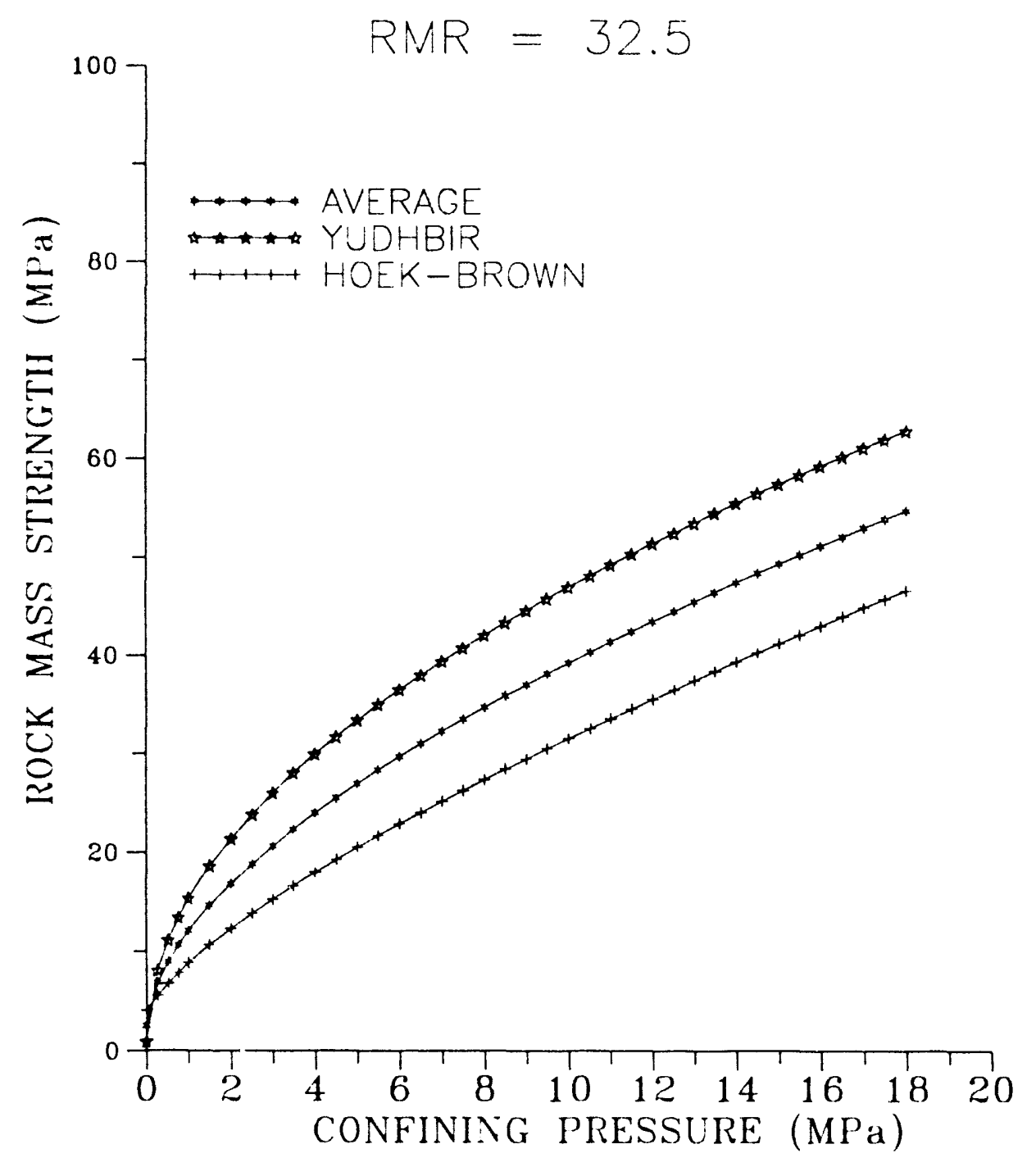

Figure 5-3. Averaging of Hoek and Brown and Yudhbir Failure Criteria for RMR $=32.5$ 
where $\sigma_{c}$ is the lab scale intact compressive strength; parameters $\alpha, \beta$ and $A$ are determined for a number of rock types. For tuff rock, Yudhbir et al. (1983) recommended that

$$
\begin{aligned}
& \alpha=0.5046 \text { and } \\
& B=1.144 .
\end{aligned}
$$

The parameter $A$ was found to be dependent on the RMR as follows:

$$
A=e^{(0.0765 \mathrm{RMR}-7.65)} \text {. }
$$

The Hoek and Brown (1988) equation for undisturbed rock is

$$
\sigma_{1}=\sigma_{3}+\sqrt{m \sigma_{c} \sigma_{3}+s \sigma_{c}^{2}},
$$

where $\begin{aligned} m & =m_{k} e^{(\mathrm{RMR} \cdot 100) / 28} \text {, and } \\ s & =e^{(\mathrm{RMR} \cdot 100) / 9}\end{aligned}$

$m_{i}$ is determined from laboratory triaxial strength data. For tuff, laboratory data indicates a value of approximately 3.0 .

Values for the parameters $\alpha$ and $B$ (Equation 8), and $s$ and $m_{i}$ (Equation 9) are found by best fit procedure for laboratory test data from the repository horizon.

Predicted values of $\sigma_{l}$ for various levels of confining stress from the two criteria are averaged and the resulting $\sigma_{1}, \sigma_{3}$ pairs fit with the power law criteria of the form $\sigma_{1}=A+B \sigma_{3}^{c}$. Figure 5-3 illustrates this process for a rock mass rating (RMR) equal to 32.5. To develop the Mohr-Coulomb strength parameters, a linear-least-square-best-fit-straight-line-curve can be developed for the $\sigma_{1}-\sigma_{3}$ relationship to approximate the power form for each rock mass category. The best fit procedure should include the range of confining pressures controlling drift stability notable from zero to approximately $3 \mathrm{MPa}$.

5.2.4.5 Rock Mass Tensile Strength Correlations between rock mass tensile strength and rock mass quality are not available, although it can be expected to be dependent on the joint strength and persistence. The rock mass tensile strength is required in several continuum models of the rock mass. For drift design, it is recommended that the rock mass tensile strength be set at the value of one-half the rock mass cohesion, predicted using the joint persistence criteria derived in the following section. Sensitivity of drift stability to the rock mass tensile strength should consider the zero tensile strength condition.

5.2.4.6 Joint Properties For the mechanistic methods of estimating rock mass properties, an estimate of the joint orientation, patterns (number of joint sets), spacing, and continuity are required, as well as estimates of their mechanical properties such as stiffness, strength, and roughness. The mechanical response of joints to normal and shear displacements is complex and variable requiring definition of a joint model. The CJM of Thomas (1982) and Chen (1987) uses a joint model describing the normal closure, normal stress relationship of the form

$$
\sigma_{n n}=\frac{A_{n} u}{u_{\max }-u},
$$

where $\begin{array}{ll}A_{n} & =\text { the half-closure stress, } \\ u_{\max } & =\text { the maximum closure of the joint, } \\ u & =\text { the joint normal closure, and } \\ \sigma_{n n} & =\text { the joint nomal stress. }\end{array}$ 
The shear characteristics are described by the elastic shear stiffness $G_{s}$, a post-yield shear stiffness $G_{s}^{\prime}$, and a linear Mohr-Coulomb criterion to determine the onset of yield. Other methods of characterization of the joints, such as that of Barton (1982) which incorporates joint dilation, have also been used within the YMP (Costin and Bauer, 1991).

The most common method used to quantify the strength of a joint uses a Mohr-Coulomb strength envelope that is described by the joint cohesion and friction angle. Barton (1982) uses the joint roughness and rock wall strength in a formulation of strength. Cundall and Hart (1984) describe the joint behavior using a continuously yielding mudel which allows for path dependence in the joint response.

In practice, many joints are discontinuous, requiring both failure of intact material at the termination of joints and slip along existing joints for large-scale failure to occur. One simple method to approximate the strength of a discontinuous joint is to assign a strength to the joint that is equal to the length-weighted average of the strengths of the joint and the unjointed material. Brown (1971) evaluated the validity of such an approach using model materials and found the approach reasonable for higher stress levels. For a Coulomb representation of the joint strength, the weighted average strength for the effective joint properties would be

$$
c_{j}^{e}=\chi c_{j}+(1-\chi) c_{r}
$$

and

$$
\phi_{j}^{e}=\chi \phi_{j}+(1-\chi) \phi_{r}
$$

where $\chi=$ continuity of the joint,

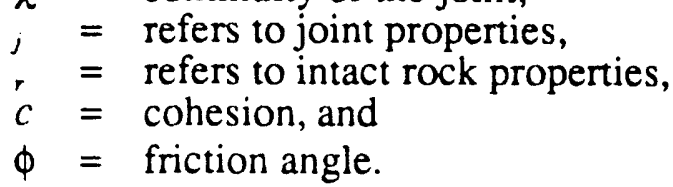

For drift stability assessment, a $1 \mathrm{~m}$ zone around the drift perimeter is defined in which the joint strength and response is controlled by the actual joint, not the average joint characteristics. In this zone, the unweighted joint properties should be used. The actual zone in which damage or slip occurs may exceed this $1 \mathrm{~m}$ but should not exceed $3 \mathrm{~m}$ if the damage control goal established in Chapter 4 is to be met.

\subsubsection{Waste Characteristics}

Two types of fuel will be disposed of in the repository: (1) spent fuel consisting of a mixture of rods from either pressurized water reactors (PWR) or boiling water reactors (BWR), and (2) defense high-level waste (DHLW). The initial power per container and the decay over time is different for both types of waste. In addition, the burnup, the degree of heavy metal concentration, and the waste age influence the thermal decay characteristics. For convenience in analyses, the decay is represented by a series of exponential functions.

In assessing drift stability, the thermal loading is a function of the waste characteristics and the spacings of the waste and the timing of emplacement. One parameter used to quantify the density of the emplacement waste which is directly correlated to the thennal loads on the drifts is the APD. The APD is the total thermal power of waste containers in a panel at the time of 
emplacement divided by the area of the panel. For average spent fuel waste $(60 \% 33,000$ MWd/MTIHM* PWR, 40\% 27,500 MWd/MTIHM BWR) at 8.55 years out of reactor, the APD per emplacement panel given by the SCP-CDR is $57 \mathrm{~kW} /$ acre. The allowable APD of $57 \mathrm{~kW} /$ acre was selected by Johnstone et al. (1984) to meet thermal and stability criteria established at that time. The allowable APD for the Advanced Conceptual Design (ACD) should be reevaluated with regard to current performance assessment objectives, goals, and criteria for temperature and stability.

For ACD drift design, the highest possible and the most probable thermal loading should be considered. The highest possible thermal impact to stability may include younger waste at higher APD or older waste. The most probable thermal loading should be based on the design basis APD (currently $57 \mathrm{~kW} /$ acre) with the highest possible up to $40 \%$ higher. The least thermal load, although less critical, should be evaluated in combination with seismic loads. It is suggested that the design basis APD be used in regional studies with local variations in APD loading being considered for single drifts, but not averaged over an entire panel. Locally, higher APD may be specified at the perimeter of the repository to ensure that temperature criteria are met throughout the emplacement drifts and emplacement boreholes during the postclosure period.

\subsubsection{Ground Support Properties}

The mechanical and chemical properties of the ground support components are required for the design of the drifts. The mechanical properties of supports (stiffness and strength) can be more easily quantified than the mechanical properties of the rock and the potential water chemistry interactions between the support components and the groundwater. The postclosure performance goals may restrict the selection of materials available for ground support.

Properties of typical components for repository drift ground support include bolt strength and stiffness; grout strength, stiffness, and durability; and shotcrete strength and corrosion potential. Properties of bolts are generally available from commercial suppliers. The bonding and anchorage characteristics depend on local conditions. Shotcrete and concrete mixes can be designed to meet specifications for strength and deformability. The effect of elevated temperature on ground support/rock reinforcement components should be assessed before final selection.

\subsection{ESF Repository Layout}

The repository and ESF layout described in the SCP-CDR is presented for reference and to provide the starting point for future drift designs. This layout provides the dimensions of panels, the standoff between heated areas and drifts, and the size and shapes of the drifts. These sizes and shapes have been selected on the basis of earlier design efforts intended to ensure that the excavation will meet the functional requirements. So far the methodology described in this report has not been used to determine whether the design also meets stability requirements.

Layouts and three-dimensional perspectives of the repository and ESF are presented in Figures 5-4, 5-5, and 5-6. The Main Test Level (MTL) of the ESF is designed to accommodate specific tests and to explore ground conditions over a significant area of the repository. Provided the site is acceptable, portions of the ESF are then converted for repository use. The ESF design (Figure 5-5) represents the Title I design phase described in Section 8.4 of the SCP.

\footnotetext{
*megawatt day/metric ton of initial heavy metal
} 


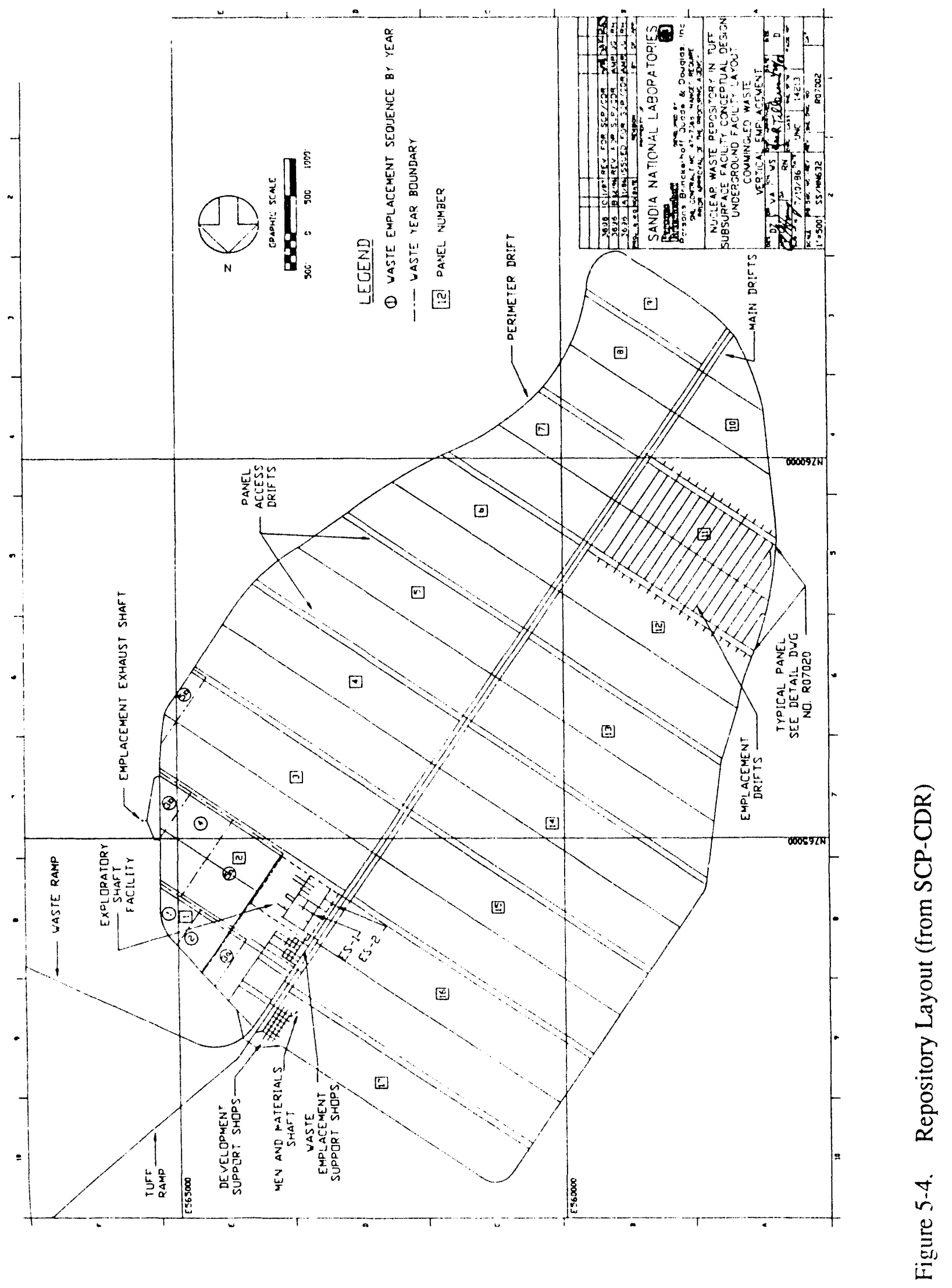




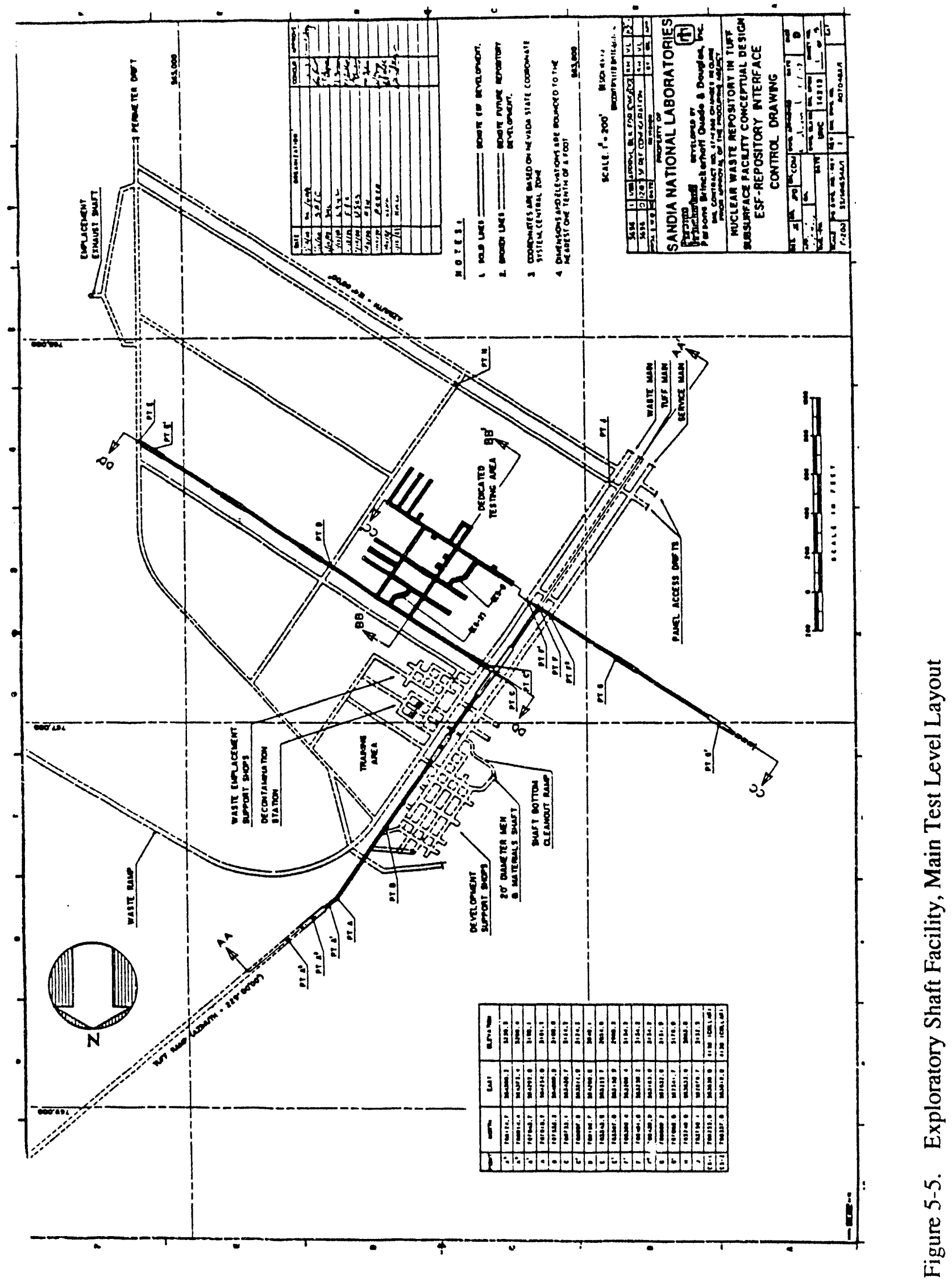



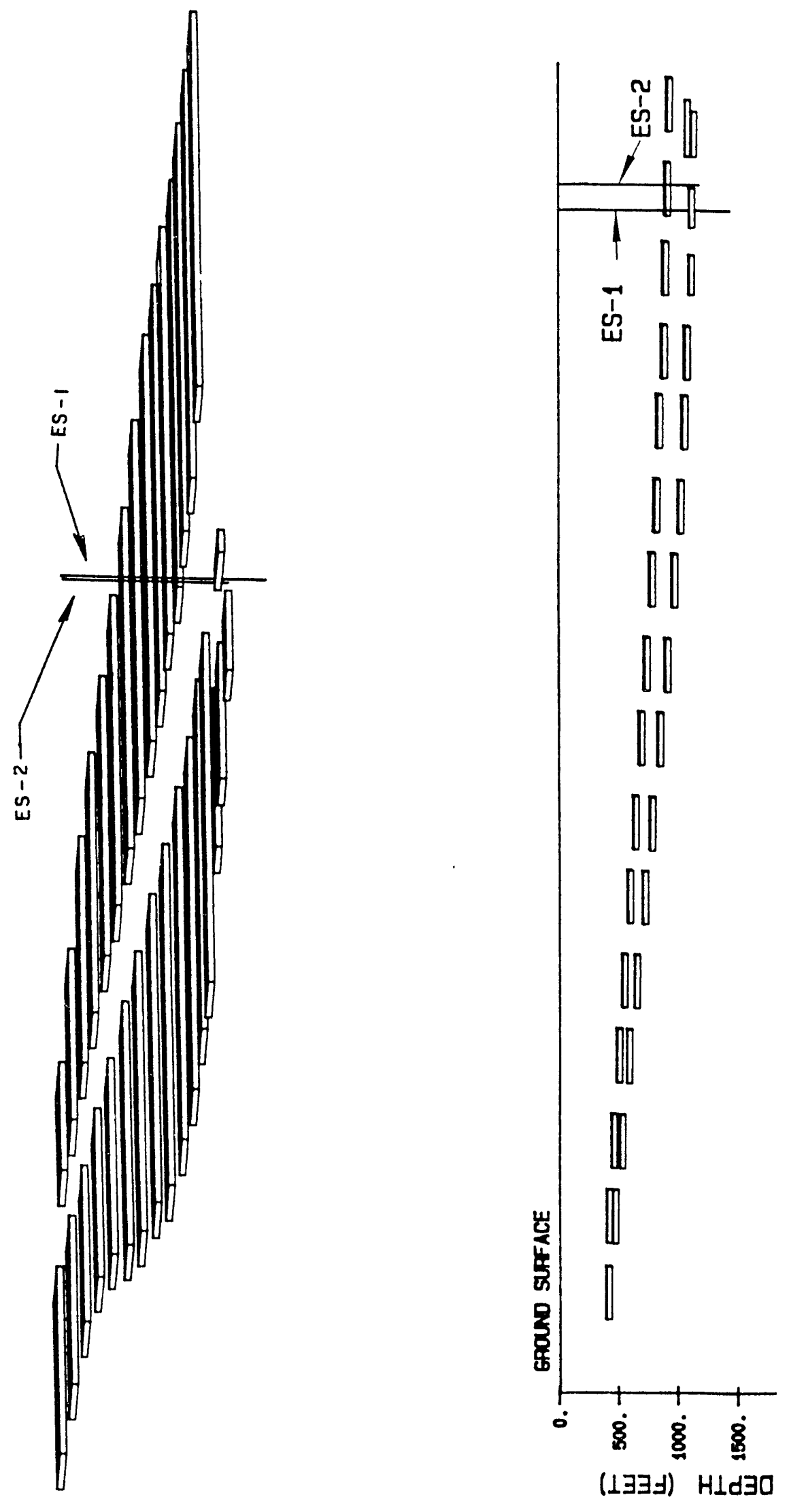

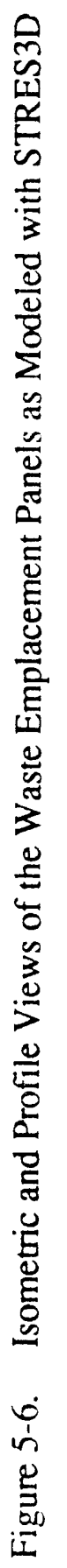


Many of the fundamental layout concepts of the ESF and repository design may be changed before either is built. The ESF and repository layouts presented here are intended for illustration purposes only. For example, the concept of a single-level repository, emplacement horizon, and ESF area may be reviewed. Similarly, several geometric parameters are still under consideration. These include standoff distances, drift and borehole spacings, waste-emplacement configuration, drift shape, mains orientation, ground support, and some panel shapes.

\subsubsection{Exploratory Shaft Facility}

The Title I ESF design includes two levels: the MTL (Figure 5-5) and the Upper Demonstration Breakout Room. The drifts in the MTL will function as ventilation routes during repository operations. The long lateral drifts will be used later during repository development as either access drifts for the waste panels or as repository mains. The drift in the Upper Demonstration Breakout Room will probably not be used for repository operations. The exploratory shafts will be converted to ventilation shafts should repository construction follow site characterization.

\subsubsection{Repository}

Figure 5-7 shows the panel layout detail with standoffs and some drift dimensions for the vertical waste-emplacement configuration. Figure 5-8 shows emplacement drift dimensions for vertical waste emplacement. The conceptual design has the option to emplace waste vertically in boreholes in the floor of emplacement drifts.

The repository excavations comprise main drifts, access drifts, waste-emplacement drifts, perimeter drifts, and drifts associated with the shop area. Two ramps and shafts, including ES 1 and ES2, will supply the necessary routes for ventilation, men and materials, and waste transportation. Waste will not be transported in the shafts.

The drift shape indicates that both conventional drill-and-blast and full-face boring machines are anticipated as excavation methods. The ground support system identified in the SCP-CDR includes five categories ranging from light to heavy support, depending on site conditions exposed during construction. 


\section{0}

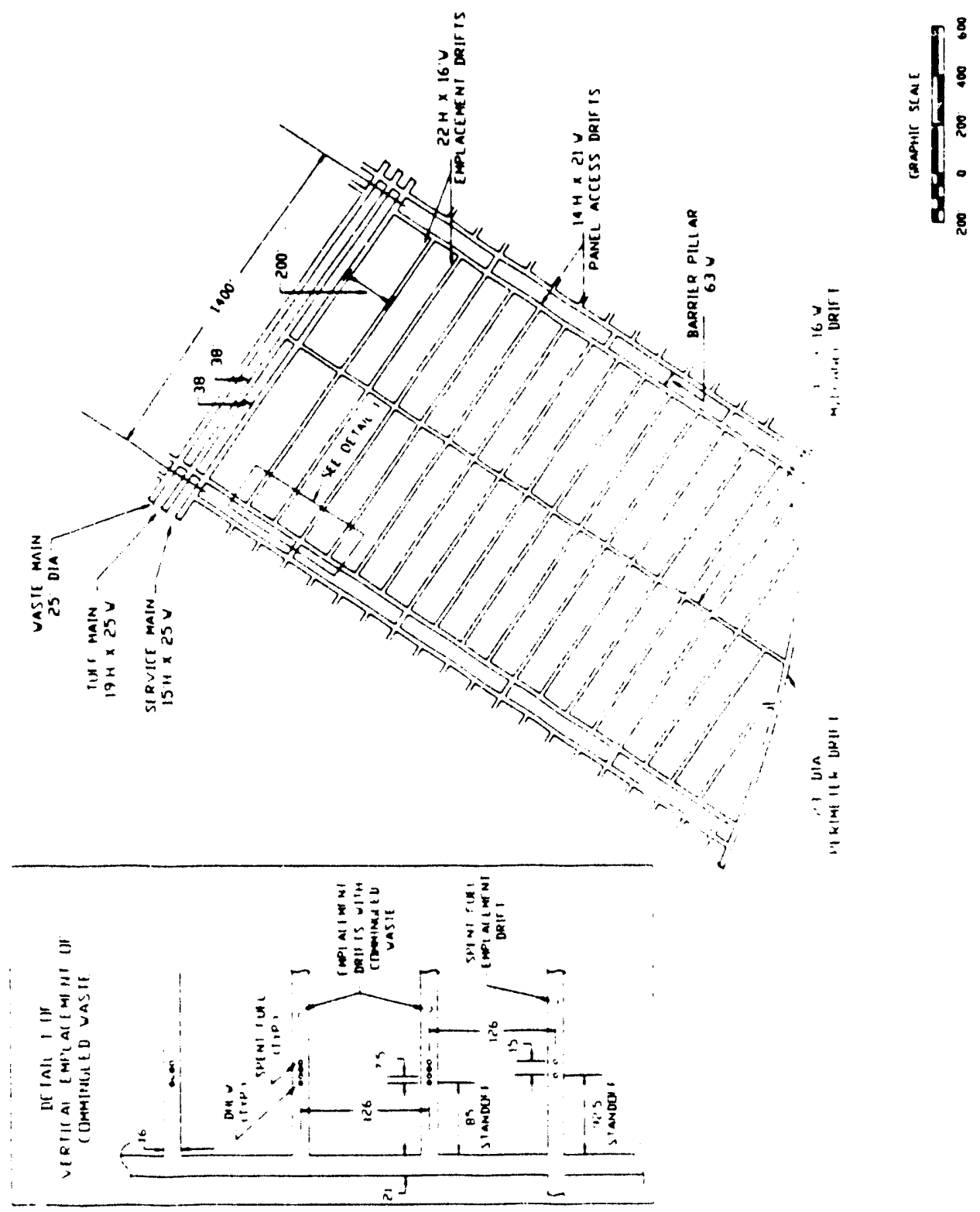

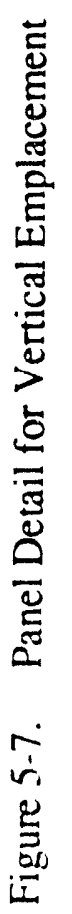



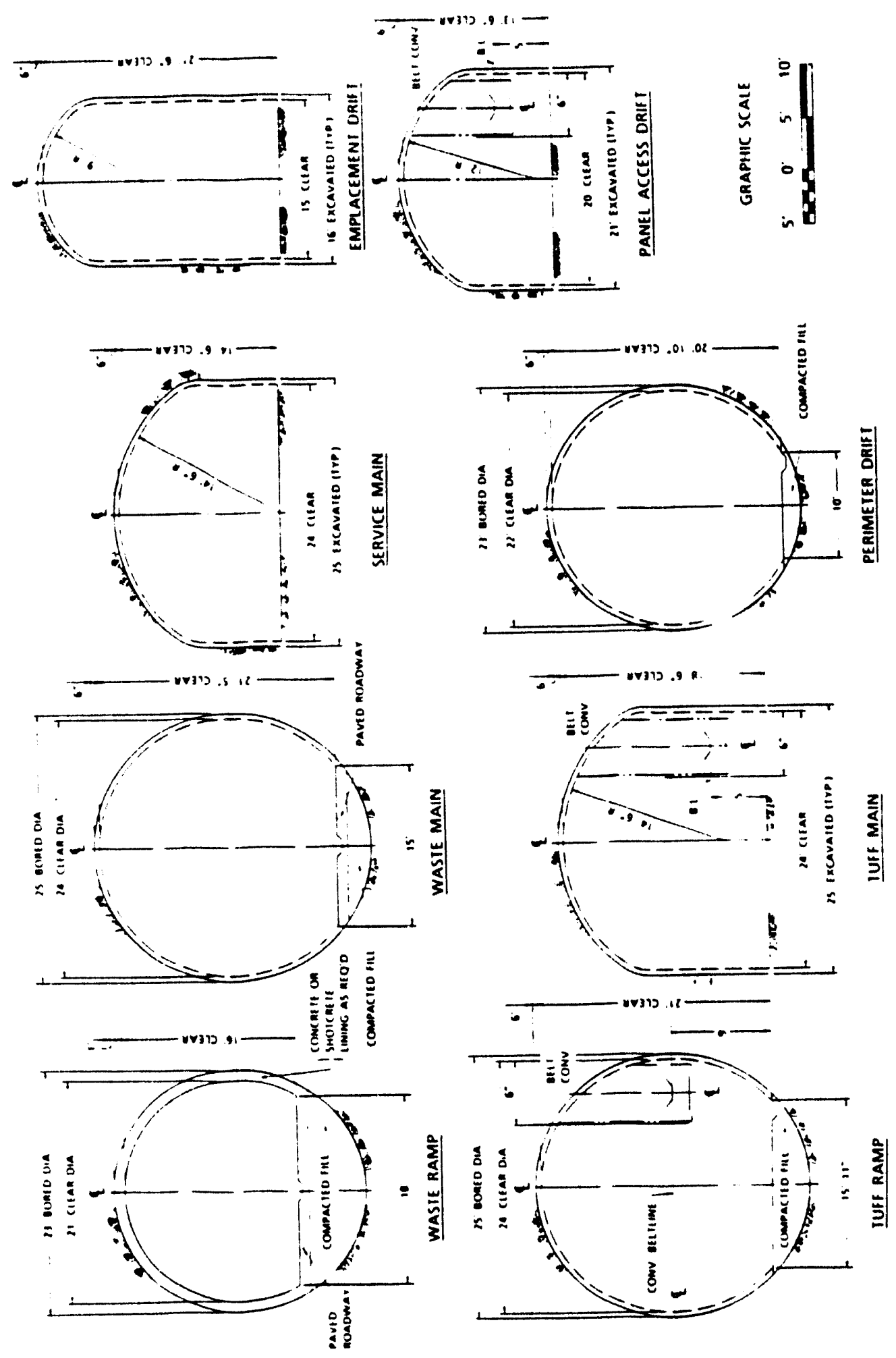


\subsection{ANAI,YSIS OF UNSUPPORTED DRIFTS}

In this section, we discuss the methodology for analysis of the drift exclusive of the ground support system and the method of preliminary ground support selection. Here the designer has the option to modify drift size or shape, and to impact the placement and density of waste containers. The major steps used to design the repository drifts are to develop candidate drift designs (Section 6.1) that meet the functional requirements, perform parametric and tradeoff studies (Section 6.2) of the different design options; and to select the potentially suitable options (Section 6.3) for detailed analysis using empirical (Section 6.4) and numerical (Section 6.5) methods. Based on the analysis of the unsupported drifts, preliminary ground support/reinforcement systems are selected (Section 6.9). The drift design is not complete until the analyses are evaluated (Chapter 7) and the ground support is designed (Chapter 8). These steps, up through the analysis of the unsupported drifts, are discussed below.

\subsection{Candidate Drift Designs}

The candidate drift designs are developed to meet the functional requirements such as size and area (see Section 3.1), and shapes are chosen that enhance stability (see Section 3.2.2). In some cases, such items as temporary ventilation ducting may be required during construction and could affect drift size and shape. Candidate drift designs could include shapes and sizes to accommodate more than one function or to combine two smaller parallel drifts into one larger drift. The candidate drift designs should recognize alternate construction techniques; rock support system options; in situ conditions such as in situ stress; variations in rock quality, rock structure, and joint orientations; and thermal and seismic loads.

\subsection{Parametric and Tradeoff Studies}

Parametric and tradeoff studies are performed on the candidate drift designs to narrow the selection and to identify significant or controlling parameters in the design. The parametric studies address tradeoffs in the areas of geologic variability, stability, economics, constructibility, safety, construction method, support installation, and waste emplacement configurations, and use simple analyses, empirical guidelines, construction experience, scheduling, and cost considerations. The tradeoff studies may use specific analytic methods, as discussed below, to evaluate the impact of such variables as loading or geologic features on potential drift shapes. The parametric tradeoff studies should assess the various candidate drift design's compatibility with closure and postclosure performance goals.

\subsection{Select Preliminary Drift Configurations}

This step compiles the results of the parametric and tradeoff studies and synthesizes the results to select appropriate drift shapes and sizes. The selection process may use a formal methodology and weighting factors. The product from the preliminary drift design is a number of alternate drift shapes for each drift type (emplacement drift, mains, midpanel access drifts, etc.) that meet the functional requirements and are compatible with construction techniques, loadings, and expected geologic conditions. Suitability of the drifts to withstand the thermal and seismic loadings must be assessed using empirical and numerical methods (discussed below).

\subsection{Empirical Methods}

Empirical methods are used to evaluate the impact of the ranges of expected natural conditions on drift stability and ground support requirements. General purpose methods can be 
augmented by specific case studies of excavations either in tuff or similar rocks subjected to loads within the range expected for the repository. Together these provide a basis for engineering judgment and development of rules of thumb (heuristic rules) that might apply to repository design.

Generally, empirical methods are developed by relating key parameters that affect stability to the support used in existing tunnels and caverns. Empirical techniques are useful in repository design to accomplish the following:

- Qurntify rock quality by an index that combines different characteristics of a rock ması.

- $\quad$ Assess stability of a given opening span either by indicating the estimated standup time or by indicating for what span ground support is required.

- Conduct preliminary assessment of ground support requirements for a given size opening.

- Estimate rock mass mechanical properties such as rock mass modulus or strength.

Empirical methods for ground support/rock reinforcement design are presented by Terzaghi (1946), Deere et al. (1967), Wickham et al. (1972), Barton et al. (1974) and Bi'niawski (1973; $1976 ; 1979)$. Einstein et al. (1979) provide a useful discussion of the development of empirical methods and compare the predictive capability of the above five methods with actual experience in a number of well documented tunnels, and conclude that none of the methods completely represent all the influencing factors.

The Barton Rock Mass Quality (Q) Method (Barton et al., 1974) and the RMR Method (Bieniawski, 1973; 1976) both contain six rock parameters related to joint frequency, number of joint sets, water conditions, joint roughness, joint alteration, intact rock properties, and stress. The main difference between the two is that the stress state is not explicitly considered in Bieniawski's method, whereas the discontinuity attitude is. In the Q Method, the stress reduction factor (SRF) accounts for the ratio of the in situ stress field to the rock strength. This parameter can be used to account for additional thermal and seismic loads in drift design (Barton, 1984).

Using the $Q$ system requires an estimate of $Q$, the opening span, and the ESR. The equivalent dimension is defined as the span divided by the ESR. By plotting the $Q$ versus the equivalent dimension on the design chart shown in Figure 6-1, the type of support, if any, can be determined. Barton et al. (1974) provide specific details on the recommended support for 38 regions on their design chart (not shown here). Barton er al. (1974) also provide methods to estimate the roof and wall support pressures.

Several modifications of the RMR system have been proposed so that account can be taken of such factors as induced stress and construction methods. The Modified Basic RMR (MBR) proposed by Cummings et al. (1982) and Kendorski et al. (1983) was developed specifically for block caving mines and introduces factors specific to that application, but it nonetheless indicates a method of incorporating stress change, construction method (in the format of a factor related to blast damage), and fracture orientation into an empirical method.

Hoek (1981) and Laubscher (1984) have both related ground support selection and mechanisms of failure to the relationship between the rock mass strength and the local state of stress around the drift. Where the design rock mass strength is high relative to the local stress, no failure is predicted; hence, no ground support is required. Alternatively, where the local stress is high relative to design rock mass strength, stress-induced failures can occur requiring ground support. Figure 6-2, reproduced from Hoek (198i), indicates where stress-induced failure or structurally' controlled failures would be predicted and general ground support required for ranges of rock quality 


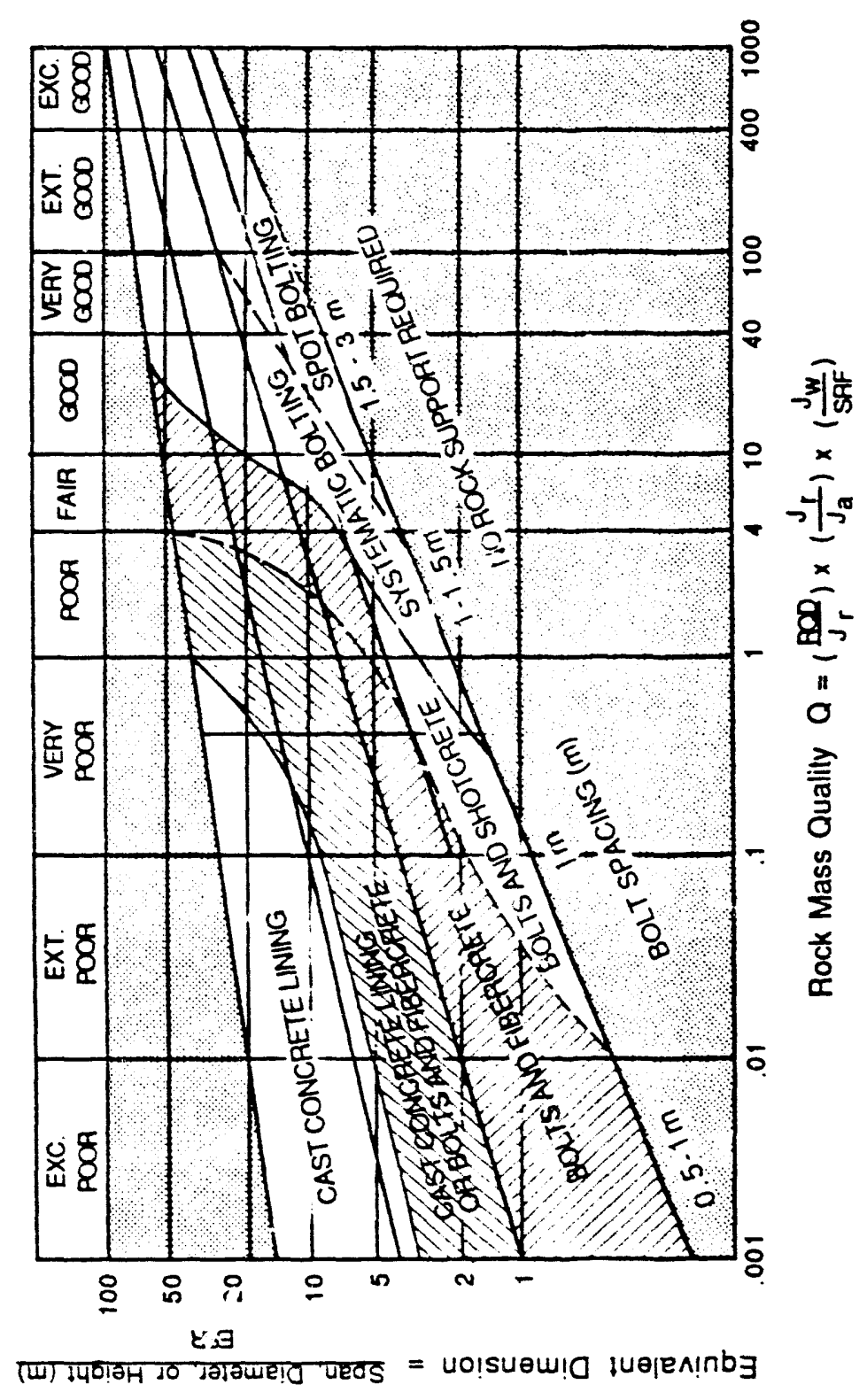

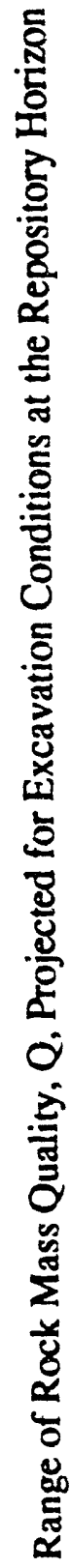




\section{TUNNELNG QUALTTY INDEX Q}

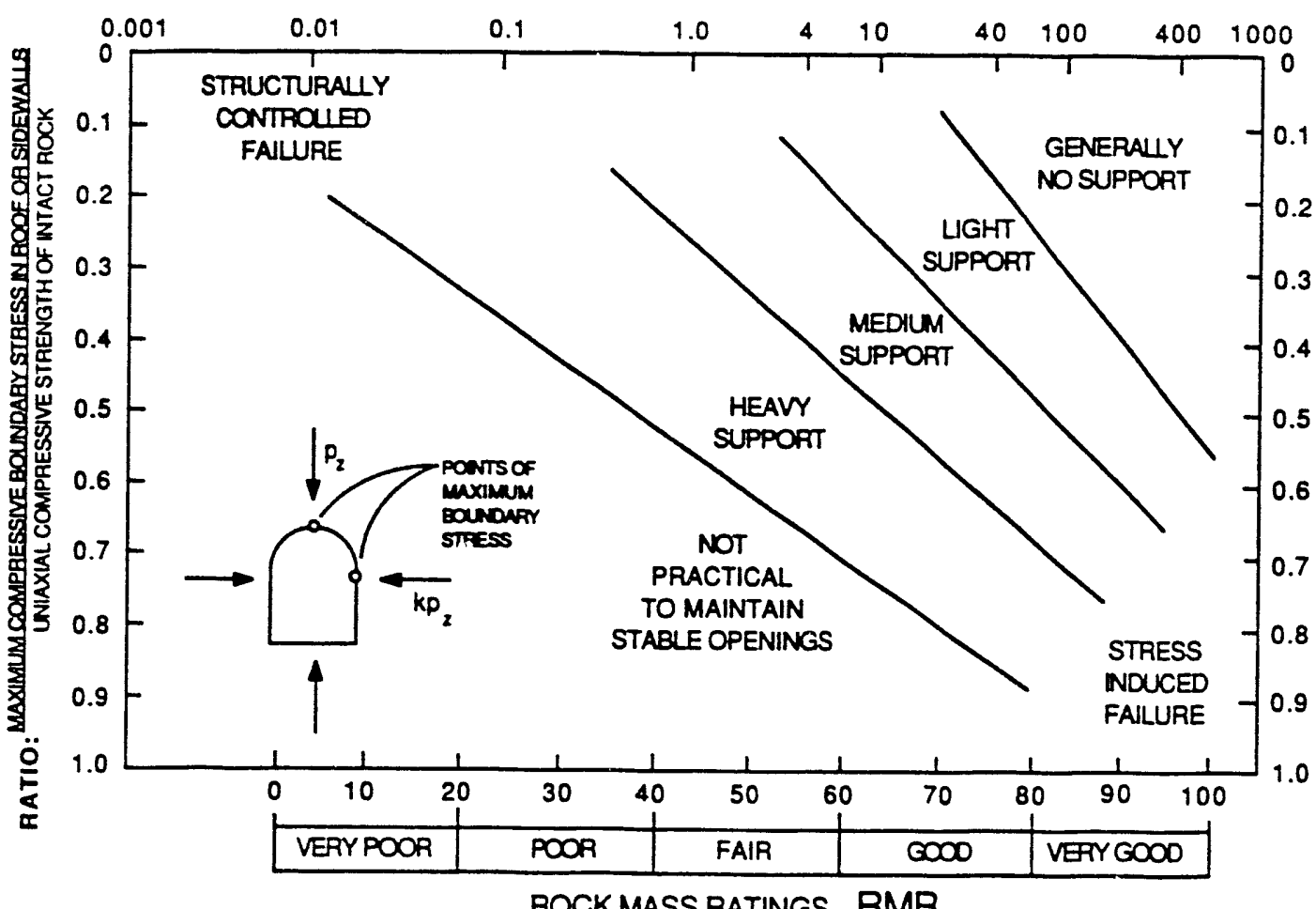

Figure 6-2. Approximate Support Guidelines for Underground Excavations Proposed by Hoek (1981)

and stress/strength ratio. The design rock mass strength of Laubscher (1984) is estimated from the laboratory rock strength modified by a factor developed from the RMR, and further reduced by factors representing weathering effects, blasting damage, and joint orientation. These methods are a little more appealing than the Q and RMR methods because they correlate support needs with the stress-to-strength relationships around the opening.

The approaches of Hoek (1981) and Laubscher (1984) form the basis of an empirical scheme proposed by Schmidt (1987) to identify the modes of failure around a drift. This method is based on the stress-to-strength relationship and a rock-quality index (a modified RQD). Figure 6-3 shows the regions on the plot of stress/strength ratio versus modified RQD where particular modes of failure are projected. With the mode of failure established, analytical techniques that specifically address that mode of failure can be selected and a ground support system designed to effectively control the rock failure.

A criticism of empirical techniques in applying them to repository design is that case studies upon which they are based do not include the conditions expected at the repository site, nor do they incorporate some of the important thermal and seismic loads expected during the life of the repository. In the Q system (Barton et al., 1984), the thermal or seismic loads can be incorporated by combining the induced loads and treating this value as an in situ load. A similar approach could be used with the MBR system where the thermal and seismic loads are equated to the stress change induced by mining. The former procedures are recommended for assessing preliminary ground support requirements under the thermal and seismic loads. 


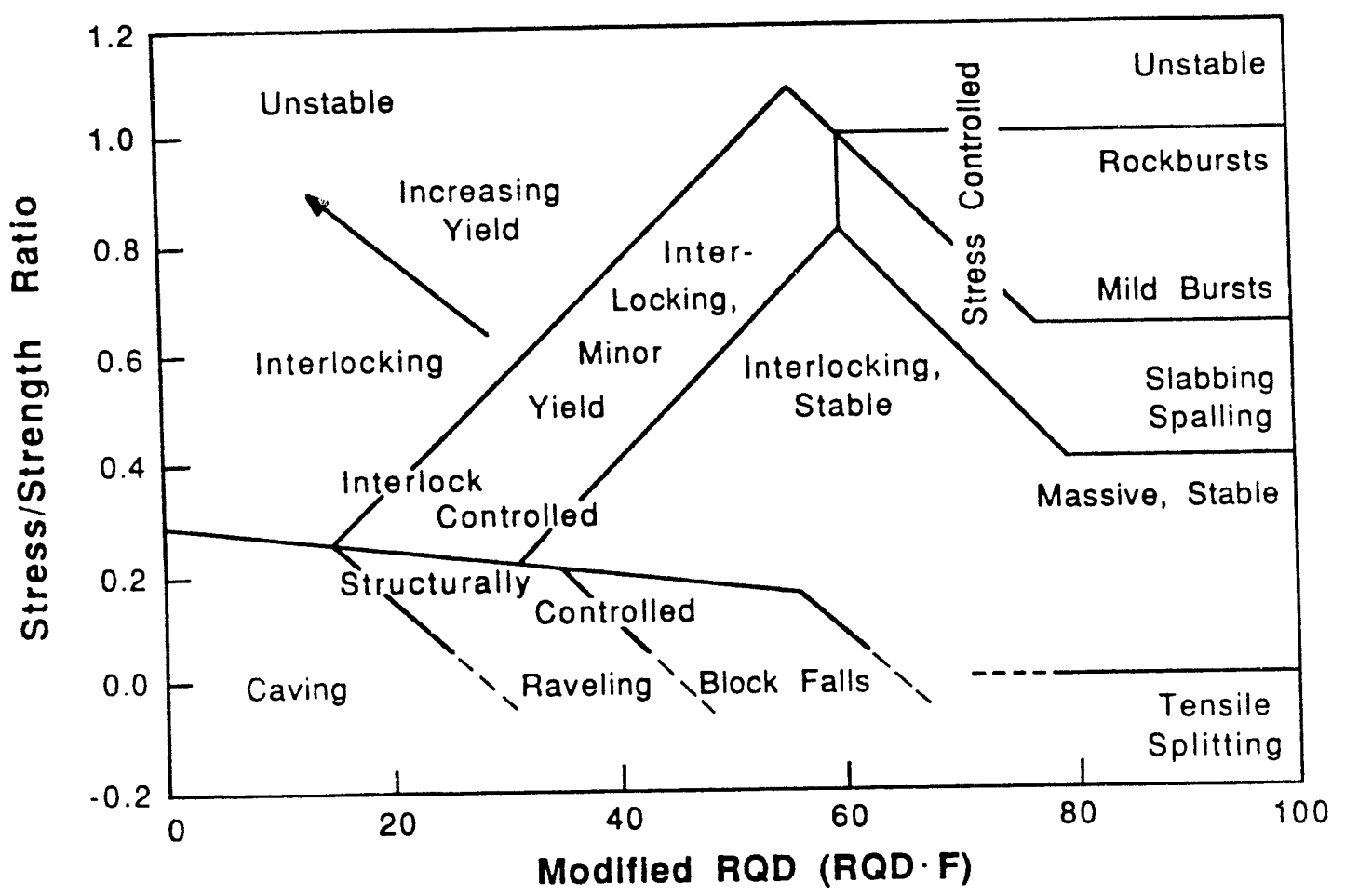

Figure 6-3. Chart for Estimating Modes of Failure Around Drifts Proposed by Schmidt (1987)

A first indication of the potential impact of seismic loads can be obtained from empirical evidence of damage in underground openings. Dowding and Rozen (1978) compiled case studies of seismically induced damage to underground drifts and tunnels. Owens and Scholl (1981) updated that work and provided a summary of these findings (Figure 6-4). Dowding and Rozen suggest that no damage should be expected if the peak surface accelerations are less than $0.2 \mathrm{~g}$, and only minor damage should be experienced between 0.2 and $0.4 \mathrm{~g}$. It is worth pointing out that Figure 6-4 was deduced from earthquake data, whereas thresholds for damage caused by UNEs are much higher. Applying the factor of 1.67 sugge sted by the Working Group to the recommended control motions listed in Section 5.1.3 would increase the loads sufficiently to be above the $0.4-\mathrm{g}$ transition from "minor damage" to "damage." The "minor damage" described by Dowding and Rozen (1978) included "fall of stones and formation of new cracks." Such occurrences would disrupt neither waste-transport operation nor performance of emplacement drifts, and may be tolerable because of the planned inspections and maintenance of underground openings. A limiting factor in applying this empirical evidence to other situations is that neither the stability conditions of the underground opening before the seismic event nor the design basis of the ground support systems is known for the cases included in the study.

In summary, all empirical systems inadequately account for the combined effects of in situ, thermal, and seismic loadings, thus necessitating the need for more detailed analyses of the drift stability (Section 6.5) and the interaction of the support/reinforcement components, as discussed in Chapter 8 . In the preliminary design stages, the results of the classification should not focus on the ground support design, but on classification of the expected in situ conditions into groups for analysis, identification of the potential failure mechanisms that should be addressed analytically, and identification of shapes or loading that, in combination with specific in situ conditions, would pose constructibility problems and should be redesigned. 

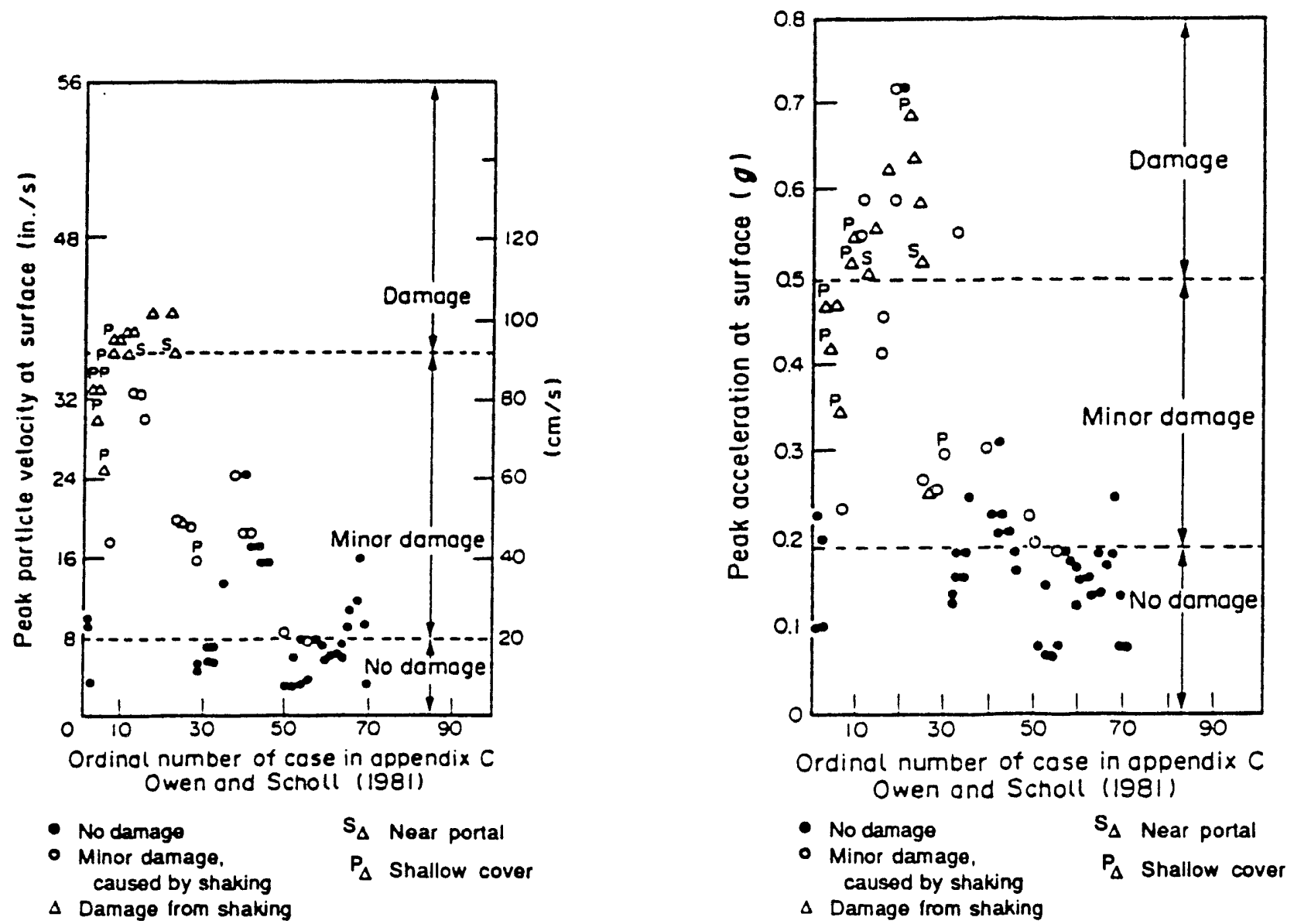

Figure 6-4. Calculated Peak Particle Velocities and Acceleration and Associated Damage Observations on Underground Openings (Owens and Scholl, 1981)

\subsubsection{Technique Selection}

In the absence of any important distinguishing characteristic, it is recommended that aspects of both the $\mathrm{Q}$ and RMR systems be incorporated into the drift design methodology. Both have been applied to the G-tunnel and expected repository conditions by Langkopf and Gnirk (1986), and during the unit evaluation studies by Johnstone et al. (1984). Both methods are based on extensive case histories, and the parameters included in each technique are considered appropriate for repository design. The RMR system is used as an index property in assessing rock mass mechanical properties (as shown in Section 5.2.4). The $Q$ system can be used to develop preliminary recommendations for ground support requirements.

However, because the database used to develop both of these methods does not include case studies of excavations in welded tuff, a site-specific technique should be developed by reassessing the case studies on which those methods are based and by the addition of case studies specific to the tuffs at the NTS. Construction experience at the ESF will provide a basis for assessing the applicability of these empirical methods to the welded tuff, and for their adaptation to the specific conditions of the repository drift. 


\subsubsection{Application of Empirical Techniques}

The basic inputs of the rock mass classification methods include the unconfined rock strength, the amount of water present, the applied stress field, the geometric characteristics of joints, joint physical properties, and width of excavation. The empirical techniques should be applied to the five rock quality categories representing the expected range of conditions.

In the Q System, the ESR is a design selected parameter that reflects the degree of conservatism desired in the design. For example, temporary mine openings have an ESR of 3 to 5 , whereas major road and railway tunnels should have an ESR of 1.0. Minor roads or railway tunnels have an ESR of 1.3. For the repository, a high degree of conservatism is required, so a low ESR is recommended; see, for example, Table 4-3. The $Q$ system should be applied to all load combinations identified in Section 5.1.4.

The empirical techniques can be used to accomplish the following:

- determine the expected standup time for the excavation shapes and sizes; conditions with projected standup times of less than one week would be considered

inappropriate for waste emplacement, and those with projected standup times of less than one day unsuitable for construction;

- define an expected range of ground support requirements;

- evaluate the probabilities of encountering each class of rock and ground support;

- evaluate the potential impact of encountering off-normal combinations of design parameters; and

- $\quad$ make a preliminary estimate of ground support requirements (see Section 8).

The empirical approach assumes that the rock mass material properties are not affected by heating of the rock and that the seismic loads are adequately represented by a quasi-static approach presented in Section 5.1.3. Empirical evidence of the effect of heating on drift performance is even further limited with only a handful of case examples available in the literature.

Barton et al. (1974) use the Q system to estimate the roof support pressure requirement.

$$
P_{\text {roof }}=\frac{2 J_{N}^{1 / 2} Q^{-1 / 3}}{3 J_{R}}
$$

where $J_{N}$ is the joint set number and $J_{R}$, the joint roughness (see Table 12-2 in Section 12.2.1 for example). The same expression is suggested by Barton et al. (1974) to estimate the wall pressure with $Q_{w}$ substituted for $\mathrm{Q}$. $Q_{w}$ is defined as

$$
\begin{aligned}
& Q_{w}=5 Q \quad \text { when } Q>10, \\
& Q_{w}=2.5 Q \text { when } 0.1<Q<10, \text { and } \\
& Q_{w}=Q \quad \text { when } Q<0.1 .
\end{aligned}
$$




\subsubsection{Results of Empirical Techniques}

The results of the techniques include an estimate of the maximum unsupported span and standup time, the rock mass strength (see Sections 5.2.4.4 and 5.2.4.5), and preliminary ground support requirements. Because the database used in developing the technique includes few highstress cases, the appropriate application is to mains and other drifts that experience low to moderate thermal loads.

\subsubsection{Interaction of Empirical and Numerical Methods}

Empirical methods are helpful in identifying possible modes of failure, providing input for estimating the rock mass deformability and strength characteristics and in providing guidance in the selection of analytical models appropriate for specific rock characteristics. The empirical techniques also provide preliminary estimates of ground support requirements for all drifts and final ground support requirements for the nonthermally loaded repository drifts. All final designs must, however, explicitly consider thermal and seismic loads.

Numerical methods in repository drift design are primarily used to estimate the effect of in situ thermal and seismic loads on stability conditions in the drift. The analyses are relied upon solely to predict the thermal conditions and thermal loads in the drift, whereas empirical methods can be used to evaluate the effect of in situ loads on drift stability.

\subsection{Numerical Methods for Unsupported Drifts}

The application of numerical methods to modeling the behavior of rock masses is limited by the understanding of the rock structure, material properties, strength, and failure mechanisms. Often, as a first approximation, failure mechanisms and ground support/rock reinforcement components are not incorporated into the model used in the analyses. Typically, the stresses are predicted on the basis of an assumed linear elastic rock mass response and thic resulting state of stress in tive vicinity of the drift processed to determine potential regions of appropriate inelastic rock or joint slip. Such analysis may be used in conjunction with tradeoff studies of alternate drift shapes.

The effect of processed ground support is not usually modeled in preiinininary designs because light bolting or thin coatings of shotcrete typically used in many stable openings have a negligible effect on stresses and displacement of the rock. Their function is to retain localized blocks of rock defined by joints or blasting features, and thereby prevent larger blocks from moving. More massive supports, such as thick coatings of shotcrete or concrete, utilized to inhibit massive rock failouts resulting from yielding of the rock matrix and slip along joint surfaces can be modeled explicitly.

Incorporation of rockbolts and drift lining into the analytical design is desirable after the basic drift geometries and thermal loadings have been established to assess stability in the poorer quality ground and to evaluate the thermal effects on the ground support component performance. Analysis of ground support systems is deferred until Chapter 8.

\subsubsection{Model Selection}

Before undertaking any numerical modeling of the behavior of the rock mass in which the repository is constructed, it is necessary to decide on geometrical material and other simplifications. Such simplifications include the adoption of two-dimensional models of long tunnels, continuum approximations of the rock mass, and the treatment of seismic loading as quasi-static. The following subsections discuss the simplification considered appropriate to the implementation of this design 
methodology. At a future time, and as required for design confirmation, detailed mesh assessment and other purposes, several of the assumptions will be relaxed and detailed numerical modeling will be completed.

6.5.1.1 Thermal Model In assessing thermal loads for drift design, two distinct approaches can be adopted. The first is appropriate for waste-emplacement drifts in the interior of an emplacement panel. Here, at least immediately after waste emplacement, it is reasonable to assume that the drift centerline and the center of the pillars between emplacement drifts is a plane of symmetry. The symmetry condition implies no lateral heat transfer at these boundaries because of equal heat generation from waste in adjacent emplacement drifts. For emplacement drifts near the boundary of a panel and for midpanel drifts and mains, the thermal loads are not symmetric and depend on the emplacement sequence and other repository-scale factors. Assessment of the thermal loads is then more complex because the situation is truly three-dimensional. However, simplification involving the integration of three-dimensional, thermomechanical analysis and local twodimensional mechanical analysis is possible. The separation and evaluation of the thermal load from the drift mechanical response for drifts requiring repository-scale thermal analysis to determine the local thermal loads is appropriate (see Section 5.1.2).

The thermal material model used for drift design must incorporate the predominant heat transfer mechanisms. The predominant mechanism of heat transfer in the rock mass is conduction, whereas radiation and convection heat transfer can be significant in the container or across the emplacement drift. Ventilation can transfer heat along drifts either during emplacement operations or during cooling before inspection, maintenance, drift rehabilitation, waste retrieval, or closure operations. The effect of cooling on drift stability must be evaluated during the design process to assess the potential for de-stressing the rock mass or inducing cracks in the ground support system.

The thermal properties that are temperature-dependent must be accounted for in the thermal model. For example, the thermal capacitance of tuff at the repository site exhibits significant increases around $100^{\circ} \mathrm{C}$ as associated water molecules are released.

Many thermal analysis codes incorporate the appropriate phenomena for modeling the twoor three-dimensional temperature response to heating from waste emplacement. To model the three-dimensional complexity of the repository with different waste-emplacement times for individual panels requires some simplification and idealization. Either the geometry modeled or the characterization of the host material or both must be simplified.

The link between thermal and mechanical models is through the thermal expansion coefficient and possibly through temperature-dependent mechanical properties. For the welded tuffs of the repository horizon, no data which indicates temperature-dependent mechanical properties are available. The thermal expansion coefficient is temperature-dependent for welded tuff above approximately $200^{\circ} \mathrm{C}$. Such dependence could be a factor in and around the emplacement borehole where temperatures could exceed $200^{\circ} \mathrm{C}$.

6.5.1.2 Mechanical Model Several types of constitutive models are available to represent the rock mass. They include linear elastic, elasto-plastic, jointed rock continuum, the Compliant Joint Model (CJM) of Chen (1986), the joint empirical model (JEM) of Blanford and Key (1990), distinct block models (Cundall, 1980), and discrete joint/fault representation models (Crouch, 1976). The linear elastic, elasto-plastic, jointed rock continuum, CJM, and JEM are all equivalentcontinuum models. Figure 6-5 shows a simplified method of selection based on rock jointing characteristics. In some cases, a particular material model can represent a range of rock characteristics, and the actual loading conditions will determine if a particular mechanism of deformation is operative. Alternatively, empirical techniques, such as depicted in Figure 6-3, can be used to predict which mechanisms of deformation or failure are likely to be operative and, hence, help in the selection of the numerical model used for design. 

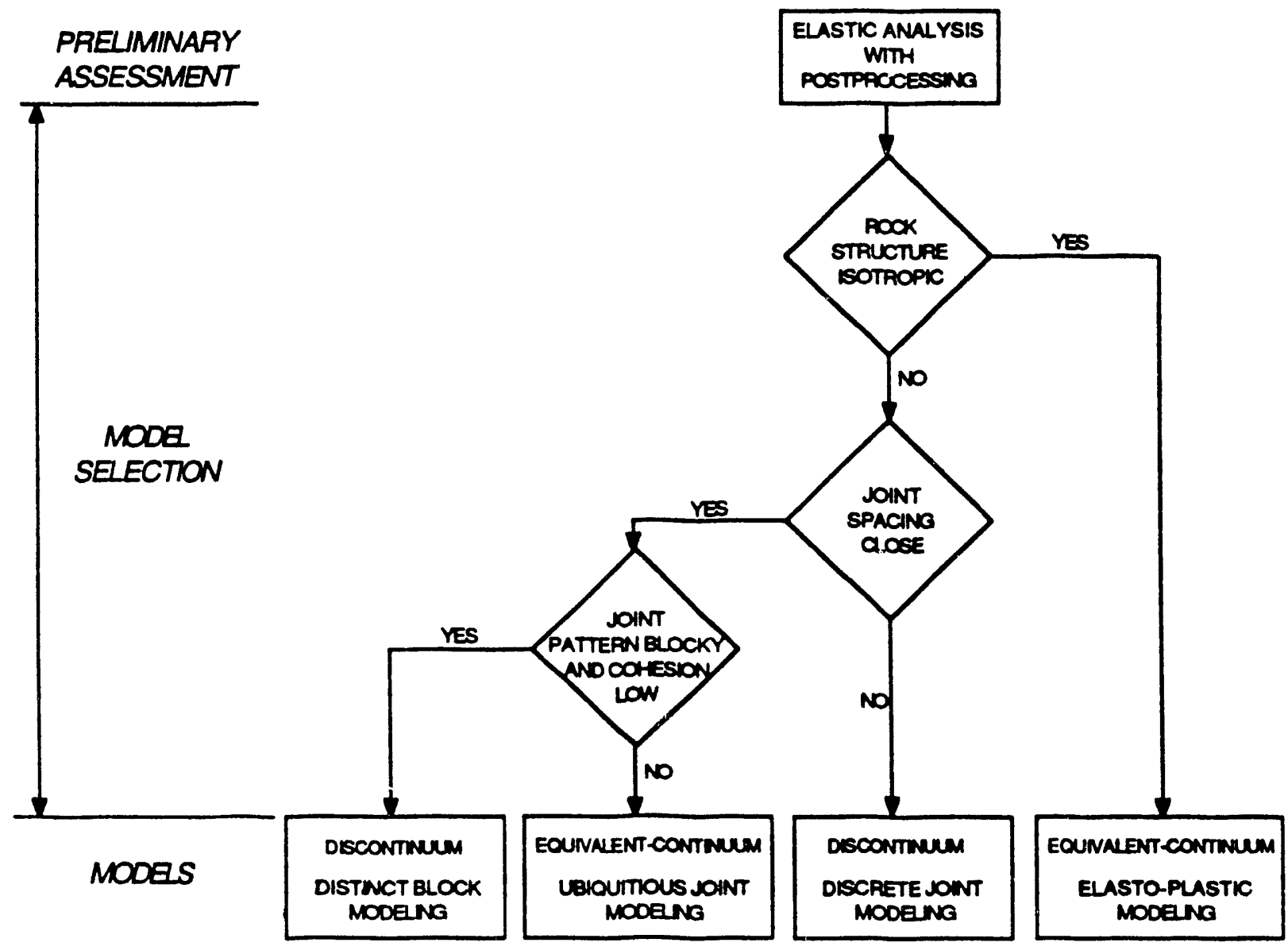

Figure 6-5. Selection of Appropriate Rock Model for Design Analysis 
Elastic analysis has traditionally been used to assess the potential impacts of waste emplacement on drift stability (see, for example, St. John (1987a)), to assess potential modes of rock or joint failure, and for preliminary scoping studies, such as required for drift shape optimization. The elastic analysis also is very useful for evaluating the sensitivity of rock stresses to rock mass parameters or changes in waste-emplacement configurations. Because elastic analysis is helpful in selecting the constitutive models or in identifying deformation mechanisms that need to be modeled by more detailed analysis, it is required as the first step in the model selection process as illustrated in Figure 6-5.

Elastic analyses of long drifts can assess three-dimensional loadings and directional strengths in three dimensions by relieving the out-of-plane shear stresses as well as the in-plane stresses (the horizontal, vertical, and in-plane shear) around a drift. This is known as generalized plane-strain. Brady and Bray (1978) discuss the application of this method to boundary-element linear elastic analysis. The results from the generalized plane-strain analysis can be analyzed to assess the safety factors or potential for slip along joints of any orientation relative to the drift axis.

This is a powerful tool to assess the three-dimensional loading effects of seismic and thermal loads which may not be orthogonal with respect to the drift axis or to assess the potential for failure or slip along structures that are also not orthogonal to the drift axis.

As implied by the selection process shown in Figure 6-5, the characteristics of joint geometry and frequency at the repository horizon have a major impact on the model selection for repository drift design. All models may have their uses in various aspects of design, for appropriate ranges of rock characteristics and for the scale of interest relative to the jointing pattern. The effect of size on the selection of the appropriate representation of a jointed rock mass is illustrated by Hoek and Brown (1980) (Figure 6-6). For drift design, the scale of concerns ranges from the immediate perimeter of the drift to the entire repository.

The characteristics of the jointing are also important in selecting the appropriate model. If the jointing is tight and exhibits some cohesion, its impact on stability may be negligible and, hence, need not be modeled explicitly. At the other extreme, there may be joints or faults at particular locations that need to be represented directly in the model. In between are cases in which the joint spacings may be too numerous for discrete modeling, but may be modeled by an equivalentcontinuum model.

The range of expected conditions evident in core and surface exposures near the proposed repository location indicates that elasto-plastic, ubiquitous joint, and distinct block-type models will be required. The joint spacings appear to be sufficiently close that discrete joint modeling may not be required except for specific cases where a significant structural feature can be distinguished from the ubiquitous jointing. This condition may arise when a drift intersects a fault.

\subsubsection{Application of Numerical Models}

In the design phase, the numerical models will be applied to the assessment of the stability conditions under the expected range of geologic conditions at the repository horizon. Because the loads on all drifts vary with location within the repository, the analysis should be applied to a representative number of drift geometries at critical locations throughout the repository. Critical locations are those that bracket the range of expected loadings to the drift. For example, the emplacement drift at the center of a panel will be exposed to the most extreme thermal loads. The thermal loadings on the tuff main drift range from near zero near the ramps to a moderate value in the middle of the repository. The critical thermal loading on the midpanel drifts will occur at midlength of a panel. Critical conditions for stability also depend on in situ and seismic loads and do not necessarily coincide with the locations of highest thermal load. 


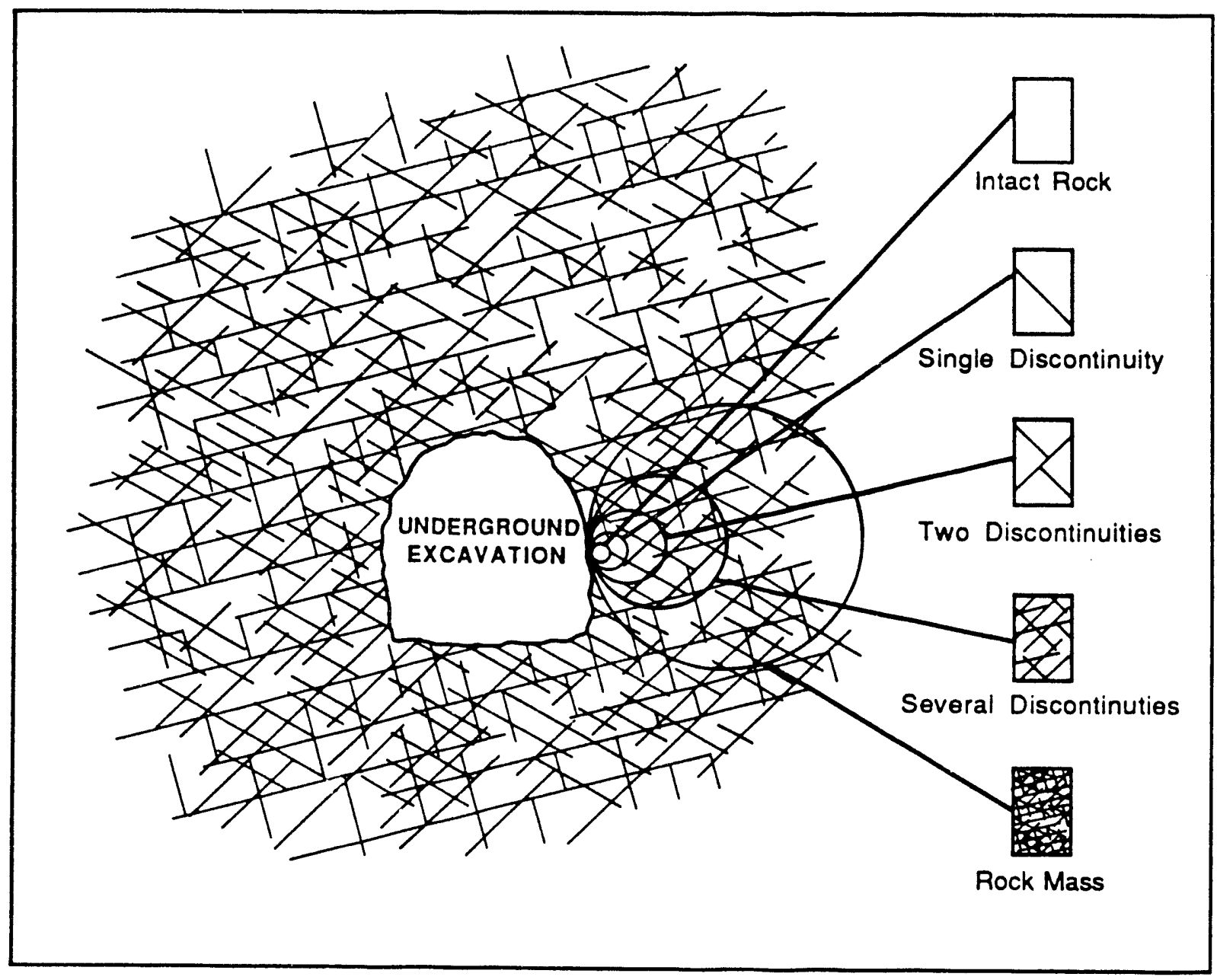

Figure 6-6. Idealized Diagram Showing the Transition from Intact Rock to a Heavily Jointed Rock Mass with Increasing Sample Size (from Hoek and Brown, 1980)

For design simplicity, the range of geologic conditions are grouped into a manageable number of categories as discussed in Section 5.2. Analysis should be performed on the credible combination of loads and geologic conditions using the appropriate mechanical models. Care should be exercised to avoid excessive analysis for all combinations of loadings, conditions, and drift geometries.

6.5.2.1 Elastic Model The linear elastic model, the simplest of the equivalent-continuum models, uses the rock mass properties for each rock mass category to represent the response of the rock mass. The mechanical properties assume the rock mass to be homogeneous and isotropic. Elastic moduli are estimated from intact rock properties and rock quality indices discussed in Section 5.2.4.1

When evaluating the results of linear elastic analysis, areas around the drift where the stress exceeds the strength either of the rock mass or of the joints can be identified. The rock mass strength should be estimated as discussed in Section 5.2.4.4 and the joint strengths from Section 5.2.4.6. 
6.5.2.2 Elasto-Plastic Continuum Mociel The elasto-plastic continuum models use empirically derived values of the rock mass properties, but incorporate stress redistribution in accordance with the selected yield model.

The yield criterion for rock is generally based on either the Mohr-Coulomb or DruckerPrager models for frictional materials. One objection to both models is that adoption of an associated flow rule implies large extensional volumetric plastic strains or dilation with yielding. This can be overcome by using a flow function that differs from the yield criterion (nonassociative flow rule). Soils have been commonly modeled using nonassociated flow rule, whereas rocks generally experience dilation with yielding, so the associated flow rules are of ten applied. Recent experimental results from simulated rock mass models (Michelis and Brown, 1986) suggest that a dilation angle equal to about half that for an associated flow rule provides a good approximation. Selection of a flow rule that is appropriate for the Yucca Mountain repository must be deferred until additional field and laboratory testing has been completed. For the present, it is recommended that a nonassociated flow rule be used for analysis of drift stability with the dilation angle equal to one-half the friction angle.

Table 6-1 lists the input parameters for the elasto-plastic continuum models for drift design. The properties used are based on the rock quality data and laboratory values.

In the application of the elasto-plastic models, the zones where yield has occurred are identified and the magnitude of the compressive strain monitored. When interpreting the results of the analysis, a limiting value of the compressive strain is used as a criterion to assess the extent of damage sustained and the need for ground support. The maximum allowable compressive strain is similar in concept to the maximum allowable strain adopted in ultimate load-design methodology in concrete. In using this method, the American Concrete Institute (ACI) code allows a maximum compressive strain in concrete of $0.3 \%$. Appendix A discusses the basis of this criterion in concrete and reviews laboratory data for the welded tuff.

6.5.2.3 Regularly Jointed Continuum Modeling Equivalent-continuum modeling includes application of the CJM (Chen, 1987) and the JEM (Blanford and Key, 1990). Both models were recently applied to the same problem in a preliminary benchmark exercise (Costin and Bauer, 1991). The suggested application discussed here focuses on the CJM; similar suggested parameters should be developed for the JEM.

The CJM incorporates the joint normal stress/joint closure relationship shown in Equation 10 and the shear stress/shear strain relationship. The shear stress/shear strain relationship models the joint shear stiffness and strength defined by the traditional Coulomb friction model. Thomas (1982) incorporated this model into the JAC code (Biffle, 1984) for a single joint set, and Chen (1987) has extended the model to include two orthogonal joint sets and non-orthogonal joint sets (Chen, 1990). The single joint model has been used by Bauer et al. (1985b) to model the response of a thermally fractured granite and by Costin and Chen (1988) to model the response of the heated block experiment of Zimmerman et al. (1984). These investigators report reasonable success, even though the model does not include joint dilation with joint slip.

Table 6-2 lists the input parameters for application of the CJM. These parameters are developed in Section 12 for the expected range of conditions at the repository location. The maximum allowable effective extensile strain is introduced for evaluation of the analysis. The joint strength away from the opening is based on a weighted average of the joint and intact properties depending on the continuity $(\chi)$ of the joint surface. At the perimeter of the opening, the unweighted joint properties should be used to assess joint slip. 


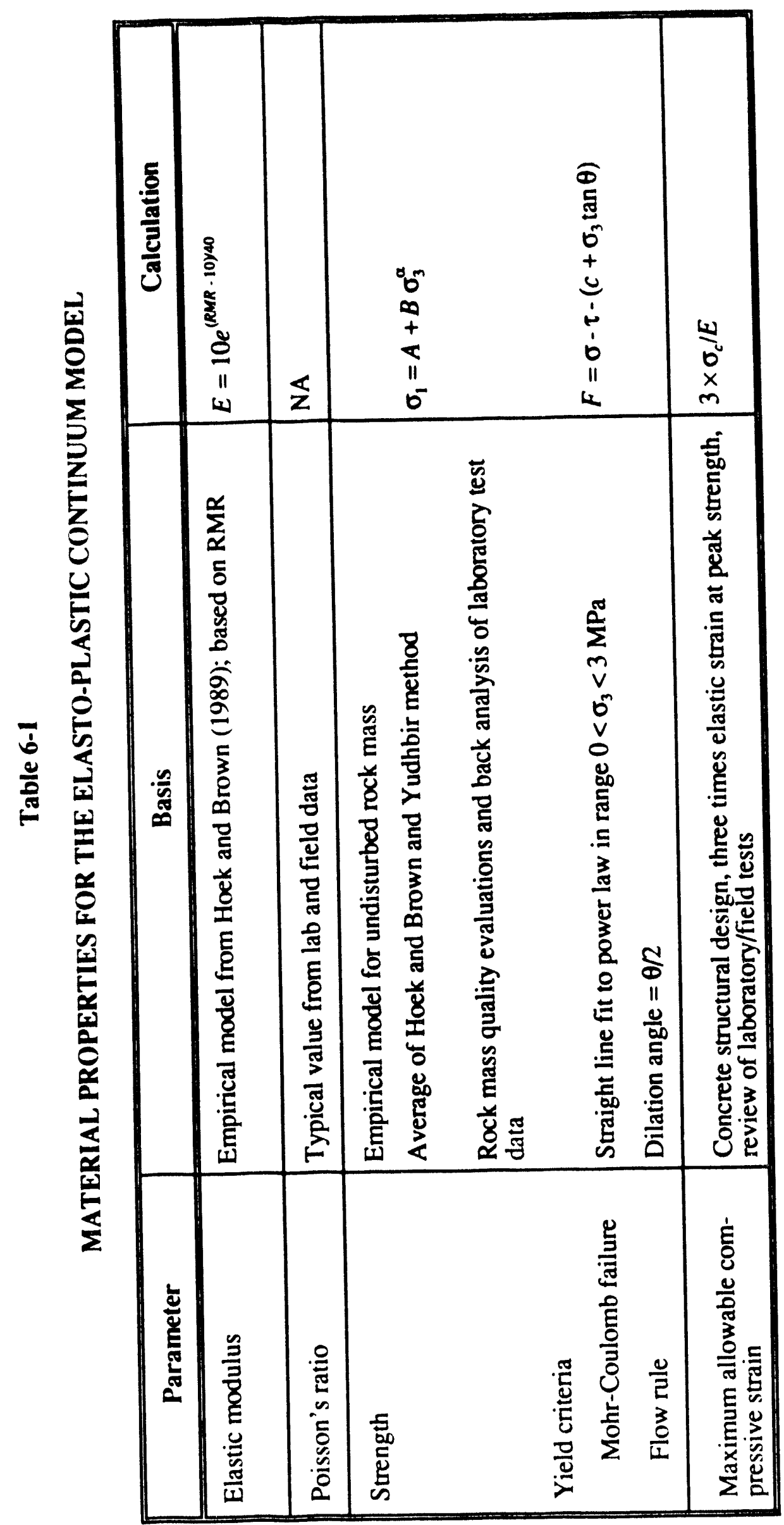




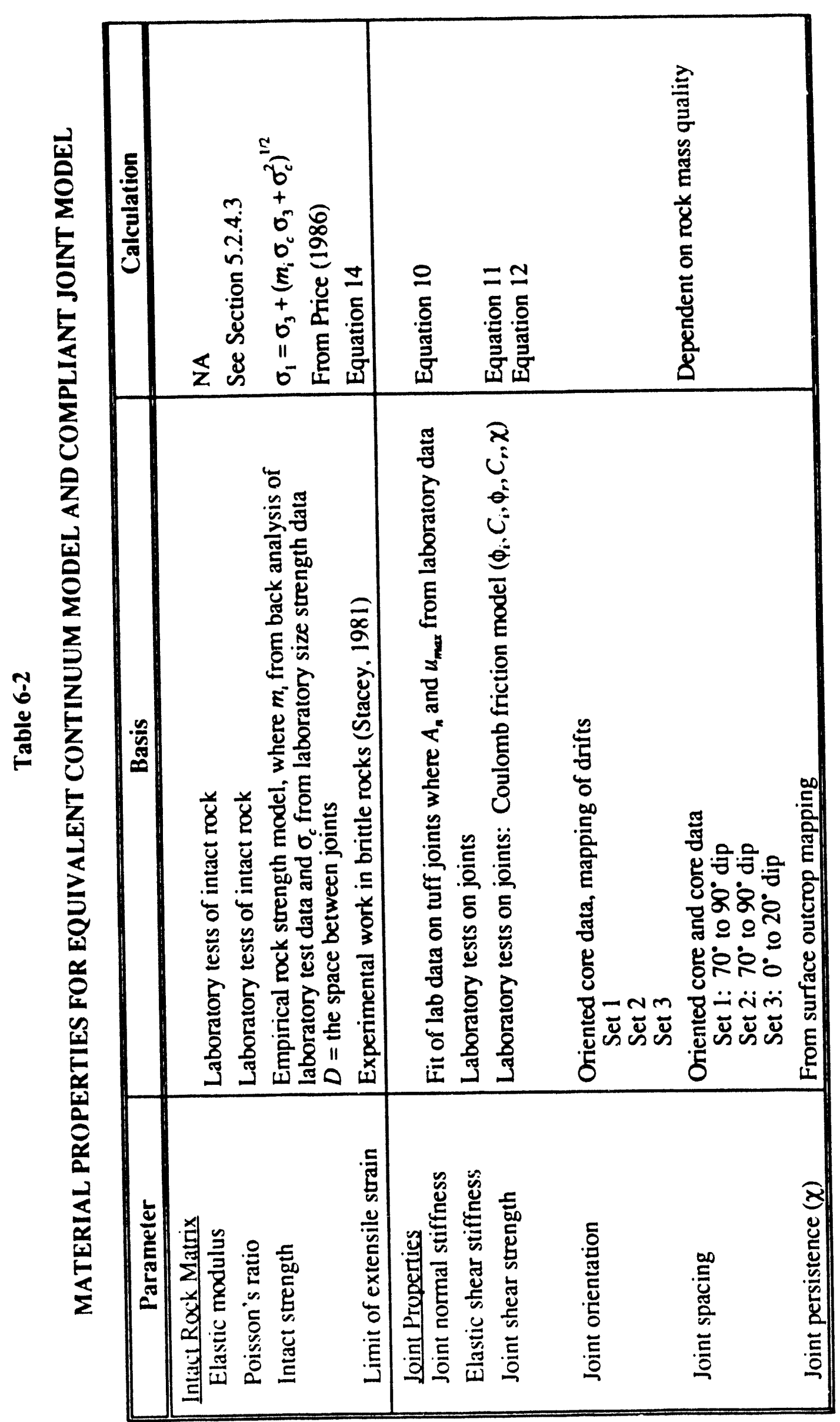


For the CJM, yielding within the rock is limited to slip along joints. A criterion must be established to limit the stresses in the intact rock between the joints and to limit the total displacements within the rock caused by slip along joints. The criteria for crushing or splitting of the intact rock similar to the yield criteria used for the elasto-plastic analysis (without the joint weakening effect) or an effective extensile strain is proposed.

The criterion for the intact rock matrix strength indicated in Table 6-2 is based on the empirical rock mass strength envelope developed by Hoek and Brown (1980) with the uniaxial compressive strength reduced to reflect the size effect observed by Price (1986) for tuff.

The extensile strain $\left(\varepsilon_{t}\right)$ is calculated from the stresses

$$
\epsilon_{t}=\frac{1}{E}\left[\sigma_{3}-v\left(\sigma_{1}+\sigma_{2}\right)\right],
$$

where $\sigma_{1}, \sigma_{2}, \sigma_{3}=$ the maximum, intermediate and least principal stress (with compression positive), and

$E$ and $v=$ elastic constants for the rock.

The extensile strain concept has been introduced by Stacey (1981), following the concept of effective tensile stress theory presented by Brown and Trollope (1967). The criterion is simple and appears to predict zones of slabbing and rock failure around openings in high-stress zones where failure was not always predicted by the Mohr-Coulomb theory. The limit of 0.0004 is proposed for the extensile strain in tuff. This value is half the extensile strain at failure for the uniaxial compressive strength tests, and is estimated to be approximately twice the critical extensile strain proposed by Stacey (1981) as the level at which fracture of brittle rock will initiate. Borg et al. (1984) found a value for the limiting extensile strain of 0.0004 to 0.00075 from back calculation of failures in an underground zinc mine in Sweden. This criterion is not expected to be a controlling parameter around room-scale excavations, but could indicate spalling around the emplacement boreholes.

The maximum allowable joint slip could be introduced to limit the total displacements around the room. "Failure" of an excavation with a particular geometry or set of loading conditions is indicated either by nonconvergence of the numerical model because of excessive movement or by excessive shear deformation resulting from slip along joints.

6.5.2.4 Distinct Block Model The distinct block model requires a geometric representation of the joints as well as the joint and intact rock properties. The joint properties can be represented by a Mohr-Coulomb strength criterion with the joint stiffness either constant or dependent on stress and displacements. Blocks can deform, rotate, and split. The key to application of this model is in the geometric representation of the joint system. Guidelines for applicaticn of this method to the Yucca Mountain repository are to be developed if it is considered an appropriate model for design. The joint properties and block strength criteria would be the same as for the CJM with the limits on joint slip also applied to ensure conservative stable drift designs. Should welldefined joint sets that are significantly weaker than the intact rock be identified, and block motions be demonstrated to be important, then this model may become more widely applicable in drift stability design.

\subsubsection{Results of Analyses}

The results needed for the evaluation of the drift must be readily available. From the elastic models, safety factor contours of the ratio of stress-to-strength of the rock mass and joints should be presented. For the nonlinear analysis, the location of zones of inelastic behavior, contours of irelastic strains, extensile strains, joint slips, and the safety factor for crushing of intact blocks are required for drift stability evaluation. 
The analytical results are required for the stress combinations listed in Section 5.1.4 and for the complete range of expected repository geologic conditions. Appendix B discusses the results of analysis using the CJM for emplacement drift design and illustrates the results expected for joint slip and failure of the intact rock for a typical case. The appendix also illustrates the application of the criteria on extensile strain and intact rock crushing for the emplacement drift example.

The results of numerical modeling may indicate regions of slip or yield of the rock, but they do not necessarily predict or model rock tallout or collapse. Hence, to assess the stability or suitability of the drift, acceptance criteria have to be adopted. The drift design criteria detailed in Chapter 4 are expressed in terms of safety factors on the ground support/rock reinforcement components, but to this point, analysis (Part A of the methodology) has not incorporated explicitly any function of the ground support/rock reinforcement system. To bridge this gap, a method of relating the analytical results to ground support requirements is required. For the preliminary drift design, the following is proposed:

- If no rock mass yield or joint slip is projected, no ground support is required.

- When yield or failure of intact blocks is projected in the roof, the ground support/rock reinforcement components should be sized to be anchored in elastic or nonyielded rock and be designed to support the graviry load (dead weight) of the yielded material. This assumption is considered conservative because the yielded rock will maintain some post-yield strength.

- When yield or failure of intact blocks is projected in the walls, the rock support/rock reinforcement components should be sized to be anchored in elastic or nonyielding material and should be designed to pin the gravity load of the failed material. The wall pressure supplied by the ground support can be calculated from the methodology presented below.

Figure 6-7 illustrates the recommended method for estimating the wall pressure. The block bounded by joint $\mathrm{AB}$ is loaded by its self-weight and the pressure of the yielded rock of height $h$. The inclined plane $A B$ is assumed to be a preexisting joint with no cohesion. The wall pressure $\left(P_{w}\right)$ can be calculated from

$$
P_{w}=2 w(\sin \theta-\cos \theta \tan \alpha) / H_{w},
$$

where $\alpha=$ the friction angle for joints,

$w=$ the weight of the sliding block plus the pressure of the yielded rock of height $h$,

$w=\gamma d\left[H-\frac{d}{2} \tan \theta+h\right]$,

$H_{w}=$ wall height (see Figure 6-7), and

$d^{w}=$ width of yield at midheight of drift wall.

This equation can be used to size the diameter and spacings of horizontal bolts to provide a capacity of $P_{w}$ with an appropriate safety factor. Equation 15 assumes that the horizontal bolt will pin the joint with the bolt shear capacity equal to half its tensile strength. The most adverse orientation of $\theta$ is assumed.

\subsection{Drift Intersections}

Roof falls and rock instabilities often occur at drift intersections, which often require additional ground support. Intersections of particular interest in the repository include those of the 


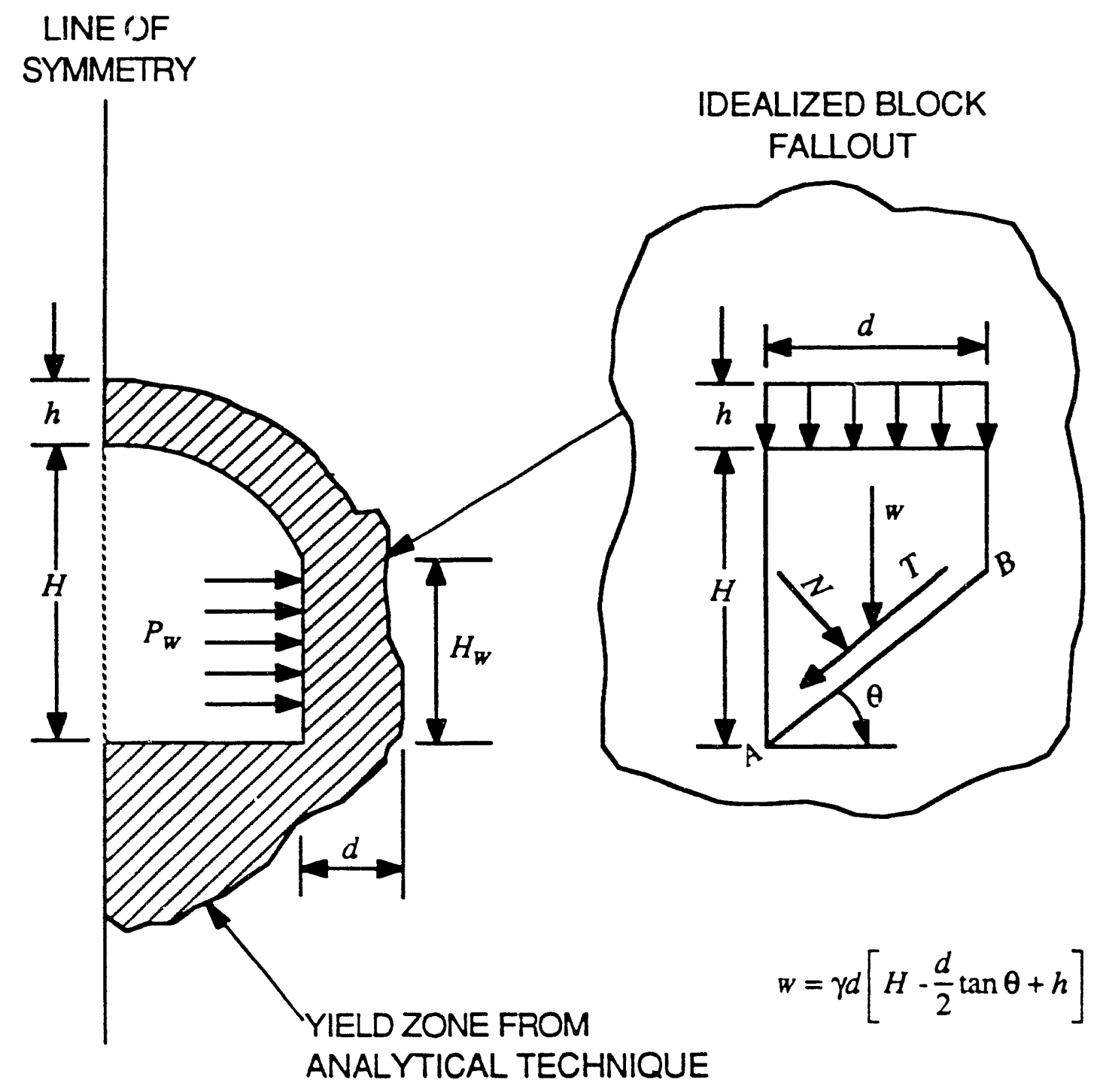

Figure 6-7. Schematic Illustrating Geometry and Loads for Calculation of Wall Support Pressure 
midpanel drifts and mains, the midpanel and emplacement drifts, and the emplacement borehole and room. Design of ground support systems at intersections is currently not well developed because of the complexity of the problem.

Analytical methods used to evaluate intersections have included three-dimensional, finite-element, and boundary-element methods (Ushijima and Einstein, 1985). Realistically, such models can only represent a small part of the repository. The basic methodology for design of intersections is the same as for drifts; the thermal and seismic loads can be assessed without the presence of the drifts, and in a second stage of analysis, the boundary loads relieved by the excavation. Initially, elastic analyses should be performed and an assessment of the potential for inelastic behavior and joint slip made. It is believed that because the intersections are removed from the immediate waste emplacement areas, the loads at intersections will be less than the loads on emplacement drifts, so linear elastic analysis may be sufficient. For such elastic analysis, the boundary-element method is preferred because of simplicity in input definition and efficiency in analyses. Some threc-dimensional, nonlinear analysis may be necessary to confirm the simplifying assumptions in the elastic three-dimensional analysis.

\subsection{Borehole Drift Intersections}

The intersection of the borehole and the drift perimeter presents unique design requirements. For some rock conditions, it is anticipated that joint slip or yielding of the rock mass will occur at this interface. Such movement may require rock reinforcement and special care in designing the borehole-lining and drift-lining interface to assure retrievability. Development of these design procedures are outside the scope of this report.

\subsection{Fault Zones and Zones of Poor Rock Quality}

Fault zones and areas where rock quality is well below the expected range should be considered differently from routine drift design. Fault zones may be extensive and similar to areas of poor rock quality, or the faults may be localized planar features. In the latter case, the orientation of a fault relative to the thermal loads and the drift axis is of primary concern. If the stress changes across a known fault surface indicate a significant potential for slip, then either the waste emplacement sequencing can be rearranged around the fault or the area isolated from waste emplacement. However, it is anticipated that fault zones and areas of extremely poor quality rock will be excluded from the repository area during site characterization and preliminary repository layout studies. Issues to be considered for design of drifts that pass through faults include the following:

- Constructibility Through the Zone-If the zone has very poor rock quality, collapse or squeezing could accompany construction, requiring installation of bolts, forepoling, staged construction, or steel sets.

- Ground Support Requirements-Ground support requirements can be expected to be more severe in lower quality rock or in fault zones.

- Waste Emplacement-Waste emplacement may be excluded from an area near ground of poor quality or the waste-emplacement density may be restricted. The drift stability may impact that decision.

- Rock Mass Deformation Mechanisms (RMDM)-Additional RMDM may need to he considered for design through such zones. In zones of poor ground such deformation mechanisms as creep, or shrinkage or swelling with moisture changes might require special consideration. 
Where faults are localized and they interact with joints to form blocks, distinct element methods (Cundall and Hart, 1984) can be applied. For poor ground conditions requiring special construction techniques or special ground support systems, empirical techniques and soft rock tunneling experience can be used to select the initial ground support system. Numerical models can be used to perform parametric studies intended to define the rock characteristic for which waste emplacement should be restricted or eliminated.

\subsection{Preliminary Ground Support Selection}

The preliminary ground support design is established from the empirical and numerical analysis completed during the drift stability assessment. From the analytical methods, the ground support system is introduced essentially to hold up the yielded rock. The preliminary ground support design includes selection of specific components; bolt spacings, length, diameter and capacities; plates, mesh, straps, and/or shotcrete. The selection of bolt lengths and spacings should recognize the empirical design rules developed by Lang (1961). Lang (1961) gives the minimum bolt length $L$ as the greatest of these measurements:

- $\quad$ twice the bolt spacing;

- three times the width of critical and potentially unstable rock blocks defined by the average discontinuity spacing $(b)$ in the rock mass; and

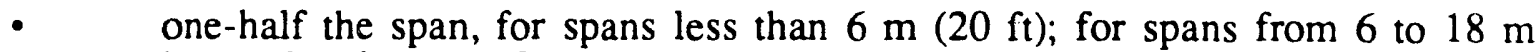
interpolate between 3 and $5 \mathrm{~m}$ lengths, respectively; for spans from 18 to $30 \mathrm{~m}$ (60 to $100 \mathrm{ft}$ ) bolt lengths of one-quarter of the span (approximately $L=B^{2: 3}$ where $B$ is in feet).

The maximum bolt spacing is given as the least of $0.5 \mathrm{~L}$ and $1.5 \mathrm{~b}$. For cases where the rock is intensely jointed, these rules break down and welded wire mesh or chain link mesh is recommended with a bolt spacing of less than $2 \mathrm{~m}$. The empirical method of Barton et al. (1974) provide guidance on bolt spacing, bolt lengths, and bolt support pressure capacities based on the rock mass quality, $\mathrm{Q}$, and the opening dimensions.

The more conservative of the two ground support systems developed from empirical and numerical methods should be selected for further analysis and refinement using both uncoupled and coupled techniques.

The ground support designs will be developed for five rock mass quality caregories representing the expected range of site conditions. The ground support system selected for installation in a particular drift during construction will be suitable for the majority of conditions encountered during construction, even though lesser support, such as no support or minimal support, may be sufficient over much of the length of the drift. The site conditions that would require deviation from the basic ground support system should be well defined so that such conditions can be recognized during construction and the ground support enhanced without prolonged construction delays. 


\subsection{EVALUATION OF DRIFT ANALYSIS}

Once the drifts have been analyzed and a preliminary ground support/reinforcement selected, the results should be assessed relative to the requirements and criteria presented in Chapter 4. The evaluations of the design (Section 7.1) can result in a need to modify the drift geometry or thermal loads (Section 7.2) if the evaluation indicates unsatisfactory performance.

\subsection{Evaluation of Drift Design}

This step in the design is used as a screening step to eliminate designs that are inherently unstable or in which drift temperatures are too high. Interpretations are made using numerical and empirical results to ensure that stability criteria and temperature goals are met (see Chapter 4). Important concepts used during evaluation of designs are safety factors in the rock mass using rock mass strength, joint or intact rock strength, and extent of rock yielding around the drift.

\subsubsection{Evaluation of Thermal Goals}

The temperature performance goals will be evaluated by comparing the predicted temperatures with the temperature criteria. The comprehensive evaluation of the thermal goals will be the subject of other thermal studies unassociated with the stability assessment and are not discussed in detail here. These other thermal studies will include the effects of ventilation, and moisture and the three-dimensional interactions between the container and drift and will be more extensive than those used in the drift stability assessment.

\subsubsection{Evaluation of Drift Stability}

This section discusses the evaluation of the projected drift response relative to the drift design criteria of Chapter 4. Stability is a subjective term that must be quantified through the use of failure criteria associated with the modes of failure. At this stage in the design, although the rock response is decoupled from the ground support, the drift suitability is based on the projected capacity of the ground support system. The preliminary ground support is estimated either from empirical methods or from numerical analysis of the unsupported drifts.

The application of empirical methods is limited to evaluation of the standup time, or estimates of final support system requirements (Barton et al., 1974) without consideration of the seismic or thermal loads. For the $Q$ system, the required support can range from "no support" to massive supports consisting of cast-in-place concrete up to a meter thick for poor ground. The method also has been used to identify the limits of unsupported spans (Barton et al., 1980) and to quantify the roof and wall pressures required from the support system.

It is recommended that a rock mass quality, $Q$, of less than 0.1 where the standup time projected to be less than one day should indicate unstable, unfavorable conditions for repository emplacement. Because $Q$ is a combination of in situ rock conditions and loads (through the SRF term), some accommodation may be possible by limiting the thermal loads in the poorer rock regions. Otherwise these areas, if known in advance from core holes or geophysical data, should be excluded from repository activities. If, however, areas of rock quality are encountered during construction with a Q rating lower than 0.1 , a ground support system and local waste emplacement layouts should be specifically designed.

Assessment of drift stability during thermal and seismic loading requires definition of limits and criteria directly related to the output of the analysis and specific to mechanisms of failure. 
Criteria developed and presented in Chapter 4 are based on the extent of excessive nonlinear strains surrounding the drift and a preliminary assessment of the practicality of a ground support system for reinforcing or supporting the zones of yielded rock.

\subsubsection{Drift Stability Criteria}

To evaluate the suitability of drift design, two sets of criteria must be met. The first set relates to the conditions of the rock mass under the imposed loads and the second to the practicality of installing a ground support system to support yielded rock. Figure 7-1 summarizes the steps involved in applying the criteria. The set of criteria relating to the condition of the rock mass are as follows:

- projected standup time of greater than one day (empirical method),

- $\quad \mathrm{Q}$ of greater than 0.1 (empirical method), and

- no crushed rock where the compressive strain is greater than $0.8 \%$ (based on equivalent elasto-plastic continuum model).

If the rock mass does not meet the above criteria, drift construction and waste emplacement would be impractical, and if required, would necessitate careful review of conditions, construction procedures, and emplacement densities.

A preliminary ground support design must be completed to evaluate the capacity and practicality of the system to support yielded rock as discussed in Section 6.9. The ground support system should be conservatively designed to support the mass of rock in the crown under conditions where such rock has

- $\quad y i e l d e d$ based on the equivalent-continuum elasto-plastic model,

- been crushed based on yield of intact rock in the CJM or distinct block model, or

- $\quad$ exceeded the critical extensile strain criteria of 0.0004 .

For the drift walls, the ground support system should be designed conservatively to resist the lateral movement of the yielded rock mass. The higher wall pressures from either the empirical or analytical method should be used.

The criteria developed in Chapter 4 are then applied to drift stability and suitability.

For roof and crown areas of drift relying, in part, on internal fixtures, such as rockbolts, dowels or cables, the inelastic zone, or region of excessive extensile strains predicted by numerical models for in situ and thermal loads should not exceed one-half the length of the fixtures that can be installed effectively during the construction cycle. For ribs and walls of drifts, the internal fixtures should be anchored in nonyielding rock. The required ground support system for the normal ground conditions should not be excessive and should be both practical and economical.

The above criteria incorporate three rock deformation mechanisms: rock mass yield (inelastic zone), yield of intact rock and spalling (excessive extensile strain), and a conservative assumption on support interaction. 


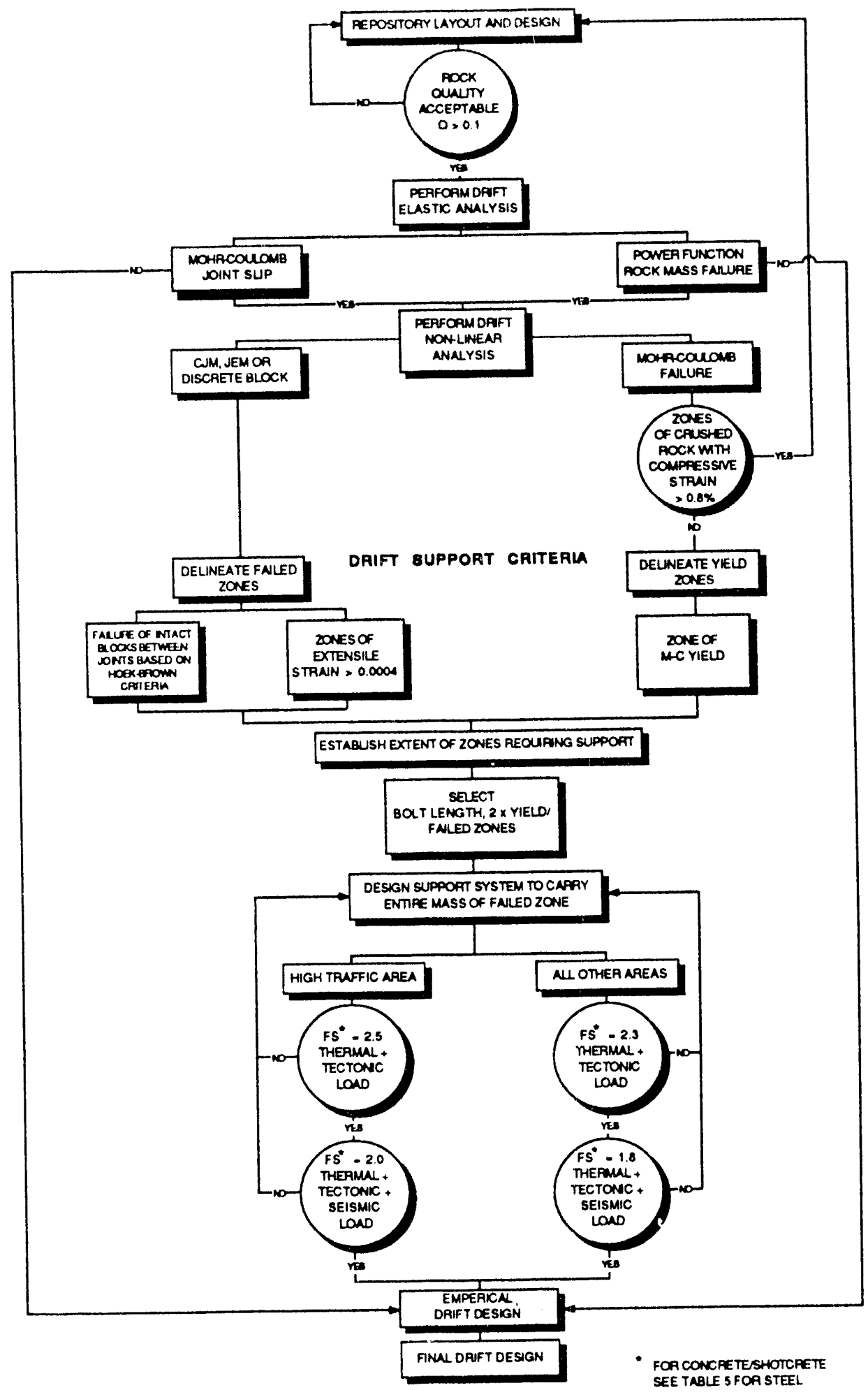

Figure 7-1. Flowchart Illustrating Application of Drift Support Design Criteria to Drift Analysis 
The criteria placed on the rock support system are that it not be excessive and be both economical and practical, recognizing that stability can possibly be maintained under almost any ground or thermally induced loading conditions at an unreasonable cost. Defining unreasonable cost is beyond the scope of these technical guidelines, but drifts with a minimal ground support system are preferred. Minimal ground support systems could incorporate rockbolts, straps, wire mesh, and shotcrete. For poorer ground conditions, some enhancement of the basic rock support system would be acceptable and would require more detailed analysis of the interaction of the support system and rock deformation as outlined in Chapter 8. The practical limit on the length of bolts under normal geologic conditions would be from one-half to three-quarters of the opening dimension.

\subsection{Evaluation of Field Demonstration Studies}

A series of measurements, experiments, and demonstrations will be performed as part of the geomechanical effort in the ESF. This geomechanical effort will be used to evaluate, validate, and help determine the limitation of the analysis methods discussed above. The experiments and demonstrations will be analyzed using the recommended drift design methodology. These exercises will be used as the basis for validating these models and/or for providing the rationale to modify them.

\subsection{Preliminary Modifications}

If the drift stability criteria are not met, three options are available, as shown in Figure 2-2: modification of the drift design, modification of the loads through changes in APD or waste emplacement configuration, or modification of the goals.

Modifications to the APD (the only load that is modifiable) or waste emplacement layout (standoff, spacings, etc.) can result ir. reduction in the stresses, the inelastic deformations, or the temperatures, so that the drift design criteria and temperature goals can be met. However, the modifications may affect borehole and panel designs and the potential impacts on the overall system must be examined before changing either the APD or panel layout. Modification of the drift design criteria should not be attempted until the drift shape, preliminary ground support system, and layouts have been modified, and such modifications must be defensible relative to the functional requirements, performance goals, and excavation and stability experience in exploratory excavations. For example, the goals related to standup time could not be relaxed without a significant potential impact on construction methods, worker safety, practicability, and economy of the support system. 


\subsection{GROUND SUPPORT DESIGN}

In general, the rock characterization schemes such as the $Q$ and $R M R$ methods will be used to define the ranges of ground support systems required to accommodate the expected in situ geologic conditions. The preliminary ground support based on the numerical modeling of unsupported drifts will provide a preliminary estimate of the length, spacing, and area of rock reinforcement components and shotcrete/concrete lining requirements to accommodate the combined in situ, thermal, and seismic loads. Coupled analysis will be performed to assess the interaction of the ground support system and the host rock to confirm conservatism in the support components.

The ground conditions expected require little or no ground support over most of the excavated areas. The range of conditions and the percentage of drifts to be excavated in specific rock quality categories is unknown at this time, although it is clear from the limited core hole data that a wide range of rock qualities can be anticipated.

The drift design will be verified by monitoring performance during construction of the ESF, during performance confirmation testing, and later during construction of the repository. The results of such monitoring will confirm the modes of behavior or failure and allow verification that different methods of ground support or ground reinforcement limit any tendency for excess deformation. Any deterioration of the engineered components of the ground support system will also be monitored.

Ground support materials will be selected for durability, strength, thermal compatibility, and recognition of chemical restrictions that might be imposed by long-term (postclosure) repository performance requirements.

The inputs for ground support design (Section 8.1), the ground support design analysis (Section 8.2), and the evaluation of the ground support system (Section 8.3) are described below.

\subsection{Inputs for Ground Support Design}

This section discusses the inputs required for design of the ground support systems. These include the timing of installation of the ground support system, the rock mass failure mechanisms, the functional requirements of the ground support system, the material behavior, and potential failure mechanisms of the support systems.

\subsubsection{In Situ Stress Relief and Ground Support Loading}

The load applied to the ground support systems resulting from relaxation of the in situ stress will depend on the timing of support installation relative to excavation, stiffness of the supports, and on time-dependent deformations or changes in the rock mass. The interaction of the rock deformation and loads applied to the rock support/reinforcement system is often illustrated by the use of the ground reaction curve shown in Figure 8-1. Figure 8-1a shows the ground reaction curve and the support deformation characteristic of three support systems of differing stiffness. In Figure 8-1a, the rock remains elastic, so the rock ground reaction curve, curve A-B, is linear. Point A represents the conditions at the boundary of the drift before excavation. After excavation, the support pressure is zero, but now the drift perimeter has deformed as represented by Point B. In Figure $8-1 \mathrm{~b}$, the rock behaves elastically initially, but then deforms inelastically, so the ground reaction curve $A-B$ is nonlinear. In unstable ground, the ground reaction curve may not intersect the zero pressure line (as indicated by the dotted ground reaction curve), indicating the need for a rock support system designed to provide at least a minimum support pressure. 


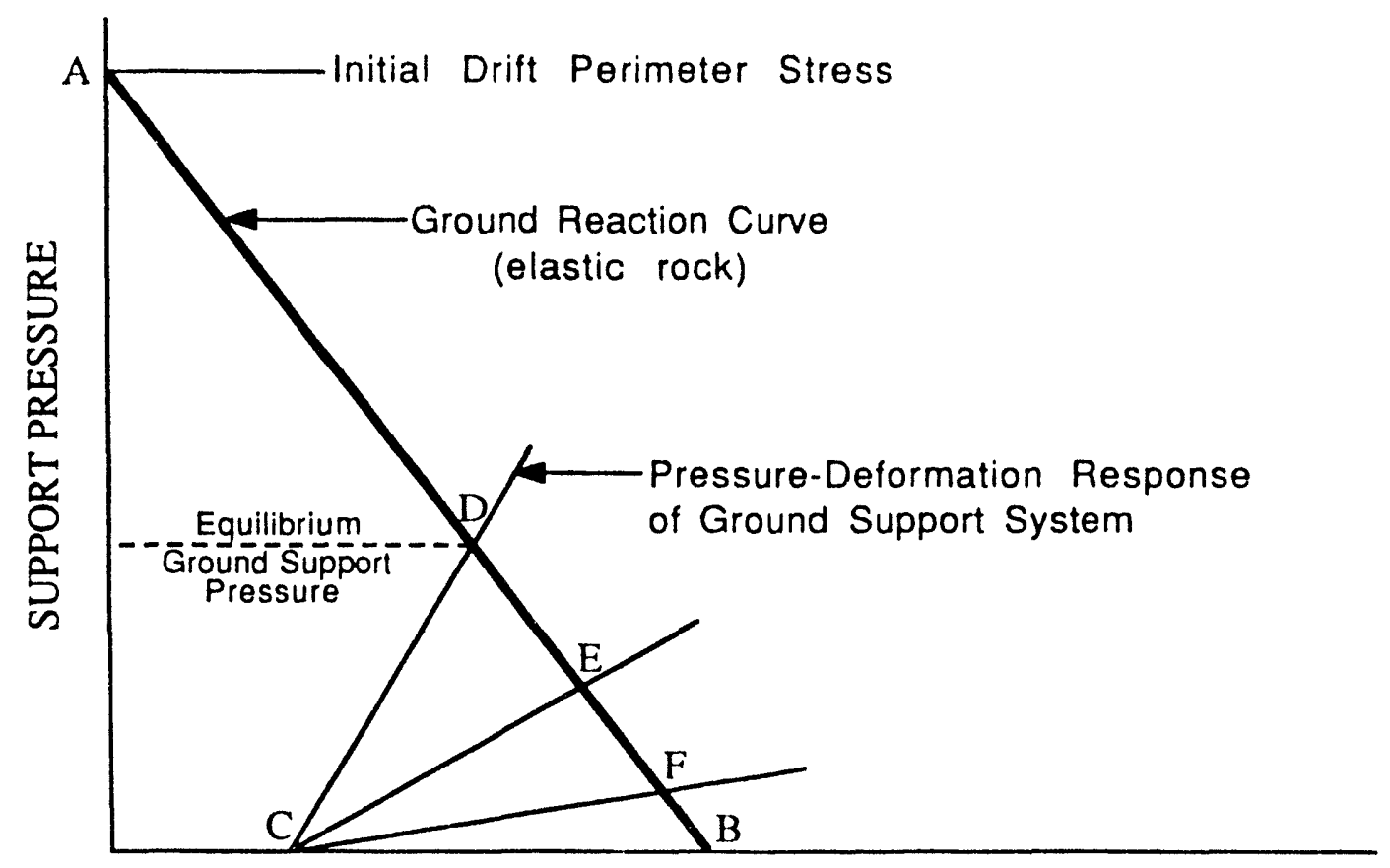

INWARD RADIAL DEFORMATION

a) With Elastic Rock

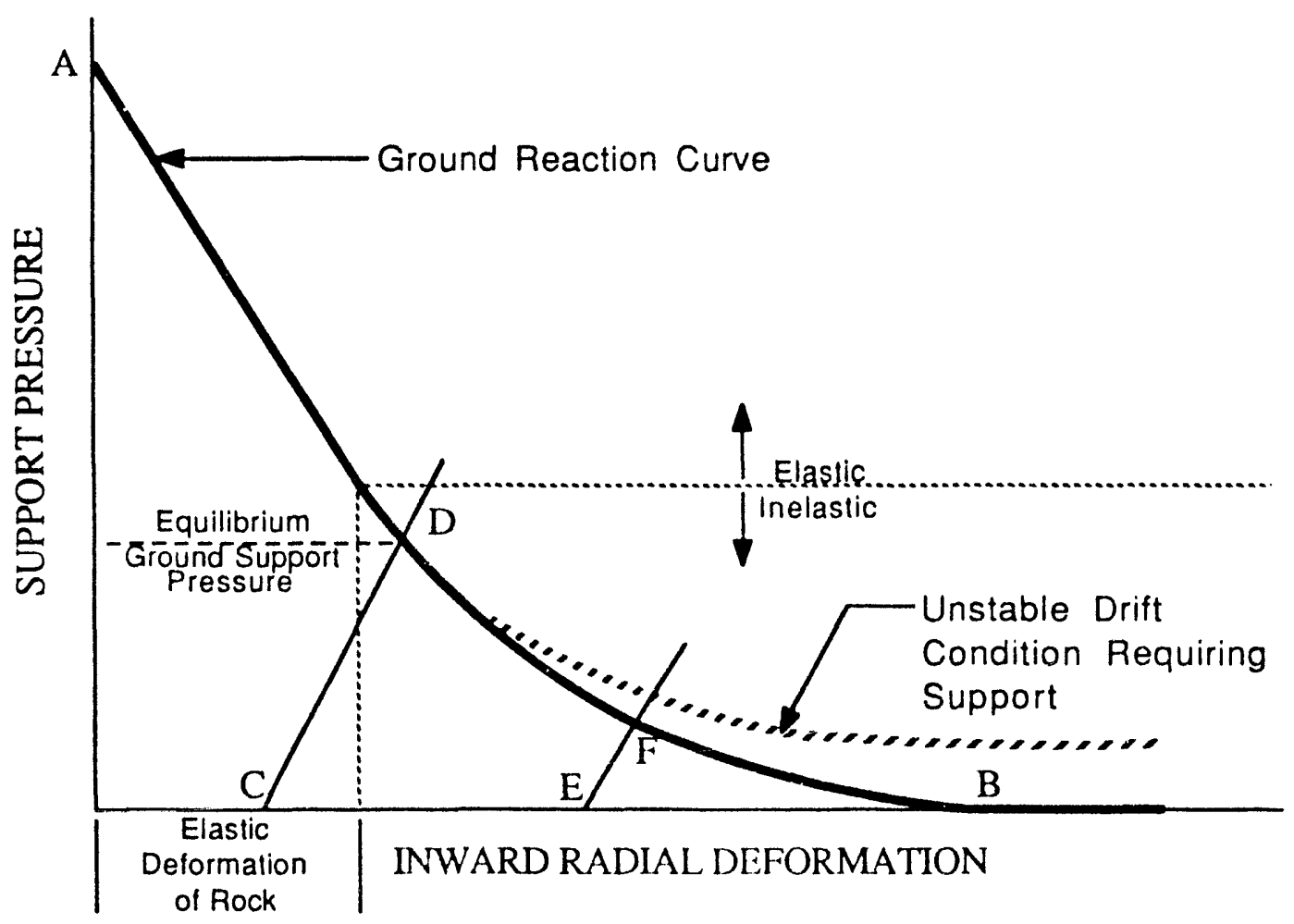

b) With Inelastic Rock

Figure 8-1. Illustration of Interaction of the Ground Reaction Curve and Ground Support System 
The timing of support installation often determines the load assumed by the rock support/reinforcement system. Rockbolts are typically installed near the face as soon as practical after each blast round, and are thus loaded by rock deformations accompanying the advance of the face. Shotcrete might be installed either immediately or after the face tas been advanced sufficiently that blasting would not impact the young shotcrete. Final support, such as concrete, or in some cases additional rockbolts and shotcrete, is applied well after excavation; if the excavation has already stabilized, the final support may never experience any impact from the in situ stresses. This is illustrated in Figure 8-1b. If the supports are installed after B, no load is developed in the support. If the supports are installed near the face-for example, after deformation represerited by C-then as the face advances, the drift perimeter will further deform, loading the support system. If installed later-for example, at Point E-the load transferred to the supports will be less.

The stiffness of the support system affects the loading in the supports because stiff systems will assume high loads with little ground movement. Softer, more flexible systems do not assume high loads, but may allow excessive deformation in the rock, possibly leading to unstable conditions. This is illustrated in Figure 8-1 a by lines C-D, C-E, and C-F where C-F represents the more flexible support system.

For design of the ground support system using simplified two-dimensional techniques, the detailed sequence of support installation and excavation cannot be modeled. To overcome this, one approach suggested in the shaft design methodology document (PBQD, 1990) is to apply a reduced percentage ( $n$ percent) of the in situ stress to the support system. In essence, this method assumes that the excavation will deform under the action of most of the far-field stress $(100-\mathrm{n}$ percent) before the ground support system is installed. The ground support/rock interaction occurs during the relaxation of the remainder ( $n$ percent) of the far-field in situ stress.

Table 8-1 lists suggested percentages of the excavation-induced deformation resisted by the ground support system. Also shown is the typical distance between the face and the support system. The numerical values for the percent of excavation-induced deformation resisted by the supports shown are established as follows. The final supports are installed well beyond the face after the elastic ground deformations accompanying excavation have occurred. The $15 \%$ number for the tinal supports is taken from the shaft design methodology document (PBQD, 1990) where $15 \%$ of the in situ stress is used in the design of the concrete liner in the shaft. When rockbolts are the primary means of support, it is assumed they are installed as close to the face as practical.

Following discussions presented by St. John (1987b), it has been assumed that this will lead to the bolts being loaded by $75 \%$ of the excavation-induced deformation around the drift. Shotcrete is assumed to be installed at least one round (typically 3 to $5 \mathrm{~m}$ ) from the face; thus, the shotcrete is installed after a significant percentage of the excavation-induced deformation has occurred.

In better quality rock, when excavated using a full-face boring machine, bolts and shotcrete would be applied behind the machine or up to 10 to $15 \mathrm{~m}$ behind the face. In this case, the assumption of installation of supports close to the face, as shown in Table 8-1, should be used because these assumptions will result in conservative overestimates of bolt and shotcrete loads.

The deformation resulting from the excavation and the loads imposed on the ground support system from the relief of the in situ stress is small relative to the thermal loads and, possibly, the seismic loads. 
Table 8-1

\section{SUGGESTED PERCENTAGE OF EXCAVATION-INDUCED GROUND DEFORMATION}

\begin{tabular}{|l|c|c||}
\hline $\begin{array}{c}\text { Ground Support } \\
\text { Component Acting on } \\
\text { Supports }\end{array}$ & $\begin{array}{c}\text { Percent of Excavation- } \\
\text { Induced Ground } \\
\text { Deformation Acting on } \\
\text { Supports }\end{array}$ & $\begin{array}{c}\text { Typical Distance Between } \\
\text { Face and First Support }\end{array}$ \\
\hline \hline $\begin{array}{l}\text { Primary Supports } \\
\text { Rockbolts }\end{array}$ & 75 & 0 to $7 \mathrm{~m}$ \\
Shotcrete & 50 & 5 to $7 \mathrm{~m}$ \\
Steel sets* & 75 & 0 to $7 \mathrm{~m}$ \\
\hline Final Supports & 25 & 7 to $100 \mathrm{~m}$ \\
Rockbolts & 25 & 7 to $100 \mathrm{~m}$ \\
Shotcrete & 15 & 7 to $100 \mathrm{~m}$ \\
Concrete or steel sets, etc. & & \\
\hline * for locally very poor ground & & \\
\hline
\end{tabular}

\subsubsection{Rock Mass Failure Mechanisms}

The potential failure mechanisms of rock influence the ground support selection, selection of bolt accessories, and length and orientation of bolts. Structurally controlled mechanisms include slip-along joints, fractures, bedding planes, or faults, and result in block fallout, raveling and/or collapse. Stress-controlled mechanisms result in elastic deformation, compressive or shear yielding, splitting, or rock bursts. For weaker rocks, squeezing and heave can result from plastic yielding of the host medium.

In Part A of the drift design methodology, the nature of the host rock was assessed and the rock deformations analyzed on the basis of the expected controlling deformation modes. The ground support system provides a safety factor to account to some extent for secondary deformation mechanisms that have not been explicitly addressed in the previous analysis. The analytical results are used to evaluate the potential for unsafe conditions or rock fallout from the primary failure mechanisms of joint slip, compressive yield of the host rock, or tensile splitting. The design analysis methods do not address secondary mechanisms of failure associated with creep, rate of loading, chemical degradation, or moisture effects of the host rock.

\subsubsection{Functional Requirements of Ground Support}

The primary role of the ground support is to ensure safety and usability of the drifts during the operational period. This requires limiting rock deformations and providing superficial protection from deterioration or weathering of the host rock. To limit deformations, the ground support system may be required to reinforce the rock mass, to pin joints or blocks together, to suspend rock loads, or to support potential loose (or yielded) rock by providing struciural load transfer to the floor. In some unfavorable ground conditions, the ground support components inight be required to yield to accommodate large rock deformations. 
The requirements identified in Chapter 3 are specific to the main access and other drifts and recognize that maintenance and, for some drifts, rehabilitations of drifts and the ground support system may be required to ensure drift performance in the preclosure period. For the emplacement drifts, maintenance and rehabilitation may be required before reentry for retrieval, but when the drifts are sealed after waste emplacement, some miror rock falls can be tolerated. In the tuff main drifts, the ground support system must be conservatively designed because the drifts will be in continuous use and unscheduled downtime to repair, replace, or enhance the ground support system would be disruptive and inconvenient.

\subsubsection{Ground Support Material Behavior}

This section discusses the material properties of the ground support system and their relationship to meeting the functional requirements. Important characteristics are strength, ductility, durability, and thermal compatibility with the host rock.

Rockbolts typically are made from high-strength steel with yield strengths in the 400 to $550 \mathrm{MPa}(60,000$ to $80,000 \mathrm{psi})$ range. Commercially available bolts are also fabricated from fiber-reinforced epoxies, wood, and steel strands and wires; however, the high temperatures in the emplacement drifts and long-term performance goals would eliminate the use of wood and epoxies in those drifts. The steel yields at 60,000 psi but has an ultimate load of 90,000 psi and can sustain strains of $25 \%$. It is desirable for the thermal expansion coefficient of the rockbolts, typically $11 \times 10^{-6} \mathrm{~m} / \mathrm{m}^{\circ} \mathrm{K}$, to be similar to that of tuff $\left(8.8 \times 10^{-6} \mathrm{~m} / \mathrm{m}^{\circ} \mathrm{K}\right)$. The grade of steel used for rockbolts will be specified by the design and quality control testing performed to ensure that the steel meets the strength, ductility, and thermal expansion specifications.

Concrete, grout, and shotcrete form components of the ground support system and have widely varying properties depending on cement content, aggregate size distributions, water-tocement ratio, additive and mixing, placement, and curing conditions. Discussion of the properties for these materials is included in the ACI codes. The shotcrete/concrete mixes will have to be optimized to provide desirable strength, deformability, durability, and thermal characteristics.

The elevated temperature environment in the waste emplacement, midpanel emplacement, and to a lesser extent, tuff main drifts imposes unusual conditions for design of the ground support components. Compatibility of the components with the rock and potential long-term temperature activated chemical interactions indicate a high degree of uncertainty in the ground support components long-term performance (but still within the preclosure period). The maintenance program and replacement of components (if needed) alleviates some of the impact of this uncertainty. Maintenance/replacement can be time-consuming and expensive, and for the emplacement rooms that will require cooling, could be impractical if frequent. Hence, demonstration of performance and development of some components of the ground support system is anticipated in the ESF and performance confirmation area.

Yielding of the rock mass can cause bolt failure, particularly if the bolts are fully coupled to the rock. Special rockbolt design will be required to accommodate the thermal expansion and yield of the rock mass. Specifically, the stiffness of bolts may have to be reduced to accommodate the rock deformations.

\subsubsection{Ground Support Failure Mechanisms}

The potential failure mechanisms of typical ground support components (mainly bolts/shotcrete) consist of yield or rupture of components, corrosion and debonding, dehydration of cementitious materials, creep of grout anchor or plate failures, deterioration, and strain incompatibility. The following lists detailed failure mechanisms for specific ground support components. 


\section{Rockbolts}

corrosion of bolt

- failure of anchorage (for point-anchored bolts)

- debonding of bolt-grout or grout-rock contact

- anchorage failure

- plate bending

- plate pullthrough

- corrosion of bolt or plate

- $\quad$ stress failure of bolt (overload)

- creep/relaxation of bolt tension

- bolt bending failure because of block rotations

\section{Wire Mesh/Straps}

- failure at bolt/mesh interface

- tension failure of steel mesh

- $\quad$ puncturing of mesh by block fallout

\section{Shotcrete}

- tensile cracking

- debonding between rock and shotcrete

- compressive failure

- $\quad$ shear punching

- dehydration, chemical degradation

- corrosion of reinforcing fiber or mesh

- debonding from reinforcement application.

Failure often results from improper installation procedures or poor quality control during

\subsection{Ground Support Design Analysis}

Analysis of the ground support performance in the thermal environment imposed after waste emplacement is necessary to ensure compatibility between the rock deformations and the support system. Two types of analyses are recommended: uncoupled and coupled. Uncoupled analysis as described below is useful when the ground support system is not expected to modify the deformation response of the rock mass or significantly modify the rock mass strength. Coupled 
analysis is recommended if significant rock yield is projected. The ground support design analysis should recognize the five rock mass quality categories and the load combinations identified in Section 5.1.4.

\subsubsection{Uncoupled Analysis}

Uncoupled analysis is a technique to assess the loads in the rock support components based on the unsupported deformation projected in the rock. This technique assumes that the temperature of the ground support component is the same as the rock and will expand or contract depending on the temperature change in the rock and the thermal expansion coefficient of the component.

For a rockbolt component, the stress change $\sigma_{b}$ in a bolt can be calculated using

$$
\Delta \sigma_{b}=E_{b}\left[\Delta \varepsilon_{r}-\alpha \Delta T_{b}\right]
$$

where $E_{b}=$ the elastic modulus of the bolt,

$\alpha=$ coefficient of thermal expansion of the bolt,

$\Delta T_{b}=$ average temperature change along the bolt, and

$\Delta \varepsilon_{r}=$ strain change in the rock over the bolt length of interest.

The temperature change and strain in the bolt are determined from the unsupported drift analysis. The strain change is calculated from when the bolt is installed using the guidelines established in Section 8.1.1.

A similar approach can be used to estimate the stress in shotcrete. Here the shotcrete is assumed compatible with the perimeter of the drift and at the same temperature as the drift perimeter. Fo, both the shotcrete and bolting uncoupled analysis, thermal induced loads cannot be separated and imposed as far-field boundary stress changes without a corresponding thermal expansion of the whole system.

Rockbolts are not always compatible with deformation of the rock mass. For example, bolt anchors may slip, plates can yield, and special purpose yielding bolts can be used. The need to design for yield in the bolt, plate, or anchoring system can be assessed by the uncoupled analysis.

This method assumes that the ground support system does not impact the deformation of the rock. Clearly the intent of the ground upport sy stem is to limit rock deformations and inhibit block fallout. However, the ground support system provides only minor forces relative to those around the drift and in some cases does not significantly modify the rock stress. In cases where this is not so, fully coupled analysis is recommended.

\subsubsection{Coupled Analysis}

Coupled analysis includes the effect of the ground support component in the complete analysis. For two-dimensional analysis, this requires a simplification of the bolt geometry to that of an infinite plate, but for shotcrete linings, no geometric simplification is required.

\subsection{Ground Support Evaluation}

The ground suppont componcni stresses predicted by the uncoupled or coupled analyses are evaluated with regard to the required safety factors. In some cases, the thermal expansion misinatch between the rock and bolv/shotcrete is expected to result in overload to the component thereby requiring redesign of that component. 


\subsection{FINAL DESIGN EVALUATIONS}

This section extends the discussion presented in Chapter 7; it is necessary to reevaluate the stability goals to include the effects of the ground support. Additional performance goals such as material and nonradiation safety must be assessed for compliance. Material constraints may limit the options used for ground support systems before repository closure.

\subsection{Evaluation of Final Design}

This step involves evaluation of the drift design, together with any ground support system, against all performance goals. The performance goals and drift design criteria of Chapter 4 should be reevaluated with the results of the coupled analysis of specific ground support components. The adequacy of the support system to limit local rock fallouts and to meet the maintenance goals should be evaluated. The compatibility of the support system components with long-term performance goals should be confirmed.

During this final evaluation, the impact of stress redistribution and drift construction on the long-term performance objectives should be evaluated. In this long-term evaluation, the function of backfill should be considered. The postclosure evaluation includes assessment of the potential for one order of magnitude permeability modification beyond $3 \mathrm{~m}$ of the drift perimeter, the potential for continuum joint slip between the disturbed zone and either the water table or the surface, and the potential for more than $1 \mathrm{~m}$ of relative displacement of the top of the TSw1 Unit.

The final design should be refined to incorporate initial and final support, reviewed for compatibility with the construction method, and integrated with field procedures.

\subsection{Final Modifications}

In the final modifications of the design, the option of modifying either the loads and/or the layout (as in Section 7.2), or the performance goals is allowed. The option to modify goals is retained because as stated in the outset, the goals are not rigidly fixed requirements and are likely to change as the project matures and the repository nears licensing and construction.

\subsection{Final Design Specifications}

The final design consists of the drift dimensions (geometry) and ground support requirements for the range of expected geologic conditions. Not included here but certainly part of a final design are the procedures needed to instali and maintain the support system. If removal of the ground support is required, then removal procedures must be developed.

\subsection{Field Procedures}

Standardized field procedures must be developed to characterize the rock during construction, because such data will be used as input for selection of the appropriate support system compatible with the exposed conditions. Instrumentation must also be installed so that the adequacy of the design can be verified. Monitoring data generated by such instrumentation may also feed back into a program of adaptuve design (an observational approach). 


\subsection{SUMMARY OF METHODOLOGY}

are as follows:

This section summarizes the steps of the preliminary drift design methodology. The steps

1. Establish the functional requirements and performance goals for the drifts and develop drift stability criteria.

2. Establish site characteristics and their credible range for design.

3. Establish repository layout.

4. Define design basis loads.

5. Quantify thermal and seismic loads at specific drift locations and drift types based on thermal mechanical analysis (excluding influence of drifts) and critical incidence of seismic waves.

6. Develop candidate drift designs and perform parametric/tradeoff studies.

7. Select preliminary drift shapes.

8. Perform analyses (empirical/numerical) for drifts and intersections.

9. Select preliminary ground support system from empirical and numerical results.

10. Evaluate the drift design against stability and temperature criteria before proceeding with more detailed analyses.

11. If the criteria were nor adequately met for normal repository conditions, modify the drift shape or loads (panel APD or layout standoff distance to waste) and redo the analyses until criteria are satisfied. If criteria cannot be met, review criteria and performance goals.

12. Perform uncoupled analysis of preliminary ground support system using uncoupled methods.

13. Perform coupled analyses of the drift and ground support system including rock and thermal interactions.

14. Evaluate drift and ground support design versus all stability and temperature criteria and performance goals.

15. Establish ground conditions for which construction and/or waste emplacement should be avoided.

16. If all criteria and goals are not met, then the option exists to modify the loads and/or layout as before and redo the analyses or modify the drift stability criteria or performance goals.

17. Meet all the criteria and goals and produce the final design (drift geometry and ground support requirements).

(Figure 2-2).

lterations may occur in the above steps as indicated in the flowchart previously discussed 


\subsection{DEVELOPMENT OF DRIFT DESIGN METHODOLOGY}

The drift design methodology will evolve from its present form before repository license application. Procedures will be developed during the site characterization period to implement the design to incorporate characterization data gathered during repository drift construction. This evolution will include more reliance on field site-specific data and less reliance on numerical techniques for near-term stability assessment. Numerical predictions of drift stability will still be relied upon to assess the effects of the thermal loads or preclosure and postclosure stability but will be based on site-specific conditions.

Depending on conditions exposed during the ESF drifting, the numerical modeling basis for the design may evolve to be more or less complex than proposed at present. After exposure of ground conditions, it may be possible to demonstrate that two-dimensional elastic analysis of the drifts is sufficient and conservative for drift design. Alternatively, the rock mass structure could control drift stability and the selection and performance of the ground support systems; this may require three-dimensional modeling of the jointed system. Only the results of detailed monitoring of ground movement and support loads and specific tests to quantify rock mass or jointing material properties and geometric configurations will enable a discussion regarding the appropriate characterization of the rock mass to be undertaken. If the rock structure dominates, then an effort should be required to improve the present capabilities of modeling in three dimensions, the rock structure, opening geometries, and support system interactions. 


\subsection{PRELIMINARY APPLICATION OF DRIFT DESIGN METHODOLOGY AT YMP}

A preliminary application of the drift design methodology applied to the tuff main, midpanel emplacement, and emplacement drifts for the reference vertical emplacement is presented. For the sake of clarity, the section headings correspond directly with the 16 steps outlined in the Summary of Methodology (Chapter 10). This application is considered preliminary because

- there is limited site-specific data available at this time;

- there are incomplete iterations and some criteria are not met with the designs presented here;

- there is incomplete application (the analysis of intersections, application of the distinct joint/fault models, or final designs of the ground support/rock reinforcement system components are not included here).

For this example, the drift shape and size of the SCP-CDR will be adopted with the assumption that they meet the functional requirements.

The data presented were obtained or derived from the best available field and laboratory data at the time the report was written, and must be reevaluated prior to design. This reevaluation may include recommendations of more robust methods of data interpretation as more and better data become available. For example, the database currently available does not permit a good statistical treatment of the data.

Care should be exercised in placing undue emphasis on the currently available data because in many instances the database is incomplete and of unknown quality. Core hole data collected in the early site-screening phases were not intended for repository design purposes and could be misleading. The examples presented here are intended to illustrate the recommended procedures for processing field and laboratory data for use in design. The final repository will be based on the complete database developed during the site characterization phase.

\subsection{Establish Functional Requirements, Performance Goals and Develop Drift Stability Requirements}

The functional requirements of the tuff main, midpanel emplacement, and emplacement drifts are adopted from the SCP-CDR (SNL, 1987). Table 12-1 summarizes the functions of each of those three drifts during the preclosure period. To establish the shape and cross-sectional area requirements of the drifts requires that all pieces of equipment and their relationship with other facilities and equipment in the drift be assessed. Currently many of the mechanical components are not developed beyond conceptual sketches, but can be designed to fit within a drift envelope. The critical element controlling the emplacement-drift shape and size is the envelope of the waste transporter and shielding during emplacement. Passing of two transporters is not required in the emplacement drift. The waste transporter is approximately $25 \mathrm{ft}$ long, $10 \mathrm{ft}$ wide and $8 \mathrm{ft}$ high. The waste canister is $15 \mathrm{ft} 6$ in. long requiring an emplacement drift opening dimension of $21 \mathrm{ft} 6$ in. (Stinebaugh and Frostenson, 1986). The ventilation layouts in the SCP-CDR indicate maximum airflow requirements in the emplacement drifts to be 45,000 and $349,000 \mathrm{cfm}$ in the tuff main.

\subsection{Establish Site Characteristics and Credible Range for Design}

Site-specific geotechnical data for the repository horizon at the Yucca Miountain Site is limited at this stage of the project. As site characterization continues, the geotechnical database 


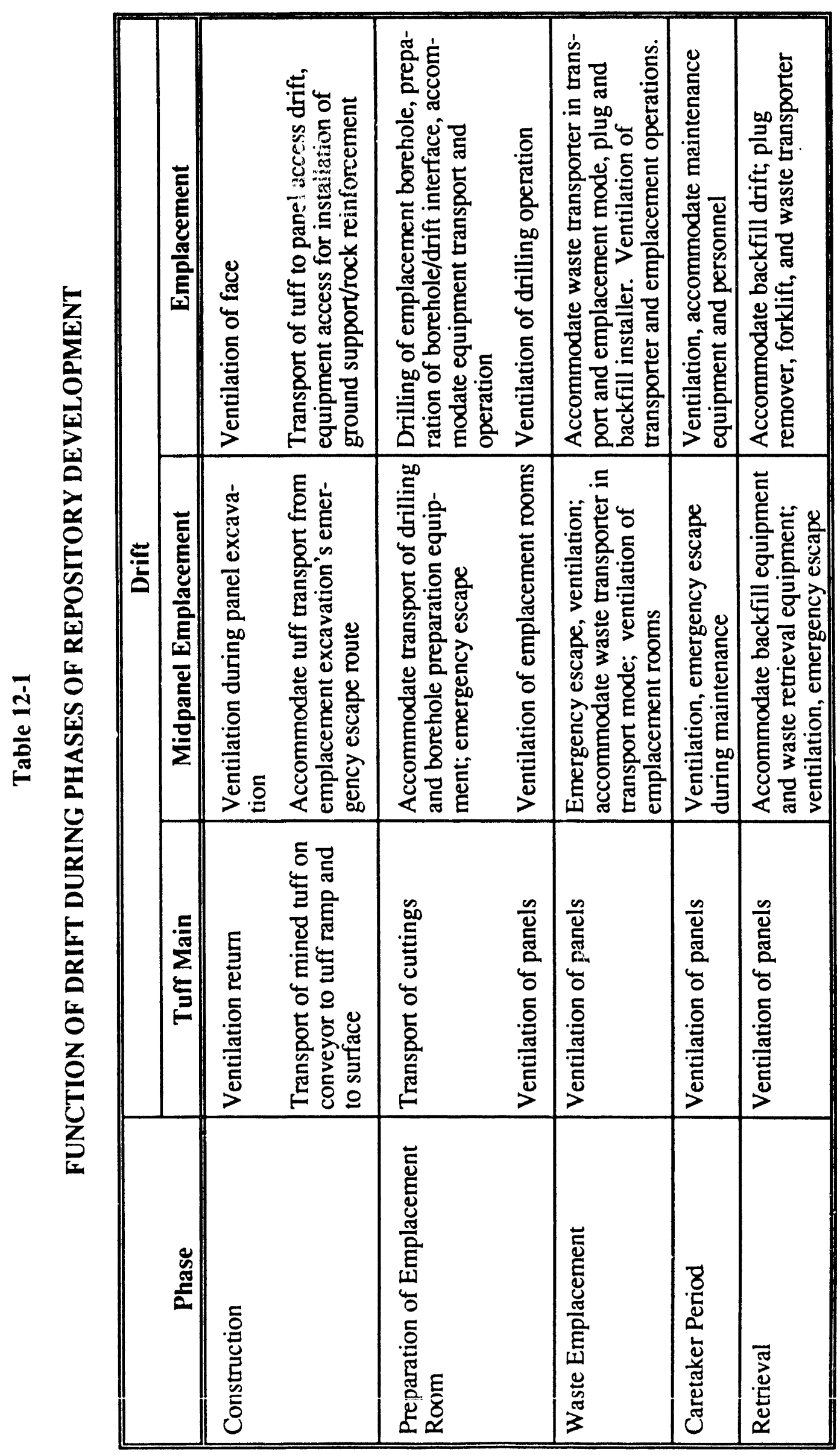


for the repository horizon will be enhanced to allow the definition of statistical levels of confidence that would bound the frequency of occurrence of different rock mass qualities and, thereby, allow better estimates of ground support requirements, construction methods, and repository construction costs. This section illustrates a methodology that uses the existing database to estimate rock mass properties for repository drift design for most expected repository conditions.

Mechanical properties consistent with the current range of rock mass quality estimates for the middle Topopah Spring Member (TSw2) at the Yucca Mountain Site are developed here to demonstrate the application of the proposed drift design methodology. Section 12.2.1, the rock mass quality estimates developed by Langkopf and Gnirk (1986) using both the Norwegian Geotechnical Institute (NGI) Q (Barton et al., 1974) and RMR (Bieniawski, 1979) indices, provided the basis for defining different rock mass categories for analysis. Empirical correlations between the rock mass quality ( $Q$ or $R M R$ ) were then used to develop values of input parameters required for the equivalent-continuum models using either the CJM or Mohr-Coulomb yield model.

The factors affecting variability of rock mass properties include joint frequency and orientation, variation of joint properties, and variability in the properties of the matrix tuff material. In this methodology, the jointing variability is represented in the RQD, RMR, and $Q$ ratings. There is also variability in the matrix materials as a result of variability in porosity and the degree of welding of the tuff. In the methodology, no attempt has been made to quantify the range of porosity and degree of welding at the repository horizon. Instead, the range of expected matrix properties is used directly from existing experimental data.

\subsubsection{Rock Mass Quality}

Rock mass quality ( $Q$ or RMR), calculated using numerical indices that describe the range of various structural geologic and geotechnical parameters, is used to estimate some rock properties and to assess ground support requirements. The parameters used in the two systems and the ranges in values determined for the TSw2 Unit by Langkopf and Gnirk (1986) are listed in Table 12-2. The RMR and $Q$ values are calculated as follows:

$$
R M R=C+R Q D+J F+J C+J W+A J O
$$

and

$$
Q=\frac{R Q D}{J_{N}} \times \frac{J_{R}}{J_{A}} \times \frac{J_{W}}{S R F} .
$$

The symbols are explained in Table 12-2. Parameter ranges used in this evaluation are the same as those recommended by Langkopf and Gnirk (1986) with the exception of the rock quality designation (RQD) parameter, common to both the RMR and NGI classification and the SRF used in the NGI system.

12.2.1.1 RQD Range $R Q D$ is an important index in both classification systems and allows site- or strata-specific variations to be introduced into the estimates of rock mass quality. Because it is usually generate 1 from cores, it allows the definition of lateral change before the development of extensive excavation. RQD values used to develop the expected range of rock mass quality were from four core holes, G-1, GU-3, G-4 and UE-25a\#1, drilled at the Yucca Mountain Site. The RQD data were not directly generated during core logging, but were later calculated by Langkopf and Gnirk (1986) from core loss and broken core on a cored interval basis. Average values of RQD for each hole ranged from 35 to $80 \%$ for the TSw2 Unit, which varied in thickness between 55.1 and $150.5 \mathrm{~m}$. 
Table 12-2

CLASSIFICATION PARAMETERS AND ESTIMATED RANGE OF VALUE

\begin{tabular}{|c|c|c|c|}
\hline $\begin{array}{c}\text { Classification } \\
\text { System }\end{array}$ & Parameter & Description & Range* \\
\hline \multirow[t]{7}{*}{ NGI-Q system } & RQD & Rock quality designation & 35.0 to 80.0 \\
\hline & $J_{N}$ & Joint set number & 6.0 to 12.0 \\
\hline & $\mathrm{J}_{\mathrm{R}}$ & Joint roughness number & 4.0 to 2.0 \\
\hline & $\mathrm{J}_{\mathrm{A}}$ & Joint alteration number & 1.0 to 4.0 \\
\hline & $\mathrm{J}_{\mathrm{w}}$ & Joint water reduction factor & 1.0 \\
\hline & SRF & Stress reduction factor & 1.0 \\
\hline & $\mathrm{Q}$ & Rock mass quality & 1.46 to 53.3 \\
\hline \multirow[t]{7}{*}{ RMR system } & $\mathrm{C}$ & Intact core strength rating & 12.0 \\
\hline & RQD & Rock quality designation rating & 8.0 to 17.0 \\
\hline & JF & Spacing of joint, rating & 10.0 to 20.0 \\
\hline & $\mathrm{JC}$ & Joint condition rating & 20.0 to 25.0 \\
\hline & JW & Groundwater rating & 10.0 \\
\hline & $\mathrm{AJO}$ & Adjustment for joint orientation & 0.0 to -12.0 \\
\hline & RMR & Rock mass rating & 48.0 to 84.0 \\
\hline
\end{tabular}

The use of the TSw2 interval averages for RQD range would not be appropriate for final design purposes because vertical intervals with thickness greater than the height of the proposed vertical emplacement drift $(5.2 \mathrm{~m})$ had RQDs that ranged from zero to $100 \%$. Ideally, lateral variation of RQD would be developed by projecting the repository horizon through the four holes. However, the current level of stratigraphic uncertainty is large and only hole G-4 was drilled within the repository boundary. To illustrate the characterization of lateral variation and overall expected $R Q D$ range of the repository horizon, a $24.4-\mathrm{m}(80 \mathrm{ft})$ interval near the center of the TSw2 Unit was chosen (Figure 12-1). Weighted average RQDs were generated for intervals above and below the center. The RQD derived in this manner varied between 9 and $100 \%$.

Figure $12-2$ shows the $6.1-\mathrm{m}(20 \mathrm{ft}$ ) interval RQD data developed in the central $24.4 \mathrm{~m}$ ( $80 \mathrm{ft}$ ) of each of the four core holes plotted as the cumulative probability of occurrence in percentage versus RQD. Values for design are selected for probability $O$. occurrence to give a range of RQD from extremely poor to good. For example, at the RQD value of $9 \%$, there is only a $5 \%$ probability of a lower value being encountered within the selected $24.4 \mathrm{~m}$ interval. The distribution of all $6.1-\mathrm{m}$ RQD from the TSw2 Unit intervals for the four holes is also shown for comparison.

12.2.1.2 Range of Parameters for Rock Mass Quality Values In establishing the range of the RMR and $Q$ values, the possible range of each individual parameter was established and a statistical approach used to select values for five possible rock mass categories. Probability levels were generated for each parameter used to calculate the rock mass quality. 

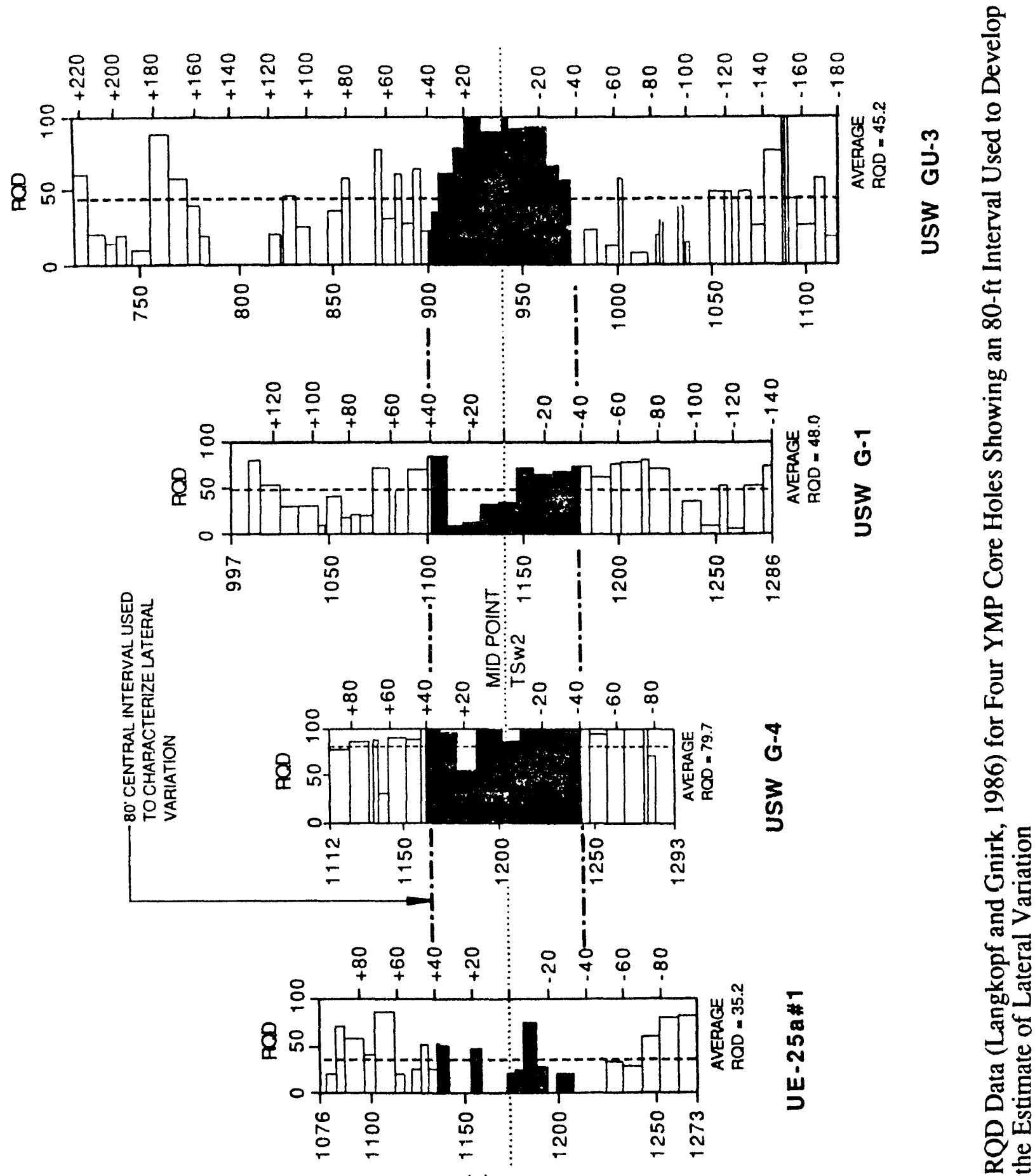

(H) $\operatorname{HId} \exists 0$
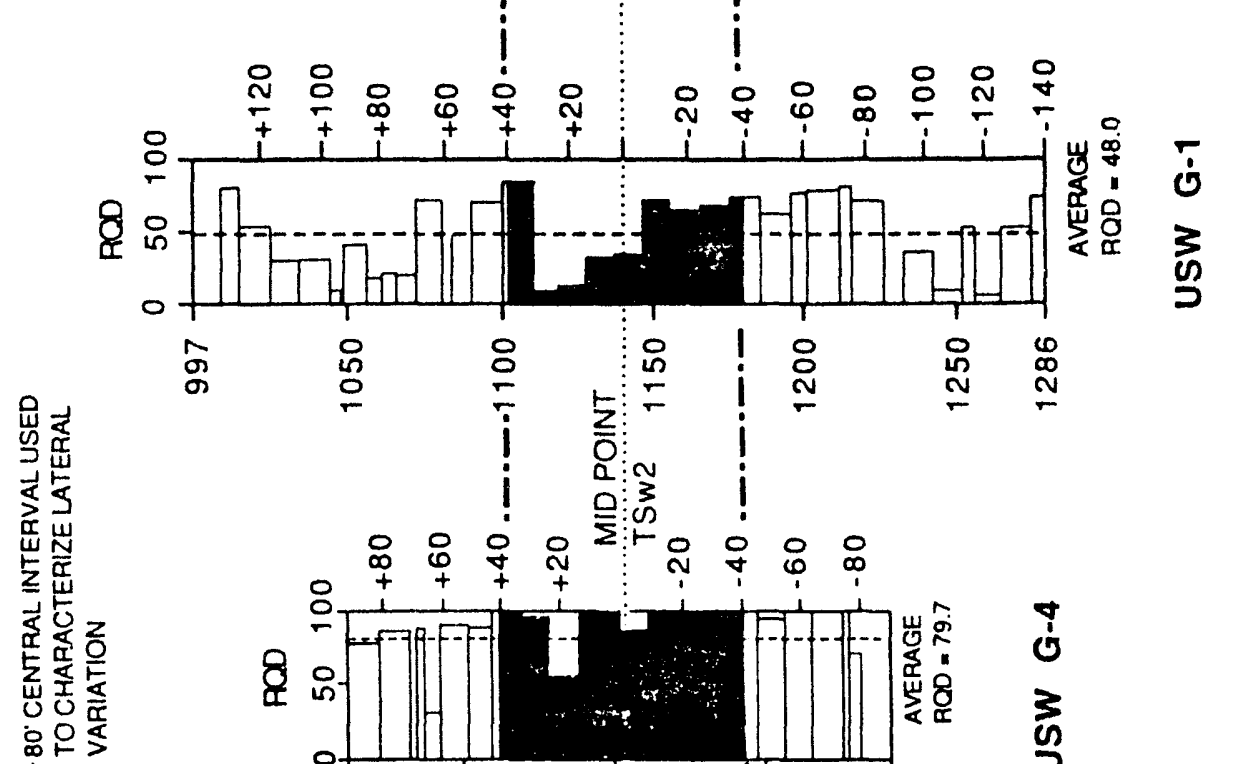


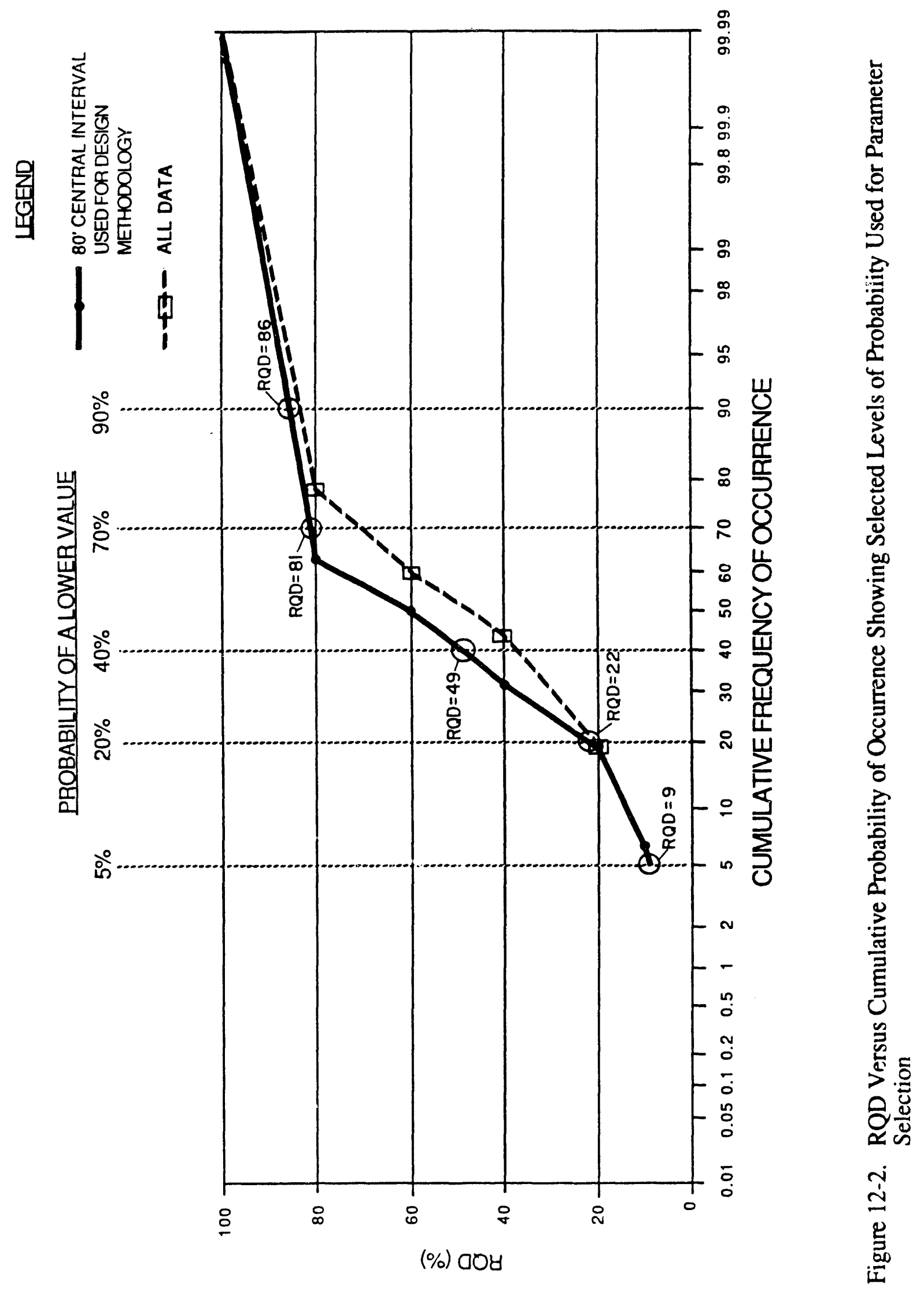


The SRF was selected to range from 5.0 for the extremely poor rock to 1.0 for the good rock. The SRF had been assigned a constant value of 1.0 by Langkopf and Gnirk (1986) based upon intact core strength data and the projected depth of the repository horizon. That approach is appropriate for competent rock with high rock mass quality and little geologic structure. Rock with low RQD and low rock mass quality, as suggested by the range of RQD, would have higher values of SRF. An SRF of 5.0 is suggested by Barton et al. ( 1774 ) for rock masses with loose open joints, heavily jointed masses, or "sugar cube," etc., at any depth.

Specific values for most other parameters $\left(J_{N}, J_{R}, J_{A}, J_{W}\right)$ were selected using a similar approach, except that the data were assumed to be uniformly distributed over the range reported by Langkopf and Gnirk (1986). Figure 12-3 illustrates the uniform distribution for the RMR parameter joint frequency $(\mathrm{JF})$.

The direction of scaling with regard to the rock mass category is based on the impact of the parameter in the rock mass quality evaluation. In the RMR system, an increasing numerical value is uniformly consistent with higher rock quality or less adverse stability impact. In the NGI system, the direction of scaling reverses depending upon whether the parameter appears in the numerator or denominator in Equation 18. and 12-4.

The parameter values corresponding to each rock mass category are listed in Tables 12-3

The effect of the thermally induced and seismic stresses can be incorporated into the $Q$ system by suitably modifying the SRF to reflect the total in situ plus thermal plus seismic stresses. The modified $Q$ values for the three drift locations and stress concentrations are presented in Section 12.7.1.

12.2.1.3 Rock Mass Quality Used for Mechanical Properties Correlation A review of thic $Q$ and RMR values in Tables 12-3 and 12-4 indicates that the relative rock qualities predicted by the two systems are different. This is due primarily to the use of a range in the SRF in the NGI system to account for changes in structural effects consistent with the RQD range, while a constant strergth index was used in the RMR system. The NGI-Q values were translated into direct RMR values using a correlation Equation 19 proposed by Bieniawski (1976):

$$
R M R=9 \operatorname{Ln} Q+44
$$

The design RMR was selected as the average of the RMR values produced using Equation 19 and the RMR values derived from Equation 18, as shown in Table 12-5.

\subsubsection{Properties for the Compliant Joint Model}

Properties required for input in the CJM include joint geometric parameters, joint mechanical properties, and mechanical properties of intact material between the joints. Rock mass quality ranges were used to develop the joint spacings. Joint persistence was then estimated from traces of joints on photographs of an outcrop of the TSw 2 horizon, and used to develop ranges of frictional properties. Joint stiffnesses were estimated based upon the range in experimental data for tests on tuff samples. Intact mechanical properties were based upon data in the RIB (see Appendix C). Properties are developed for each of the rock mass quality categories ranging from extremely poor (1) to good (5).

12.2.2.1 Joint Geometric Properties The CJM is currently based upon orthogonal orientation of two joint sets. Frequency and spacing distributions of joints logged in core holes and 


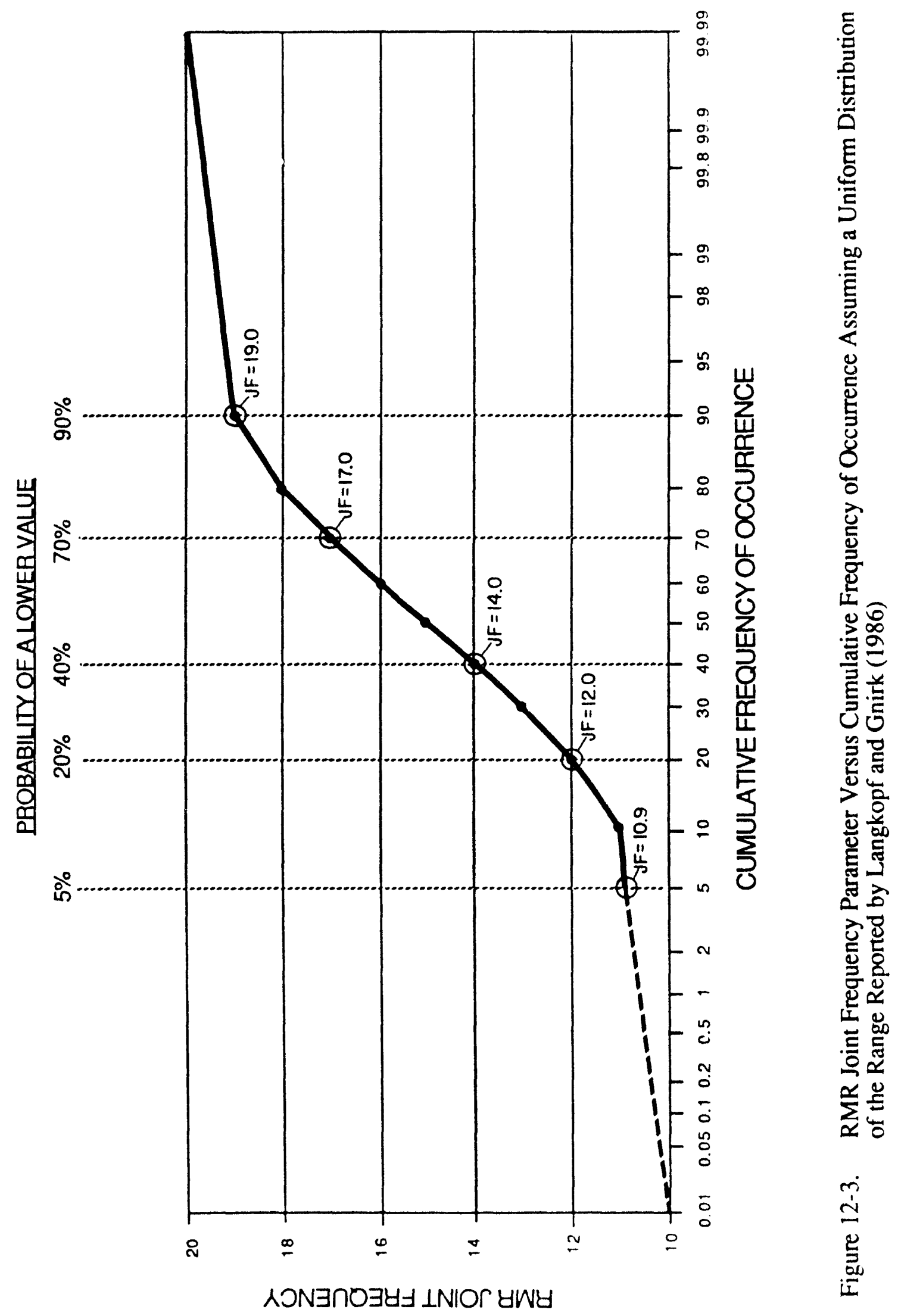


Table 12-3

LEVEL OF PROBABILITY FOR SELECTED NGI PARAMETERS

\begin{tabular}{||c|r|c|c|c|c|c|}
\hline \multirow{2}{*}{ Parameter } & Range & \multicolumn{5}{|c|}{ Value at Level of Probability } \\
\cline { 3 - 7 } & (Bad to Good) & $5 \%$ & $20 \%$ & $40 \%$ & $\mathbf{7 0 \%}$ & $90 \%$ \\
\hline RQD & 9.0 to 100.0 & 9.0 & 22.0 & 49.0 & 81.0 & 86.0 \\
\hline $\mathrm{J}_{\mathrm{N}}$ & 12.0 to 6.0 & 11.7 & 10.8 & 8.4 & 7.8 & 6.6 \\
\hline $\mathrm{J}_{\mathrm{R}}$ & 2.0 to 4.0 & 2.1 & 2.4 & 2.8 & 3.4 & 3.8 \\
\hline $\mathrm{J}_{\mathrm{A}}$ & 4.0 to 1.0 & 3.9 & 3.4 & 2.8 & 1.9 & 1.3 \\
\hline $\mathrm{SRF}$ & 5.0 to 1.0 & 4.8 & 4.2 & 3.4 & 2.2 & 1.4 \\
\hline $\mathrm{J}_{\mathrm{W}}$ & 1.0 & 1.0 & 1.0 & 1.0 & 1.0 & 1.0 \\
\hline $\mathrm{Q}$ & 0.08 to 29.4 & 0.08 & 0.34 & 1.68 & 8.4 & 27.2 \\
\hline Relative Classification & & Extremely & Very & & & \\
& & Poor & Poor & Poor & Fair & Good \\
\hline Rock Mass Category & & 1 & 2 & 3 & 4 & 5 \\
\hline
\end{tabular}

Table 12-4

LEVEL OF PROBACILITY FOR SELECTED RMR PARAMETERS

\begin{tabular}{|c|c|c|c|c|c|c|}
\hline \multirow{2}{*}{$\begin{array}{c}\text { RMR } \\
\text { Parameter }\end{array}$} & \multirow{2}{*}{$\begin{array}{c}\text { Range } \\
\text { (Bad to Good) }\end{array}$} & \multicolumn{5}{|c|}{ Value at Level of Probability } \\
\hline & & $5 \%$ & $20 \%$ & $40 \%$ & $70 \%$ & $90 \%$ \\
\hline Strength $(\mathrm{C})$ & 12.0 & 12.0 & 12.0 & 12.0 & 12.0 & 12.0 \\
\hline RQD Rating & 1.8 to 18.6 & 1.8 & 4.4 & 9.8 & 16.2 & 17.2 \\
\hline Joint frequency (JF) & 10.0 to 20.0 & 11.0 & 12.0 & 14.0 & 17.0 & 19.0 \\
\hline Joint condition (JC) & 20.0 to 25.0 & 20.3 & 21.0 & 22.0 & 23.5 & 24.5 \\
\hline Joint water (JW) & 10.0 & 10.0 & 10.0 & 10.0 & 10.0 & 10.0 \\
\hline $\begin{array}{l}\text { Adjustment for joint orien- } \\
\text { tation (AJO) }\end{array}$ & -12.0 to -0.0 & -11.4 & -9.6 & -7.2 & -3.6 & -1.2 \\
\hline RMR & 44 to 78 & 43.7 & 49.8 & 60.6 & 75.1 & 77.6 \\
\hline Relative Classification & & Fair & Fair & Good & Good & $\begin{array}{l}\text { Very } \\
\text { Good }\end{array}$ \\
\hline Rock Mass Category & & 1 & 2 & 3 & 4 & 5 \\
\hline
\end{tabular}


Table 12-5

FINAL RMR VALUES FOR LEVELS OF PROBABILITY

\begin{tabular}{|c|c|c|c|c|c|c|}
\hline \multirow{2}{*}{$\begin{array}{l}\text { Rock Mass Quality } \\
\text { Index }\end{array}$} & \multirow{2}{*}{$\begin{array}{c}\text { Range } \\
\text { (Bad to Good) }\end{array}$} & \multicolumn{5}{|c|}{ Rock Mass Quality Category } \\
\hline & & 1 & 2 & 3 & 4 & 5 \\
\hline NGI-Q & 0.08 to 27.2 & 0.08 & 0.34 & 1.68 & 8.4 & 27.2 \\
\hline $\mathrm{RMR}=9 \operatorname{Ln} Q+44$ & 21.3 to 73.7 & 21.3 & 34.3 & 48.7 & 63.2 & 73.7 \\
\hline RMR & 43.7 to 81.5 & 43.7 & 49.8 & 60.6 & 75.1 & 81.5 \\
\hline Design Value RMR & 32.5 to 77.6 & 32.5 & 42.1 & 54.7 & 69.2 & 77.6 \\
\hline
\end{tabular}

reported in the RIB are listed in Table 12-6. Predominantly vertical joints are indicated; however, because orthogonal joint sets may be considered in the compliant joint analysis, a horizontal set is included to account for the limited non-vertical joints.

The spacings of the joint sets for each rock mass quality category were required to account for the range of expected rock conditions. Equation 5 (from Section 5.2.1.3) was used to estimate the joint spacing for each rock mass quality category.

The mean joint frequency for the range in RQD reported in Table 12.7 was $40.2 \mathrm{~m}^{-1}$ $(\mathrm{RQD}=9 \%)$ to $3.6 \mathrm{~m}^{-1}(\mathrm{RQD}=95 \%)$. These values compared very well to the total joint frequency calculated by summing the upper bound and lower bound values reported in the RIB, as shown in Table 12-6.

Joint spacings calculated for each of the five rock mass quality categories are shown in Table 12-7. The method used to calculate horizontal and vertical joint spacings was as follows. The mean joint frequency from Equation 5 was assumed equal to the total frequency, and then the frequency for horizontal $\left(0\right.$ to $\left.20^{\circ}\right)$ and vertical $\left(70\right.$ to $\left.90^{\circ}\right)$ dip were calculated using recommended frequency percentages listed in Table 12-6. Spacings were then corrected using the method of Terzaghi (1965), which considers the effect of angle between the strike of the joint and the line along which joints are mapped on the spacing observed.

\subsubsection{Joint Frictional Strengih Joint frictional strength in the CJM is described by}

$$
\tau=S_{o}+\sigma \tan \phi
$$

where $\tau=$ joint shear stress,

$S_{0}=$ intrinsic shear resistance or cohesion,

$\phi=$ joint friction angle, and

$\sigma=$ joint normal stress.

The parameters $S_{o}$ and $\phi$ are established in the design methodology as a function of a weighted average of the jointed and intact properties which depends upon the continuity, $\chi$, of the joint surface. The weighted average strength for a Mohr-Coulomb representation of joint strength is described by Equations 11 and 12 in Section 5.2.4.6. 
Table 12-6

FRACTURE FREQUENCIES DERIVED FROM YUCCA MOUNTAIN CORE HOLE DATA

\begin{tabular}{|c|c|c|c|c|}
\hline $\begin{array}{c}\text { Dip } \\
\text { Interval } \\
\text { (degrees) }\end{array}$ & $\begin{array}{c}\text { Recommended } \\
\text { Frequency } \\
\left(\boldsymbol{m}^{-1}\right)\end{array}$ & $\begin{array}{c}\text { Recommended } \\
\text { Frequency } \\
(\boldsymbol{\%})\end{array}$ & $\begin{array}{c}\text { Upper } \\
\text { Bound } \\
\left(\boldsymbol{m}^{-1}\right)\end{array}$ & $\begin{array}{c}\text { Lower } \\
\text { Bound } \\
\left(\boldsymbol{m}^{-1}\right)\end{array}$ \\
\hline 0 to 10 & 0.20 & 1.23 & 0.50 & 0.05 \\
\hline 10 to 20 & 0.20 & 1.23 & 0.60 & 0.05 \\
\hline 20 to 30 & 0.20 & 1.23 & 0.60 & 0.05 \\
\hline 30 to 40 & 0.10 & 0.60 & 0.30 & 0.05 \\
\hline 40 to 50 & 0.20 & 1.23 & 0.40 & 0.05 \\
\hline 50 to 60 & 0.20 & 1.23 & 0.50 & 0.05 \\
\hline 60 to 70 & 0.30 & 1.84 & 0.70 & 0.10 \\
\hline 70 to 80 & 1.70 & 10.43 & 2.60 & 0.70 \\
\hline 80 to 90 & 13.20 & 80.98 & 32.50 & 2.50 \\
\hline TOTAL & 16.30 & 100.00 & 38.70 & 3.60 \\
\hline
\end{tabular}

Table 12.7

FRACTURE FREQUENCY AND SPACING BASED ON RQD

\begin{tabular}{|c|c|c|c|c|c|}
\hline $\begin{array}{c}\text { Rock Mass Quality } \\
\text { Category }\end{array}$ & 1 & 2 & 3 & 4 & 5 \\
\hline RQD & 9 & 22 & 49 & 81 & 86 \\
\hline Total Joints/Meter & 40.2 & 28.7 & $\overline{17.1}$ & 8.0 & 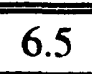 \\
\hline \multicolumn{6}{|l|}{ Fracture Frequency } \\
\hline $\begin{array}{l}\operatorname{dip} 0^{\circ} \text { to } 20^{\circ} \\
\text { (uncorrected) }\end{array}$ & 1.0 & 0.7 & 0.4 & 0.2 & 0.16 \\
\hline $\begin{array}{l}\text { dip } 70^{\circ} \text { to } 90^{\circ} \\
\text { (uncorrected) }\end{array}$ & 36.7 & 26.2 & 15.6 & 7.3 & 6.0 \\
\hline $\begin{array}{l}\text { dip } 0^{\circ} \text { to } 20^{\circ} \\
\text { (corrected) }\end{array}$ & 1.00 & 0.7 & 0.4 & 0.2 & 0.16 \\
\hline $\begin{array}{l}\text { dip } 70^{\circ} \text { to } 90^{\circ} \\
\text { (corrected) }\end{array}$ & 37.0 & 26.4 & 15.7 & 7.4 & 6.0 \\
\hline \multicolumn{6}{|c|}{ Recommended Joint Spacing $(m)$} \\
\hline Horizontal & 1.0 & 1.41 & 2.33 & 5.0 & 6.25 \\
\hline Vertical & 0.027 & 0.038 & 0.064 & 0.14 & 0.17 \\
\hline
\end{tabular}


Developm ${ }^{\prime} n$ t of the continuity, $\chi$, for the Yucca Mountain Site is preliminary and was based upon traces of joints evident in photographs of pit walls excavated in TSw 2 near the Yucca Mountain Site. The continuity, $\chi$, was defined as the percentage of length occupied by the joint along a linear path containing the joint within the boundaries of the photograph. Data developed on the fracture trace lengths from the pit photographs are listed in Table 12-8 and indicate that the vertical oriented fractures had a $10 \%$ higher continuity.

For the purpose of this pre'iminary application, it was assumed that the continuity, $\chi_{v}$, of vertical fractures would range from 0.50 to 1.00 , and for horizontal, $\chi_{\mathrm{H}}$, would range from zero to 0.50 . Continuity was assumed to be uniformly distributed between these limits, and values for each rock mass category were selected using the approach illustrated in Figure 12-3. The values are listed in Table 12-9.

Calculation of the joint strengths combined the estimates of continuity with ranges in parameters of measured joint and intact rock strength presented in the RIB (see Appendix C) and listed in Table 12-10. These strength parameters were assumed to be uniformly distributed over the ranges listed in Table 12-10 and values selected using the procedure described in Figure 12-3 for the levels of probability. Selected values of strength $(\phi, C)$ and continuity $(\chi)$ were then used to calculate the weighted overall strength according to Equations 11 and 12 in Section 5.2.4.6. The resulting joint strength and basis for their calculation are listed in Table 12-11.

12.2.2.3 Joint Stiffness Joint deformations are described by a nonlinear closure relationship and constant shear stiffnesses. The hyperbolic closure relationship incorporated with the CJM model uses two parameters, $A_{N}$ and $u_{\max }$, that are defined by laboratory experiments on tuff jnints. Shear stiffness is described using a bilinear model with an elastic stiffness, $G_{S}$, until the joint failure surface is reached and with nonlinear yield stiffness, $G_{s}{ }^{\prime}$, after the critical shear stress.

Values for the five rock mass categories were developed using the experimental ranges in normal stiffness parameters. Shear stiffness was assumed to range from $1 \times 10^{6} \mathrm{MPa} / \mathrm{m}$ to $1.0 \times 10^{3} \mathrm{MPa} / \mathrm{m}$ on the basis of experiments on tuff samples and joint experimental data reported by Barton et al. (1974). Direction of the ranges of parameters with respect to confidence levels were similar to the rock mass qualities. Parameters which produced more deformable joints were associated with lower rock mass quality. The parameters for each rock mass category are listed in Table 12-12.

12.2.2.4 Intact Material Elastic Properties Elastic modulus and Poisson's ratio for the intact blocks of material between joints was assumed to be equivalent to properties developed in laboratory tests. The intact elastic modulus of $30.4 \mathrm{GPa}$ and a Poisson's ratio of 0.22 was used.

12.2.2.5 Compressive Strength of Intact Blocks The strength of individual, intact blocks of matrix material was established by using size-strength data, reported by Price (1986). Block size was defined by the frequency of vertical joints, with the strength of the block calculated by the size-strength relationship in Equation 7 (Section 5.2.4.3). Failure strength was then evaluated using a Hoek and Brown (1980) criterion with the uniaxial compressive as given in Equation 9, $m=3.0$ and $s=1.0$. Table $12-13$ lists the block strength for each rock mass quality category.

\subsubsection{Elasto-Plastic Mechanical Properties}

Equivalent-continuum mechanical properties for the Mohr-Coulomb yield criteria were calculated for each of the five rock mass quality categories. Empirical equations correlating RMR and strength from Hoek and Brown (1988) and Yudhbir et al. (1983) were used. 
Table 12-8

PRELIMINARY CHARACTERIZATION OF FRACTURE CONTINUITY IN TSw2

\begin{tabular}{|l|c|c|c|}
\hline \multirow{2}{*}{ Orientation } & \multirow{2}{*}{ No. of Fractures } & \multicolumn{2}{|c|}{ Joint Continuity $(\chi)$} \\
\cline { 3 - 4 } & 9 & Mean & Standard Deviation \\
\hline Vertical & 5 & 0.518 & 0.191 \\
\hline Horizontal & 9.415 & 0.209 \\
\hline
\end{tabular}

Table 12-9

ESTIMATED JOINT CONTINUITY

FOR PROBABILITY LEVEL

\begin{tabular}{|c|c|c|}
\hline \multirow{2}{*}{$\begin{array}{c}\text { Rock Mass } \\
\text { Quality } \\
\text { Category }\end{array}$} & Horizontal & Vertical \\
\cline { 2 - 3 } & 0.475 & 0.975 \\
\hline 1 & 0.400 & 0.900 \\
\hline 2 & 0.300 & 0.800 \\
\hline 3 & 0.150 & 0.650 \\
\hline 4 & 0.050 & 0.550 \\
\hline 5 & & \\
\hline
\end{tabular}

Table 12-10

RANGE OF JOINT AND INTACT ROCK-STRENGTH PARAMETERS

\begin{tabular}{|l|c|c|}
\hline \multirow{2}{*}{\multicolumn{1}{|c|}{ Type }} & \multicolumn{2}{|c|}{ Mohr-Coulomb Parameters } \\
\cline { 2 - 3 } & Cohesion $(\mathrm{MPa})$ & $\phi$ (degrees) \\
\hline \hline Joints & 0.0 to 0.2 & 11.3 to 38.7 \\
\hline Intact rock & 18.3 to 37.8 & 19.7 to 36.5 \\
\hline
\end{tabular}


Table 12-11

JOINT INTACT ROCK AND WEIGHTED A VERAGE JOINT STRENGTH USED FOR THE CJM MODEL

\begin{tabular}{|c|c|c|c|c|c|c|c|c|}
\hline \multirow{2}{*}{\multicolumn{2}{|c|}{\begin{tabular}{|l} 
Rock Mass \\
Quality \\
Category
\end{tabular}}} & \multicolumn{2}{|c|}{ Joint Strength } & \multicolumn{2}{|c|}{$\begin{array}{c}\text { Intact Rock } \\
\text { Strength } \\
\end{array}$} & \multirow[b]{2}{*}{$\chi$} & \multicolumn{2}{|c|}{$\begin{array}{l}\text { Weighted A verage } \\
\text { Joint Strength }\end{array}$} \\
\hline & & $\underset{(\mathbf{M P a})}{S}$ & $\begin{array}{c}\phi \\
\text { (degrees) }\end{array}$ & $\begin{array}{c}C \\
(\mathbf{M P a})\end{array}$ & $\begin{array}{c}\phi \\
\text { (degrees) }\end{array}$ & & $\begin{array}{c}S \\
(\mathrm{MPa}) \\
\end{array}$ & $\begin{array}{c}\phi \\
\text { (degrees) }\end{array}$ \\
\hline \multirow{5}{*}{ 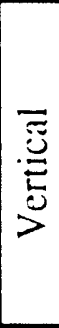 } & 1 & 0.01 & 12.6 & 19.3 & 20.5 & 0.975 & 0.49 & 12.8 \\
\hline & 2 & 0.04 & 16.8 & 22.2 & 23.1 & 0.900 & 2.26 & 17.4 \\
\hline & 3 & 0.08 & 22.3 & 26.1 & 26.4 & 0.800 & 5.28 & 23.1 \\
\hline & 4 & 0.14 & 30.5 & 31.9 & 31.5 & 0.650 & 11.26 & 30.9 \\
\hline & 5 & 0.18 & 36.0 & 35.9 & 34.8 & 0.550 & 16.25 & 35.5 \\
\hline \multirow{5}{*}{ 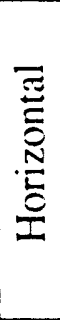 } & 1 & 0.01 & 12.6 & 19.3 & 20.5 & 0.475 & 10.14 & 16.7 \\
\hline & 2 & 0.04 & 16.8 & 22.2 & 23.1 & 0.400 & 13.30 & 20.6 \\
\hline & 3 & 0.08 & 22.3 & 26.1 & 26.4 & 0.300 & 18.30 & 25.2 \\
\hline & 4 & 0.14 & 30.5 & 31.9 & 31.5 & 0.150 & 27,10 & 34.1 \\
\hline & 5 & 0.18 & 36.0 & 35.9 & 34.8 & 0.050 & 34.10 & 34.9 \\
\hline
\end{tabular}

Table 12-12

CJM JOINT STIFFNESS PARAMETERS FOR PROBABILTTY LEVELS

\begin{tabular}{|c|c|c|c|c|c|c|}
\hline \multirow[t]{2}{*}{ Parameter } & \multirow{2}{*}{$\begin{array}{c}\text { Range } \\
\text { (Bad to Good) }\end{array}$} & \multicolumn{5}{|c|}{ Rock Mass Quality Category } \\
\hline & & 1 & 2 & 3 & 4 & 5 \\
\hline$A_{N}$ & 0.5 to 2.0 & 1.93 & 1.7 & 1.4 & 0.95 & 0.65 \\
\hline$u_{\max }$ & 0.036 to $0.003 \mathrm{~mm}$ & 0.034 & 0.029 & 0.023 & 0.013 & 0.006 \\
\hline$G_{S}$ & $10^{3}$ to $10^{6} \mathrm{MPa} / \mathrm{m}$ & 50,950 & 200,800 & 400,600 & 700,300 & 900,100 \\
\hline
\end{tabular}


Table 12-13

ESTIMATED STRENGTH OF INTACT BLOCKS

\begin{tabular}{|c|c|c|}
\hline $\begin{array}{c}\text { Rock Mass } \\
\text { Quality } \\
\text { Category }\end{array}$ & $\begin{array}{c}\text { Block* } \\
\text { Size } \\
(\mathbf{m})\end{array}$ & $\begin{array}{c}\text { Intact Block } \\
\text { Strength } \\
\text { (MPa) }\end{array}$ \\
\hline 1 & 0.027 & 155.0 \\
\hline 2 & 0.038 & 155.0 \\
\hline 3 & 0.064 & 127.1 \\
\hline 4 & 0.135 & 100.2 \\
\hline 5 & 0.170 & 94.7 \\
\hline$*$ Equivalent to vertical joint spacing \\
\hline
\end{tabular}

12.2.3.1 Rock Mass Failure Criteria The rock mass strength for each rock mass quality category was estimated following the procedure identified in Section 5.2.4. Table 12-14 lists the power law strength envelope parameters and Table 12-15 the resulting best fit Mohr-Coulomb parameters.

12.2.3.2 Rock Mass Tensile Strength Table 12-16 lists the values used in this analysis. The rock mass tensile strength was determined as half the rock mass juint cohesion.

12.2.3.3 Rock Mass Elastic Modulus Values of $E$ for the rock mass were calculated using Equation 6 up to the value of intact laboratory modulus of $30.4 \mathrm{MPa}$. Table $12-17$ lists the resulting values.

12.2.3.4 Rock Mass Poisson's Ratio Empirical correlations between Poisson's ratio and rock mass quality are not available, and there is no well defined rationale for varying its value with RMR. The value reported in the RIB was therefore used for all rock mass quality categories.

\subsubsection{Thermal Properties}

The thermal properties used directly in the drift stability assessment include the specific heat capacitance, thermal conductivity, and thermal expansion coefficient. These properties are expected to be variable throughout the repository depending on matrix porosity, moisture content, and other factors. They are not expected to be significantly influenced by the degree of jointing. No rational method has been identified io quantify the range of these parameters, so the same thermal properties were used for all analyses reported in this appendix; that is, for all rock mass qualities. The specific values used are based on the RIB values and are listed in Appendix C.

\subsection{Repository Layout}

The repository layout presented in Section 5.3 was used for this preliminary application.

\subsection{Design Basis Loads} load cases:

The preliminary application of the drift design methodology addresses the following four 
Table 12-14

POWER LAW FAILURE CRITERIA

FOR LEVELS OF PROBABILITY

\begin{tabular}{|c|c|c|c|}
\hline \multirow{2}{*}{$\begin{array}{c}\text { Rock Mass } \\
\text { Quality Category }\end{array}$} & \multicolumn{3}{|c|}{$\sigma_{1}=A+B \sigma_{3}$} \\
\cline { 2 - 4 } & $\boldsymbol{A}$ & $\boldsymbol{B}$ & $\boldsymbol{C}$ \\
\hline \hline 1 & 2.71 & 9.30 & 0.5951 \\
\hline 2 & 4.46 & 9.35 & 0.6037 \\
\hline 3 & 9.49 & 9.10 & 0.6234 \\
\hline 4 & 23.30 & 8.44 & 0.6523 \\
\hline 5 & 42.88 & 7.94 & 0.6690 \\
\hline
\end{tabular}

Table 12-15

MOHR-COULOMB FAILURE CRITERIA FOR VARIOUS ROCK MASS QUALITY

\begin{tabular}{|c|c|c|}
\hline $\begin{array}{c}\text { Rock Mass Quality } \\
\text { Category }\end{array}$ & $\begin{array}{c}\text { Cohesion } \\
(\mathbf{M P a}) \\
\text { c }\end{array}$ & $\phi$ \\
\hline \hline 1 & 1.146 & 43.9 \\
\hline 2 & 1.503 & 44.2 \\
\hline 3 & 2.533 & 44.1 \\
\hline 4 & 5.464 & 43.5 \\
\hline 5 & 9.014 & 43.0 \\
\hline
\end{tabular}


Table 12.16

ROCK MASS TENSILE STRENGTH FOR ROCK MASS QUALITY

\begin{tabular}{|c|c|c|}
\hline $\begin{array}{c}\text { Rock Mass Quality } \\
\text { Category }\end{array}$ & $\begin{array}{c}\text { Estimated } \\
\text { Cohesion } \\
\text { (MPa) }\end{array}$ & $\begin{array}{c}\text { Rock Mass } \\
\text { Tensile } \\
\text { Strength } \\
\text { (MPa) }\end{array}$ \\
\hline 1 & 0.49 & 0.25 \\
\hline 2 & 2.26 & 1.13 \\
\hline 3 & 5.28 & 2.62 \\
\hline 4 & 11.26 & 5.63 \\
\hline 5 & 16.25 & 8.10 \\
\hline
\end{tabular}

Table 12-17

ROCK MASS ELASTIC MODULUS FOR THE RANGE OF ROCK MASS QUALITY

\begin{tabular}{|c|c|}
\hline $\begin{array}{c}\text { Rock Mass } \\
\text { Quality } \\
\text { Category }\end{array}$ & $\begin{array}{c}\text { Rock Mass } \\
\text { Modulus } \\
\boldsymbol{E} \\
(\mathbf{G P a})\end{array}$ \\
\hline 1 & 3.65 \\
\hline 2 & 6.35 \\
\hline 3 & 13.11 \\
\hline 4 & 30.20 \\
\hline 5 & 30.40 \\
\hline
\end{tabular}


- in situ,

- in situ minus seismic,

- in situ plus thermal, and

- $\quad$ in situ plus seismic plus thermal.

Of these four cases, the combination of all three load types is the most adverse. However, the in situ minus seismic case does produce some tensile loading that could be adverse to drift stability.

\subsubsection{In Situ Stresses}

The magnitude and orientation of in situ stresses at Yucca Mountain listed in Table 12-18 were taken from the SCP-CDR (SNL, 1987) and correspond to expected conditions at a depth of $1000 \mathrm{ft}$. These are listed together with RIB values in Appendix C.

Repository layouts in the SCP-CDR define the direction of drift axes with respect to the orientations of principal in situ stresses. Tuff main access and waste-emplacement drift axes are parallel to the maximum horizontal stress, while the midpanel access drift is parallel to the minimum principal stress.

\subsubsection{Thermal Stresses}

Thermal stresses are introduced in the drift analysis using different approaches for the midpanel and tuff main access drifts, and the waste-emplacement drifts, respectively. Thermal effects in the waste-emplacement drifts are directly calculated by performing a transient heat flow analysis that simulates the waste container in the drift mesh over a 100 -year cycle from waste emplacement. The calculated temperature changes are then imposed in a coupled, thermomechanical analysis with thermal stress changes produced by the resulting temperature-induced thermal expansion of the rock mass. Thermal stresses of midpanel and tuff main access drifts were derived from three-dimensional, thermomechanical simulations of the repository. The three-dimensional analyses produce estimates of the stress state at the centerline of drift locations and these were imposed as boundary conditions on the finite-element meshes for the midpanel and tuff main access drifts. The corresponding change in temperature was also used so that displacements were compatible with the process simulated.

Thermal stresses used for the midpanel access and tuff main drifts were assessed for mid-length in Panel 16 (see Figure 5-4). The thermally-induced shear stresses at the drift location both in- and out-of-plane ranged between 3 and $9 \%$ of the vertical and horizontal stresses and were ignored in the drift stability calculations. The resulting thermal stresses are listed in Tables 12-19 and 12-20 for the midpanel and tuff main drifts, respectively.

The stress changes listed in Tables 12-19 and 12-20 were generated from an elastic analysis based on the assumption of a homogeneous host rock with an elastic modulus of $15.2 \mathrm{GPa}$. For the individual drift analyses using different rock mechanical properties, the stress changes were adjusted to the rock mass modulus assumed by the following equation. The thermal expansion coefficient and thermal properties were assumed to be constant independent of rock mass quality.

$$
\Delta \sigma_{D A}=\frac{E_{D A}}{15.2} \Delta \sigma_{3 D}
$$


Table 12-18

\section{MAGNITUDE AND ORIENTATION OF} IN SITU PRINCIPAL STRESSES

\begin{tabular}{|l|c|c|}
\hline \multicolumn{1}{|c|}{ Principal Stress } & $\begin{array}{c}\text { Stress } \\
\text { Magnitude } \\
(\mathrm{MPa})\end{array}$ & Orientation \\
\hline \hline Vertical & 7.0 & $\mathrm{NA}$ \\
\hline Maximum Horizontal & 4.2 & $\mathrm{~N} 32^{\circ} \mathrm{E}$ \\
\hline Minimum Horizontal & 3.5 & $\mathrm{~N} 57^{\circ} \mathrm{W}$ \\
\hline
\end{tabular}

Table 12-19

THERMAL STRESS CHANGE USED FOR MIDPANEL ACCESS DRIFT

\begin{tabular}{|c|c|c|c|c|}
\hline \multirow{2}{*}{$\begin{array}{c}\text { Time After } \\
\text { Waste } \\
\begin{array}{c}\text { Emplacement } \\
\text { (yrs) }\end{array}\end{array}$} & $\begin{array}{c}\text { Vertical } \\
\sigma_{z}\end{array}$ & $\begin{array}{c}\text { Therizontal } \\
\text { Drift Plane } \\
\sigma_{x}\end{array}$ & $\begin{array}{c}\text { Horizontal } \\
\text { Drift Axis } \\
\sigma_{y}\end{array}$ & $\begin{array}{c}\text { Temperature } \\
\text { Change } \\
\left({ }^{\circ} \mathrm{C}\right)\end{array}$ \\
\hline \hline 0 & 0.0 & 0.0 & 0.0 & 0.0 \\
\hline 10 & 0.0 & 0.0 & 0.0 & 0.0 \\
\hline 35 & -3.60 & 4.84 & 0.96 & 8.0 \\
\hline 50 & -4.16 & 7.89 & 3.17 & 23.0 \\
\hline 100 & -2.53 & 10.86 & 7.24 & 50.0 \\
\hline$x$ is perpendicular to drift axis; $y$ is parallel to drift axis \\
\hline
\end{tabular}


Table 12-20

THERMAL STRESS CHANGE USED FOR TUFF MAIN ACCESS DRIFT

\begin{tabular}{|c|c|c|c|c|}
\hline \multirow{2}{*}{$\begin{array}{c}\text { Time After } \\
\text { Waste } \\
\begin{array}{c}\text { Emplacement } \\
(\mathbf{y r})\end{array}\end{array}$} & $\begin{array}{c}\text { Vertical } \\
\sigma_{x}\end{array}$ & $\begin{array}{c}\text { Horizontal } \\
\text { Drift Plane } \\
\sigma_{x}\end{array}$ & $\begin{array}{c}\text { Horizontal } \\
\text { Drift Axis } \\
\sigma_{y}\end{array}$ & $\begin{array}{c}\text { Temperature } \\
\text { Change } \\
\left({ }^{\circ} \mathbf{C}\right)\end{array}$ \\
\hline \hline 0 & 0.0 & 0.0 & 0.0 & 0.0 \\
\hline 10 & -0.12 & 0.20 & -0.13 & 0.0 \\
\hline 35 & -1.70 & 2.05 & -0.71 & 0.6 \\
\hline 50 & -2.43 & 3.25 & -0.61 & 3.0 \\
\hline 100 & -2.68 & 5.20 & 0.58 & 13.0 \\
\hline$x$ is perpendicular to drift axis; $y$ is parallel to drift axis \\
\hline
\end{tabular}

where $\Delta \sigma_{D A}=$ thermal stress change in drift analysis, $\Delta \sigma_{3 D}=$ thermal stress change from three-dimensional analysis, and $E_{D A}=$ elastic modulus in drift analysis from Table 12-17.

Rock mass modulus ranged from 3.65 to $30.4 \mathrm{GPa}$ for various rock mass qualities assumed in the drift analysis. This scaling of loads, depending on the rock mass elastic modulus, results in significantly higher thermal loads for the better quality host rock and significantly lower thermal loads for the poorer quality rocks. The actual effect is likely to be less extreme if the variations in rock quality are not systematic.

\subsubsection{Seismic Stresses}

Seismic loads were calculated using a modified version of the procedures recommended by the Seismic Working Group (SNL, 1990) and defined in Chapter 5 . These seismic loads were calculated using the wave orientation relative to the drift axis that produced the largest hoop stress for a circular drift geometry. Peak horizontal and vertical velocities were $0.5 \mathrm{~m} / \mathrm{sec}$ and $0.33 \mathrm{~m} / \mathrm{sec}$, respectively, which includes the 1.67 magnification factor on the recomme.lded control motions as suggested by the Working Group Report (SNL, 1990). A dynamic elastic modulus of $23.5 \mathrm{GPa}$ w'as assumed based on the SNL (1990) report. Shear stresses were ignored in the calculation of normal loads applied in the drift analysis. Table 12-21 lists both the seismic loads calculated and the values used in the drift analysis, which were modified for the rock mass modulus in a manner identical to Equation 21. The static rock mass modulus was used to scale the seismic loads for each rock type because the quasi-static seismically imposed loading is expressed as a strain. This process applies the same strain to each rock mass model, but because of the different elastic modulus for each case, a different quasi-static stress is applied. 
Table 12-21

SEISMIC LOADS USED FOR ALL DRIFT ANALYSIS

\begin{tabular}{|c|c|c|c|c|}
\hline \multirow{2}{*}{$\begin{array}{c}\text { Rock Mass } \\
\text { Quality Category }\end{array}$} & $\begin{array}{c}\mathbf{E} \\
\text { Rock Mass } \\
(\mathbf{G P a})\end{array}$ & $\begin{array}{c}\text { Vertical } \\
\sigma_{x}\end{array}$ & $\begin{array}{c}\text { Horizontal } \\
\text { Drift Plane } \\
\sigma_{x}\end{array}$ & $\begin{array}{c}\text { Horizontal } \\
\text { Drift Axis } \\
\sigma_{y}\end{array}$ \\
\hline Reference Stress $\sigma_{\text {reference }}$ & 23.50 & 3.13 & 2.87 & 1.32 \\
\hline 1 & 3.65 & 0.81 & 0.74 & 0.34 \\
\hline 2 & 6.35 & 1.41 & 1.29 & 0.59 \\
\hline 3 & 13.40 & 2.91 & 2.67 & 1.23 \\
\hline 4 & 30.20 & 6.70 & 6.15 & 2.83 \\
\hline 5 & 30.40 & 6.75 & 6.18 & 2.85 \\
\hline$* \sigma=1.667(E / 23.5) \sigma_{\text {reference }}$ & & & & \\
\hline
\end{tabular}

\subsubsection{Combined In Situ. Thermal, and Seismic Stresses}

For illustrative purposes, Table 12-22 lists the in situ, seismic, and thermal stresses for a midpanel access drift for all five rock qualities and the combined compressive stress condition. The thermal stresses are based on the conditions 100 years after start of waste emplacement listed in Table 12.20 and modified according to Equation 21.

\subsubsection{Finite-Element Boundary Conditions in Drift Analysis}

Boundary loads for the tuff main and midpanel access drifts were calculated as algebraic sums of in situ, thermal, and seismic stresses, depending on the particular case. For the waste-emplacement drift, the in situ and seismic loads were applied as initial stress conditions for the waste-emplacement drift, with fixed boundaries on the sides and bottom. Thermal stresses were generated by imposing the temperature fields at various times of analysis.

Boundary loads in equilibrium with the imposed internal stresses were applied to the top and side of the midpanel access and tuff main access drifts with fixed displacement boundaries along the drift centerline and bottom of the mesh. Temperature changes were then imposed to ensure approximate displacements. Out-of-plane stresses (drift axis) were input as ratios of the vertical stress and were scaled to produce the correct stress levels under plane-strain assumptions.

\subsection{Develop Candidate Drift Designs and Perform Parametric/Tradeoff Studies}

This activity has been completed during the development of the SCP-CDR and will be repeated during future design cycles. 
Table 12.22

COMBINED LOADS (IN MPa) FOR MIDPANEL ACCESS DRIFT AT 100 YEARS

\begin{tabular}{|c|c|c|c|c|c|c|c|c|c|c|c|c|}
\hline \multirow[t]{2}{*}{$\begin{array}{c}\text { Rock Mass } \\
\text { Quality } \\
\text { Category }\end{array}$} & \multicolumn{3}{|c|}{ In situ Stress } & \multicolumn{3}{|c|}{ Seismic Stress } & \multicolumn{3}{|c|}{ Thermal Stress } & \multicolumn{3}{|c|}{$\begin{array}{l}\text { Combined In } \\
\text { situ, Thermal, } \\
\text { and Seismic }\end{array}$} \\
\hline & $\sigma_{x \alpha}$ & $\sigma_{y y}$ & $\sigma_{x z}$ & $\sigma_{x x}$ & $\sigma_{y y}$ & $\sigma_{2 x}$ & $\sigma_{x}$ & $\sigma_{y y}$ & $\sigma_{z z}$ & $\sigma_{x x}$ & $\sigma_{y y}$ & $\sigma_{x z}$ \\
\hline 1 & 4.2 & 3.5 & 7.0 & 0.7 & 0.3 & 0.8 & 2.6 & 1.7 & -0.6 & 7.5 & 5.5 & 7.2 \\
\hline 2 & 4.2 & 3.5 & 7.0 & 1.3 & 0.6 & 1.4 & 4.6 & 3.0 & -1.0 & 10.1 & 7.1 & 7.4 \\
\hline 3 & 4.2 & 3.5 & 7.0 & 2.7 & 1.2 & 2.9 & 9.6 & 6.3 & -2.2 & 16.5 & 11.0 & 7.7 \\
\hline 4 & 4.2 & 3.5 & 7.0 & 6.1 & 2.8 & 6.7 & 21.6 & 14.3 & -5.0 & 31.9 & 20.6 & 8.7 \\
\hline 5 & 4.2 & 3.5 & 7.0 & 6.2 & 2.8 & 6.7 & 21.8 & $\mathrm{i} 4.4$ & -5.0 & 32.2 & 20.7 & 8.7 \\
\hline
\end{tabular}

\subsection{Select Preliminary Drift Shapes and Sizes}

For this preliminary application, the current SCP-CDR shape and size drifts are adopted.

\subsection{Perform Analysis of Drift and Intersections}

Preliminary empirical/numerical analyses of unsupported drifts and prelininary selections of ground support/reinforcement have been performed. These are summarized in the following subsections.

\subsubsection{Empirical Analysis}

The empirical analysis results are shown in Figures 12-4, 12-5 and 12-6 and supported by Tables 12-23 through 12-28.

Results of application of the Hoek method are in Figure 12-4 for the midpanel and emplacement drift, with supporting data in Table 12-23. The maximum boundary stress was calculated for the midpanel emplacement drift based on an assumed circular excavation and the Kirsch solution. For the tuff main drift, the thermal stresses are significantly lower than those listed in Table 12-23. The emplacement drift thermal stresses are similar to the midpanel emplacement drift, and hence, the range of expected conditions for the drift woula be superimposed on the midpanel emplacement drift case. This empirical method indicates light to medium support for four of five of the rock categories with no indication of stress induced failure. For Category 4 rock, heavy support is indicated.

The conditions expected at the emplacement drift are shown on the Schmidt diagram in Figure 12-5. This method indicates that structurally controlled mechanisms will control stability.

The NGI Barton Method results are shown in Figures 12-6 and 12-7. In the NGl system, rock support system recommendations are tabulated for 38 support categories shown in Figure 12-7. Requirements for the five rock mass quality categories are listed in Table 12-24. Factor of safety is implied in the system by using a parameter called "equivalent dimension," which is the span 


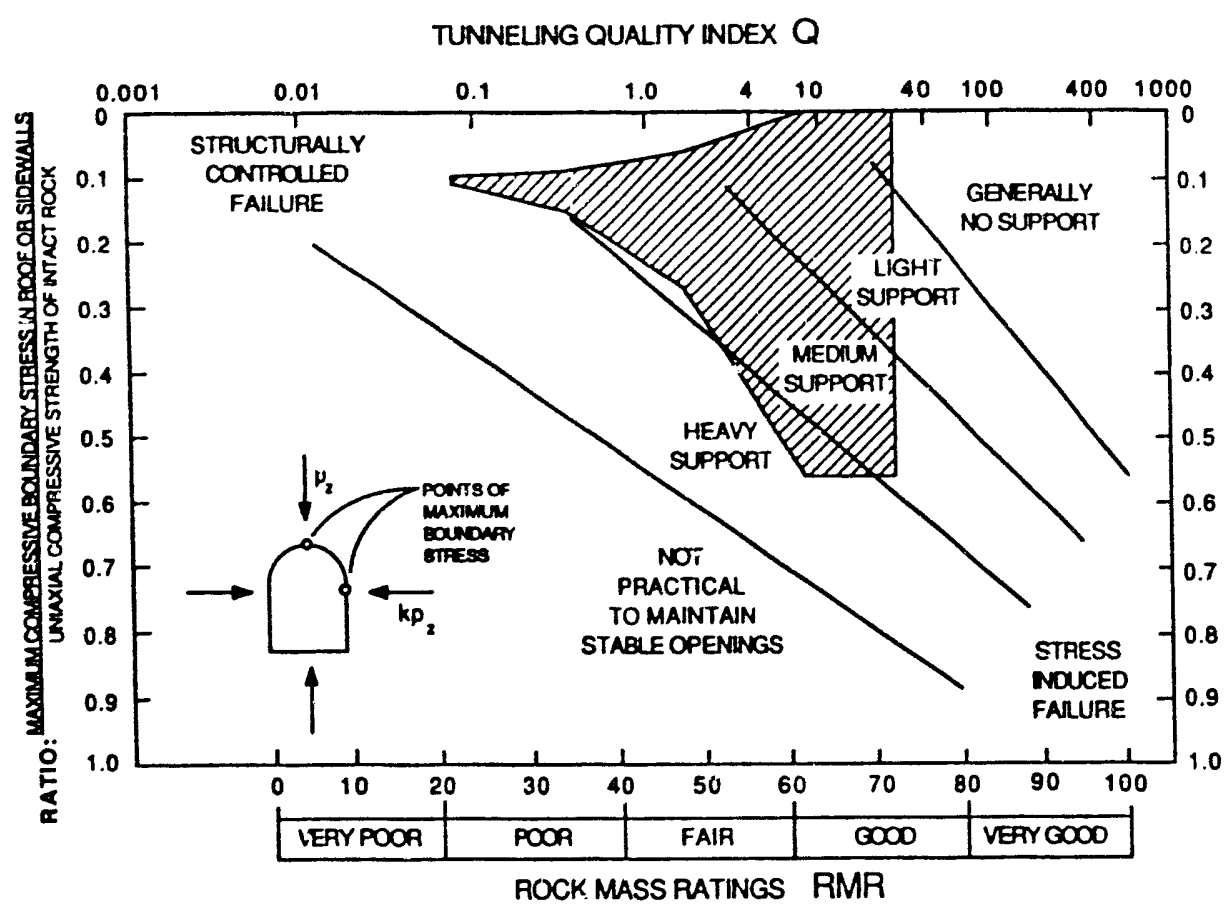

DIA PROUECTED RANGE OF CONOMONS FOR EMPLACEMENT ORIFTS

Figure 12-4. Approximate Support Guidelines for Underground Excavations Proposed by Hoek (1981) With Range of Expected Conditions for Emplacement Drifts at the YMP

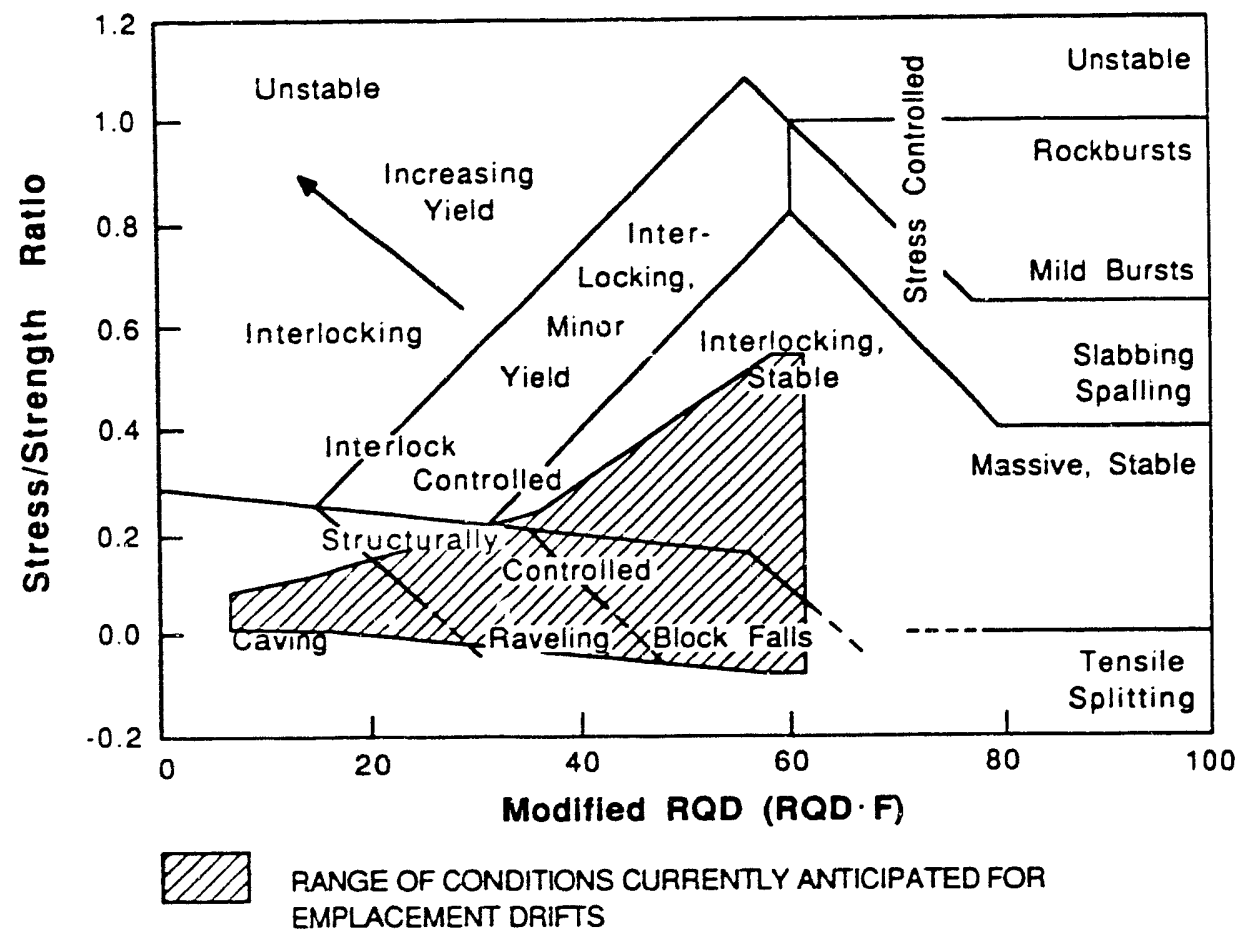

Figure 12-5. Chant for Estimating Modes of Failure Around Drifts Proposed by Schmidt (1987) With Projected Conditions for Emplacement Drift at YMP 
Table 12.23

PARAMETERS IN ASSESSING GROUND SUPPORT REQUIREMENTS FOR HOEK METHOD (Hoek, 1981)

\begin{tabular}{|c|c|c|c|c|}
\hline $\begin{array}{l}\text { Rock Quality } \\
\text { Category }\end{array}$ & $\mathbf{Q}$ & RMR & $\begin{array}{c}\text { Maximum Compressive Stress }^{1} \\
3 \sigma_{H}-\sigma_{V}(\mathrm{MPa})\end{array}$ & $\frac{\text { Stress }}{\text { Strength }^{2}}$ \\
\hline 1 & 0.08 & 32.5 & 15.3 & 0.10 \\
\hline 2 & 0.34 & 42.1 & 23 & 0.15 \\
\hline 3 & 1.68 & 54.7 & 42 & 0.27 \\
\hline 4 & 8.4 & 69.2 & 87 & 0.56 \\
\hline 5 & 27 & 77.6 & 88 & 0.56 \\
\hline
\end{tabular}



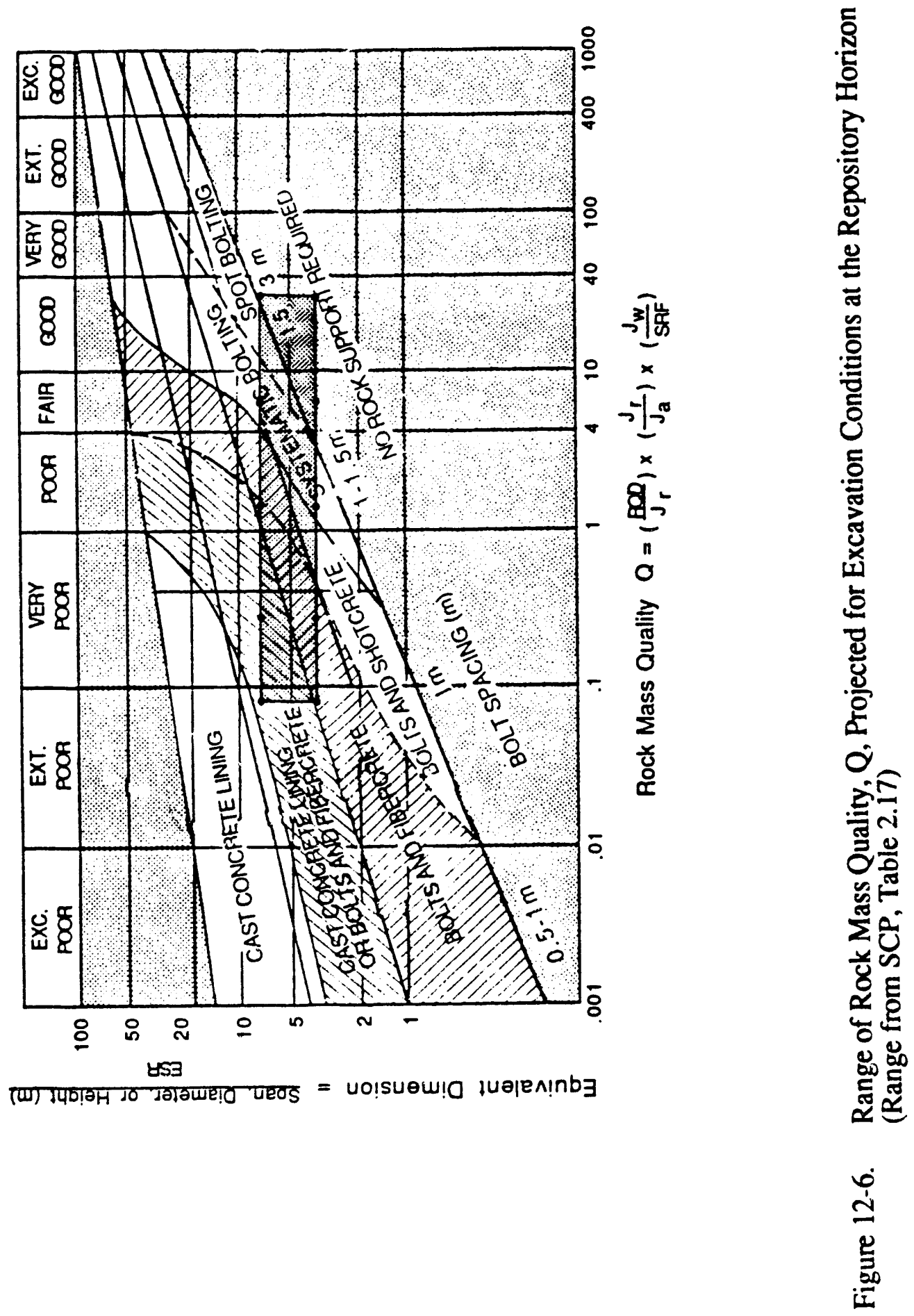


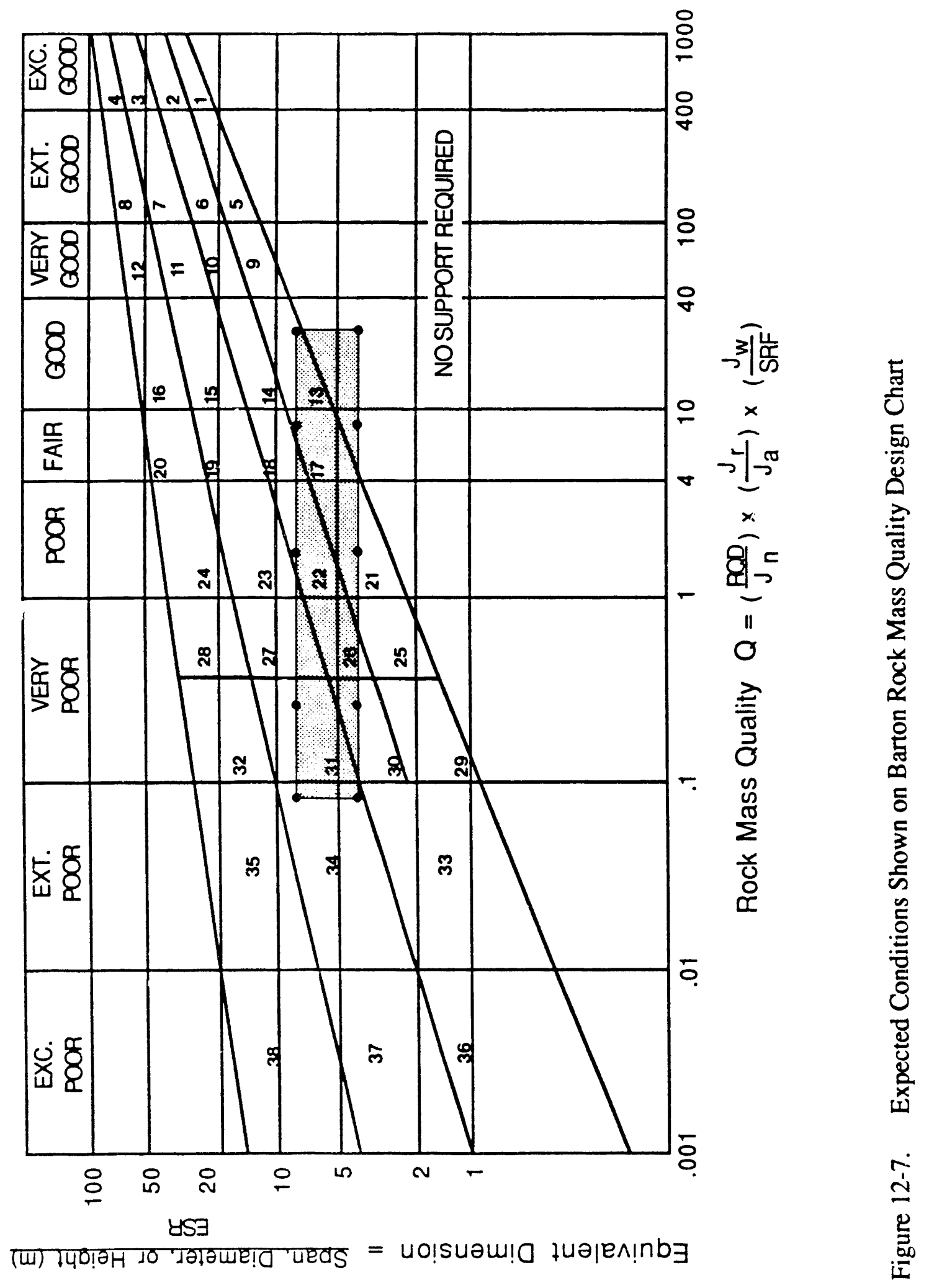




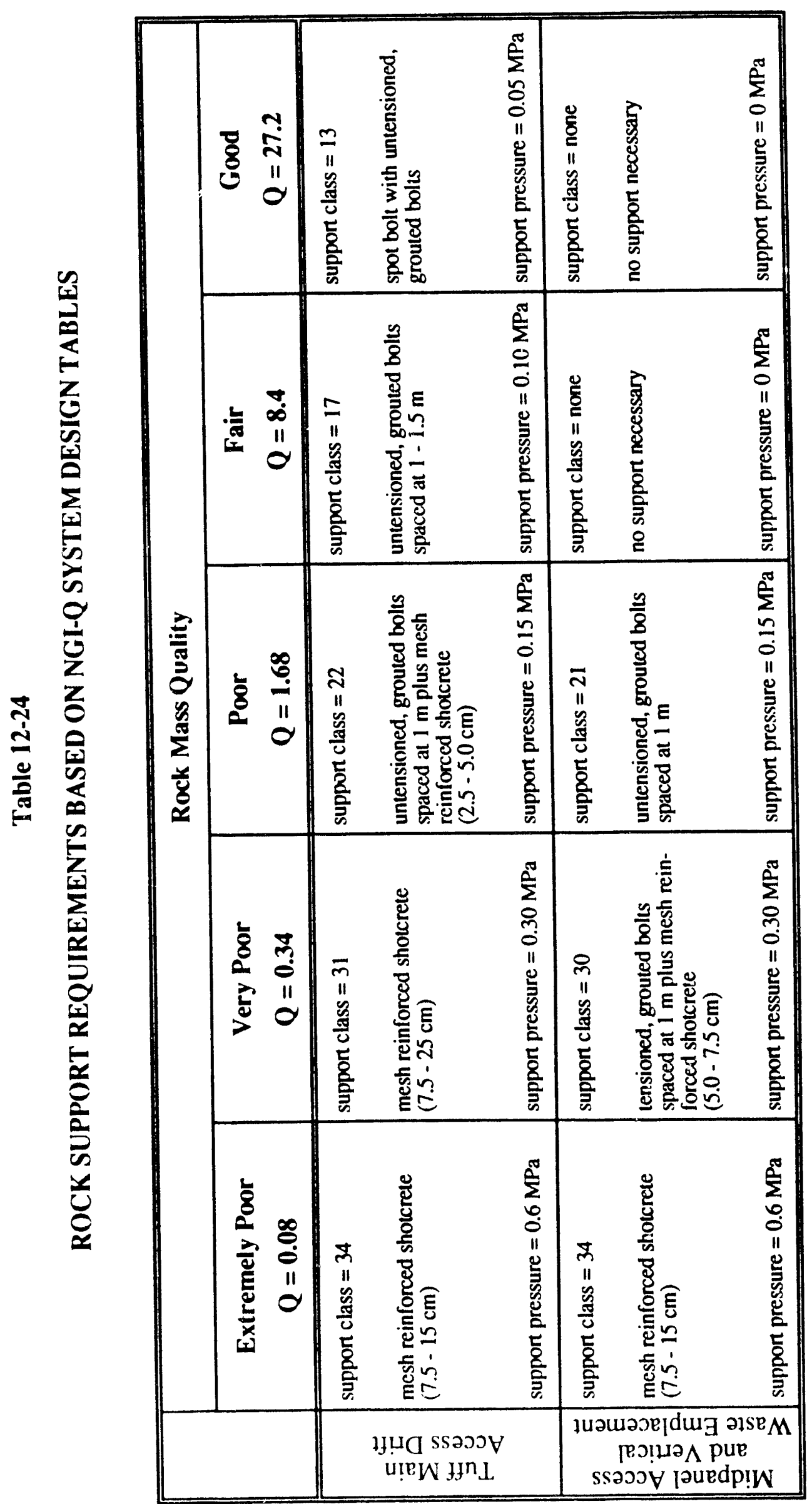


Table 12.25

MODIFIED $Q\left(Q^{M}\right)$ ADJUSTED FOR THERMAL AND SEISMIC LOADS

\begin{tabular}{|c|c|c|c|c|c|c|c|}
\hline $\begin{array}{c}\text { Rock Mass } \\
\text { Quality } \\
\text { Category }\end{array}$ & $\mathbf{Q}$ & $\begin{array}{c}\text { SRF } \\
\text { (from } \\
\text { Table 12-3 }\end{array}$ & $\begin{array}{c}\sigma_{1}^{1} \\
(\mathbf{M P a})\end{array}$ & $\sigma_{c} / \sigma_{1}{ }^{2}$ & $\begin{array}{c}\text { SRF }^{\mathbf{3}} \\
\left(\text { from } \sigma_{c} / \sigma_{1}\right)\end{array}$ & $\begin{array}{c}\text { Maximum } \\
\text { SRF }\end{array}$ & $Q^{34}$ \\
\hline 1 & 0.08 & 4.8 & 7.5 & 20.7 & 1 & 4.8 & 0.08 \\
\hline 2 & 0.34 & 4.2 & 10.1 & 15.3 & 1 & 4.2 & 0.34 \\
\hline 3 & 1.68 & 3.4 & 16.5 & 9.4 & 0.5 to 2 & 3.4 & 1.68 \\
\hline 4 & 8.4 & 2.2 & 31.9 & 4.8 & 5 to 10 & 5.0 & 3.7 \\
\hline 5 & 27.2 & 1.4 & 32.2 & 4.8 & 5 to 10 & 5.0 & 7.6 \\
\hline \multicolumn{8}{|c|}{$\begin{array}{ll}\sigma_{1} \text { for in situ }+ \text { thermal }+ \text { seismic. } \\
2 \\
{ }_{2} & \sigma_{\mathrm{c}}=155 \mathrm{MPa} . \\
{ }^{3} \mathrm{SRF} \text { for } \sigma d \sigma_{1} \text { from Barton et al. (1974). } \\
{ }^{4} \mathrm{Q}^{\mathrm{M}}=\text { modified } Q \text { to account for increased stress. }\end{array}$} \\
\hline
\end{tabular}




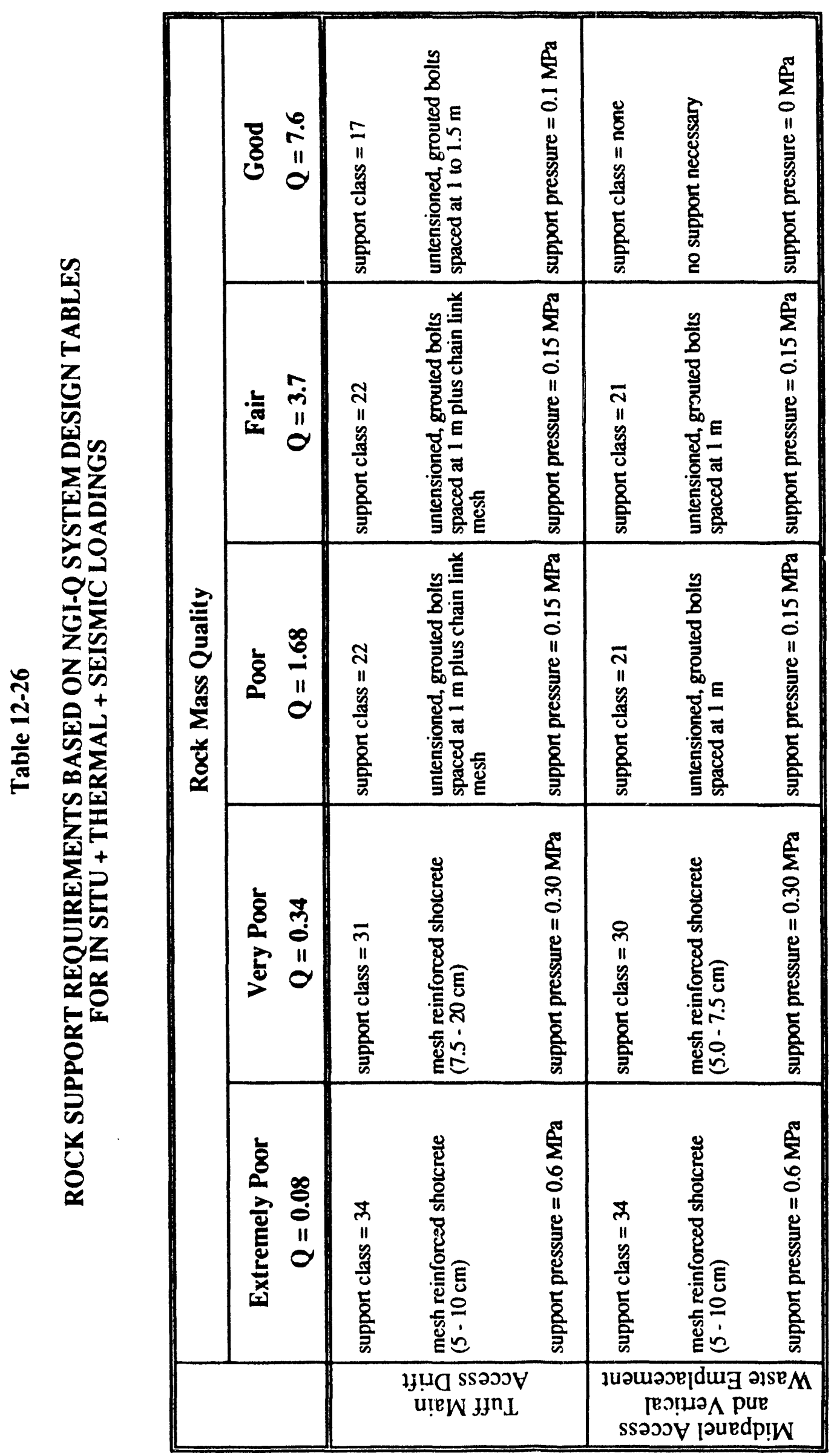


Table 12-27

ROCK SUPPORT PRESSURES (MPa)

BASED ON EQUATION 13 AND $Q^{M}$

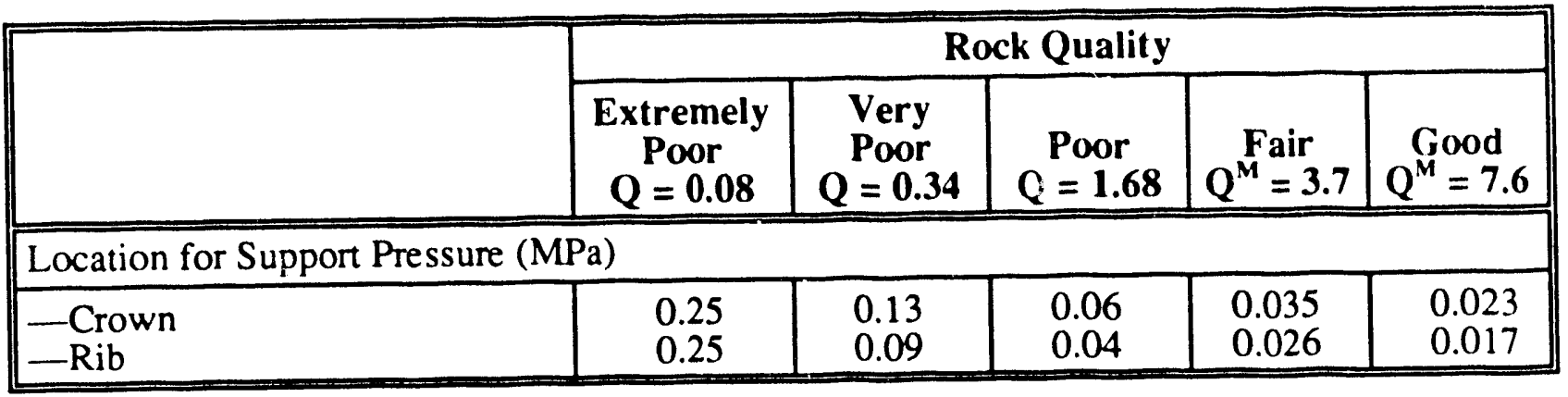

Table 12-28

STANDUP TIME BASED ON BIENIAWSKI'S RMR ROCK MASS RATING

\begin{tabular}{|c|c|c|c|c|}
\hline $\begin{array}{c}\text { Rock Mass } \\
\text { Quality } \\
\text { Category }\end{array}$ & RMR & $\begin{array}{c}\text { Tuff Main } \\
\text { (roof span = 7.63 m) }\end{array}$ & $\begin{array}{c}\text { Midpanel } \\
\text { (roof span=4.88 m) }\end{array}$ & $\begin{array}{c}\text { Emplacement } \\
\text { (roof span =4.88 } \mathbf{~ m} \text { ) }\end{array}$ \\
\hline \hline 1 & 32.5 & $0 \mathrm{hrs}$ & $2.7 \mathrm{hrs}$ & $2.7 \mathrm{hrs}$ \\
\hline 2 & 42.1 & $14 \mathrm{hrs}$ & $30 \mathrm{hrs}$ & $30 \mathrm{hrs}$ \\
\hline 3 & 54.7 & $260 \mathrm{hrs}$ & $600 \mathrm{hrs}$ & $600 \mathrm{hrs}$ \\
\hline 4 & 69.2 & $9,000 \mathrm{hrs}$ & $2,100 \mathrm{hrs}$ & $2,100 \mathrm{hrs}$ \\
\hline 5 & 77.6 & $45,000 \mathrm{hrs}$ & $11,000 \mathrm{hrs}$ & $11,000 \mathrm{hrs}$ \\
\hline
\end{tabular}


divided by a usage factor called excavation support ratio (ESR). An ESR value of 1.0 is consistent with design of major road and railway tunnels, and 1.3 for storage rooms, water treatment plants, and minor railway tunnels used for the various repository drifts.

The effect of thermal and seismic stresses can be assessed with the $Q$ system by modifying the SRF to account for the increased stresses. In applying this method only the SRF for the two better rock quality categories would change following the guidelines presented by Barton et al. (1974). Table 12-25 lists the parameters used for the waste-emplacement drift or midpanel access drift. The impact on the tuff main drift would be even less because of the thermal stresses in that area. Table 12-26 shows the rock support requirements from the modified $Q$ values and shows a modest increase in ground support/rock reinforcement for the poor and good rock categories.

The support pressures indicated by the NGI method and listed in Tables 12-24 and 12-26 for the extremely poor and very poor rock categories are very high relative to the recommended ground support pressures calculated using Equation 13 (see Section 6.4.2). The rock support pressures calculated from Equation 13 are listed in Table 12-27 using the modified $Q$ to reflect the seismic and thermal loads.

The estimated standup times for each rock mass quality category and drift type are listed in Table 12-28. For rock mass Category 1, which has a $Q$ of less than 0.1 and a low $R M R$, the standup time for the tuff main drift is estimated to be zero, an unacceptable condition.

\subsubsection{Numerical Methods}

Results of preliminary analysis of the tuff main access, midpanel access, and wasteemplacement drifts, using the finite-element program, JAC, for bounciary loads discussed in Section 12.4, are presented. Extent of the yield zones for both elasto-plastic (Mohr-Coulomb) and compliant joint models described using the various criteria of yield, crushing strain, and extensile strain were evaluated to provide a basis for preliminary design of the rock support/reinforcement system. For the elasto-plastic analysis using Mohr-Coulomb yield criteria presented here, the nonassociated flow rule with the dilation angle equal to one-half the internal firiction angle was used.

12.7.2.1 Tuff Main Access Drift The tuff main access drift was analyzed using in situ plus thermal plus seismic and in situ minus seismic loadings with the elasto-plastic equivalent and compliant joint models for all five rock quality categories. All cases were analyzed except for the CJM for the good and fair rock under the in situ minus seismic loading case. For the latter two cases, the horizontal stress field was tensile and greater than the half-closure stress of the joints. With these conditions and the finite-element boundary conditions, a solution could not be achieved. For the extremely poor rock under the in situ plus thermal plus seismic loading, joint slip could occur along horizonial joints from the drift floor and roof to the finite-element boundary resulting in horizontal block motion into the drift. An alternate fixed boundary model was used for this case. This problem arose for the extremely poor rock under in situ minus seismic loading also, but converged numerically to a solution.

The results indicate that the worst-case thermal loading occurs at 100 years after waste emplacement.

The maximum extent of the yield zone requiring support and the governing criteria for the tuff main access drifts are summarized in Table 12-29. The table indicates that only the good rock requires relatively light support with a maximum yield zone of $0.3 \mathrm{~m}$ in the drift sidewall and no yield in the crown. Yield zones develop a maximum depth of $1.87 \mathrm{~m}$ for the cases of extremely poor and very poor (Categories 1 and 2) rock qualities in the drift crown, from the Mohr-Coulomb model. The Mohr-Coulomb model predicts a yield zone of up to $1.11 \mathrm{~m}$ in the ribs for fair rock. 
Table 12-29

MAXIMUM EXTENT OF FAILED ZONE FOR THE TUFF MAIN ACCESS DRIFT

\begin{tabular}{|c|c|c|c|c|c|c|c|}
\hline \multirow[b]{2}{*}{ Rock Model } & \multirow[b]{2}{*}{$\begin{array}{c}\text { Rock } \\
\text { Mass } \\
\text { Quality } \\
\text { Category }\end{array}$} & \multicolumn{3}{|c|}{ Drift Sidewall } & \multicolumn{3}{|c|}{ Drift Crown } \\
\hline & & $\begin{array}{c}\text { Load } \\
\text { Type* }\end{array}$ & $\begin{array}{c}\text { Governing } \\
\text { Criteria }\end{array}$ & $\begin{array}{c}\text { Extent } \\
\text { of Yield } \\
\text { Zone } \\
\text { (m) }\end{array}$ & $\begin{array}{l}\text { Load } \\
\text { Type* }\end{array}$ & $\begin{array}{c}\text { Governing } \\
\text { Criteria }\end{array}$ & $\begin{array}{c}\text { Extent } \\
\text { of } \\
\text { Yield } \\
\text { Zone } \\
\text { (m) }\end{array}$ \\
\hline \multirow[t]{5}{*}{ Elasto-plastic } & 1 & ITS & M-C yield & 1.87 & ITS & M.C yield & 0.30 \\
\hline & 2 & ITS & M-C yield & 1.87 & ITS & M-C yield & 0.61 \\
\hline & 3 & ITS & M-C yield & 0.96 & ITS & $\mathrm{M}-\mathrm{C}$ yield & 0.61 \\
\hline & 4 & ITS & M-C yield & 0.25 & IS & M-C yield & 1.11 \\
\hline & 5 & ITS & M-C yield & 0.00 & ITS & M-C yield & 0.30 \\
\hline \multirow[t]{5}{*}{ CJM } & 1 & NA & NA & 0.00 & NA & NA & 0.00 \\
\hline & 2 & NA & NA & 0.00 & NA & NA & 0.00 \\
\hline & 3 & NA & NA & 0.00 & NA & NA & 0.00 \\
\hline & 4 & NA & NA & 0.00 & NA & NA & 0.00 \\
\hline & 5 & NA & NA & 0.00 & $\mathrm{NA}$ & NA & 0.00 \\
\hline
\end{tabular}

12.7.2.2 Midpanel Access Drift The midpanel access drift was analyzed for the five rock quality categories under the same load combinations for the tuff main access drift using the elasto-plastic and compliant joint models. All cases converged numerically except for the fair and good rock under in situ minus seismic loading for the CJM where the combined horizontal and tensile stresses were greater than the joint half-closure stress.

The maximum extent of the yield zone requiring support and the governing yield criteria are listed in Table 12-30. Yield zones predicted by the Mohr-Coulomb model generally varied from 0.25 to $0.96 \mathrm{~m}$. The CJM model indicates very light support for the fair and good rock quality because of extensile strain failure to a depth of $0.37 \mathrm{~m}$ in the crown.

12.7.2.3 Vertical Waste Emplacement Drift The vertical waste-emplacement drift was analyzed for all five rock quality categories with in situ minus seismic, in situ plus thermal, and in situ plus thermal plus seismic loadings and using the elasto-plastic and CJM models. Some difficulty was encountered in achieving numerical convergence for all conditions. Specifically, numerical difficulties were encountered for the elasto-plastic model for the extremely poor and very poor rock under in situ plus thermal plus seismic loading.

The maximum extent of yield zones and the criteria controlling the extent of the yield zones are listed in Tables 12-31 and 12-32 for in situ plus thermal and in situ plus thermal plus seismic loadings, respectively. Yield zones in the crown were a maximum of $0.71 \mathrm{~m}$ in the drift crown for Mohr-Coulomb yield, with sidewall failures up to $1.62 \mathrm{~m}$ deep for the in situ plus thermal loads. Comparison of Tables 12-31 and 12-32 indicates only minor changes in the extent of yielding. For 
Table 12-30

MAXIMUM EXTENT OF FAILED ZONE FOR THE MIDPANEL ACCESS DRIFT

\begin{tabular}{|c|c|c|c|c|c|c|c|}
\hline \multirow[b]{2}{*}{ Rock Model } & \multirow[b]{2}{*}{$\begin{array}{c}\text { Rock } \\
\text { Mass } \\
\text { Quality } \\
\text { Category }\end{array}$} & \multicolumn{3}{|c|}{ Drift Sidewal! } & \multicolumn{3}{|c|}{ Drift Crown } \\
\hline & & $\begin{array}{l}\text { Load } \\
\text { Type* }\end{array}$ & $\begin{array}{c}\text { Governing } \\
\text { Criteria }\end{array}$ & $\begin{array}{c}\text { Extent } \\
\text { of Yield } \\
\text { Zone } \\
\text { (m) }\end{array}$ & $\begin{array}{l}\text { Load } \\
\text { Type* }\end{array}$ & $\begin{array}{c}\text { Governing } \\
\text { Criteria }\end{array}$ & $\begin{array}{l}\text { Extent } \\
\text { of } \\
\text { Yield } \\
\text { Zone } \\
\text { (m) }\end{array}$ \\
\hline \multirow[t]{5}{*}{ Elasto-plastic } & 1 & ITS & M-C yield & 0.96 & ITS & M-C yield & 0.61 \\
\hline & 2 & ITS & M.C yield & 0.96 & ITS & M-C yield & 0.61 \\
\hline & 3 & ITS & $\mathrm{M}-\mathrm{C}$ yield & 0.61 & ITS & $M-C$ yield & 0.61 \\
\hline & 4 & ITS & M-C yield & 0.25 & ITS & M-C yield & 0.61 \\
\hline & 5 & ITS & $\mathrm{M}-\mathrm{C}$ yield & 0.25 & ITS & M-C yield & 0.30 \\
\hline \multirow[t]{5}{*}{$\mathrm{CJM}$} & 1 & & $\mathrm{NE}$ & 0.00 & NA & NE & 0.00 \\
\hline & 2 & & NE & 0.00 & $\mathrm{NA}$ & $\mathrm{NE}$ & 0.00 \\
\hline & 3 & & $\mathrm{NE}$ & 0.00 & NA & NE & 0.00 \\
\hline & 4 & & $\mathrm{NE}$ & 0.00 & ITS & $\begin{array}{l}\text { extensile } \\
\text { strain }\end{array}$ & 0.37 \\
\hline & 5 & & $\mathrm{NE}$ & 0.00 & ITS & \begin{tabular}{|l} 
extensile \\
strain
\end{tabular} & 0.37 \\
\hline
\end{tabular}


Table 12-31

MAXIMUM EXTENT OF FAILED ZONE FOR WASTE EMPLACEMENT DRIFT FOR IN SITU PLUS THERMAL LOADS

\begin{tabular}{|c|c|c|c|c|c|}
\hline \multirow[b]{2}{*}{ Rock Model } & \multirow[b]{2}{*}{$\begin{array}{c}\text { Rock Mass } \\
\text { Quality } \\
\text { Category }\end{array}$} & \multicolumn{2}{|c|}{ Drift Sidewall } & \multicolumn{2}{|c|}{ Drift Crown } \\
\hline & & $\begin{array}{c}\text { Governing } \\
\text { Criteria } \\
\end{array}$ & $\begin{array}{c}\text { Extent of } \\
\text { Yield Zone } \\
(\mathrm{m})\end{array}$ & $\begin{array}{c}\text { Governing } \\
\text { Criteria }\end{array}$ & $\begin{array}{c}\text { Extent of } \\
\text { Yield Zone } \\
(\mathrm{m})\end{array}$ \\
\hline \multirow[t]{5}{*}{ Elasto-plastic } & 1 & M-C yield & 1.62 & M-C yield & 0.35 \\
\hline & 2 & M-C yield & 1.62 & M-C yield & 0.71 \\
\hline & 3 & M-C yield & 0.64 & M-C yield & 0.71 \\
\hline & 4 & M-C yield & 1.62 & M-C yield & 0.71 \\
\hline & 5 & M-C yield & 0.64 & M-C yield & 0.35 \\
\hline \multirow[t]{5}{*}{$\mathrm{CJM}$} & 1 & $\mathrm{NE}$ & & $\begin{array}{l}\text { extensile } \\
\text { strain }\end{array}$ & 0.17 \\
\hline & 2 & $\mathrm{NE}$ & & $\begin{array}{l}\text { extensile } \\
\text { strain }\end{array}$ & 0.21 \\
\hline & 3 & NE & & $\begin{array}{l}\text { extensile } \\
\text { strain }\end{array}$ & 0.30 \\
\hline & 4 & NE & & $\begin{array}{l}\text { extensile } \\
\text { strain }\end{array}$ & 0.34 \\
\hline & 5 & $N E$ & & $\begin{array}{l}\text { extensile } \\
\text { strain }\end{array}$ & 0.34 \\
\hline
\end{tabular}


Table 12-32

MAXIMUM EXTENT OF FAILED ZONE FOR WASTE-EMPLACEMENT DRIFT FOR IN SITU PLUS THERMAL PLUS SEISMIC LOADS

\begin{tabular}{|c|c|c|c|c|c|}
\hline \multirow[b]{2}{*}{ Rock Model } & \multirow[b]{2}{*}{$\begin{array}{c}\text { Rock Mass } \\
\text { Quality } \\
\text { Category }\end{array}$} & \multicolumn{2}{|c|}{ Drift Sidewall } & \multicolumn{2}{|c|}{ Drift Crown } \\
\hline & & $\begin{array}{c}\text { Governing } \\
\text { Criteria } \\
\end{array}$ & $\begin{array}{c}\text { Extent of } \\
\text { Yield Zone } \\
(\mathrm{m})\end{array}$ & $\begin{array}{c}\text { Governing } \\
\text { Criteria } \\
\end{array}$ & $\begin{array}{c}\text { Extent of } \\
\text { Yield Zone } \\
(\mathbf{m})\end{array}$ \\
\hline \multirow[t]{5}{*}{ Elasto-plastic } & 1 & M-C yield & 1.62 & M-C yield & 0.64 \\
\hline & 2 & M-C yield & 1.62 & M-C yield & 0.71 \\
\hline & 3 & M-C yield & 1.62 & M-C yield & 0.71 \\
\hline & 4 & M-C yield & 0.64 & M-C yield & 0.71 \\
\hline & 5 & M-C yield & 0.00 & M-C yield & 0.35 \\
\hline \multirow[t]{5}{*}{ CJM } & 1 & NE & & $\begin{array}{l}\text { extensile } \\
\text { strain }\end{array}$ & 0.25 \\
\hline & 2 & $\mathrm{NE}$ & & $\begin{array}{l}\text { extensile } \\
\text { strain }\end{array}$ & 0.30 \\
\hline & 3 & $\mathrm{NE}$ & & $\begin{array}{l}\text { extensile } \\
\text { strain }\end{array}$ & 0.37 \\
\hline & 4 & $\mathrm{NE}$ & & $\begin{array}{l}\text { extensile } \\
\text { strain }\end{array}$ & 0.42 \\
\hline & 5 & NE & & $\begin{array}{l}\text { extensile } \\
\text { strain }\end{array}$ & 0.42 \\
\hline
\end{tabular}

the drift walls, the extent of yield increased for the poor rock but decreased for the fair and good rock. In the crown, the extent of yield increased in the fair and good rock, but otherwise was unchanged when the seismic loads were added. The CJM model indicates relatively limited extensile strain failure depths up to $0.42 \mathrm{~m}$.

\subsubsection{Preliminary Ground Support Parameters}

Based on the depth of yield listed in Tables 12-29 to 12-32 and the wall pressure support requirements identified in Section 6.5.3, the support pressure, bolt spacing, and bolt lengths were estimated for the three drift types and listed in Table 12-33. The bolt lengths range from 1.22 to $2.44 \mathrm{~m}(4$ to $8 \mathrm{ft})$ for all the cases and conditions considered. The bolt spacings are based on No. 5 bolts ( $1.6 \mathrm{~cm}$ diameter), grade 60 steel. The ground support/rock reinforcement recommendations from the empirical methods shown in Table 12-26 indicate higher support pressures than the numerical results. As noted earlier, the support pressures shown in Tables 12-24 and 12-26 are higher than that calculated by Equation 13 (based on the $Q$ value). Even so the support pressures based on Equation 13 (Table 12-27) are higher than that estimated by the numerical technique. 
Table 12-33

\section{ROCKBOLT SUPPORT SYSTEMS BASED ON NUMERICAL ANALYSIS OF UNSUPPORTED DRIFTS}

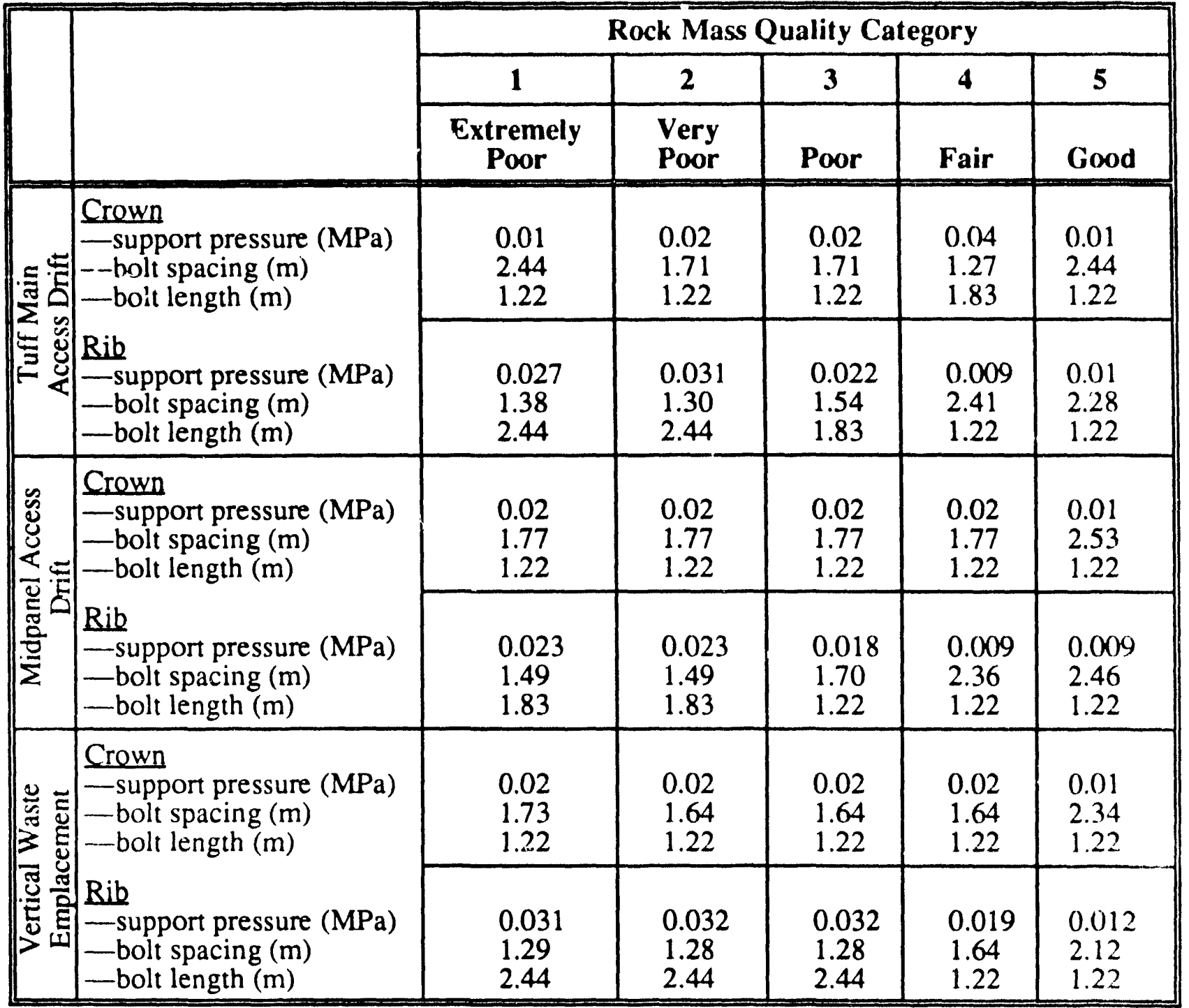

\subsection{Evaluate Drift Design}

Drift design evaluation follows the logic shown in Figure 7-1. The loading condition of in situ minus seismic for rock Categories 4 and 5 produces extensile strains that exceed the allow able strains in the rock mass.

Table 12-34 summarizes the evaluation of the three drifts for each category under the maximum compressive stress (in situ plus thermal plus seismic) field. The maximum allowable compressive strain is exceeded for the full compressive loading when the in situ plus thermal plus seismic stresses are applied to rock Categories 1 and 2 for the tuff main, Categories 1 through 4 , midpanel access drifts, and for all categories for the emplacement drift. 
Table 12-34

\section{CASES WHERE MAXIMUM ALLOWABLE COMPRESSIVE STRAIN EXCEEDED WHEN LOADED BY IN SITU PLUS THERMAL PLUS SEISMIC STRESSES}

\begin{tabular}{|c|c|c|c|c|}
\hline \multirow{2}{*}{$\begin{array}{c}\text { Rock Mass } \\
\text { Category }\end{array}$} & $\begin{array}{c}\text { Rock Quality } \\
\mathbf{< 0 . 1}\end{array}$ & $\begin{array}{c}\text { Tuff Main } \\
\text { Drift }\end{array}$ & $\begin{array}{c}\text { Midpanel Access } \\
\text { Drift }\end{array}$ & $\begin{array}{c}\text { Emplacement } \\
\text { Drift }\end{array}$ \\
\hline & $\mathrm{X}$ & $\mathrm{X}$ & $\mathrm{X}$ & $\mathrm{X}$ \\
\hline 1 & & $\mathrm{X}$ & & $\mathrm{X}$ \\
\hline 2 & & & & $\mathrm{X}$ \\
\hline 3 & & & & $\mathrm{X}$ \\
\hline 4 & & & & \\
\hline 5 & & & & \\
\hline
\end{tabular}

Further evaluation of the drift design involves preliminary assessment of the practicality and cost of installing ground support/rock reinforcement. The bolt lengths determined from either the empirical or analytical techniques are not excessive. All ground support/rock reinforcement categories shown in Tables 12-26, 12-27 and 12-33 appear to be reasonable. Bolt spacings of 0.5 $\mathrm{m}$ are not common as shown in Table $12-27$ for the extremely poor rock (Category 1 ). This spacing is required to develop a support pressure of $0.25 \mathrm{MPa}$, which is high for rockbolt support. Typically such support pressures would be provided by a combination of bolts, shotcrete and possibly poured-in-place concrete. For the very poor rock (Category 2), the bolt spacing of $0.69 \mathrm{~m}$ is also very tight and would normally require some form of concrete/shotcrete lining. Table 12-26 indicates that for these poorer rock quality categories, up to $20 \mathrm{~cm}$ of shotcrete would be required.

The support pressures listed in Tables 12-26 and 12-27 are not consistent and illustrate one of the problems of adopting empirical schemes. The support pressures estimated from the analytical techniques (Table 12-33) are lower in general than the empirical estimates and hence would not control the selection of the ground support system.

\subsection{Modify Drift ShapeiLoads and Review Goals and Criteria}

From the preliminary application of the methodology to the data and drift shapes given above, the criteria that cannot be met are the maximum complessive strain for the poorer rock and the tensile strength for the better rock categories. This compressive strain criteria is not exceeded at construction when only the in situ stresses are relieved, hence, a reduction in the thermal load in areas where the rock quality is low may allow these drift shapes to meet the existing criteria. Alternatively, the criteria of the maximum compressive strain might need to be reassessed.

The tensile strength criteria is exceeded for the better rock quality grouping (Categories 4 and 5) when loaded by in situ minus seismic loads. This loading results in excessive tensile strain throughout the region of the drift, particularly for the CJM when the half-closure stress is exceeded in tension. A numerical solution is not achieved. In practice the tensile stress would be attenuated by joint opening. This loading condition needs to be further reviewed. Either the loading is impractically high or the design method needs to be refined to better model the tensile phase of the seismic load. 


\subsection{Ground Support Design}

The ground support design involves evaluation of the performance of the ground support/rock reinforcement components selected as part of the preliminary ground support selection and redesign if necessary. This involves evaluation of the preliminary support design, ground support analyses (both uncoupled and coupled), and evaluation. The rockbolt properties used for the uncoupled and coupled analyses were elastic modulus, $200 \mathrm{GPa}$, and thermal expansion coefficient, $11.5 \times 10^{-6} \mathrm{~m} / \mathrm{m}^{\circ} \mathrm{C}$. For the shotcrete, the following properties for a typical $34.5 \mathrm{MPa}$ (5000 psi) 28-day-strength shotcrete were assumed: elastic modulus is $22 \mathrm{GPa}$, thermal expansion coefficient is $12 \times 10^{-6} \mathrm{~m} / \mathrm{m}^{\circ} \mathrm{C}$, and Poisson's ratio is 0.18 . Bolt lengths of $2.44 \mathrm{~m}(8 \mathrm{ft})$ were assumed, even though for some cases, shorter bolts would be acceptable (based on the preliminary design).

\subsubsection{Uncoupled Analysis}

Rockbolt and shotcrete loads were calculated for each rock quality case based on an uncoupled approach. The uncoupled approach calculates bolt or shotcrete stresses from rock displacement and temperature changes (from the drift analyses completed earlier) and assumes that the bolt has no effect on rock deformation. The bolt stress is based on the strain change in the rock mass, the temperature change in the bolt, and the bolt modulus and therrral expansion coefficient as described in Section 8.2.1. The in situ loads resisted by the rockbolt or shotcrete during relaxation with excavation was as listed in Table 8-1. All results reported for the bolt loads assume pointanchored bolts. Fully bonded bolts result in high bolt stresses near the perimeter of the drift and could result in debonding of the bolt. Point-anchored bolts average the strains over a larger distance and result in lower overall bolt loads. Partially bonded bolts could be designed to meet the design requirements but are beyond this preliminary application of the methodology.

12.10.1.1 Tuff Main Drift Tables 12-35 and 12-36 list the maximum bolt and shotcrete loads respectively calculated for in situ plus seismic plus thermal and in situ minus seismic stresses. Bolt loads are very high for both the extremely poor rock quality and indicate minimum bolt factors of safety at bolt yield (yield strength of $410.0 \mathrm{MPa}$ ) of 0.48 . Minimum factors of safety for bolt yield are 1.13 for very poor rock, 2.66 for the poor rock, and 3.0 or above for fair and good rock. The shotcrete loads are higher than the shotcrete strength $(34.4 \mathrm{MPa})$ for all rock mass quality categories when loaded by in situ plus thermal plus seismic. Tensile stresses sufficient to cause cracking in unreinforced shotcrete are predicted in the wails for the compressive loading.

12.10.1.2 Midpanel Access Drift Rockbolt loads calculated from the uncoupled analysis for the midpanei access drift are listed in Table 12-37. Bolt factors of safety at bolt yield reach 1.15 for the extremely poor rock quality, are 1.58 for the very poor rock, and over 2.0 for the three better rock quality categories. The in situ minus seismic loading produces acceptable stresses in the bolts for all cases except for the sidewall bolts for the extremely poor rock. Table 12-38 shows the shotcrete loads. The loads are very high relative to the shotcrete strength when loaded by the in situ plus thermal plus seismic loads.

12.10.1.3 Emplacement Drift The bolt loads calculated from uncoupled analysis of the elasto-plastic yield rock model for the waste emplacement drift are shown in Table 12-39 for in situ plus thermal and in situ plus thermal plus seismic loadings, respectively. The rib bolts would be overstressed for the extremely poor rock. 
Table 12-35

PREDICTED BOLT LOADS (MPa), TUFF MAIN ACCESS DRIFT, UNCOUPLED ANAL YSIS

\begin{tabular}{|c|c|c|c|c|c|}
\hline \multirow{2}{*}{$\begin{array}{c}\text { Rock Mass } \\
\text { Ruality Category }\end{array}$} & RMR & \multicolumn{4}{|c|}{ Load Type } \\
\cline { 3 - 6 } & \multicolumn{2}{|c|}{$\begin{array}{c}\text { In situ + Thermal + } \\
\text { Seismic }\end{array}$} & \multicolumn{2}{c|}{ In situ - Seismic } \\
\cline { 3 - 6 } & Bolts & $\begin{array}{c}\text { Sidewall } \\
\text { Bolts }\end{array}$ & $\begin{array}{c}\text { Crown } \\
\text { Bolts }\end{array}$ & $\begin{array}{c}\text { Sidewall } \\
\text { Bolts }\end{array}$ \\
\hline 1 & 32.5 & 377 & 852 & 223 & 633 \\
\hline 2 & 42.1 & 230 & 362 & 132 & 256 \\
\hline 3 & 54.7 & 154 & 108 & 60 & 34 \\
\hline 4 & 69.2 & 112 & -27 & 26 & 12 \\
\hline 5 & 77.6 & 51 & -29 & 26 & 12 \\
\hline
\end{tabular}

Table 12-36

PREDICTED SHOTCRETE LOADS (MPa), TUFF MAIN ACCESS DRIFT, UNCOUPLED ANALYSIS

\begin{tabular}{|c|c|c|c|c|c|}
\hline \multirow{2}{*}{$\begin{array}{c}\text { Rock Mass } \\
\text { Ruality Category }\end{array}$} & RMR & \multicolumn{4}{|c|}{ Load Type } \\
\cline { 3 - 6 } & & \multicolumn{2}{|c|}{$\begin{array}{c}\text { In situ + Thermal + } \\
\text { Seismic }\end{array}$} & \multicolumn{2}{c|}{ In situ - Seismic } \\
\cline { 2 - 6 } & Crown & Sidewall & Crown & Sidewall \\
\hline 1 & 32.5 & 77 & 86 & 26 & 74 \\
\hline 2 & 42.1 & 50 & 50 & 12 & 34 \\
\hline 3 & 54.7 & 44 & 26 & 2 & 6 \\
\hline 4 & 69.2 & 44 & -12 & -4 & -1 \\
\hline 5 & 77.6 & 36 & -13 & -3 & -1 \\
\hline
\end{tabular}


Table 12-37

PREDICTED BOLT LOADS (MPa), MIDPANEL ACCESS DRIFT, UNCOUPLED ANALYSIS

\begin{tabular}{|c|c|c|c|c|}
\hline \multirow{2}{*}{$\begin{array}{c}\text { Rock Mass } \\
\text { Quality Category }\end{array}$} & \multicolumn{4}{|c|}{ Load Type } \\
\cline { 2 - 5 } & $\begin{array}{c}\text { In situ + Thermal + } \\
\text { Seismic }\end{array}$ & \multicolumn{2}{c|}{ In situ - Seismic } \\
\hline 1 & $\begin{array}{c}\text { Crown } \\
\text { Bolts }\end{array}$ & $\begin{array}{c}\text { Sidewall* } \\
\text { Bolts }\end{array}$ & $\begin{array}{c}\text { Crown } \\
\text { Bolts }\end{array}$ & $\begin{array}{c}\text { Sidewall } \\
\text { Bolts }\end{array}$ \\
\hline 2 & 306 & 357 & 193 & 283 \\
\hline 3 & 259 & 204 & 112 & 107 \\
\hline 4 & 206 & -36 & 56 & 24 \\
\hline 5 & 165 & -60 & 27 & 12 \\
\hline$*$ Bolts are 2.4 m long, point-anchored, tension positive. & & 11 \\
\hline
\end{tabular}

Table 12-38

PREDICTED SHOTCRETE LOADS (MPa), MIDPANEL ACCESS DRIFT, UNCOUPLED ANALYSIS

\begin{tabular}{|c|c|c|c|c|c|}
\hline \multirow{2}{*}{$\begin{array}{c}\text { Rock Mass } \\
\text { Ruality Category }\end{array}$} & RMR & \multicolumn{4}{|c|}{ Load Type } \\
\cline { 3 - 6 } & & \multicolumn{2}{|c|}{$\begin{array}{c}\text { In situ + Thermal + } \\
\text { Seismic }\end{array}$} & \multicolumn{2}{c|}{ In situ - Seismic } \\
\cline { 2 - 6 } & Crown & Wall & Crown & Wall \\
\hline \hline 1 & 32.5 & 101 & 59 & 27 & 40 \\
\hline 2 & 42.1 & 102 & 39 & 11 & 13 \\
\hline 3 & 54.7 & 100 & -8 & 2 & 1 \\
\hline 4 & 69.2 & 95 & -20 & -4 & -1 \\
\hline 5 & 77.6 & 73 & -16 & -4 & -1 \\
\hline
\end{tabular}


Table 12-39

\section{PREDICTED BOLT LOADS (MPa), VERTICAL WASTE-EMPLACEMENT DRIFT, UNCOUPLED ANALYSIS}

\begin{tabular}{|c|c|c|c|c|}
\hline \multirow{2}{*}{$\begin{array}{c}\text { Rock Mass } \\
\text { Quality Category }\end{array}$} & \multicolumn{4}{|c|}{ Load Type } \\
\cline { 2 - 5 } & $\begin{array}{c}\text { In situ + Thermal } \\
\text { Crown }\end{array}$ & $\begin{array}{c}\text { Sidewall* } \\
\text { Bolts } \\
\text { Bolts }\end{array}$ & $\begin{array}{c}\text { Crown } \\
\text { Bolts }\end{array}$ & $\begin{array}{c}\text { Sidewall } \\
\text { Bolts }\end{array}$ \\
\hline 1 & 292 & 428 & 378 & 647 \\
\hline 2 & 234 & 140 & 310 & 303 \\
\hline 3 & 192 & -7 & 271 & 89 \\
\hline 4 & 156 & -23 & 236 & 41 \\
\hline 5 & 61 & -29 & 118 & 41 \\
\hline
\end{tabular}

The shotcrete loads are shown in Table 12-40 for in situ plus thermal and in situ plus thermal plus seismic. The stresses in the shotcrete at the crown are in excess of the shotcrete strength for all rock mass categories.

\subsubsection{Coupled Analysis}

Fully coupled analysis of rockbolt and shotcrete loads have been completed for a number of specific drifts, rock mass categories and loadings, but not for all combinations.

12.10.2.1 Rockbolt Loads Preliminary results for the elastic rock mass model indicated no significant difference between the uncoupled and coupled analysis for rockbolt loads. The compliant joint model produced similar uncoupled rockbolt loads to the elastic rock mass and hence little difference is expected from coupled bolt analysis with the CJM. The Mohr-Coulomb yield model produces larger deformations than the elastic analysis because of the dilation in the rock mass, and hence, larger loads in the rockbolts in the uncoupled analysis. Some modification of these bolt loads are expected with coupled analysis.

12.10.2.2 Shotcrete Loads Coupled analysis of the waste-emplacement drift using the three rock mass models (elastic, CIM and Mohr-Coulon:b) have been completed for rock mass Category 3 (the "poor" rock) for a 3-in. layer of shotcrete. In each case, the shotcrete was applied after 50\% the in situ stresses had been relieved. The numerical results of the lining stresses in the crown and rib 100 years after waste emplacement are listed in Tables 12-41,12-42, and 12-43. Listed in each table is the stress in the inner and outer element of the shotcrete liner and the estimate of liner stress from the uncoupled analysis. Good agreement between the coupled and uncoupled analysis is apparent for the elastic and CJM rock models, whereas a significant different exists for the elasto-plastic (Mohr-Coulomb) model. The shotcrete liner inhibits some yield and deformation, thereby resulting in lower shotcrete stresses than predicted by the uncoupled analysis. Coupled analysis is thus necessary for estimating shotcrete lining stresses when the rock response is characterized by a dilating elasto-plastic response of the rock mass. 
Table 12-40

PREDICTED SHOTCRETE LOADS (MPa), EMPLACEMENT DRIFT, UNCOUPLED ANALYSIS

\begin{tabular}{|c|c|c|c|c|c|}
\hline \multirow{2}{*}{$\begin{array}{c}\text { Rock Mass } \\
\text { Quality Category }\end{array}$} & \multirow{4}{*}{ RMR } & \multicolumn{4}{|c|}{ Load Type } \\
\cline { 2 - 6 } & & \multicolumn{2}{|c|}{ In situ + Thermal } & \multicolumn{2}{c|}{$\begin{array}{c}\text { In situ + Thermal + } \\
\text { Seismic }\end{array}$} \\
\cline { 2 - 6 } & Crown & Wall & Crown & Wall \\
\hline \hline 1 & 32.5 & 86 & 62 & 102 & 76 \\
\hline 2 & 42.1 & 89 & 30 & 100 & 47 \\
\hline 3 & 54.7 & 90 & -7 & 103 & 18 \\
\hline 4 & 69.2 & 87 & -8 & 101 & -9 \\
\hline 5 & 77.6 & 73 & -8 & 83 & -7 \\
\hline
\end{tabular}

Table 12-41

COMPARISON OF COUPLED AND UNCOUPLED SHOTCRETE

STRESSES FOR ELASTIC ROCK MASS

\begin{tabular}{||l|c|c|}
\hline \multirow{2}{*}{\multicolumn{1}{|c|}{ Type }} & \multicolumn{2}{|c|}{ Stress (MPa) } \\
\cline { 2 - 3 } & Crown & Rib \\
\hline \hline Coupled analysis, outer ring & 61.9 & -5.8 \\
\hline Coupled analysis, inner ring & 60.2 & -5.4 \\
\hline Uncoupled analysis & 62.0 & -6.0 \\
\hline
\end{tabular}


Table 12-42

COMPARISON OF COUPLED AND UNCOUPLED SHOTCRETE STRESSES FOR COMPLIANT JOINT ROCK MODEL

\begin{tabular}{|l|c|c|}
\hline \multirow{2}{*}{\multicolumn{1}{|c|}{ Type }} & \multicolumn{2}{|c|}{ Stress (MPa) } \\
\cline { 2 - 3 } & Crown & Rib \\
\hline \hline Coupled analysis, outer ring & 64.4 & -2.0 \\
\hline Coupled analysis, inner ring & 62.6 & -1.1 \\
\hline Uncoupled analysis & 67.0 & -2.8 \\
\hline
\end{tabular}

Table $12-43$

COMPARISON OF COUPLED AND UNCOUPLED SHOTCRETE STRESSES FOR MOHR-COULOMB ROCK MODEL

\begin{tabular}{||c|c|c|}
\hline \multirow{2}{*}{ Type } & \multicolumn{2}{|c|}{ Stress (MPa) } \\
\cline { 2 - 3 } & Crown & Rib \\
\hline Coupled analysis, outer ring & 69.6 & -2.7 \\
\hline Coupled analysis, inner ring & 68.0 & -2.3 \\
\hline Uncoupled analysis & 90.0 & -7.0 \\
\hline
\end{tabular}




\subsection{Final Design Evaluation}

The rockbolt and shotcrete stresses shown in the preceding sections exceed the allowable stress levels in most cases. For the shotcrete, the allowable stress for the tuff main drift would be 13.7 $\mathrm{MPa}(2000 \mathrm{psi})$ for in situ plus thermal loadings and $15.3 \mathrm{MPa}(2200 \mathrm{psi})$ for in situ plus thermal plus seismic. For the typical schedule 60 rockbolts with a yield strength of $410 \mathrm{MPa}$ $(60,000 \mathrm{psi})$, the allowable stress is $230 \mathrm{MPa}(33,000 \mathrm{psi})$ for the tuff main drift, $240 \mathrm{MPa}(35,00)$ psi) for the emplacement and midpanel access drifts under in sita plus thermal loads, and $275 \mathrm{MPa}$ $(40,000 \mathrm{psi})$ or $295 \mathrm{MPa}(43,000 \mathrm{psi})$ when acted on by the in situ plus thermal plus seismic stresses.

The rockbolt stresses can be relieved by designing yielding bolts or soft bolts with spring components. Analysis of bolt stresses induced in fully bonded bolts show that the strength of the bolts would be exceeded in the region closest to the drift perimeter, suggesting that fully bonded bolts would be inappropriate. Averaging the rock strains over the bolt length reduces the effect of the locally high strains. The use of conventional shotcrete appears unacceptable from the information presented in Tables 12-36, 12-38, and 12-40. Preliminary evaluation of alternate shotcrete mix designs, such as low modulus or low thermal expansion coefficient concretes, indicate that the low strengths associated with these specialized mixes would not meet the design requirements in the emplacement and midpanel access drifts. Hence, preliminary indications are that shotcrete/concrete would not be suitable for the emplacement or midpanel access drifts. In the tuff main drift where temperature increase in the shotcrete is not significant, specialized high-strength or reinforced shotcrete may be acceptable.

Recognizing the above, the ground suppurt components listed in Table 12-44 were selected as examples that meet the empirical and numerical requirements identified in Part $\mathrm{A}$ of the methodology and the constraints indicated by the analysis of the drift and ground support/rock reinforcement system in Part B (i.e., no shotcrete/concrete in the emplacement and midpanel access drifts). Bolt diameters and the bolt sled were selected to have a minimum bolt spacing of $0.9 \mathrm{~m}$. Clearly, other combinations of bolt diameters, spacings, and steel strengths can be selected to provide the required support pressure.

Further detailed design and analysis is required before this preliminary design example would be complete. Detailed design is required of bolt anchors, plates and connections with straps, mesh, and cable. Design analysis using the CJM with lower joint strengths near the drift perimeter is required. 


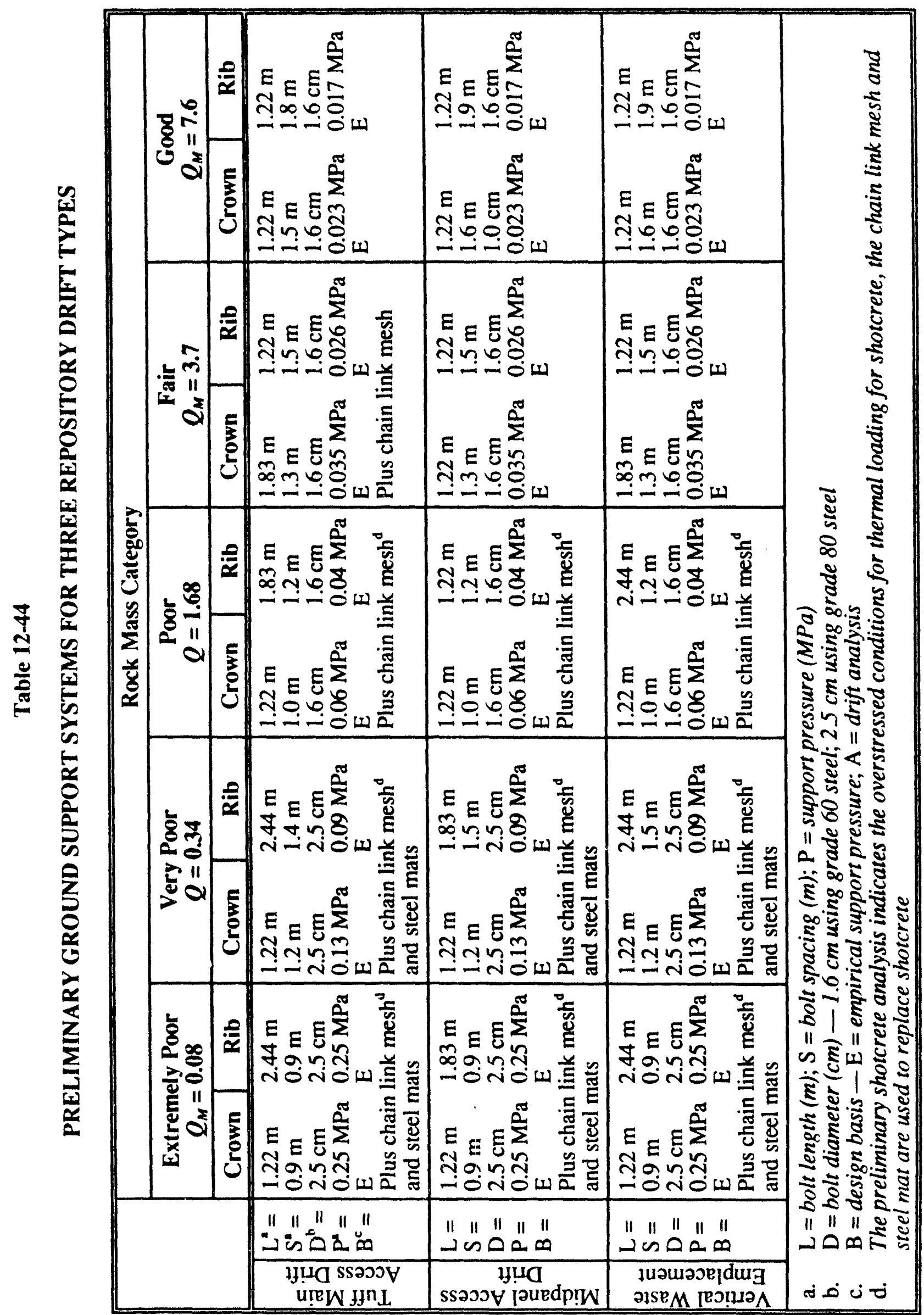




\subsection{REFERENCES}

Barton, N., Modeling Rock Joint Behavior for In-Situ Block Tests: Implications for Nuclear Waste Repository Design (Office of Nuclear Waste Isolation, Report No. ONWI-308, September, 1982). (HQS.880517.2252)

Barton, N., Rock Mass Quality and Support Recommendations for Basalt at the Candidate Repository Horizon. Based on the O-System (Richland, WA: Terra Tek Engineering for Rockwell Hanford Operations, Report No. SD-BWI-ER-012, Revision 1, 1984). (NNA.910412.0002)

Barton, N., R. Lien, and J. Lunde, "Engineering Classification of Rock Masses for the Design of Tunnel Support," Rock Mechanics, 6:189-236 (Springer Verlag, 1974). (NNA.870406.0237)

Barton, N., F. Loset, R. Lien, and J. Lunde, "Application of Q System in Design Decisions Concerning Dimensions and Appropriate Support for Underground Installations," Proceedings. International Conference on Subsurface Space. Rockstore, 2:553-561 (Stockholm, Sweden: Pergamon Press, 1980). (NNA.900404.0197)

Bauer, S. J., J. F. Holland, and D. K. Parrish, "Implications About In-Situ Stress at Yucca Mountain," Proceedings, 26th U. S. Symposium on Rock Mechanics. Rapid City. SD (A. A. Balkema, June, 1985a). (HQS.880517.1611)

Bauer, S. J., R. K. Thomas, and L. M. Ford, "Measurements and Calculation of the Mechanical Response of a Highly Frac.ured Rock," Proceedings, 26th U. S. Symposium on Rock Mechanics. Research and Engineering Application in Rock Masses. South Dakota School of Mines and Technology, Rapid City, SD (A. A. Balkema, 1985b). (HQS.880517.2255)

Bieniawski, Z. T., "Engineering Classification of Jointed Rock Masses," Transactions, South African Institution of Civil Engineers, 15(12):335-343 (np, 1973). (NNA.900917.0121)

Bieniawski, Z. T., "Rock Mass Classification in Rock Engineering," Proceedings, Symposium on Exploration for Rock Engineering, Johannesburg, South Africa, pp. 97-106 (A. A. Balkema, November, 1976). (NNA.870406.0217)

Bieniawski, Z. T., "The Geomechanics Classification in Rock Engineering Applications," Proceedings. 4th International Congress on Rock Mechanics. Montreaux. Switzerland, 2:41-48 (A. A. Balkema, 1979). (NNA.900404.0198)

Biffle, J. H., JAC-A Two-Dimensional Finite Element Computer Program for the Non-Linear Quasistatic Response of Solids with the Conjugate Gradient Method (Albuquerque, NM and Livermore, CA: SAND81-0998, Sandia National Laboratories, April, 1984). (HQS.880517.2257)

Blanford, M. L., and S. W. Key, "The Joint Empirical Model — An Equivalent Continuum Model for Jointed Rock Model" (Albuquerque, NM: SAND87-7072, Sandia National Laboratories, 1980). (NNA.910416.0046)

Borg, T., B. Leijon, K. Roshoff and O. Stephansson, "Stability Prediction for the Zinkgruvan Mine, Central Sweden," E. T. Brown and J. A. Hudson, eds., ISRM Symposium, Design and Performance of Underground Excavations, pp. 113-121 (British Geotechnical Society, 1984). (NNA.900404.0199)

Brady, B. H. G., and J. W. Bray, "The Boundary-Element Method for Determining Stresses and Displacements Around Long Openings in a Triaxial Stress Field," International Journal of Rock Mechanics and Mining Science, 15:21-28 (Pergamon Press, 1978). (NNA.900404.0200) 
Brown, E. T., "Strength of Models of Rock with Intermittent Joints," Juurnal of the Soil Mechanics and Foundation Division, 96(SM6):1935-1949, 1971. (NNA.89 1222.0017)

Brown, E. T., and D. H. Trollope, "The Failure of Linear Brittle Materials Under Effective Tensile Stress," Rock Mechanics Engineering Geology, V:229-241, 1967. (NNA.900420.0089)

Chen, E. P., "Two-Dimensional Continuum Model for Jointed Media with Orthogonal Sets of Joints," Proceedings, 27th U.S. Symposium on Rock Mechanics. University of Alabama, pp. 862-867 (SME/AIME, 1986). (NNA.891109.0126)

Chen, E. P., A Computation Model for Jointed Media with Orthogonal Sets of Joints (Albuquerque, NM: SAND86-1122, Sandia National Laboratories, 1987). (NNA.891020.0180)

Chen, E. P., A Constitutive Model for Jointed Rock Mass with Two Intersecting Sets of Joints (Albuquerque, NM: SAlND89-0592, Sandia National Laboratories, March, 1990). (NNA.900521.0129)

Costin, L. S., and S. J. Bauer, Yucca Mountain Project Thermal and Mechanical Codes First Benchmark Exercise Part III: Jointed Rock Mass Analysis (Albuquerque, NM: SAND891639, Sandia National Laboratories, 1991). (NNA.910925.0059)

Costin, L. S., and E. P. Chen, "An Analysis of the G-Tunnel Heated Block Experiment Using a Complaint Joint Rock-Mass Model," Proceedings, 29th U. S. Symposium. Key Questions in Rock Mechanics. University of Minnesota. Minneapolis (A. A. Balkema, 1988). (NNA.891013.0217)

Crouch, S. L., Analysis of Stresses and Displacements Around Underground Excavations: An Application of the Displacement Discontinuity Method (Minnesota: University of Minnesota, 1976). (NNA.900515.0017)

Cummings, R. A., F. S. Kendorski, and Z. T. Bieniawski, Caving Mine Rock Mass Classification and Support Estimation, p. 195 (U. S. Bureau of Mines Contract No. J0100103, Engineers International, 1982). (NNA.900727.0303)

Cundall, P. A., UDEC - A Generalized Distinct Element Program for Modelling Jointed Rock (U.S. Army Contract No. DAJA37-79-C-0548, European Research Office, 1980). (NNA.900404.0201)

Cundall, P. A., and R. D. Hart, Analysis of Block Test No. 1 Inelastic Rock Mass Behavior Phase 2. A Characterization of Joint Behavior (Itasca Consulting Group, Inc. prepared for Rock Hanford Operations, Richland Washington, 1984). (NWA.900420.0088)

Deere, D. U., A. Hendron, F. D. Patton, and E. J. Cording, "Design of Surface and Near Surface Construction in Rock," C. Farnhurst, ed., Proceedings. 8th U. S. Symposium on Rock Mechanics. Failure and Breakage of Rock. Minneapolis. Minnesota. September. 1966, pip. 237-302 (Baltimore, MD: Port City Press, Inc., 1967). (NNA.900404.0202)

DOE (U. S. Department of Energy), Site Characterization Plan. Yucca Mountain Site Nevada Research and Development Area.Nevada (DOE/RW-0199, Chapter 8, 1988). (HQO.881201.0002)

DOE (U. S. Department of Energy), Yucca Mountain Project Reference Information Base, Version 4 (Las Vegas, NV: YMP/CC-0002, Nevada Operations Office, February, 1989). (NNA.890330.0077) 
Dowding, C. H. and A. Rozen, "Damage to Rock Tunnels from Earthquake Shaking" Journal of Geotechnical Engineering. Division of American Society of Civil Engincers, 104 (GT2): 175-191, 1978. (NNA.9()()405.()()()6)

Dravo Engineers, Inc., Effect of Variation in the Geologic Dala Base on Mining at Yuccal Mountain for NNWSI (Albuquerrue, NM: SAND84-7125, Sandia National Laboratories, 1984). (HQS.880517.2283)

Einstein, H. H., W. Steiner, and G. B. Baecher, "Assessment of Empirical Design Methods for Tunnels in Rock," A. Maevis and W. Hustrulid, eds., Proceedings, 1979 Rapid Excavation and Tunneling Conference, 1:683-706 (Baltimore, MD: Port City Press, Inc., 1979). (NNA.900720.0037)

Gaylord, E. H., Jr. and C. N. Gaylord, Design of Steel Structures, p. 23 (New York, NY: McGraw-Hill Book Company, Inc., 1957). (NNA.901005.0(034)

Gerrard, C. M., "Elastic Models of Rock Masses Having One, Two and Three Sets of Joints," International Journal of Rock Mechanics and Mining Science \& Geomechanics Abstracts, 19:15-23, [MF 3221; V; C-61] (Pergamon Press, 1982). (NNA.900404.0203)

Hendron, A., and G. Fernandez, "Dynamic and Static Design Considerations for Underground Chambers," T. R. Howard, ed., Proceedings, Symposium on Seismic Design of Embankments and Caverns, pp. 157-197 (ASCE, 1983). (NNA.890522.0247)

Hoek, E., "Geotechnical Design of Large Openings at Depth," Proceedings, Rapid Excavation \& Tunnel Conference, 2:1167-1180 (New York, NY: AIME, 1981). (NNA.900403.0380)

Hoek, E., and E. T. Brown, Underground Excavations in Rock, pp. 132 and 527 (London, England: Institution of Mining and Metallurgy, 1980). (NNA.891208.0052)

Hoek, E., and E. T. Brown, "The Hoek-Brown Failure Criterion- 91988 Update," Canadian Rock Mechanics Symposium (np, 1988). (NNA.900515.0018)

Hognestad, E., N. W. Hanson, and D. McHenry, "Concrete Stress Distribution in Ultimate Strength Design," ACl Journal. Proceedings, 52:455-479 (np, December, 1955). (NNA.900403.0398)

Hudson, J. A. and S. D. Priest, "Discontinuities and Rock Mass Geometry," Intermational Journal of Rock Mechanics. Mining Science and Geomechanics Abstracts, 16:339-362 (Pergamon Press, 1979). (NNA.900403.0399)

Johnstone, J. Keith, R. R. Peters, and P. F. Gnirk, Unit Evaluation of Yucca Mountain, Nevada Test Site: Summary Report and Recommendation (Albuquerque, NM: SAND83-(0372, Sandia National Laboratories, June, 1984). (NNA.870519.0052)

Kendorski, F. S., R. A. Cummings, Z. T. Bieniawski, and E. H. Skinner, "Rock Mass Classification for Block Caving Mine Drift Support," Proceedings, 15th International Congress on Rock Mechanics, pp. B101-113 (Melbourne, Australia: ISRM, 1983). (NNA.900403.0(27)

Lang, T. A., "Theory and Practice of Rock Bolting," Transactions, Society of Mining Engineers. American Institute of Mining, Metallurgy. Petroleum Engineering, 22():333-348 (np, 1961). (NNA.900403.04(K))

Langkopf, B. S., and P. R. Gnirk, Rock-Mass Classification of Candidate Repository Units at Yucca Mountain, Nye County, Nevada (Albuquerque, NM: SAND82-2034, Sandia National Laboratories, 1986). (HQS.880517.1662) 
Laubscher, D. H., "Design Aspects and Effectiveness of Support Systems in Different Mining Conditions, Transactions, Section A, Institution of Mining and Metallurgy, Vol. 93 (Institution of Mining and Metallurgy, April, 1984). (NNA.9)()129.(05.53)

Mattock, A. H., L. B. Kriz, and E. Hognestad, "Rectangular Concrete Stress Distribution in Ultimate Strength Design," $\mathrm{ACI}$ Journal, Proceedings, 57(8):875-925 (np, February, 1961). (NNA.9()()403.(04()4)

Michelis, P. and E. T. Brown, "A Yield Equation for Rock," Canadian Geotechnical Journal, 23:9-17 (np, 1986). (NNA.9010(05.0(0)31)

Newmark, N. M., and W. J. Hall, Development of Criteria for Seismic Review of Selected Nuclear Power Plans (Washington, DC: NUREG/CR-0098, U. S. Nuclear Regulatory Commission, September, 1977). (NNA.890327.0045)

Nimick, F. B., R. G. V. Buskirk, and A. F. McFarland, Uniaxial and Triaxial Compression Test Series on the Topopah Spring Member from USW G-2, Yucca Mountain, Nevada (Albuquerque, NM: SAND85-(0703, Sandia National Laboratories, 1987). (NNA.891019.(0289)

Owens, G. N. and R. E. Scholl, Earthquake Engineering of Large Underground Structures (San Francisco: JAB-7821, URS/John A. Blume, 1981). (NNA.870406.0151)

PBQD (Parsons Brinckerhoff Quade \& Douglas, Inc.), "Preliminary Shaft Design Criteria and Methodology Guide" (Albuquerque, NM: SAND88-7060), Sandia National Laboratories, 1990). (NNA.9()0305.0001)

Price, R. H., Analysis of Rock Mechanics Properties of Volcanic Tuff Units from Yucca Mountain, Nevada Test Site (Albuquerque, NM: SAND82-1315, Sandia National Laboratories, 1983). (NNA.870406.0181)

Price, R. H., Effects of Sample Size on the Mechanical Behavior of Topopah Spring Tuff (Albuquerque, NM: SAND85-()709, Sandia National Liaboraturies, August, 1986). (HQS.88(0517.1696)

Price, R. H., J. R. Connolly, and K. Keil, Petrologic and Mechanical Properties of Outcrop Samples of the Welded, Devitrified Topopah Spring Member of the Paintbrush Tuff (Albuquerque, NM: SAND86-1131, Sandia National Laboratories, 1987). (HQS.880517.17()4)

Price, R. H., S. J. Spena, and A. K. Jones, Uniaxial Compression Test Series on Topopah Spring Tuff from USW GU-3, Yucca Mountain, Southern Nevada (Albuquerque, NM: SAND83-1646, Sandia National Laboratories, 1984). (NNA.870406.0252)

SNI, (Sandia National Laboratories), Nevada Nuclear Waste Storage Investigations Project, Site Characterization Plan Conceptual Design Report, compiled by H. R. MacDougall, L. IV. Scully, and J. R. Tillerson (Albuquerque, NM: SAND84-2641, Sandia National Laboratories, 1987). (NNI.880902.0(014-.0019)

SNL (Sandia National Laboratories), Working Group Report, Exploratory Shaft Seismic Design Basis, Yucca Mountain Project, Compiled by C. V. Subramanian, et al. (Albuquerque, NM: SAND88-1203, Sandia National L aboratories, April, 1990). (NN.A.90(09()2.0014-.(0)19)

St. John, C. M., Reference Thermal and Thermal/Mechanical Analyses of Drifts for Vertical and Horizontal Emplacement of Nuclear Waste in a Repository in Tuff (Albuquerque, NM: SAND86-7()(5.), Sandia National Laboratories, 1987a). (HQS.88()517.2342) 
St. John, C. M., Investigative Study of the Underground Excavations for a Nuclear Waste Repository in Tuff (Albuquerque, NM: SAND83-7451, Sandia National Laboratories, 1987b). (NNA.891027.0219)

St. John, C. M., and T. F. Zahrah, "Aseismic Design of Underground Structures," Tunneling and Underground Space Technology, 2(2):165-197 (Pergamon Journals, Ltd., 1987). (NNA.900308.0326)

Schmidt, B., "Learning From Nuclear Waste Repository Design: The Ground-Control Plan," VI Austra.ian Tunnelling Conference, 1:11-19 (Victoria, Australia: The Australian Institute of Mining and Metallurgy, March., 1987). (NNA.900403.0401)

Serafim, J. L. and J. P. Periera, "Consideration of the Geomechanics Classification of Bieniawski," Proceedings. International Symposium on Engineering Geology and Underground Construction, 1133-1144 (np, 1983). (NNA.910327.0063)

Singh, B., "Continuum Characterization of Jointed Rock Masses, Part I - The Constitutive Equations," International Journal of Rock Mechanics and Mining Sciences \& Geomechanics Abstracts, 10(4):311-335 [MF 3215; V; C-6] (Pergamon Press, 1973). (NNA.900308.0331)

Stacey, T. R., "A Simple Extension Strain Criterion for Fracture of Brittle Rock," International Journal of Rock Mechanics and Mining Sciences \& Geomechanics Abstracts, 18(6):469-474 (Pergamon Press, 1981). (NNA.900212.0009)

Stinebaugh, R. E. and J. C. Frostenson, Disposal of Radioactive Waste Packages in Vertical Boreholes - A Description of the Operations and Equipment for Emplacement and Retrieval (Albuquerque, NM: SAND84-1010, Sandia National Laboratories, 1986). (HQS.880517.2878)

Terzaghi, K., "Rock Defects and Loads on Tunnel Supports," Proctor and White, eds., Rock Tunneling with Steel Supports, pp. 15-99 (Youngstown, OH: Commercial Shearing Co., 1946). (NNA.900919.0176)

Terzaghi, R. D., "Sources of Error in Joint Surveys," Geotechnique, 15:287-304 (np, 1965). $(N \times A .9(K) 403.0402)$

Thomas, R. K., A Continuum Description for Jointed Media (Albuquerque, NM: SAND81-2615, Sandia National Laboratories, 1982). (HQS.880517.1714)

Ushijima, R. S., and H. H. Einstein, "Application of a Three-Dimensional Coupled Finite Element-Boundary Element Method," Dowding, C. H., ed., Proceedings. Rock Masses: Modeling of Underground Openings/Probability of Slope Failure/Fracture of Intact Rock. Denver. Colorado, pp. 21-37 (ASCE, April 29-30, 1985). (NNA.900403.0403)

Wickham, G. E., H. R. Tiedeman and E. H. Skinner, "Support Determinations Based on Geologic Predictions," Proceedings, Rapid Excavation \& Tunneling Conference, 1:43-64 (np, 1972). (NNA.900404.0204)

Yudhbir, W. Lemonza, and F. Prinzl, "An Empirical Failure Criterion for Rock Masses," 5 th International Congress on Rock Mechanics, pp. B1-B8 (Melbourne, Australia: ISRM, 1983). (NNA.900123.0087)

Zimmerman, R. M., M. P. Board, E. L. Hardin, and M. D. Voegele, "Ambient Temperature Testing of the G-Tunnel Heated Block," Proceedings, 25th Symposium on Rock Mechanics. Rock Mechanics in Productivity and Protection, Northwestern University, Evanston, IL (New York, NY: SME, 1984). (HQS.880517.1721) 


\section{APPENDIX A}

\section{MAXIMUM ALLOWABLE COMPRESSIVE STRAIN}

\section{A.1 Introruction}

In application of the elasto-plastic continuum model to drift design in tuff, a limit on the compressive strain has been proposed. This limit is proposed based on similarities in the design approach to that found in the American Concrete Institute (ACI), Building Code Requirements for Reinforced Concrete ACI 318-37 Design Assumptions, Section 10.2.3. This appendix summarizes the background for the ACI strain criteria, data from laboratory tests on tuff, and reviews the expected strain around an emplacement drift based on the elasto-plastic model proposed for drift design in tuff.

\section{A.2 Concrete Ultimate Compressive Strain}

The ACI Code 318-37, Section 10.2.2, specifies that the maximum usable strain at the extreme concrete compresion fiber for design of members for flexure and axial load shall be assumed equal to 0.003 .

The design methodology applied to design of reinforced concrete members for flexure and axial loads assumes that the strain in the reinforcement steel and concrete is directly proportional to the distance from the neutral axis and that the relationship between stress and strain may be assumed rectangular, trapezoidal, parabolic, or any other shape that results in prediction of strength. in substantial agreement with results of compressive tests.

The Building Code Commentary 318-83 states that the maximum concrete compressive strain at crushing of concrete has been observed in tests of various kinds to vary from 0.003 to higher than 0.008 under special conditions. That claim is supported by test results for various concrete designs reported by Hognestad et al. (1955) and Mattock et al. (1961). Figure A-1 shows the stress-strain results for concrete from both flexure and compression tests from Hognestad, et al. (1955) and Figure A-2 shows ultimate strain test results as a function of compressive strength for three types of concrete tested in compression and flexure. The design maximum compressive strain is apparently independent of other strength variables for concrete.

\section{A-3 Ultimate Strain for Tuff}

It is unknown at this time if the concept of ultimate strain can be applied to drift design in tuff because the complete stress-strain curve for representative samples of tuff are not available. Existing laboratory uniaxial compressive-strength test data has been reviewed to evaluate the compressive behavior of tuff; additional compressive strain tests and preliminary flexure tests similar to those discussed by Hognestad et al. (1955) should be performed. These tests are similar to laterally constrained beam-flexure tests. The applicability of the laboratory results in developing an ultimate strain criteria for room-scale material behavior must be also assessed. It is expected that natural jointing would lower the strength and stiffness, but would not affect the ultimate strain as evident in the test results of strong and weak concretes.

Laboratory compressive tests on welded tuffs are reported by Price et al. (1984 and 1987), whereas results of compressive strain at failure for nonwelded tuffs are presented by Price (1983). Figure A-3 shows a plot of axial strain at failure as a function of grain density for nonwelded tuff. Nimick et al. (1987) indicates that the axial strain at failure for 14 samples of welded tuff from core from USW G-2 was $0.0051 \pm 0.001$. Table A- 1 ists the uitimate strain for four samples from the 


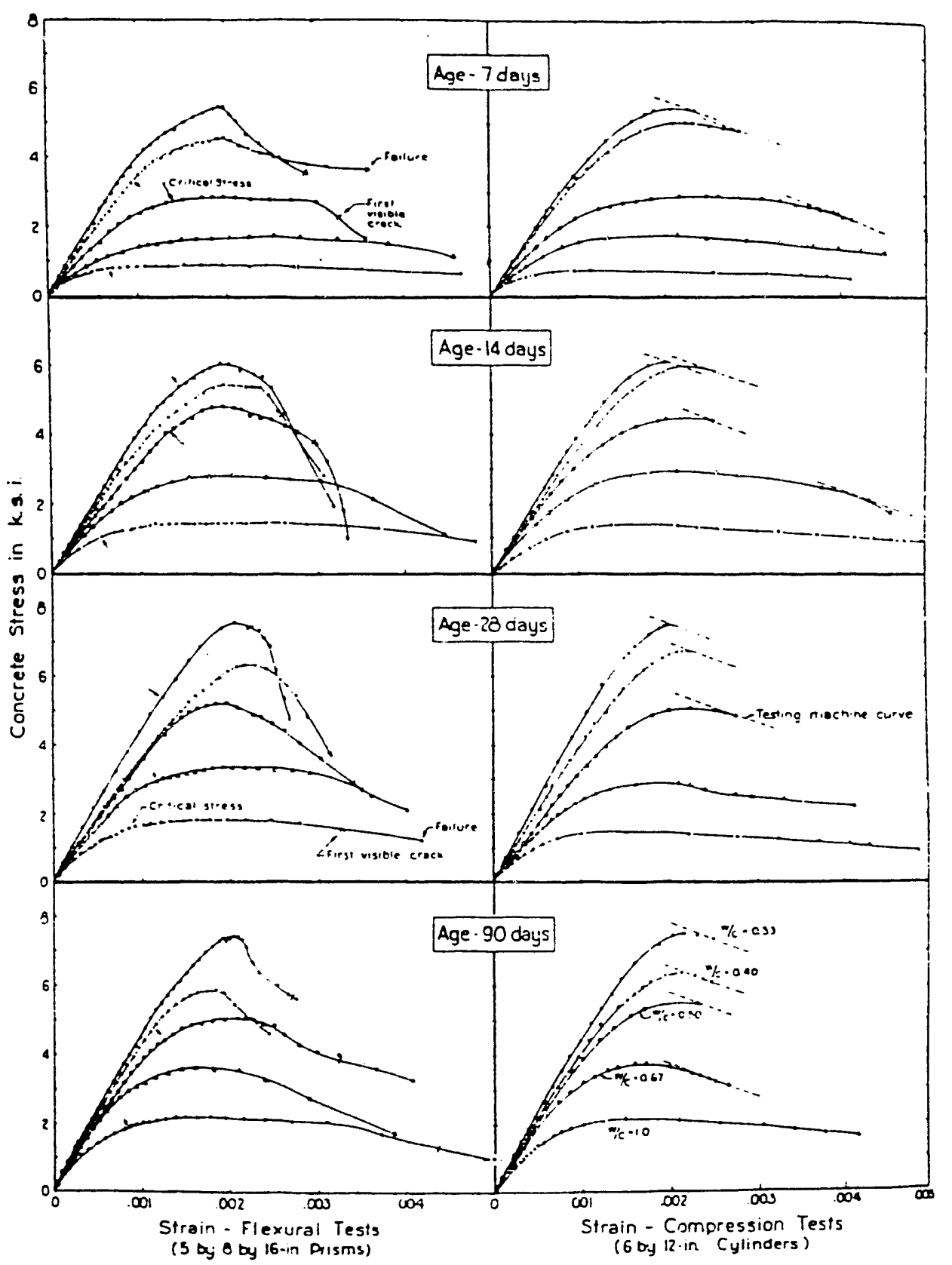

Figure A-1. Concrete Stress-Strain Relations (Hognestad at al., 1955) 


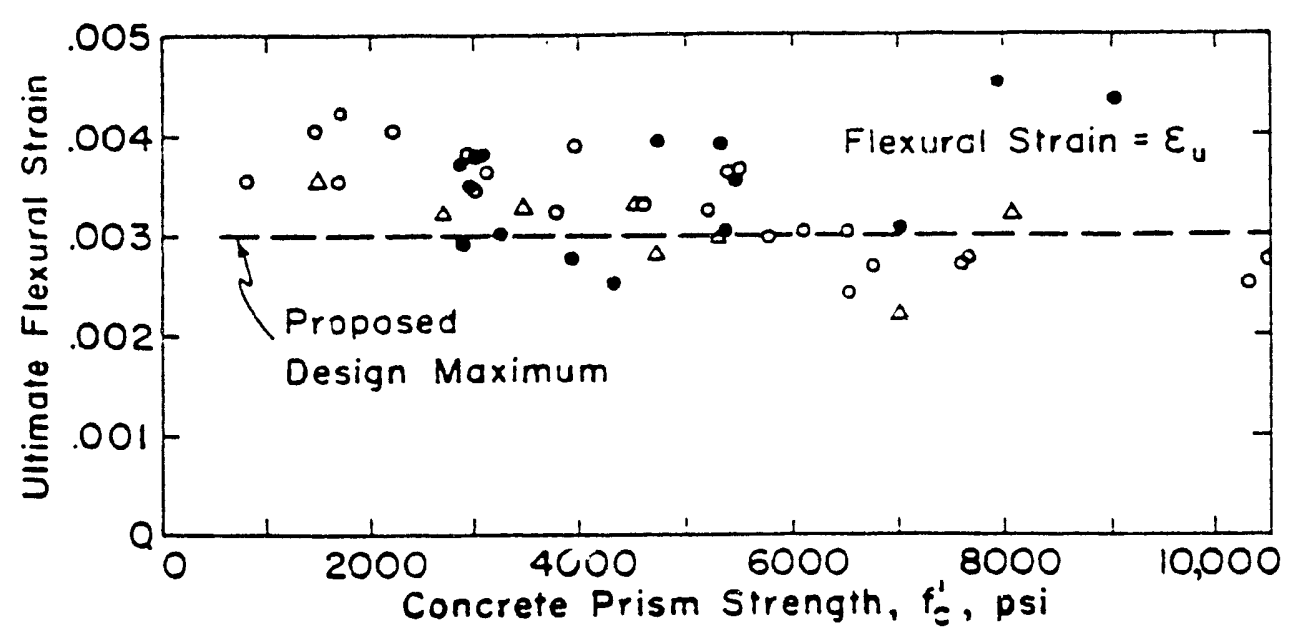

- Portland Cement Association Sand and Gravel

$\Delta$ Rusch's Tests

- Portland Cement Association Lightweight

Figure A-2. Ultimate Strain From Tests of Plain Concrete Specimens (Hognestad et al., 1955) 


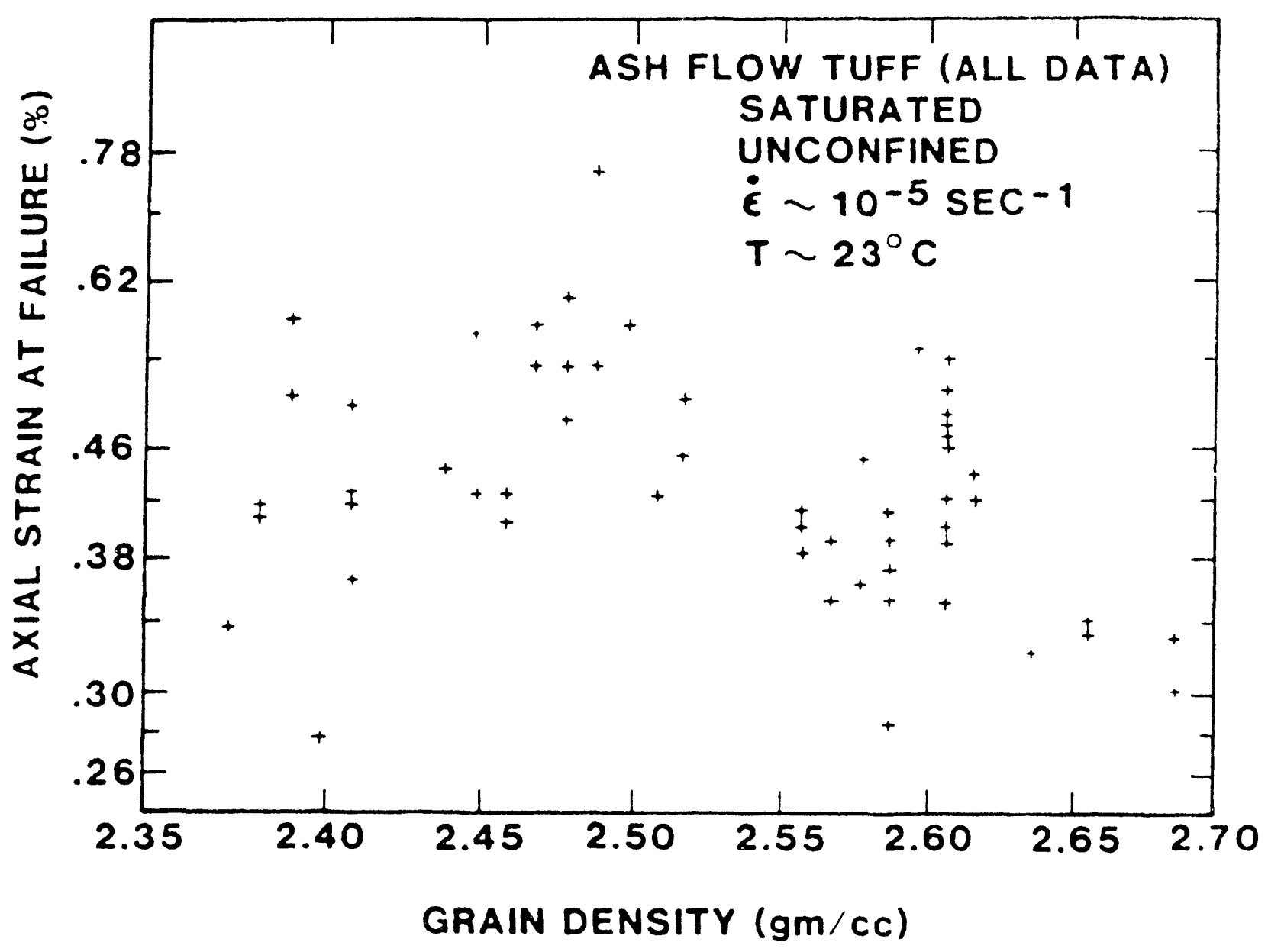

Figure A-3. Axial Strain at Failure as a Function of Grain Density for Nonwelded Tuff (Price, 1983) 
Table A-1

ULTIMATE STRAIN FOR WELDED TUFF

\begin{tabular}{||c|c|c|c|c||}
\hline Sample & $\begin{array}{c}\text { Ultimate } \\
\text { Strength } \\
(\mathbf{M P a})\end{array}$ & $\begin{array}{c}\text { Ultimate } \\
\text { Strain } \\
(\boldsymbol{\%})\end{array}$ & $\begin{array}{c}\text { Confining } \\
\text { Stress } \\
(\mathbf{M P a})\end{array}$ & Source \\
\hline \hline GU3 & 1501 & 0.85 & 0 & Price et al. (1984) \\
\hline $24 \mathrm{~W}$ & 166 & 0.68 & 0 & Price et al. (1987) \\
\hline $9 \mathrm{X}$ & 220 & 0.84 & 5 & Price et al. (1987) \\
\hline $43 \mathrm{~W}$ & 183 & 1.23 & 10 & Price et al. (1987) \\
\hline
\end{tabular}

Topopah Spring tuff. The ultimate strain is higher than the strain at failure, which is usually the strain at the maximum stress in the sample. The ultimate strain is poorly defined because the explosive failure of brittle rock is of ten dependent on the loading machine stiffness or control system. Nonetheless, the available results for welded intact tuff suggest that an ultimate strain higher than for concrete may be appropriate. For a fractured rock mass, the ultimate strain can be expected to be higher than the strain at failure for intact brittle rock. The value of $0.8 \%$ for the design ultimate strain is supported by the limited data currently available.

\section{A.4 Strain Around Emplacement Drift}

The results of analysis of an emplacement drift using elasto-plastic material behavior are presented. This analysis was completed as part of preliminary analyses related to development of this drift design methodology. The drift shape and emplacement configuration were based on the SCP-CDR design with the 8.55-year old waste emplacement at an APD of $57 \mathrm{~kW} / \mathrm{acre}$. The analyses assumed elasto-plastic characteristics for the "poor" rock type identified in Chapter 12 and used a nonassociated Mohr-Coulomb yield criteria. Figures A-4 through A-7 show the analytical results 100 years after emplacement for in situ plus thermal loading. Figures A-4 and A-5 show the principal stress magnitude contours, Figure A-6, the zone of yield.

The strain around the drift is shown in Figures A-7 through and A-9. The second invariant of total strain is plotted in Figure A-7, and in Figures A-8 and A-9, the principal compressive and tensile strains. The second invariant is equal to the square root of the sum of the squares of the principal strains and is typically larger than either component. The contours show that the maximum of the second invariant of strain around the drift is 0.077 . In this example, the maximum compressive strain is 0.003 , and the tensile strain is 0.006 . All three strains are less than the maximum allowed 0.008 for welded tuff. In the example application of the methodology, the second invariant of strain is used as the controlling criteria because it is always larger than either the compressive or tensile strain. Further study is recommended to assess the appropriate ultimate strain. The 0.008 would not be exceeded by this configuration. loading, and rock quality. 
EMPLACEMENT DRIFT, MOHR-COULOMB, POOR ROCK, INSITU+THERMAL PRINCIPAL STRESS, SIG 1

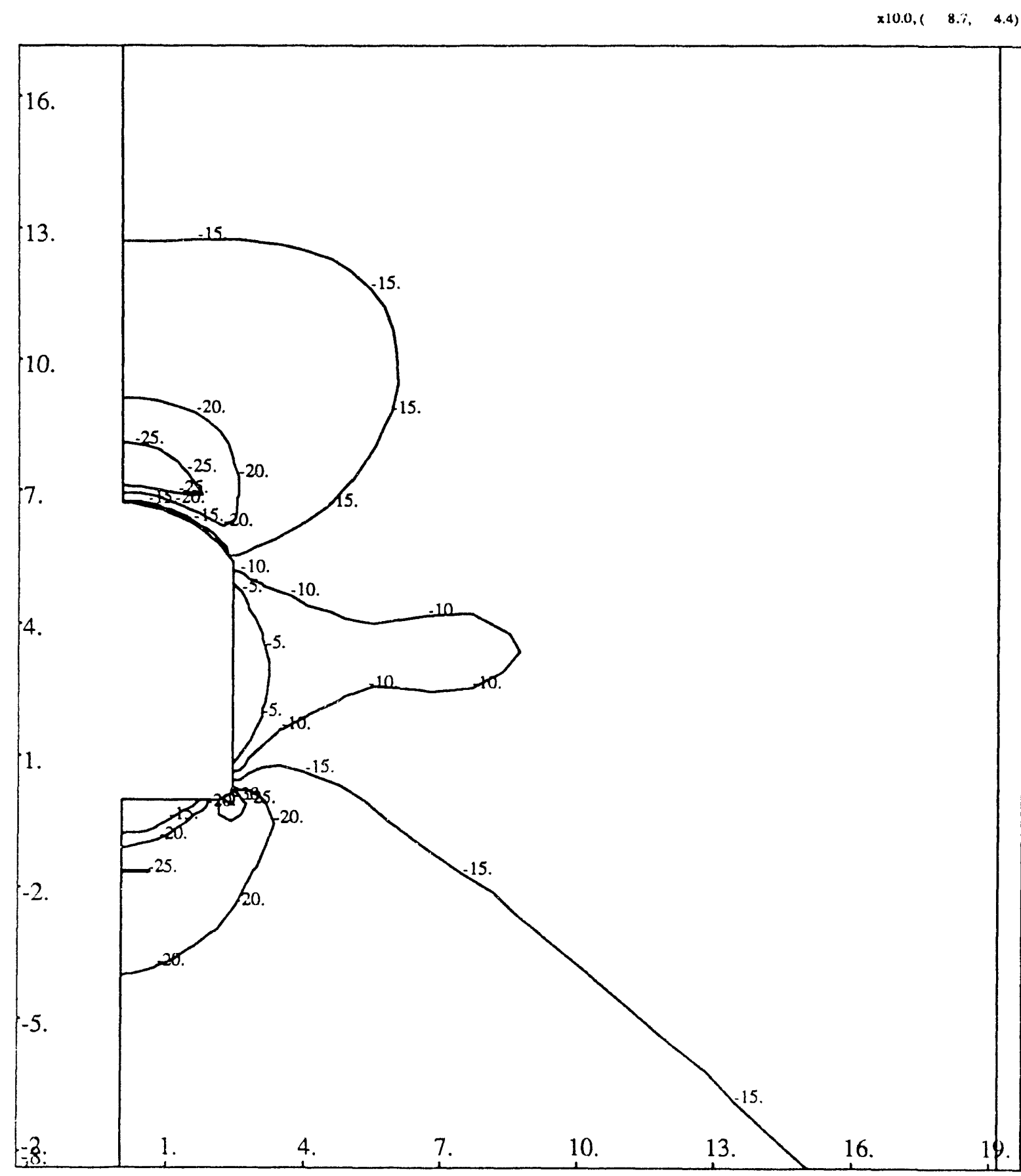

Minimum value is $\quad-34.91513$ Maximum value is $\quad-.54421$

POSTJAC, V5.0, DATE PLOTTED: $1 / 16 / 91$ FILE $=3 \mathrm{MC} 101-\mathrm{A} . \mathrm{UPL}$

Figure A-4. Maximum Principal Stress Around Emplacement Drift, Mohr-Coulomb Yield Surface, Poor Rock 
EMPLACEMENT DRIFT, MOHIR-COULOMB, POOR ROCK, INSITU+THERMAL PRINCIPAL STRESS, SIG $\angle$ STEP 4 TIME .1010E+03 $\times 10.0 .(8.7,4.4)$

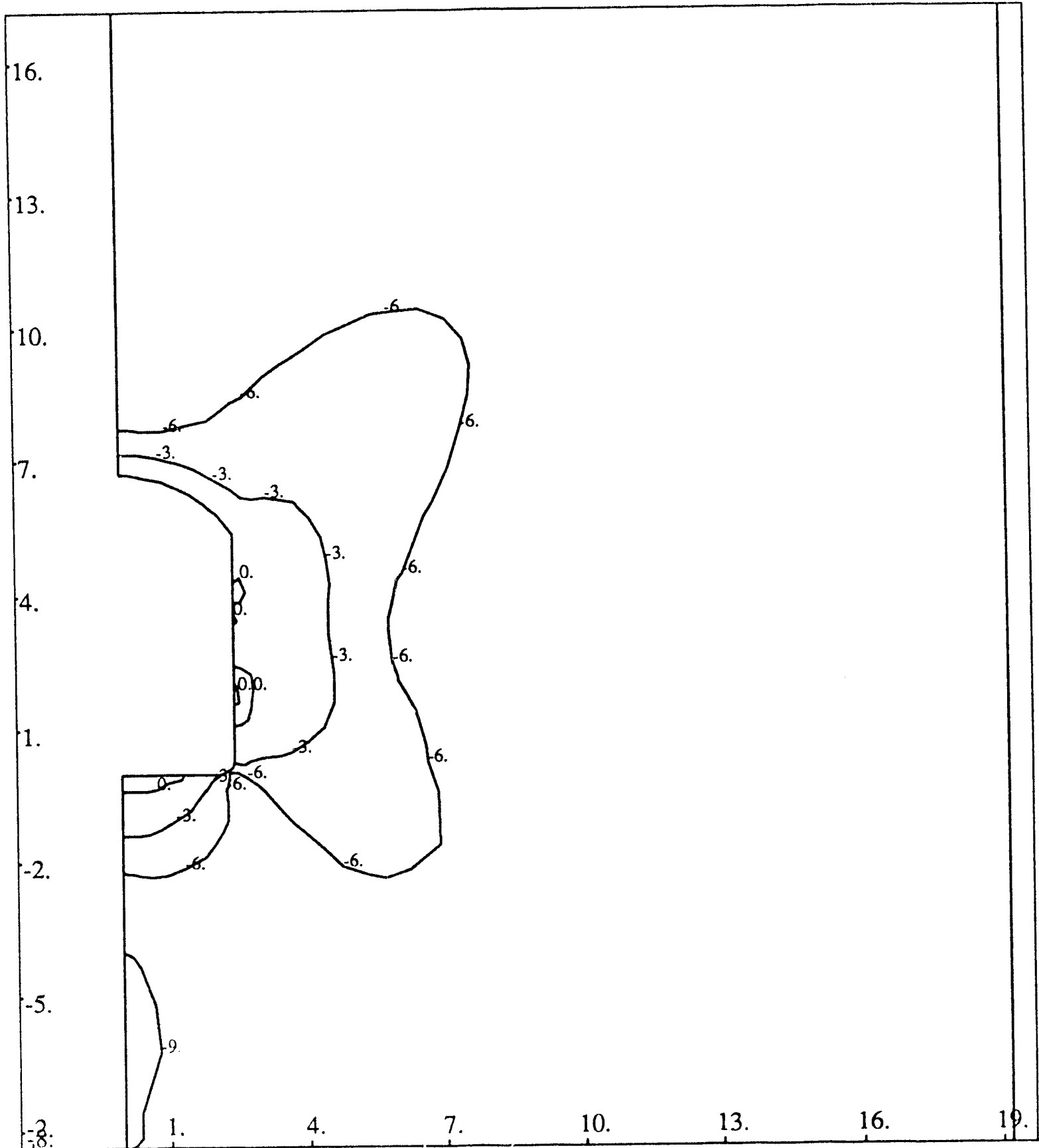

Minimum value is $\quad-9.57801$ Maximum value is $\quad .22911$

POSTJAC, V5.0, DATE PLOTTED: 1/16/91 FILE=3MC101-A.UPL

Figure A-5. Minimum Principal Stress Around Emplacement Drift, Mohr-Coulomb Yield Surface, Poor Rock 
EMPLACEMENT DRIFT, MOHR-COULOMB, POOR ROCK, INSITU+THERMAL

FAILED ELEMENTS

STEP 4 TIMIE .1010E+03

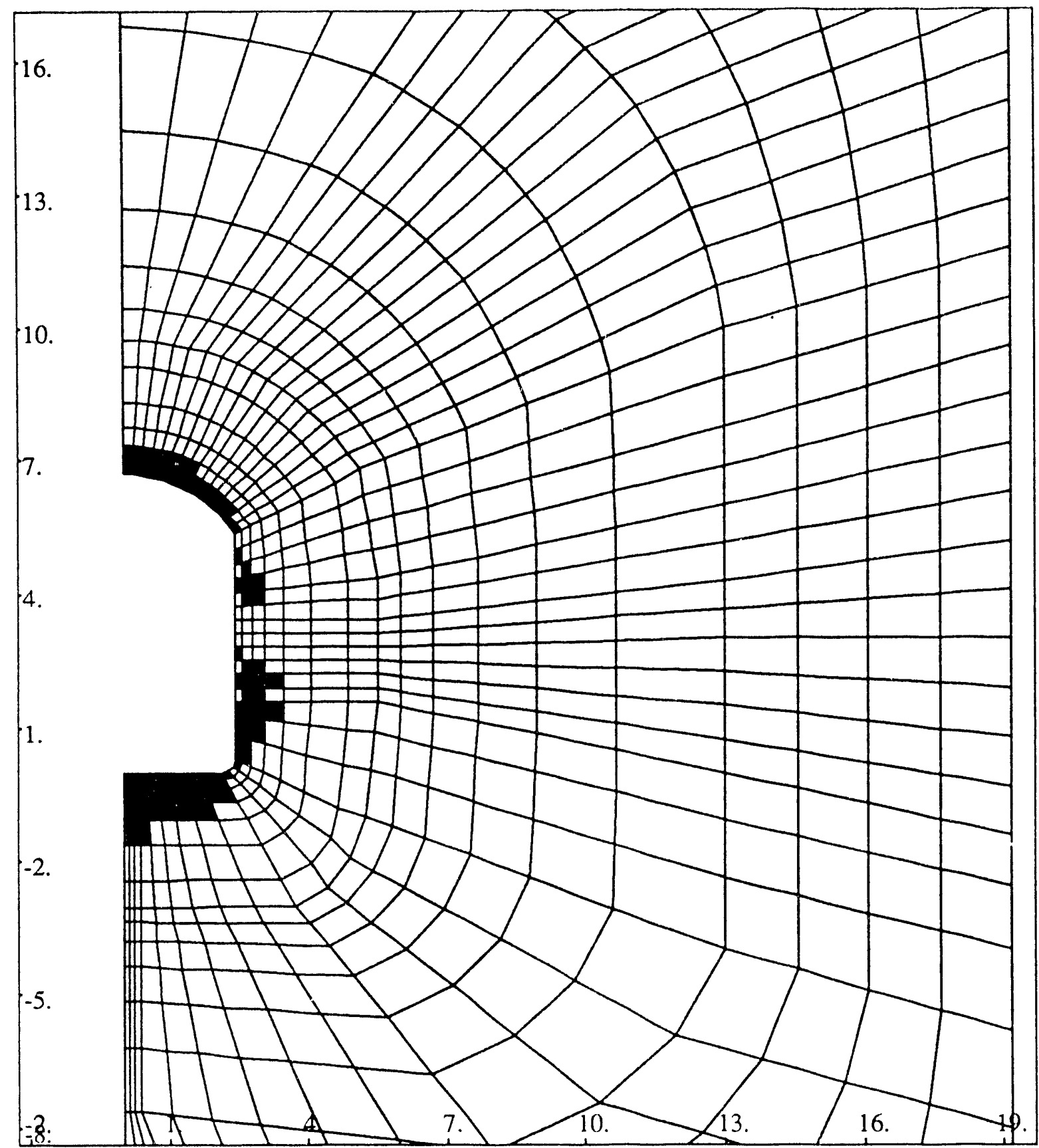

POSTJAC, V5.0, DATE PLOTTED: 1/16/91 FILE $=3 \mathrm{MC} 101-\mathrm{A}$. UPL

Figure A-6. Failed Zones Around Emplacement Drift, Mohr-Coulomb Yield Surface, Poor Rock 
EMPLACEMENT DRIFT, MOHR-COULOMB, POOR ROCK, INSITU+THERMAL SECOND INVARIANT OF TOTAL STRAIN

STEP 4 TIME $\quad .1010 \mathrm{E}+03$

ELASTIC MODULUS $=13110.0$, POISSON'S RATIO $=.22$

$\times 10.0 .($ 8.7, 4.4)

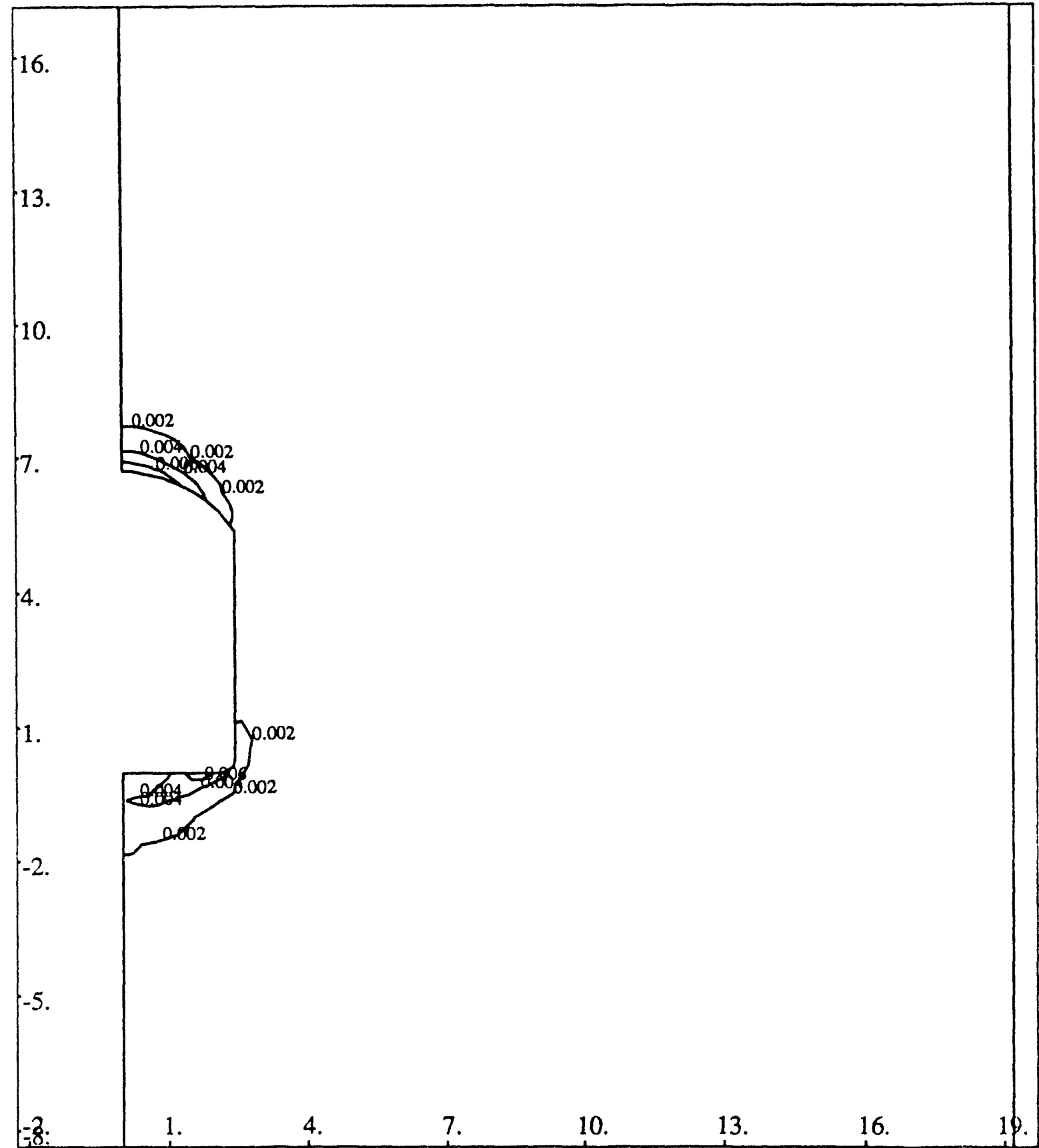

Minimum value is $\quad .00042$

Maximum value is $\quad .00767$

POSTJAC, V5.0, DATE PLOTTED: 1/16/91 FILE=3mc101-a.upl

Figure A-7. Second Invariant of Total Strain Around Emplacement Drift, Mohr-Coulomb Yield Surface, Poor Rock 
EMPLACEMENT DRIFT, MOHR-COULOMB, POOR ROCK (TENSILE AS POSITIVE) PRINCIPAL COMPRESSIVE STRAIN

STEP 4 TIME $.1010 E+03$

ELASTIC MODULUS $=13110.0$, POISSON'S RATIO $=.22$

$\times 10.0,(\quad 8.7,4.4)$

16.

13.

10.

7

4.

1.
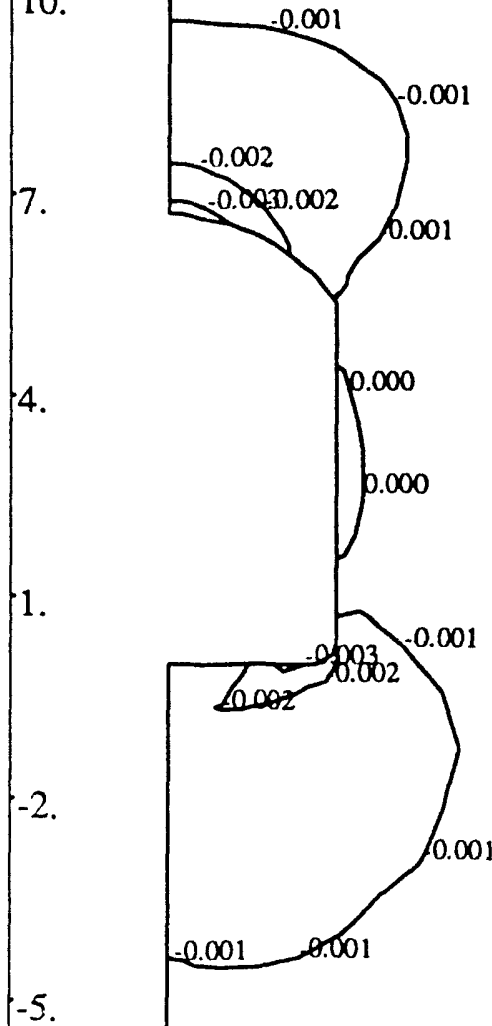

-5 .

-2. $\quad 1$.

7.

10.

13.

16.

Minimum value is $\quad-.00340$

Maximum value is $\quad .00015$

POSTJAC, V5.0, DATE PLOTTED: $1 / 16 / 91$ FILE $=3 \mathrm{MC} 101-\mathrm{A} . \mathrm{UPL}$

Figure A-8. Compressive Strain Around Emplacement Drift, Mohr-Coulomb Yield Surface, Poor Rock 
EMPLACEMENT DRIFT, MOHR-COULOMB, POOR ROCK (TENSILE AS POSITIVE) PRINCIPAL TENSILE STRAIN

ELASTIC MODULUS $=13110.0$, POISSON'S RATIO $=.22$

$\times 10.0 .(8.7,4.4)$

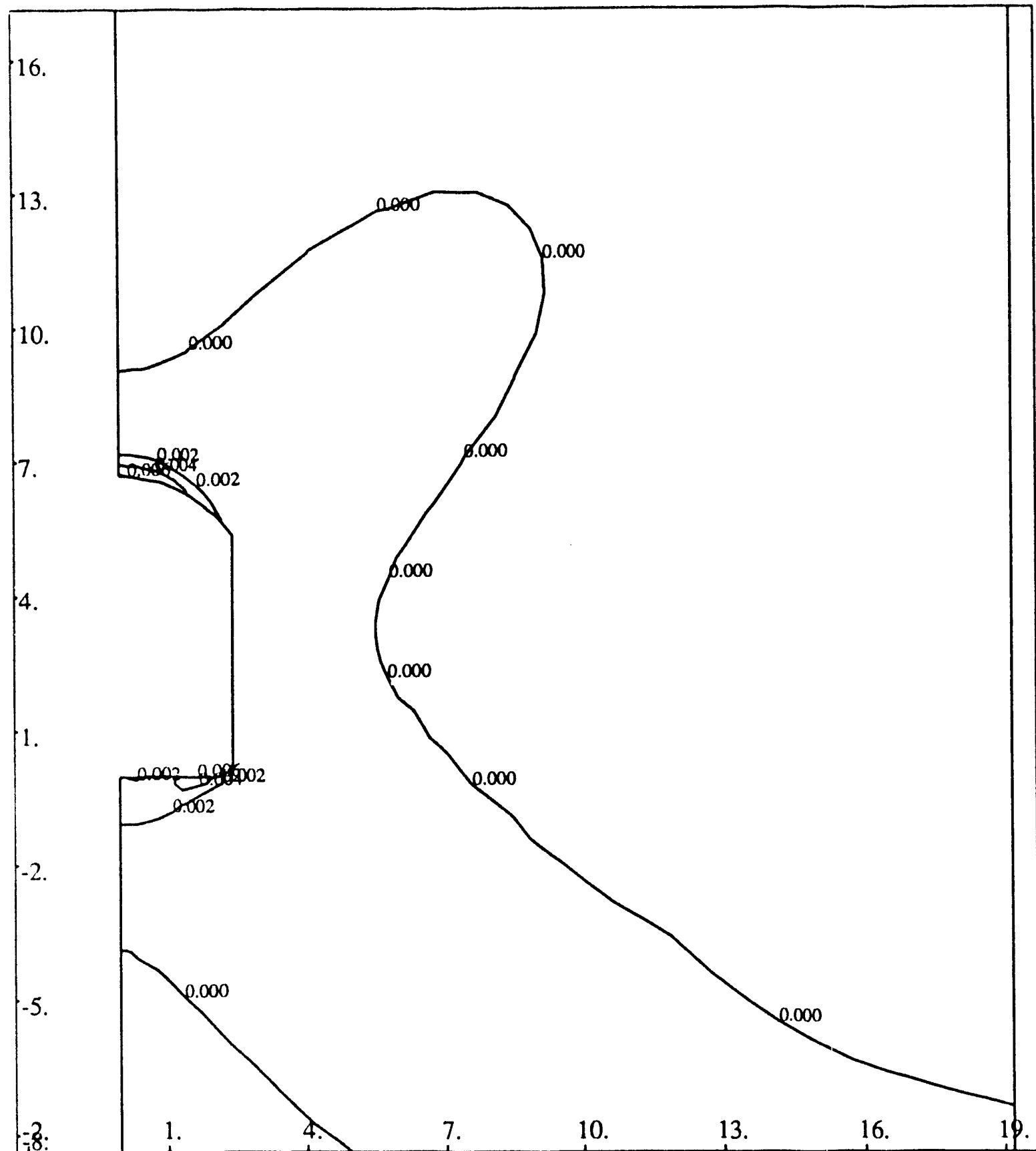

Minimum value is $\quad-.00035$

POSTJAC, V5.0, DATE PLOTTED: $1 / 16 / 91$

Maximum value is $\quad .00620$

FILE=3MC101-A.UPL

Figure A-9. Tensile Strain Around Emplacement Drift, Mohr-Coulomb Yield Surface, Poor Rock 


\section{APPENDIX B \\ REPOSITORY DRIFT PERFORMANCE USING COMPLIANT JOINT MODEI.}

\section{B.1 Introduction}

The Compliant Joint Model (CJM) of Chen (1987) has been applied in the analysis of the stresses and displacements around an emplacement drift as part of the preliminary application of the drift design methodology, with results summarized in Chapter 12. More detailed results for the poor rock quality category are provided here as an example of output of the analysis using this model.

\section{B.2 Problem Definition}

The problem analyzed corresponds to an emplacement drift for vertical waste emplacement described in the SCP-CDR (DOE, 1988), with an areal power density (APD) of $57 \mathrm{~kW} / \mathrm{acre}$. The material properties used are described in Chapter 12 for the poor rock; that is, the case for the $R M R=55$. Sixty percent of the rock is projected to have a higher RMR than the 55 value. The thermomechanical properties were temperature-dependent, the waste 8.55-years-old, the rock modulus $30.4 \mathrm{GPa}$, and the joint properties from Chapter 12 . The vertical joint strengths were cohesion 5.3 MPa, friction angle 23.1 degrees, and for the horizontal joints, cohesion $18.3 \mathrm{MPa}$, and friction angle 25.2 degrees. The joint maximum closure was $0.023 \mathrm{~m}$, and the shear stiffness, $400,600 \mathrm{MPa} / \mathrm{m}$ for both vertical and horizontal joints. Joint spacing was $0.060 \mathrm{~m}$ and $2.33 \mathrm{~m}$ for the vertical and horizontal joints, respectively. The joint half-closure stress was $1.4 \mathrm{MPa}$. The problem was run without strain hardening.

\section{B.3 Results of Analysis}

Figures B-1 through B-4 show analytical results for the conditions 100 years after waste emplacement. The 100-year case was chosen for example because it often, but not always, produces the most adverse stability conditions in the preclosure period. Shown are the contours of the two principal stresses, contours of rock matrix safety factors, and contours of the tensile strain. Figure B-3, the rock matrix strength/stress safety factors, indicates stable conditions. Figure B-4 shows contours of the tensile strain (as a percent) in the rock matrix. A very small area in the crown and floor exceeds the $0.04 \%$ limit indicating a limited zone of possible spalling. This zone should be easily supported by a minimal ground support system.

The slip along the joints is indicated in Figures B-5 through B-7. The first of these figures shows zones in which slip along joints is predicted. Figures B-6 and B-7 show contours of the absolute magnitude of the slip along Joints Set 1 (horizontal) and Joint Set 2 (vertical). For both joint sets, the slip is projected to be less than $0.01 \mathrm{~m}$. 
JAC ANALYSIS, 100 YEARS AFTER WASTE EMPLACEMENT, POOR ROCK

3J51-101, NO SHOTCR., RESTART, 51 YRS TO 101 YRS, ORTHOG. JOINTS

PRINCIPAL STRESS, SIG 1

STEP 11 TIME $.1010 \mathrm{E}+03$

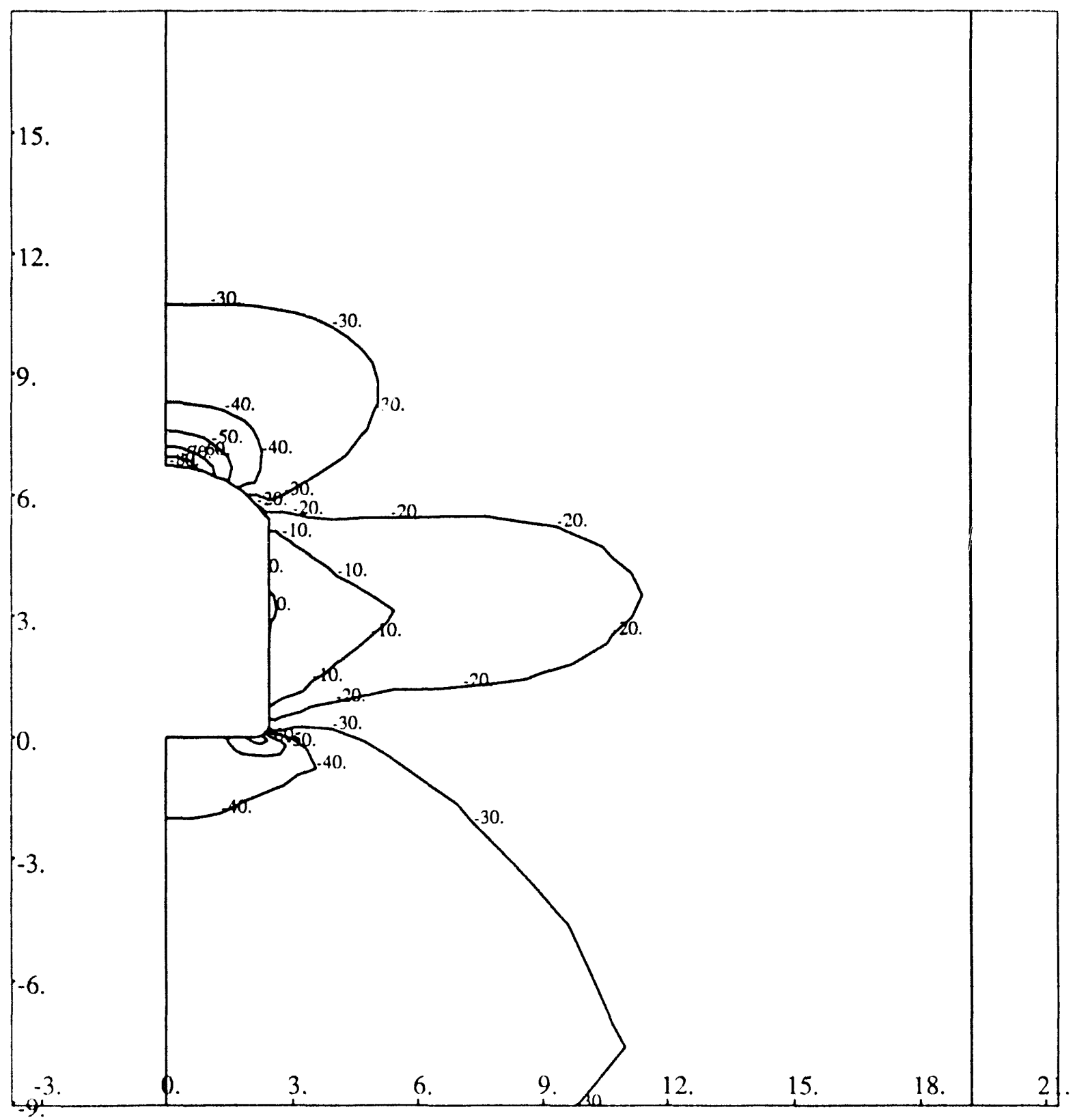

Minimum value is $\quad-80.24998$

POSTJAC, V1.0, DATE PLOTTED:11/13/89

Maximum value is $\quad .01079$

FILE $=3 J 51-101$. UPL

Figure B-1. Maximum Principal Stress for Poor Rock 
JAC ANALYSIS, 100 YEARS AFTER WASTE EMPLACEMENT, POOR ROCK

3J51-101, NO SHOTCR., RES ^ART, 51 YRS TO 101 YRS, ORTHOG. JOINTS

PRINCIPAL STRESS, SIG2

STEP 11 TIME $.1010 \mathrm{E}+03$

$\checkmark$

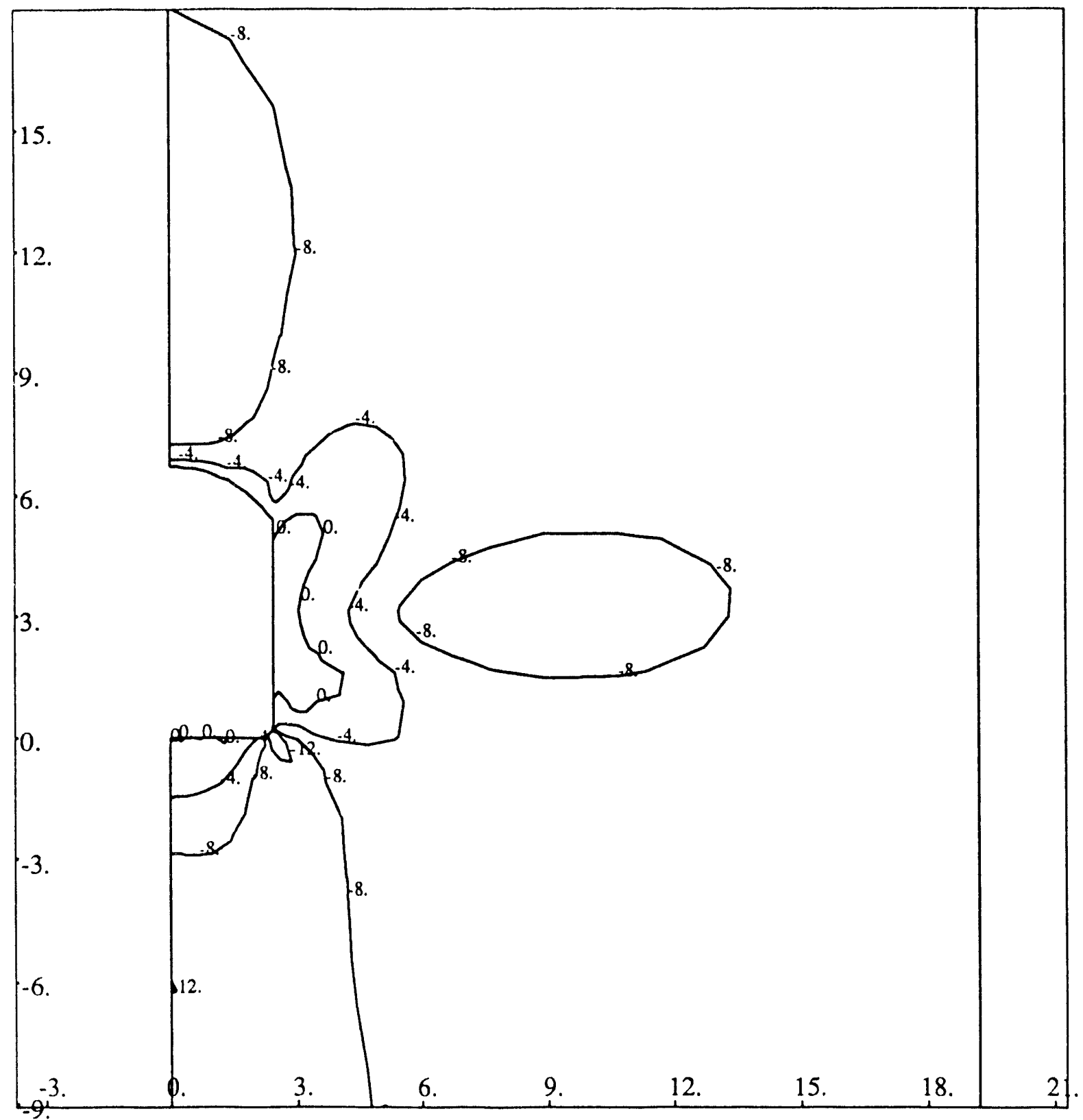

Minimum value is $\quad-14.97898$

Maximum value is $\quad 1.40619$

POSTJAC, V1.0, DATE PLOTTED: $11 / 13 / 89$ FILE $=3 J 51-101 . U P L$

Figure B-2. Minimum Principal Stress for CJM, Poor Rock 
JAC ANALYSIS, 100 YEARS AFTER WASTE EMPLACEMENT

3J51-101, NO SHOTCR., RESTART, 51 YRS TO 101 YRS, ORTHOG. JOINTS

SAFETY FACTOR (HOEK-BROWN)

STEP 11 TIME .1010E+03

$\mathrm{UCS}=127.1, \mathrm{TENS} . \mathrm{STR} .=2.6, \mathrm{M}(\mathrm{i})=3.00, \mathrm{RMR}=100.0$

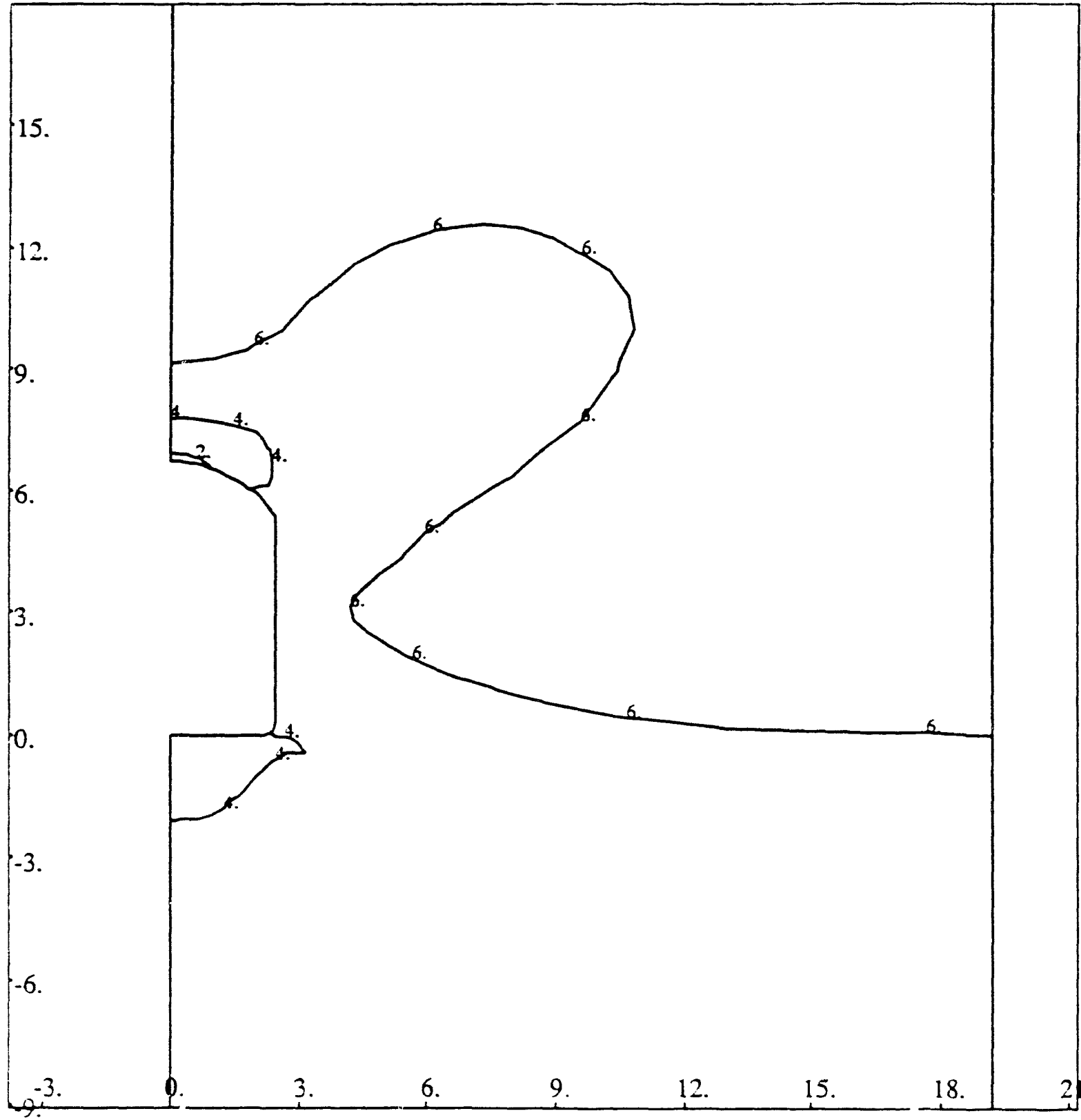

Mininum value is $\quad 1.65687$

Maximum value is $\quad 29.12869$

POSTJAC, V1.0, DATE PLOTTED:10/26/89 FILE $=3 \mathrm{~J} 51-101 . \mathrm{UPL}$

Figure B-3. Safety Factor Contours for Matrix Failure in Compression 


\section{JAC ANALYSIS}

3J51-101, NO SHOTCR., RESTART, 51 YRS TO 101 YRS, ORTHOG. JOINTS

$\begin{array}{lllll}\text { EXTENSILE STRAIN (\%) } & \text { TOTAL } & \text { STEP } 11 & \text { TIME } & .10 E+03\end{array}$

Elastic modulus $=30400.0$, Poisson's ratio $=.24$

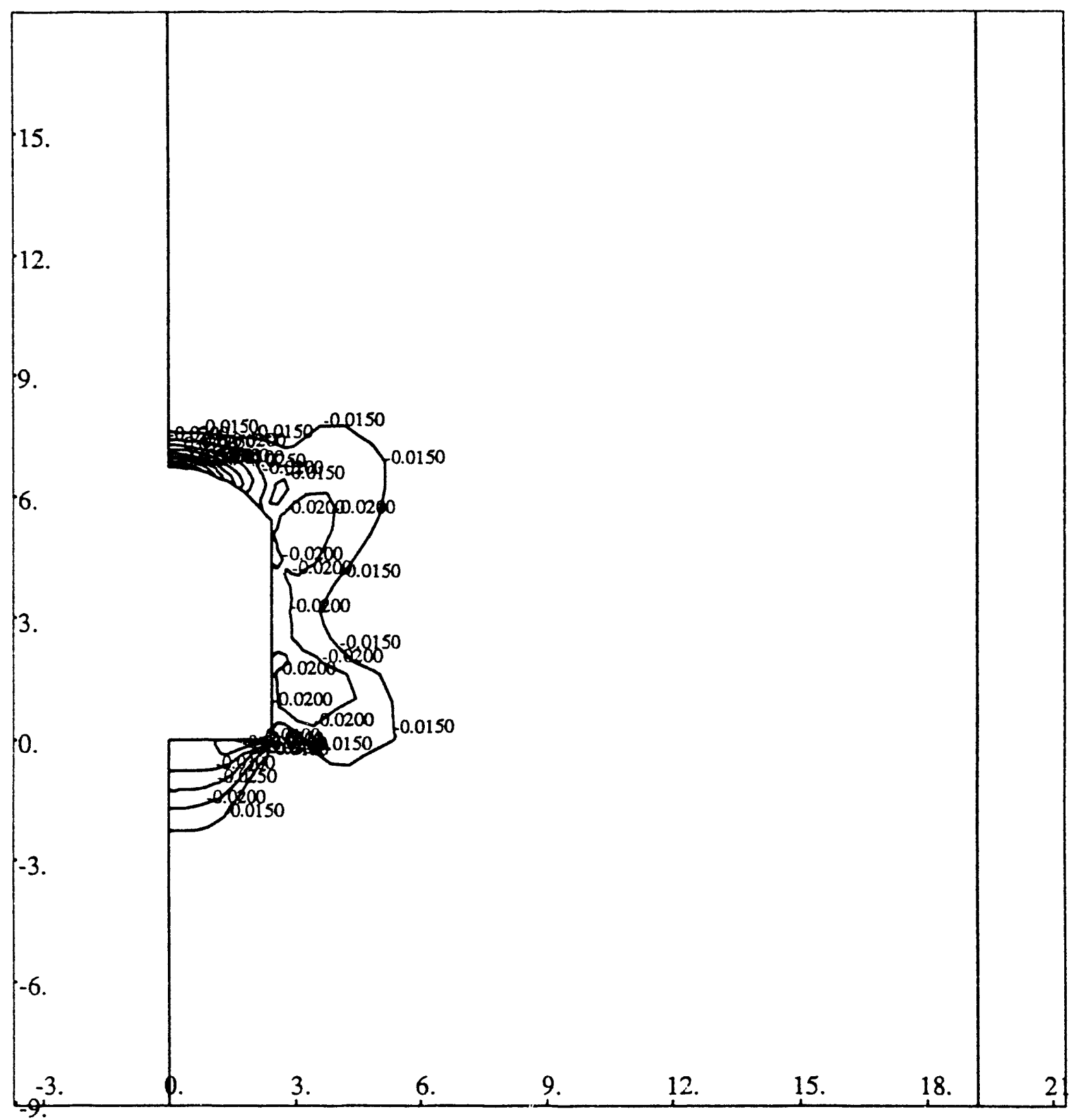

$\begin{array}{lr}\text { Minimum value is } & -.05869 \\ \text { Maximum value is } & .01149\end{array}$

POSTVI, V5.6, DATE PLOTTED: 10/10/89 FILE $=3$ J51-101.UPL

Figure B-4. Extensile Strain Contours for Matrix Material 
JAC ANALYSIS

3J51-101, NO SHOTCR., RESTART, 51 YRS TO 101 YRS, ORTHOG. JOINTS

FAILED ZONES

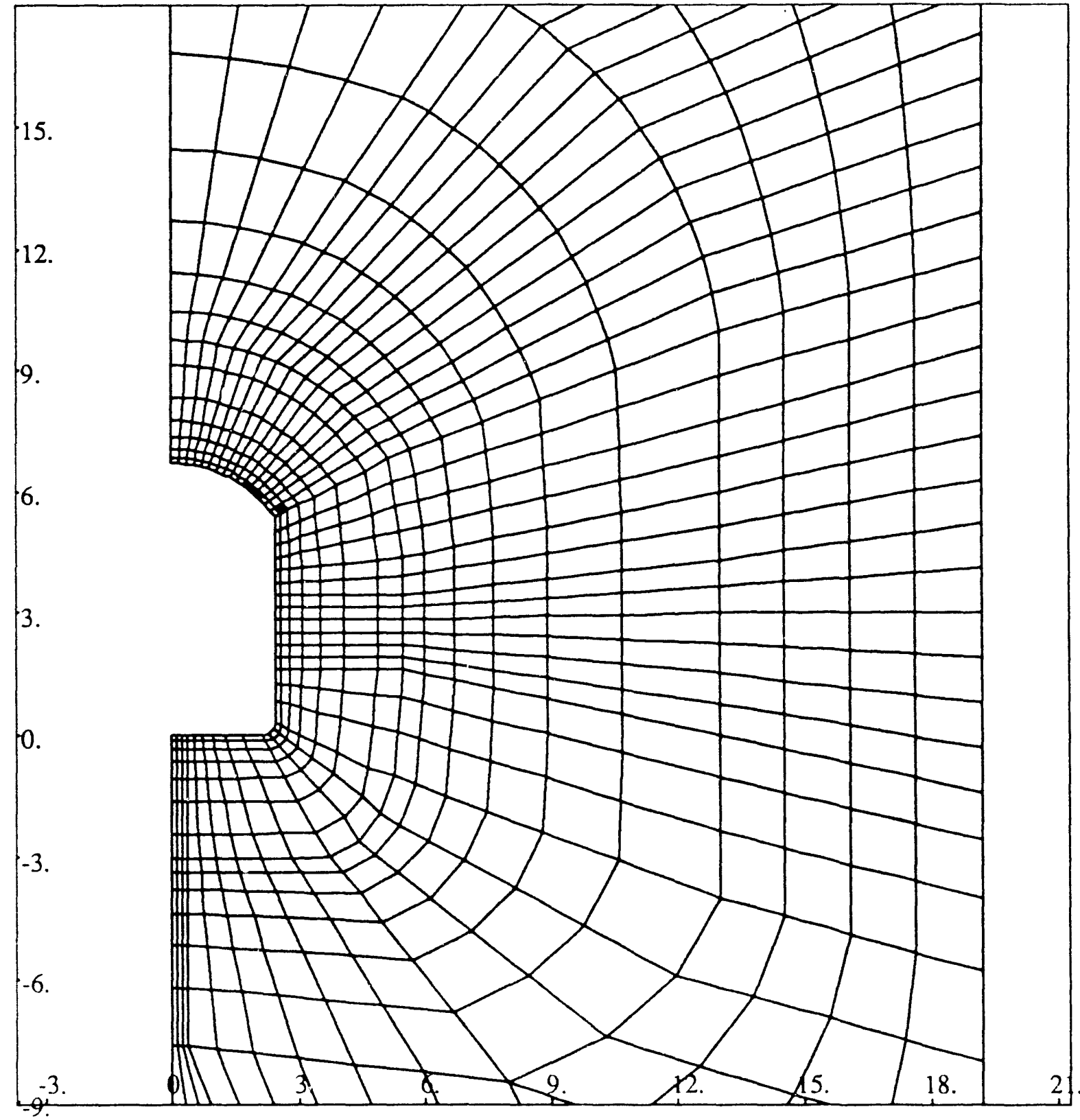

POSTVI, V5.6, DATE PLOTTED: 10/10/89 FILE $=3$ J51-101.UPL

Figure B-5. Zones with Slip Along Either Joint Set for CJM, Poor Rock 
JAC ANALYSIS, SLIP ON JOINT SET 2

3J51-101, NO SHOTCR., REST.ART, 51 YRS TO 101 YRS, ORTHOG. JOINTS

STEP 11 TIME .10E +03

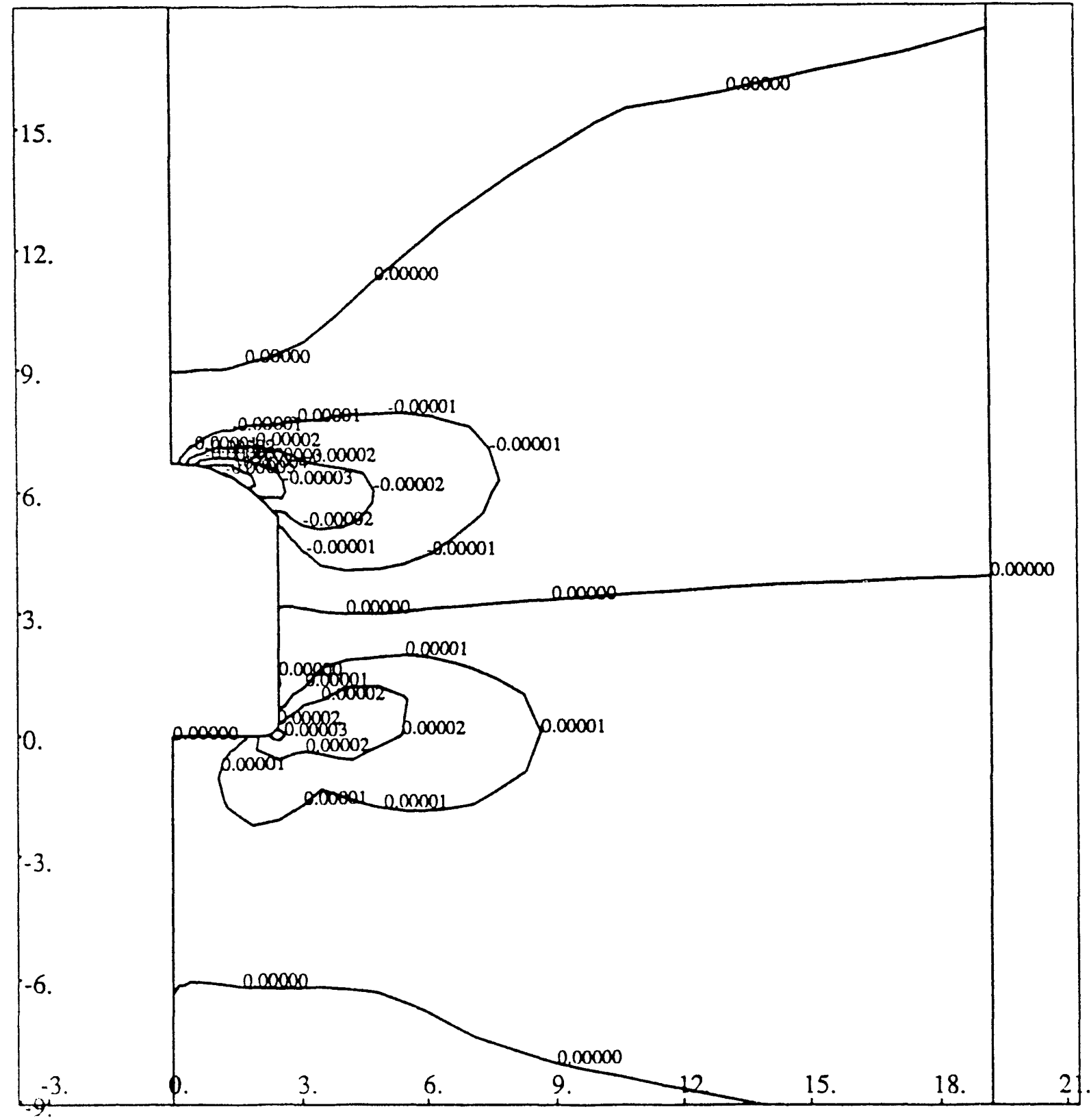

Minimum value is $\quad-.00005$

POSTVI, V5.6, DATE PLOTTED: 10/10/89

Maximum value is $\quad .00004$

FILE=3J51-101.UPL

Figure B-6. Joint Slip (in meters) Along Horizontal Joint Set 
JAC ANALYSIS, SLIP ON JOINT SET 1

3J51-101, NO SHOTCR., RESTẠR, 51 YRS TO 101 YRS, ORTHOG. JOINTS

STEP 11 TIME .10E+(03

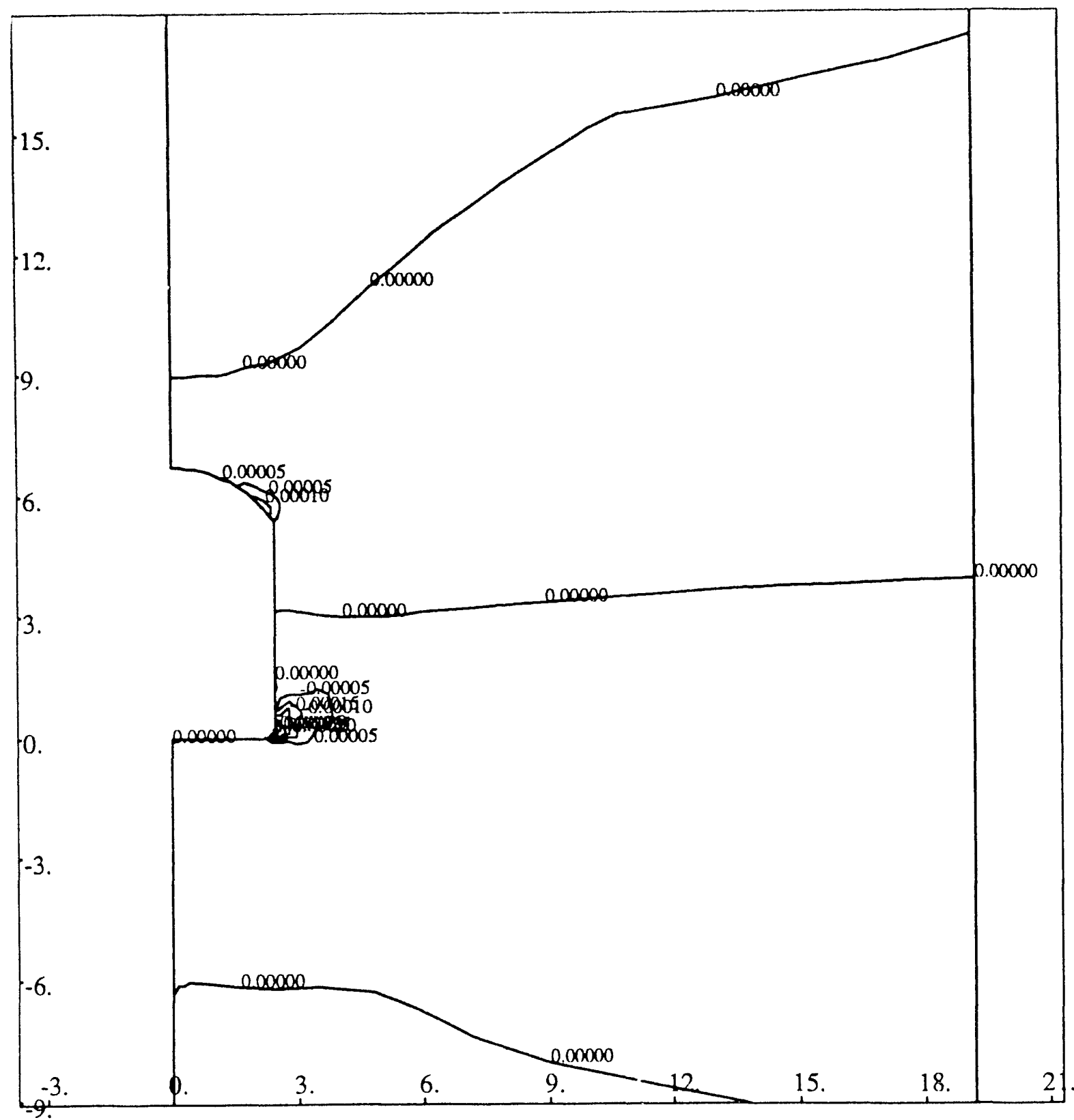

Minimum value is $\quad-.00039$

Maximum value is $\quad .00013$

POSTVI, V5.6, DATE PLOTTED: 10/10/89

FILE $=3 \mathrm{~J} 51-101 . \mathrm{UPL}$

Figure B-7. Joint Slip (in meters) Along Vertical Joint Set 


\section{APPENDIX C}

INFORMATION FROM, AND CANDIDATE INFORMATION FOR, THE SITE AND

ENGINEERING PROPERTY DATABASE AND THE

REFERENCE INFORMATION BASE

\section{C.1 Information from the RIB Used in this Report}

The report is based on information from the Reference Information Base where available.

Table C-1 lists the values used in this study, the RIB mean value, and standard deviation.

\section{C.2 Candidate Information for the RIB}

The report contains no candidate information for the Reference Information Base.

\section{C.3 Candidate Information for the Site and Engineering Properties Database} Database.

This report contains no candidate information for the Site and Engineering Properties 
Table C-1

PARAMETER LIST

\begin{tabular}{|c|c|c|c|}
\hline Parameter & Study Value & $\begin{array}{l}\text { RIB } \\
\text { Value }\end{array}$ & $\begin{array}{l}\text { RIB } \\
\text { Range or } \\
\text { Standard } \\
\text { Deviation }\end{array}$ \\
\hline \multicolumn{4}{|l|}{ Thermal Properties } \\
\hline $\begin{array}{l}\text { Matrix thermal conductivities } \\
\left(\mathrm{W} / \mathrm{m}^{\circ} \mathrm{K}\right)\end{array}$ & 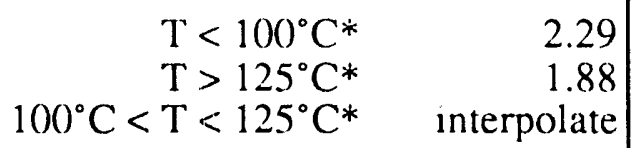 & 2.231 & $\pm(0.047$ \\
\hline $\begin{array}{l}\text { Rock mass thermal } \\
\text { conductivities } \\
\text { saturated }\left(\mathrm{W} / \mathrm{m}^{\circ} \mathrm{K}\right) \\
\text { dry }\left(\mathrm{W} / \mathrm{m}^{\circ} \mathrm{K}\right)\end{array}$ & $\begin{array}{l}\text { NA } \\
\text { NA }\end{array}$ & $\begin{array}{r}1.91 \\
1.839\end{array}$ & $\begin{array}{l} \pm 0.083 \\
\pm 0.064\end{array}$ \\
\hline $\begin{array}{l}\text { Coefficient of linear thermal } \\
\text { expansion }\left(10^{6} /{ }^{\circ} \mathrm{C}\right) \\
25 \text { to } 50 \\
50 \text { to } 100 \\
100 \text { to } 150 \\
150 \text { to } 200 \\
200 \text { to } 250\end{array}$ & $\begin{array}{c}8.8 \\
8.8 \\
8.8 \\
8.8 \\
24.0\end{array}$ & $\begin{array}{r}9.1 \\
8.2 \\
6.8 \\
9.7 \\
\text { No data }\end{array}$ & $\begin{array}{l} \pm 1.3 \\
\pm(0.8 \\
\pm(0.5 \\
\text { NA } \\
\text { NA }\end{array}$ \\
\hline $\begin{array}{l}\text { Heat capacitance of rock mass } \\
\left(\mathrm{J} / \mathrm{cm}^{3} \mathrm{~K}\right) \text { at temperatures } \\
2.5 \\
50 \\
94 \\
9.5 \\
10() \\
105 \\
114 \\
115 \\
125 \\
1.55 \\
19.5 \\
2.35 \\
27.5 \\
\end{array}$ & $\begin{array}{l}2.16 \\
2.16 \\
2.16 \\
2.16 \\
9.26 \\
9.26 \\
9.26 \\
9.26 \\
2.17 \\
2.17 \\
2.17 \\
2.17 \\
2.17 \\
\end{array}$ & $\begin{array}{r}2.0324 \\
2.1280 \\
2.2638 \\
10.7683 \\
10.61^{*} \\
10.4690 \\
10.1984 \\
2.0065 \\
2.0327^{*} \\
2.1114 \\
2.1912 \\
2.2692 \\
2.3410 \\
\end{array}$ & $\begin{array}{l}\text { NA } \\
\text { NA } \\
\text { NA } \\
\text { NA } \\
\text { NA } \\
\text { NA } \\
\text { NA } \\
\text { NA } \\
\text { NA } \\
\text { NA } \\
\text { NA } \\
\text { NA } \\
\text { NA }\end{array}$ \\
\hline \multicolumn{4}{|l|}{ Mechanical Properties } \\
\hline $\begin{array}{l}\text { Unconfined compressive strength } \\
\text { (MPa) }\end{array}$ & 155 to 85.1 & 155 & \pm 59 \\
\hline Y'oung's modulus (GPa) & 30.4 & 32.7 & \pm 4.6 \\
\hline
\end{tabular}


Table C-1

PARAMETER LIST (Cont'd)

\begin{tabular}{|c|c|c|c|}
\hline Parameter & Study Value & $\begin{array}{c}\text { RIB } \\
\text { Value }\end{array}$ & $\begin{array}{l}\text { RIB } \\
\text { Range or } \\
\text { Standard } \\
\text { Deviation } \\
\end{array}$ \\
\hline \multicolumn{4}{|l|}{ Mechanical Properties (Concluded) } \\
\hline Poisson's ratio & 0.22 & $\begin{array}{l}0.22 \\
0.30\end{array}$ & $\begin{array}{l}0.03 \\
0.05\end{array}$ \\
\hline $\begin{array}{l}\text { Coulomb parameters for intact } \\
\text { rock } \\
\text { cohesion (MPa) } \\
\text { angle of internal friction }\left(^{\circ}\right)\end{array}$ & $\begin{array}{l}19.3 \text { to } 35.9 \\
20.5 \text { to } 34.8\end{array}$ & $\begin{array}{l}18.3 \\
37.8 \\
19.7 \\
36.5\end{array}$ & $\begin{array}{l} \pm 5.2 \\
\pm 12.4 \\
\pm 5.2 \\
\pm 9.0\end{array}$ \\
\hline \multicolumn{4}{|l|}{ Rock Mass Strength } \\
\hline $\begin{array}{c}\sigma=A+B \sigma_{3}^{C} \\
\mathrm{~A} \\
\mathrm{~B} \\
\mathrm{C}\end{array}$ & $\begin{array}{c}2.71 \text { to } 43.0 \\
9.3 \text { to } 7.9 \\
0.59 \text { to } 0.67 \\
\end{array}$ & $\begin{array}{r}16.0 \\
10.2 \\
0.602 \\
\end{array}$ & $\begin{array}{l}\text { NA } \\
\text { NA } \\
\text { NA }\end{array}$ \\
\hline $\begin{array}{l}\text { Unconfined compressive strength } \\
\text { (MPa) }\end{array}$ & 2.71 to 43.0 & 16.0 & NA \\
\hline $\begin{array}{l}\text { Input values for the finite- } \\
\text { element analysis } \\
\text { elastic modulus (GPa) } \\
\text { Poisson's ratio } \\
\end{array}$ & $\begin{array}{c}3.64 \text { to } 30.4 \\
0.22 \\
\end{array}$ & $\begin{array}{l}16.4 \\
0.26\end{array}$ & $\begin{array}{l}\text { NA } \\
\text { NA }\end{array}$ \\
\hline \multicolumn{4}{|l|}{ In Situ Stress } \\
\hline $\begin{array}{l}\text { At } 323.4 \text { m depth } \\
\text { vertical stress }(\mathrm{MPa}) \\
\text { max. horizontal stress }(\mathrm{MPa}) \\
\text { min. horizontal stress }(\mathrm{MPa})\end{array}$ & $\begin{array}{l}7.0 \\
4.2 \\
3.5 \\
\end{array}$ & $\begin{array}{l}6.46 \\
5.32 \\
2.66 \\
\end{array}$ & $\begin{array}{l}\text { NA } \\
\text { NA } \\
\text { NA }\end{array}$ \\
\hline \multicolumn{4}{|l|}{ Fracture Properties } \\
\hline $\begin{array}{l}\text { Fracture frequency }\left(\mathrm{m}^{-1}\right) \\
\text { Dip } 0^{\circ} \text { to } 10^{\circ} \\
10^{\circ} \text { to } 20^{\circ} \\
20^{\circ} \text { to } 30^{\circ} \\
30^{\circ} \text { to } 40^{\circ} \\
40^{\circ} \text { to } 50^{\circ} \\
50^{\circ} \text { to } 60^{\circ}\end{array}$ & $\begin{array}{l}1.0 \text { to } 0.16 \\
\text { NA } \\
\text { NA } \\
\text { NA } \\
\text { NA } \\
\text { NA }\end{array}$ & $\begin{array}{l}0.2 \\
0.2 \\
0.2 \\
0.1 \\
0.2 \\
0.2\end{array}$ & $\begin{array}{l}0.5-0.05 \\
0.6-0.05 \\
0.6-0.05 \\
0.3-0.05 \\
0.4-0.05 \\
0.5-0.05\end{array}$ \\
\hline
\end{tabular}


Table C-1

PARAMETER LIST (Concluded)

\begin{tabular}{|c|c|c|c|}
\hline Parameter & Study Value & $\begin{array}{c}\text { RIB } \\
\text { Value }\end{array}$ & $\begin{array}{l}\text { RIB } \\
\text { Range or } \\
\text { Standard } \\
\text { Deviation }\end{array}$ \\
\hline \multicolumn{4}{|l|}{ Fracture Properties (Concluded) } \\
\hline $\begin{array}{l}\text { Fracture frequency }\left(\mathrm{m}^{-1}\right) \\
60^{\circ} \text { to } 70^{\circ} \\
70^{\circ} \text { to } 80^{\circ} \\
80^{\circ} \text { to } 90^{\circ}\end{array}$ & $\begin{array}{l}\text { NA } \\
6.0 \text { to } 37.0 \\
6.0 \text { to } 37.0\end{array}$ & $\begin{array}{r}0.3 \\
1.7 \\
13.2\end{array}$ & $\begin{array}{c}0.7-0.10 \\
2.6-0.7 \\
32.5-2.5\end{array}$ \\
\hline \multicolumn{4}{|l|}{ Seismic Loads } \\
\hline $\begin{array}{l}\text { Recommended control motion } \\
\text { values for natural earthquake } \\
\text { ESF design } \\
\text { horizontal velocity }(\mathrm{cm} / \mathrm{sec}) \\
\text { vertical velocity }(\mathrm{cm} / \mathrm{sec})\end{array}$ & $\begin{array}{l}50 \\
33\end{array}$ & $\begin{array}{l}30 \\
20\end{array}$ & $\begin{array}{l}\text { NA } \\
\text { NA }\end{array}$ \\
\hline
\end{tabular}


L J. W. Bartlett, Director (RW-1) office of Civilian Radioactive haste Managenent

U.S. Department of Energy

1000 Independence Avenue, S.W.

Washington, D.C. 20585

1 F. G. Peters, Deputy Director (RW-2)

Office of Civilian Radioactive Waste Management

U.S. Department of Energy

1000 Independence Avenue, S.W.

Washington, D.C. 20585

1 T. H. Isaacs (RW-4)

Office of Strategic Planning and International Programs

Office of Civilian Radioactive Waste Management

U.S. Department of Energy

1000 Independence Avenue, S.W.

Washington, D.C. 20585

1 J. D. Salt zman (RW-5)

Office of External Relations

Office of Civilian Radioactive Waste Management

U.S. Department of Energy

1000 Independence Avenua, S.W.

Washington, D.C. 20585

1 Samule 1 Rousso (RW-10)

Office of Program and Resources Management

Office of Civilian Radioactive Waste Management

U.S. Department of Energy

1000 Independence Avenue, S.W.

Washington, D.C. 20585

1 J. C. Bresee (RW-10)

Office of Civilian Radioactive Waste Management

U.S. Department of Energy

1000 Independence Avenue, S.W.

Washington, D.C. 20585

1 C. P. Certz (RW-20)

office of Geologic Disposal

Office of Civilian Radioactive Waste Management

U.S. Department of Energy

1000 Independence Avenue, S.W.

Washington, D.C. 20585
1 S. J. Brocoum (RW-22)

Analysis and Verification Division

office of Civilian Radioactive

Waste Management.

U.S. Department of Energy

1000 Independence Avenue, S.W.

Washington, D.C. 20585

1 D. D. Shelor (RW-30)

office of systems and Compliance

Office of Civilian Radioactive Waste Management

U.S. Department of Energy

1000 Independence Avenue, S.W.

Washington, D.C. 20585

$1 \mathrm{~J}$. Roberts (RW-33)

Office of Civilian Radioactive Waste Management

U.S. Department of Energy

1000 Independence Avenue, S.W.

Washington, D.C. 20585

1 G. J. Parker (RW-332)

Office of Civilian Radioactive Waste Management

U.S. Department of Energy

1000 Independence Avenue, S.W.

Washington, D.C. 20585

1 Associate Director (RW-40)

Office of Storage and Transportation

office of Civilian Radioactive Waste Management

U.S. Department of Energy

1000 Independence Avenue, S.W.

Washington, D.C. 20585

1 Associate Director (RW-50)

office of Contract Business Management

Of fice of Civilian Radioactive Waste Management

U.S. Department of Energy

1000 Independence Avenue, S.W.

Washington, D.C. 20585

1 C. G. Russomanno (RW-52)

Office of Civilian Radioactive Waste Management

U.S. Department of Energy

1000 Independence Avenue, S.W.

Washington, D.C. 20585 
1 D. U. Deere, Chairman

Nuclear Waste Technical

Review Board

1100 Wilson Blvd. $\$ 910$

Arlington, VA 22209-229)

1 Dr. Clarence R. Allen

Nuclear Waste Technical Revicw Board 1000 E. California Blvd.

Pasadena, CA 91106

1 Dr. John E. Cantlon

Nuclear Waste Technical Review Board 1795 Bramble Dr.

East Lansing, MI 48823

1 Dr. Melvin W. Carter

Nuclear Waste Technical Review Board 4621 E11 isbury Dr., N.E.

Atlanta, GA 30332

1 Dr. Donald Langmuir

Vuclear Waste Technical Review Board 109 So. Lookout Mountain $\mathrm{Cr}$.

(iolden, CO 80401

1 Dr. D. Warner North

Nuclear Waste Technical Roviow Board Decision Focus, Inc.

$498: 4$ El Camino Real

Los Altos, CA 94062

1 Dr. Dennis L. Price

Nuclear Wast Technical Revifw Poard

1011 Evergreen Way

Blacksburg, VA 24060

1 Dr. Ellis D. Verink

Nuclear Waste Technical Review Poard 4401 N.W. 18th Place

Cainesville, FL 32605

5 C. P. Gertz, Project Manager

Yucca Mountain Project office

U.S. Department of Energy

P.O. Box 98608 -MS 523

las Vegas, NV 89193-8608

1 M. O. Cloninger

Vilsca Mountain Project of fice

U.S. Department of Ener $\}, y$

P. (). Box 98608--MS 523

las Vegas, NV 89193-8608
1 E. H. Petrie

Yucca Mountain Project offire.

U.S. Department of Energy

P.O. Box 98608 - MS 523

las Vegas, NV 89193-8608

$1 \mathrm{~J}$. M. White

Yucca Mountain Project of $\mathrm{f}$ ce

U.S. Department of Energy

P.O. BOX 98608-MS 523

Las Vegas, NV 89193-8608

1 C. I. West, Director

office of External Affairs

DOE Field office, Nevada

U.S. Department of Energy

P.O. Box 98518

Las Vegas, NV 89193-85180

12 Technical Information of ficer DOE Field Office, Nevada

U.S. Department of Energy

P.O. Box 98518

Las Vegas, NV 89193-8518

1 P. K. Fitzsimmons, Director

Heal th Physics \& Environnent al Division

DOE Field Office, Nevada

U.S. Department of Energy

P.O. Box 98518

Las Vegas, NV 89193-8518

1 D. R. Elle, Director

Environmental Protection Division DOE Field Office, Nevada

U.S. Department of Energy P.O. Box 98518

Las Vegas, Nv 89193-8518

1 Repository Licensing \& Quality Assurance Project Directorat

Division of Waste Managenent

U.S. Nuclear Regulatory Commissim Washington, D.C. 20555

1 Senior Project Manager for Yuluca

Mountain Repository Project Branch Division of Waste Management

U.S. Nuclear Regulatory Commission Washington, D.C. 20555

1 NRC Document Control Desk Division of Waste Management.

U.S. Huclear Regulatory Commis.sion Washington, D.C. 20555 
1 P. T. Prestholt

NRC Site Representative

301 E. Stewart Ave.

las Vegas, NV 89101

1 E. P. Binnall.

Field Systems Group Leader

Building 50B/4235

Lawrence Berkeley Laboratory

Berkeley, CA 94720

1 Center for Nuclear Waste Regulatory Analyses

6220 Culebra Road

Drawer 28510

San Antonio, TX 78284

3 L. J. Jardine

Technical Project officer for SMP

Mail Stop L. 204

latwence livermore National laboratory

P.o. Pox 808

livermore, CA 94550

4 R.J. Herbst

Technical Project Officer for YMP N-5, Mail Stop J52l

Los Alamos Natjonal Laboratory

P.o. Bo: 1663

Los Alamos, NM 87545

1 H. N. Kalia

Feploratory Shaft Test Manager

los Alamos Nat ional laboratory

Misil siop 52l

lil Convention Center Dr.

Silito 820

las, Vegas, NV 89109

1 I. F. Divine:

Assistant Director for

fing ineering, (ieology

U.S. Geological Survey

106 National Center

12201 Suntise Vall(:y Dr.

Reston, VA 22092

b 1. R. Hayes

Technical project officer

rucca Mountain Project Branch-MS 425

1]. S. Cienlogical Survey

P.o. Box 25046

Denver, co 80225
1 V. R. Schneider

Asst. Chief Hydrologist-MS 414

office of Progran Coordination

\& Technical Support

U.S. Geological Survey

12201 Sumrise Valley Drive

Reston, VA 22092

1 R. B. Raup, Jr.

Geological Division Coordinator MS 913

Yucca Mountain Project

U.S. Geological Survey

P.O. Box 25046

Denver, CO 80225

1 D. H. Appe1, Chief

Hydrologic Investigations Program MS 421

U.S. Geological Survey

P.O. Box 25046

Deriver, (0) 80225

1 E. J. Helley

Branch of Western Regional Geology MS 427

U.S. Geological Survey

345 Middlefield Road

Menlo Park, CA 94025

1 Chief

Nevada Operations Office

U.S. Geological Survey

101 Convention Center Drive

Suite 860 , MS 509

las Vegas, NV 89109

1 D. Zosiger

U.S. Geological Survey

101 Convention Center Dr.

Suite 860 - MS 509

Las Vegas, NV 89109

1 R. V. Watkins, Chief

Project Planning and Management

U.S. Geological Survey

P.O. Box 25046

421 Federal Conter

Denver, CO 80225

1 A. L. Flint

U.S. Geological Survey

MS 721

P.O. Box 327

Mercury, NV 89023 


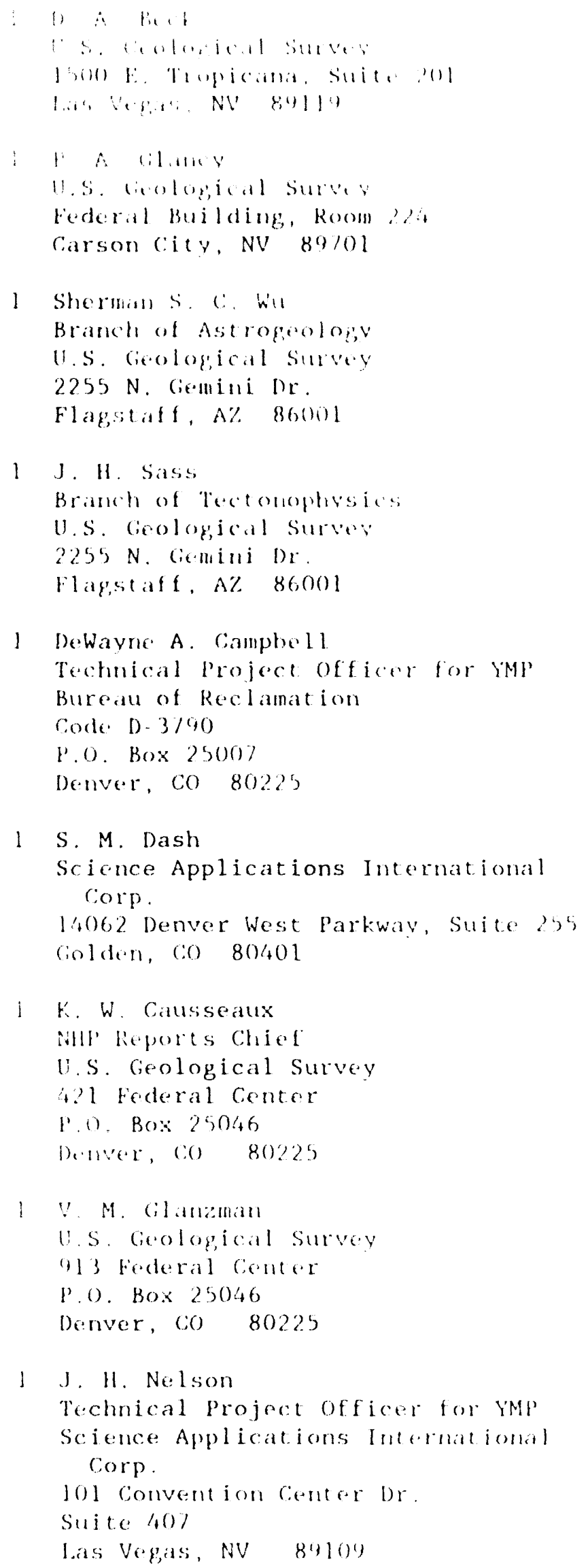

I R. E. Jackson, Progran Manager koy $F$. Weston, Ine.

955 L'Enfant Plaza, Southwest

Washington, D.C. 20024

1 Technical Information Centri Roy $F$. Weston, Inc.

955 L'Enfant Plaza, Southwest

Washington, D.C. 20024

1 D. Hedges, Vice President, Quality Assurance?

Roy F. Weston, Inc.

4425 Spring Mountain Road, Suite 300 Las Vegas, Nevada 89102

1 D. L. Fraser, General Manager Reynolds Electrical \& Engineroing C. Mail Stop 555

P.O. Box 98521

las Vegas, NV 89193-8521

I R. F. Pritchett

lechnical Project officer for YMr Roynolds Electrical \& Engineeriug co. MS 408 P. (1). Box 98921 las Vogras, NV +93-8s?

I B. W. lolston

General Manager \& President

lats Vegats Branch

Raylhoon Services Nevada

Mil Stop 416

P. (). Box $195 / 487$

lass Ver,as, NV 84193.5487

I R. L. Ballort

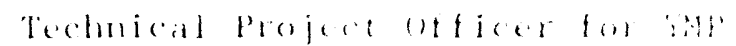

Raytheon Servides Nevada

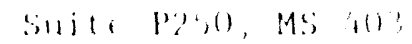

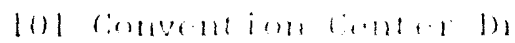

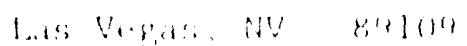


1 R. E. lowder

Technical project officer for YMP

Mar Technical Services

101 Convention Center Drive

Suite 1100

las Vegas, NV 89109

1 C. K. Hastings, Manager

PASS Program

Pacific Northwest Laboratoriess

P.O. Box 999

Richland, WA 99352

1 A. T. Tamura

Science and Technology Division

office of Scientific and Technical Information

U.S. Department of Energy

P.O. Box 62

Oak Ridge, TN 37831

1 Carlos G. Bell, Jr.

Professor of Civil Engineering

Civil and Mechanical Engineering Departinent

University of Nevada, Las Vegas

4505 South Maryland Parkway

Las Vegas, NV 89154

1 C. F. Costa, Director

Nuclear Radiation Assessment Division

U.S. Environmental Protection Agency

Environmental Monitoring Systems Laboratory

P.O. Box 93478

Las Vegas, NV 89193-3478

1 ONWI Library

Battelle Columbus Laboratory office of Nuclear Waste Isolation 505 king Avenue

Columbus, $\mathrm{OH} \quad 43201$

1 T. Hay, Executive Assistant

Office of the Governor

State of Nevada

Capitol Complex

Carson City, NV

89710
3 R. R. Loux, Jr.

Executive Director

Nuclear Waste Project office

State of Nevada

Evergreen Center, Suite 2.52

1802 North Carson Street

Carson City, NV 89710

1 C. H. Johnson

Technical Program Manager Nuclear Waste Project Office

State of Nevada

Evergreen Center, Suite 252

1802 North Carson Street.

Carson City, NV 89710

1 John Fordham

Water Resources Center

Desert Research Institute

P.J. Box 60220

Reno, NV 89506

1 Dr. Martin Mifflin

Water Resources Center

Desert Research Institute

2505 Chandler Avenue

Suite 1

Las Vegas, NV 89120

1 Eric Anderson

Mountain West Research-Southwest Inc.

2901 N. Central Ave. \#1000

Phoenix, AZ 85012-2730

1 Department of Comprehensive Planning Clark County

225 Bridger Avenue, 7th Floor

Las Vegas, NV 89155

1 Planning Department

Nye County

P.O. Box 153

Tonopah, NV 89049

1 Lincoln County Commission

Lincoln County

P.O. Box 90

Pioche, NV 89043

5 Judy Foremaster

City of Caliente

P.O. Box 158

Caliente, NV 89008 
1 Economic Development Department City of Las Vegas 400 East Stewart Avenue Las Vegas, NV 89101

1 Community Planning \& Development City of North Las Vegas P.O. Box 4086 North Las Vegas, NV 89030

1 Director of Community Planning City of Boulder City

P.O. Box 367

Boulder City, NV 89005

1 Commission of the European

Communities

200 Rue de la Loi

B-1049 Brussels

BELGIUM

2 M. J. Dorsey, Librarian

YMP Research and Study Center

Reynolds Electrical \& Engineering Co., Inc.

MS 407

P.O. Box 98521

Las Vegas, NV 89193-8521

1 Amy Anderson

Argonne National Laboratory

Building 362

9700 So. Cass Ave.

Argonne, IL 60439

Li) M. P. Hardy

Agapito and Associates

715 Horizon Drive

Suite 300

Grand Junction, CO 81506

1 Dr. W. Hustrulid

Colorado School of Mines

Yinng Department

(i)lden, co 80401

1 Dr. Z. T. Bienewski

Yineral Res. Inst.

Penn State University

University Paik, PA 16802

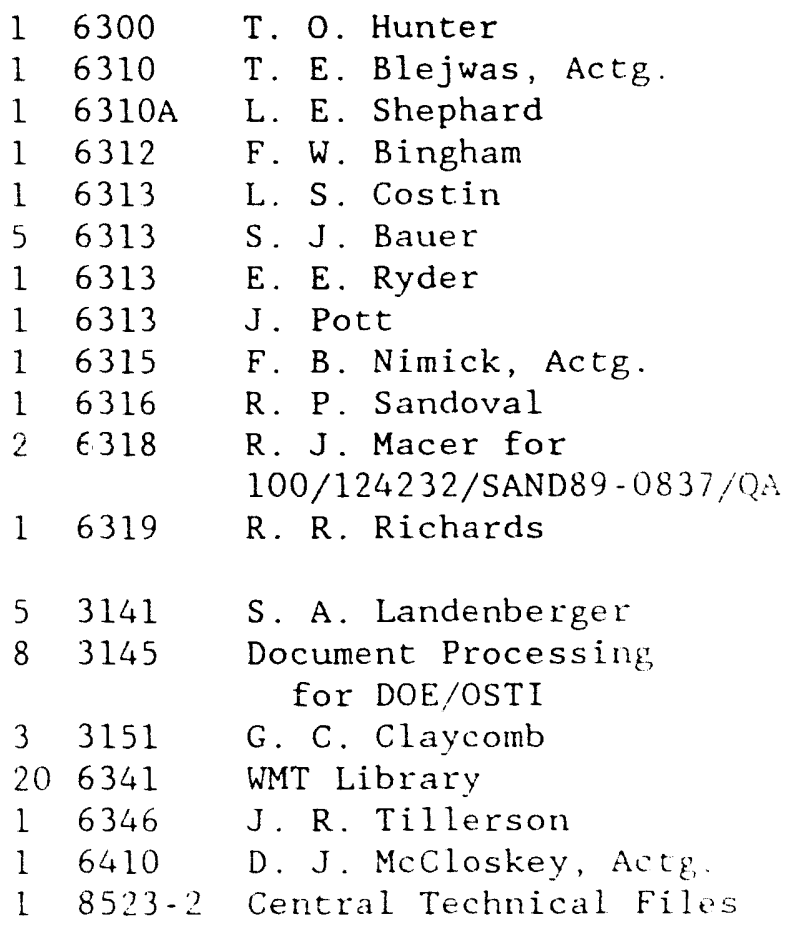


The number in the lower right-hand corner is an accession number used for Office of Civilian Radioactive Waste Management purposes only. It should not be used when ordering this publication.

NNA.910808.0105 

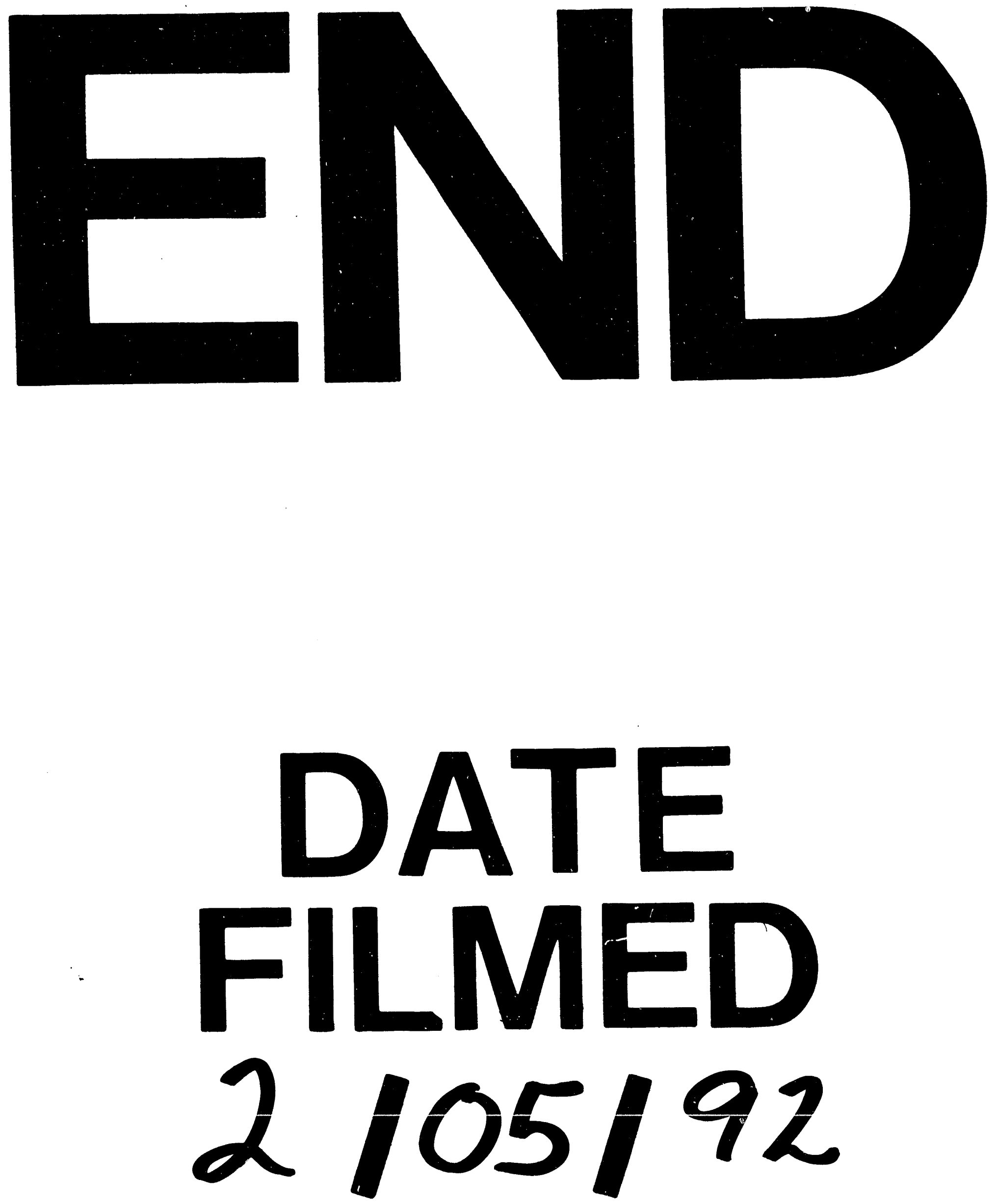


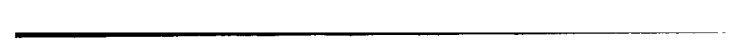

